\title{
Food and Agriculture
Organization of the
United Nations
}

\section{Wood Energy in the ECE Region}

Data, trends and outlook in Europe, the Commonwealth of Independent States and North America
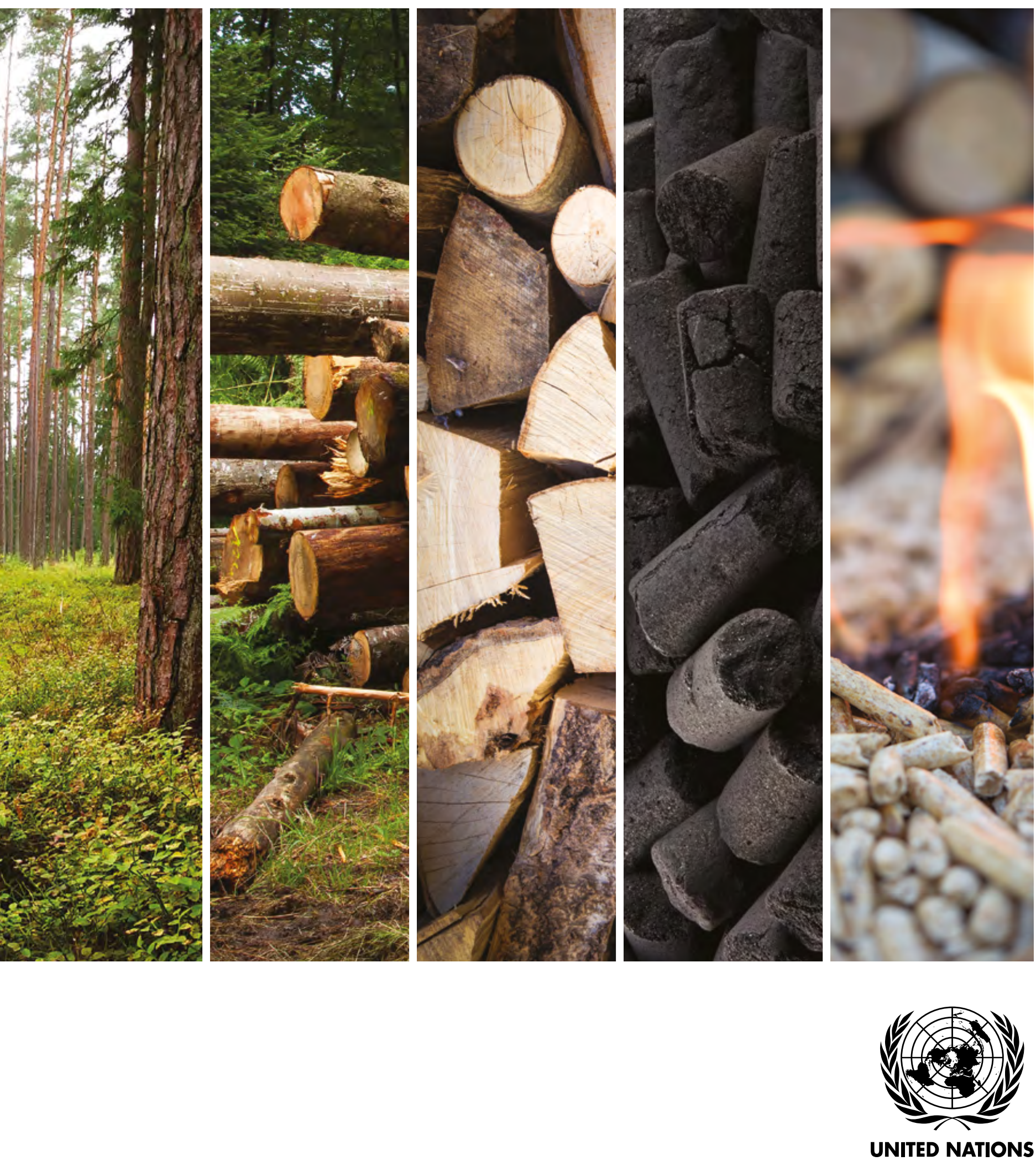


\section{Wood Energy in the ECE Region}

Data, trends and outlook in Europe, the Commonwealth of Independent States and North America 


\section{NOTE}

The designations employed and the presentation of material in this publication do not imply the expression of any opinion whatsoever on the part of the secretariat of the United Nations concerning the legal status of any country, territory, city or area, or of its authorities, or concerning the delimitation of its frontiers or boundaries.

\section{DISCLAIMER}

The contents of this paper do not necessarily reflect the views or policies of the United Nations, the ECE/FAO secretariat, the ECE Committee on Forests and the Forest Industry or the FAO European Forestry Commission.

Totals may not sum due to rounding.

\section{ABSTRACT}

This publication highlights the use of wood for energy and includes the most recent statistics on wood energy markets across the UNECE region. It aims to communicate the relevance of wood energy in the region and help bridge information about the forest and energy sectors. It also intends to offer some of the best-available information on the role that wood energy can play in various sectors to support environmental, energy, and socio-economic strategies toward a greener economy. It focuses on commercial wood energy uses in the UNECE inclusive of energy generated for cooking, heating and electricity generation.

$\mathrm{ECE} / \mathrm{TIM} / \mathrm{SP} / 42$

\begin{tabular}{|r|}
\hline UNITED NATIONS PUBLICATION \\
\hline Sales No.: E.18.II.E.9 \\
ISBN: $978-92-1-117154-9$ \\
e-ISBN: 978-92-1-363109-6 \\
\hline
\end{tabular}

Copyright @ 2018 United Nations

All rights reserved worldwide

United Nations publication issued by the Economic Commission for Europe (ECE) 


\section{FOREWORD}

Wood energy is humanity's first fuel and continues to be an important source of energy. In many developing countries, wood energy provides the majority of total energy supply and, surprisingly, in several developed countries, wood energy provides nearly $25 \%$ of total energy supply. Wood energy continues to be the leading renewable energy source in Europe, accounting for about $45 \%$ of primary energy from renewable sources.

Wood energy is also modern. Wood pellets, made from compressed wood particles, are changing the way wood is used for heat and power generation in the ECE region by virtue of their efficient combustion, convenience and the fact that they are more energy dense than traditional firewood. The manufacture of wood pellets and their distribution supports employment in the ECE region's forest sector, often in rural areas where job opportunities are needed. This development has also provided market options for what had been low value residual wood products, such as sawdust, post-consumer wood and wood from harvest sites, which had often been seen as not having value and thus left in the forest or burned in the harvest area.

Policy measures to increase the share of renewable energy and decrease carbon emissions have played a strong role in the increased use of wood for energy and, together with the rapidly increasing oil prices at the beginning of this millennium, contributed to jumpstart a wider use of wood energy, particularly in Europe. Within the portfolio of renewable energy sources, wood energy has some clear advantages. It does not have the same limitations that other renewable energy sources have, as it is storable and will continue to provide energy even when there is no sun, wind, or when hydroelectricity generation potential is limited.

The use of wood for energy can have negative ramifications if not used properly. Wood energy can be a significant source of indoor and outdoor pollution if used inefficiently. The harvest of wood fuels can degrade forests if sustainable practices are not observed. Nonetheless, wood energy can be a very clean and sustainable fuel, if best practices are applied to sourcing, processing and combustion efficiency.

This publication sheds light on the current situation of: wood energy in the ECE region, types of wood fuels used, major sources and users, public policy instruments that support (and hinder) its use, and how to sustainably source wood. Moreover, it provides a future outlook on how the current social, economic and political trends and developments may mould the use of wood for energy and its sustainable production. Finally, we believe that this publication will show the current progress and future potential of wood energy to contribute in achieving the United Nations Sustainable Development Goals.

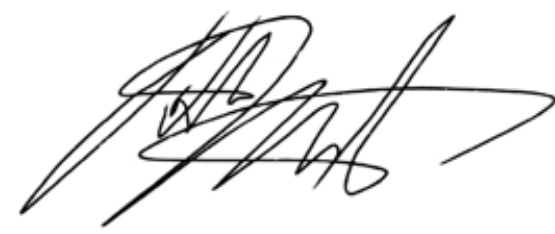

Hiroto MITSUGI

Assistant Director-General,

Forestry Department of the Food and Agriculture Organization of the United Nations

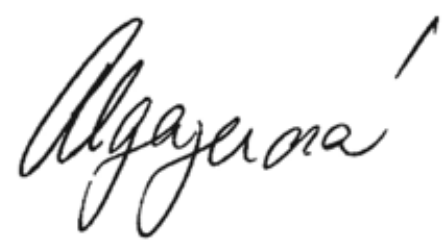

\section{Olga ALGAYEROVA}

Under-Secretary-General of the United Nations,

Executive Secretary of the United Nations Economic Commission for Europe 


\section{CONTENTS}

1 The multiple functions of wood energy............................................................................................ 1

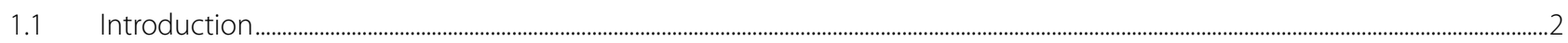

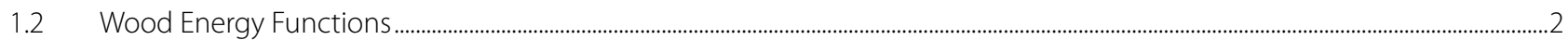

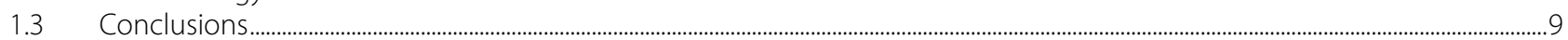

1.4 References.

2 Wood energy data: the joint wood energy enquiry...................................................................12

2.1 Historical development of the Joint Wood Energy Enquiry ……………………………………………............................................................. 14

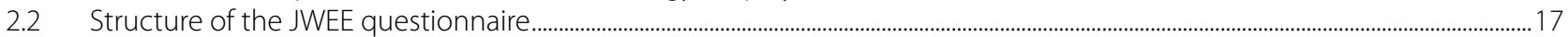

2.3 Joint Wood Energy Enquiry within the international reporting schemes ................................................................................................. 19

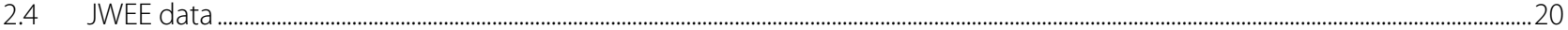

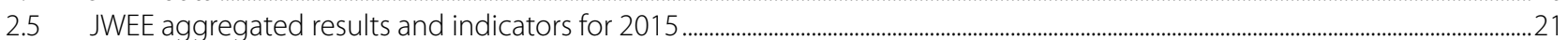

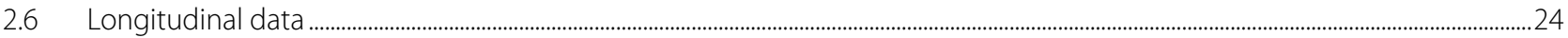

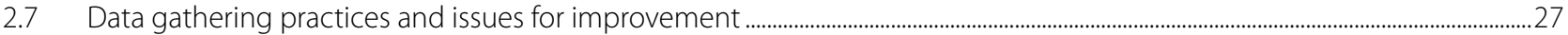

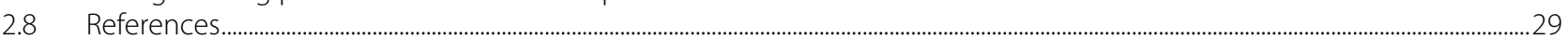

3 Wood fuels ..................................................................................................................................... 30

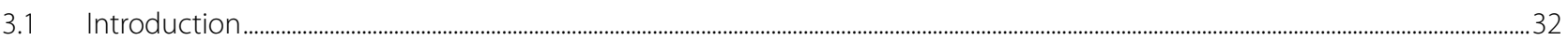

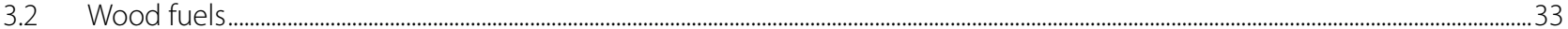

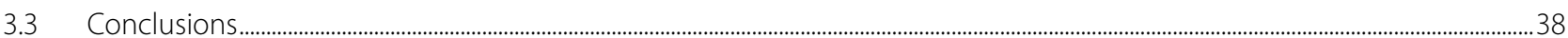

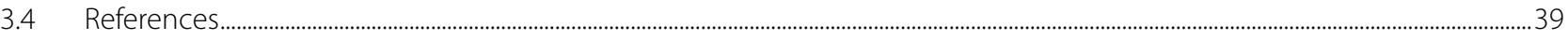

$4 \quad$ Public policy instruments to support sustainable wood energy ..........................................40

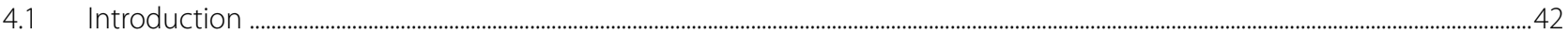

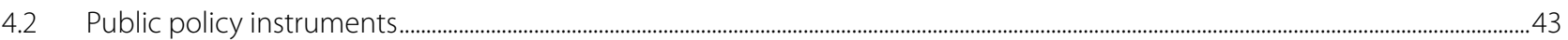

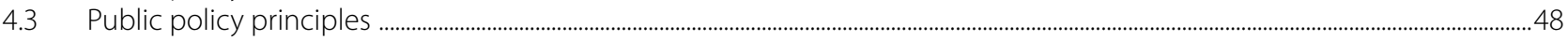

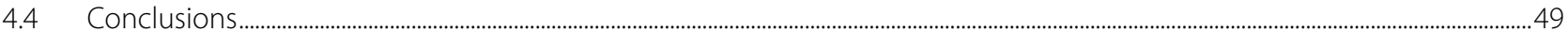

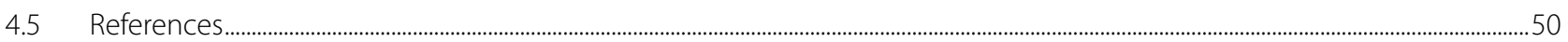

5 Outlook for future wood fuel markets ........................................................................................52

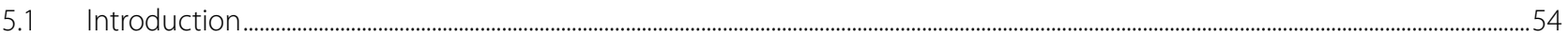

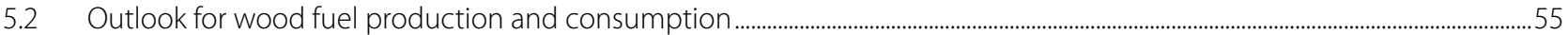

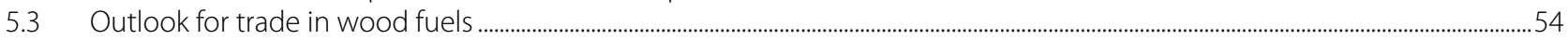

5.4 Outlook for Wood Fuels and Energy - Barriers and Opportunities ..............................................................................................................58

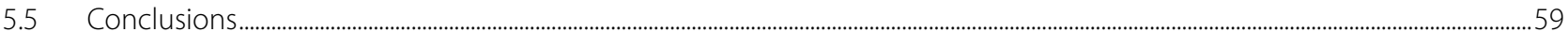

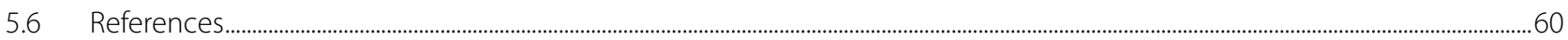

6 Sustainable levels of wood fuel removals ...............................................................................62

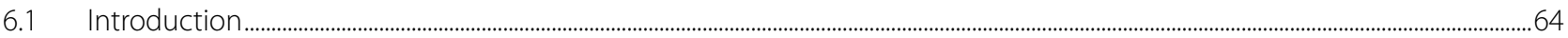

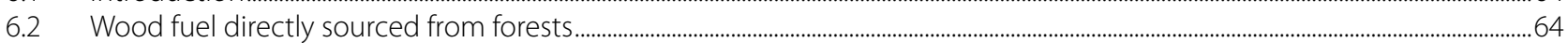

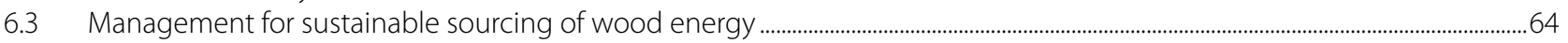

6.4 Assessments of sustainable wood energy feedstocks ................................................................................................................................67

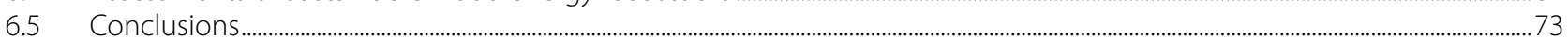

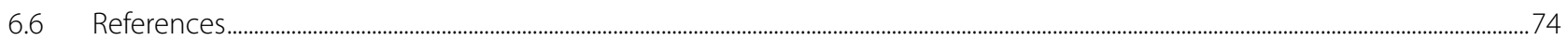

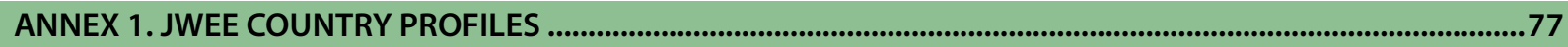

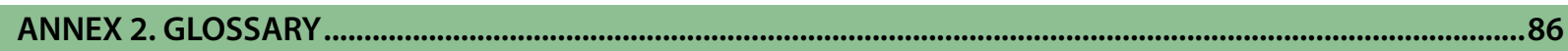

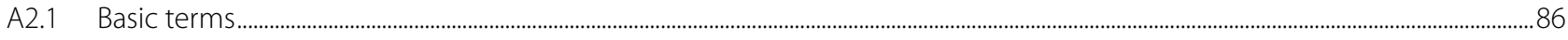

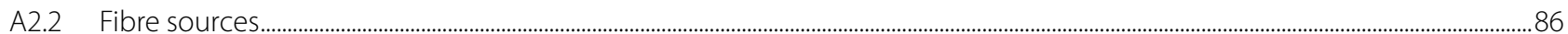

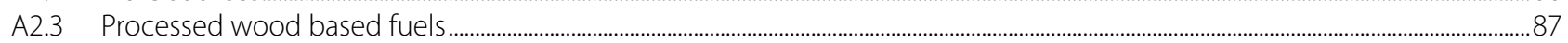

A2.4 Energy use

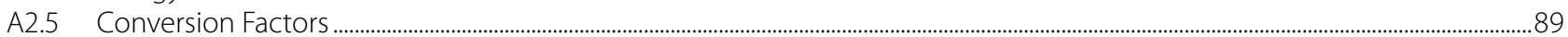

A2.6 References 


\section{LIST OF TABLES}

2.1 Production and trade of wood raw material in JWEE table I..

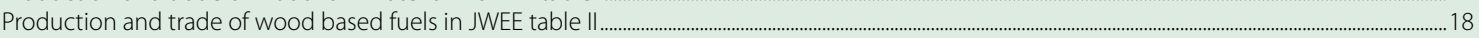

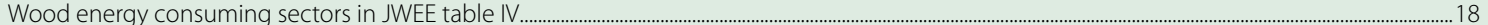

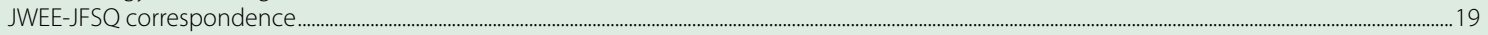

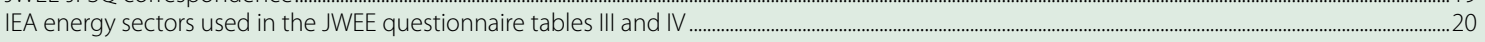

Ranges of higher heating values (total amount of energy recoverable from moisture free biomass) for common wood specie ...................................32

Selected parameters for the European Pellet Council's ENplus Certification Scheme and respective ISO testing standards........................................35

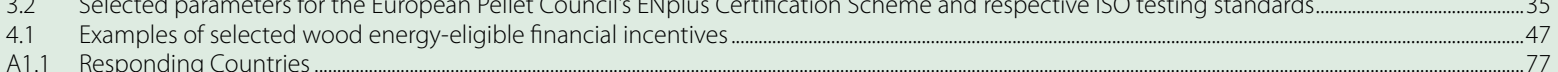

A1.2 Aggregated country data for 2015

\section{LIST OF FIGURES}

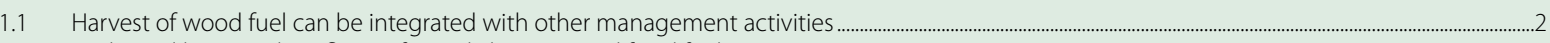

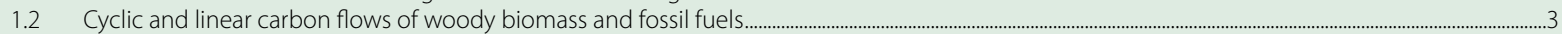

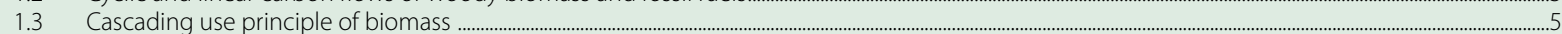

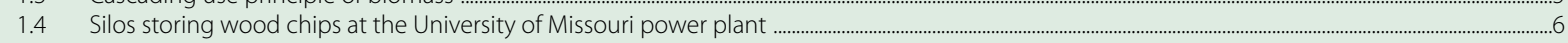

1.5 Pekka Halonen's work chronicled the Finnish landscape and its people in his painting "In the sauna" (1925) ...............................................................................

1.6 Forest and wood use in EU in $2010 \ldots \ldots \ldots$

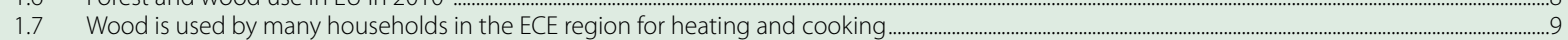

2.1 Wood price index for Finland and Lithuania and world oil price index (indexes for 2000), 1995-2016 ……..........................................................................14

$2.2 \quad$ JWEE aggregate table example, based on United Bioenergy Terminology ..............................................................................................................................................15

2.3 History of the JWEE reporting ……

2.4 Structure of the Joint Wood Energy Enquiry

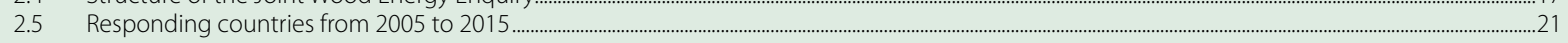

2.6 Consumption of Biomass, 2015

2.7 Share of Biomass in Total Primary Energy Supply, 2015

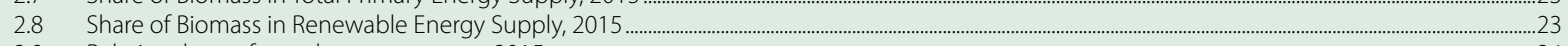

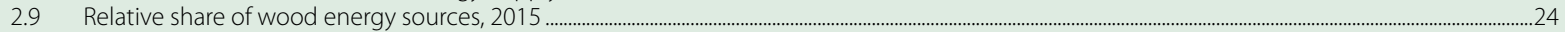

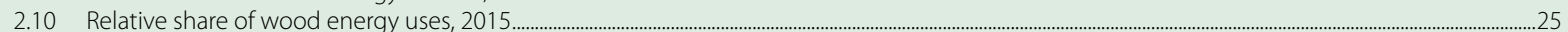

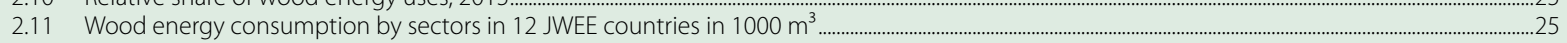

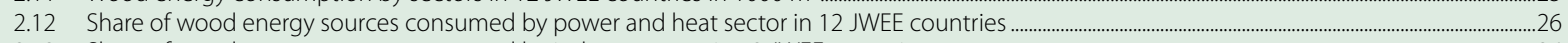

2.13 Share of wood energy sources consumed by industry sector in 12 JWEE countries

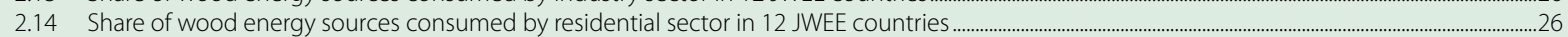

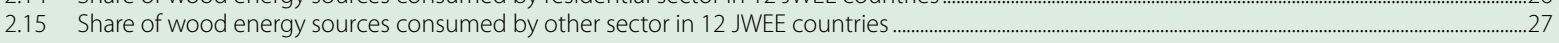

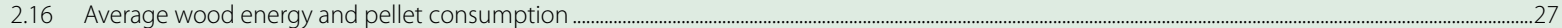

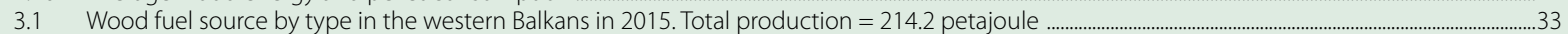

3.2 Roundwood and fuelwood production for various regions, 1990-2016

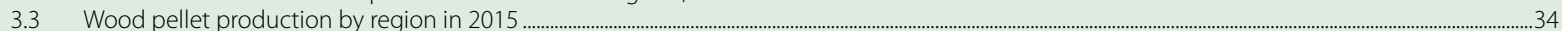

3.4 Annual charcoal production in North America, Europe and the Russian Federation (2010-2016) ....................................................................................35

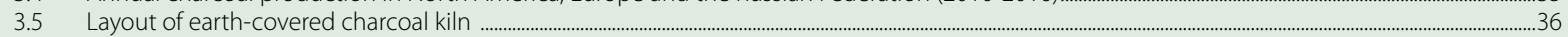

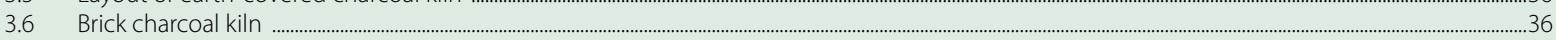

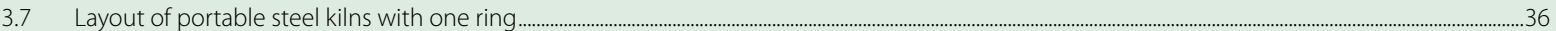

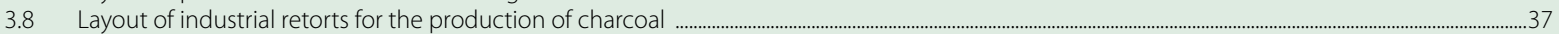

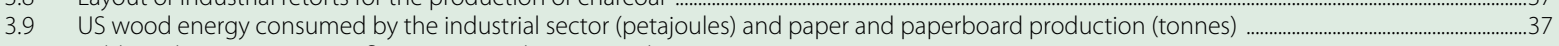

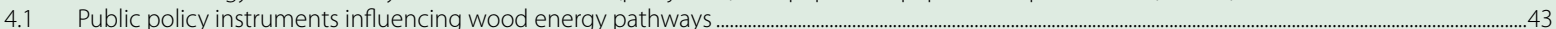

5.1 Actual and extrapolated wood fuel consumption, reported industrial roundwood production, and estimated potential

wood fuel production in the EU28, North America and other UNECE member States in 2013.........................................................................................5

Global chemical pulp production, 1996-2015, for North America, EU28 and all other ECE and for the Rest of the World .................................................56

(A) Imports and (B) exports of all fuelwood (code 4401) from 2000 to 2015

(A) Imports and (B) exports of fuelwood in logs (code 4401 10) from 2012 to 2015 ..............................................................................................................5

(A) Imports and (B) exports of wood pellets (code 4401 31) from 2012 to 2015

Imports into the EU by region of origin for (A) fuelwood in logs and (B) wood pellets from 2012 to 2015 ...........................................................................58

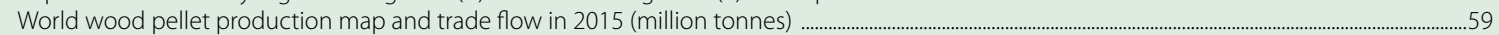

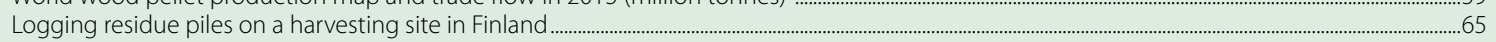

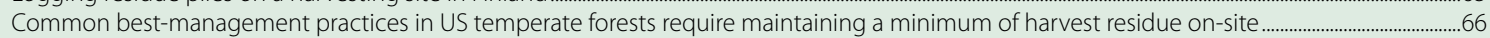

Mixed production design with Poplar trees, providing 5 meter-long high-grade logs and tops chipped for energy use ............................................67

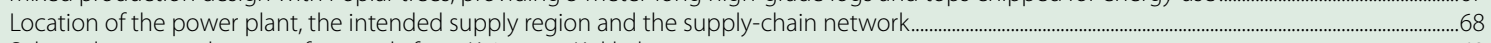

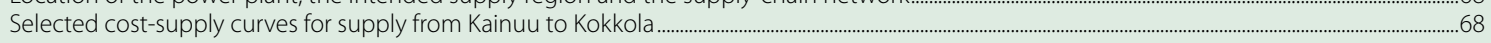

Spatially-explicit, sustainable levels of removal of logging residues ( $\mathrm{m}^{3}$ per km² per year) in 2012 and 2020

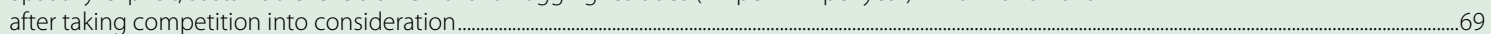

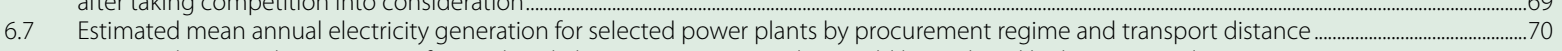

6.8 Estimated potential percentage of annual coal electricity generation that could be replaced by logging residues

for each selected power plant at a $60 \mathrm{~km}$ concentric procurement radius....

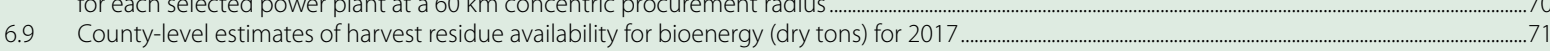

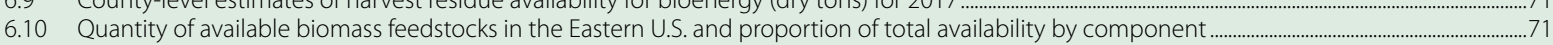

6.11 Screenshot of the publicly available viewer of biomass potentials in Europe $\ldots$ 


\section{ACKNOWLEDGEMENTS}

The secretariat of the ECE/FAO Forestry and Timber Section would like to recognize the following people for their contributions toward the production of this publication:

\section{EDITOR}

Francisco X. Aguilar, University of Missouri, USA

\section{LEAD AUTHORS}

\begin{tabular}{|c|c|c|}
\hline CHAPTER & & \\
\hline $\begin{array}{l}\text { 1. The multiple functions of wood } \\
\text { energy }\end{array}$ & $\begin{array}{l}\text { Antti Asikainen } \\
\text { Francisco X. Aguilar }\end{array}$ & $\begin{array}{l}\text { Natural Resources Institute Finland } \\
\text { University of Missouri, USA }\end{array}$ \\
\hline $\begin{array}{l}\text { 2. Wood energy data: the joint wood } \\
\text { energy enquiry }\end{array}$ & $\begin{array}{l}\text { Sebastian Glasenapp } \\
\text { Alex McCusker }\end{array}$ & $\begin{array}{l}\text { UNECE/FAO, Thünen Institute, Germany } \\
\text { UNECE/FAO }\end{array}$ \\
\hline 3. Wood fuels & $\begin{array}{l}\text { Branko Glavonjic } \\
\text { Warren Mabee }\end{array}$ & $\begin{array}{l}\text { University of Belgrade, Serbia } \\
\text { Queen's University, Canada }\end{array}$ \\
\hline $\begin{array}{l}\text { 4. Public policy instruments to } \\
\text { support sustainable wood energy }\end{array}$ & Francisco X. Aguilar & University of Missouri \\
\hline $\begin{array}{l}\text { 5. Outlook for future wood fuel } \\
\text { markets }\end{array}$ & Karen Abt & US Department of Agriculture Forest Service, USA \\
\hline $\begin{array}{l}\text { 6. Sustainable levels of wood fuel } \\
\text { removals }\end{array}$ & Perttu Anttila & Natural Resources Institute Finland \\
\hline Annex: JWEE country profiles & $\begin{array}{l}\text { Sebastian Glasenapp } \\
\text { Alex McCusker }\end{array}$ & $\begin{array}{l}\text { UNECE/FAO, Thünen Institute, Germany } \\
\text { UNECE/FAO }\end{array}$ \\
\hline Annex: Glossary & Dinko Vusić & University of Zagreb, Croatia \\
\hline
\end{tabular}

\section{CONTRIBUTORS (IN ALPHABETICAL ORDER)}

Eija Alakangas, VTT Technical Research Centre of Finland

Tuukka Castren, The World Bank

Gillian Cerbu, The World Bank

Matthias Dees, University of Freiburg, Germany

Michael Goerndt, Missouri State University, USA

Pierre Hermans, Forest and Timber Consultancy, Belgium 
Markus Lier, Natural Resources Institute Finland

Andrew Mitchell, The World Bank

Jan Radermacher, The World Bank

Klas Sander, The World Bank

Richard Sikkema, European Commission (JRC)

Oleg I. Vasilyev, Saint Petersburg Forestry Research Institute, Russian Federation

Holger Weimar, Thünen Institute of International Forestry and Forest Economics, Germany

\section{REVIEWERS (IN ALPHABETICAL ORDER)}

Cristina Calderón, European Biomass Association

Anthony D'Amato, University of Vermont, USA

Fernando Diaz Alonso, European Commission, Statistical Office of the European Communities

Anna Ebers, University of St. Gallen, Switzerland

John Kabrick, US Department of Agriculture Forest Service, USA

Mark Knaebe, US Department of Agriculture Forest Service, USA

Vladimir Kubecek, International Energy Agency

Dae Yong Kwon, International Energy Agency

Pharoah Le Feuvre, International Energy Agency

David L. Nicholls, US Department of Agriculture Forest Service, USA

Arnaud Pincet, International Energy Agency

Adrian Whiteman, International Renewable Energy Agency

Zuzhang Xia, Food and Agriculture Organization of the United Nations

The following individuals also contributed as members of a Taskforce created in 2016 to delineate the initial contents for this publication:

Isabelle Brose, European Confederation of Woodworking Industries (CEI-Bois)

Surendra Joshi, Swedish Forestry Agency

Alicja Kacprzak, UNECE/FAO

Florian Kraxner, International Institute for Applied Systems Analysis, Ecosystems Services and Management Program, Austria

Fanny Langue, European Biomass Association

Kasimir Nemestothy, Austrian Chamber of Agriculture

Richard Vlosky, Louisiana State University, USA

Jeremy Wall, European Commission 


\section{INTRODUCTION TO THE PUBLICATION}

Wood is a major source of renewable energy in the UNECE region offering a scalable, flexible and, in many instances, the only reliable source of energy. Wood energy is used by households (34.6\%), the wood-processing industry (39.3\%), power and heat (19.6\%) and other sectors (4.1\%) as per the 2015 data from the Joint Wood Energy Enquiry (JWEE), led by the UNECE/FAO Forestry and Timber Section. Beyond helping meet energy demands, wood energy has historically contributed to wellbeing by bringing people together, back to nature and its use is included in many cultural traditions - although inefficient combustion can have detrimental consequences to human health.

This publication highlights some of the common uses and most recent statistics on wood energy markets across the UNECE region. It aims to communicate the relevance of wood energy in the region and help bridge information about the forest and energy sectors. It also intends to offer some of the best-available information on the role that wood energy can play in various sectors to support environmental, energy, and socio-economic strategies toward a greener economy. It focuses on commercial wood energy uses in the UNECE inclusive of energy generated for cooking, heating and electricity generation. The potential for use in advanced transportation fuels is noted but is not a central component here as they largely remain at a research and development stage.

Chapter 1 describes how wood energy is an integral component to forest management and wood utilization across the UNECE region. Procurement of wood fuel can support sound forest management in early stand development stages by promoting thinnings and fuel treatments and also enhance the production of high-value timber in later stages of stand development. Use of wood energy can have positive climate implications if it substitutes fossil fuels and reduces the net release of carbon into the atmosphere through sequestration in biomass and long-lived products. Wood energy is highly scalable from use in small-scale residential units to large-scale industrial settings to generate heat and electricity. Use of wood for energy creates job opportunities not only along the supply-chain of woody biomass feedstocks, but also through investments in technology development and energy conversion and final consumption. Optimal use of wood for energy should take into account local and regional infrastructures along idiosyncratic characteristics of forests, soils, climatic conditions and types of energy demanded to yield the greatest economic, environmental and social benefits. Wood energy can play a central role in supporting resilient and secure energy systems; it holds important but often intangible values to support livelihoods across the UNECE region.

Chapter 2 provides an overview on the historical development and background on the JWEE as an effort by the UNECE/ FAO to help enhance data accuracy and completeness that had likely resulted in the underestimation of wood energy supply and consumption in national assessments. Completeness of data on wood energy is challenged by large shares of wood fuel being traded in informal markets (often directly between landowners and final consumers), procured and consumed locally - although larger amounts are being traded internationally. The structure of the questionnaire is explained and an outline of other international wood energy data providers (FAO, Eurostat, International Energy Agency and International Renewable Energy Agency) is offered and compared with the JWEE. Data gathered through the JWEE over the 2007-2015 period present the most current statistics and trends of wood energy sources, uses, and consumption indicators in the UNECE region. Aggregated data for each member state that responded to the JWEE 2015 are provided in an Appendix.

Chapter 3 offers descriptions and commonly-used wood energy fuels. It highlights how wood offers a fuel that is flexible for different energy uses and is a low-cost energy storage system. Firewood is one of the most commonly used wood energy fuels and some of the methods used to process it at artisanal and industrial scales are included. Densified wood energy fuels, particularly use of black liquors and wood pellets, are described and data used to reflect on their importance to energy and electricity systems, respectively. Increased use of wood energy in modern household, industrial, power and combined heat-andpower plants has required standardization of fuel specifications which is illustrated in this Chapter by wood pellets.

Chapter 4 describes how public policy has offered a foundational framework to promote the role that renewable energies have in supporting energy diversification, efficiency and security, promoting economic development, reducing greenhouse gas emissions, and enhancing forest health. Public policy instruments implemented most frequently include (i) rules and regulations, (ii) incentives, and (iii) research and education. Specific public programs influencing wood energy supply-chains vary greatly among UNECE member nations due to differences in governance and administrative structures as well as forest resources, among others. These are often implemented jointly but their simultaneous application can result in a cumbersome structure 
and hinder effectiveness. There are ongoing efforts to streamline their implementation toward more efficient outcomes. But not all nations have wood energy supply-chains to be readily affected by public policy interventions. Such is the case in Central Asia where households depend heavily on wood, largely procured from public lands, to meet their basic cooking and heating needs. The dominance of public lands in Central Asia may offer opportunities for the reconsideration of land use and usufruct rights to address issues of energy poverty, insecurity and sound forest management. Public policy affecting wood energy markets should follow principles of stakeholder inclusiveness, incremental and permanence of targets, uniformity in incentives, flexibility in their application, tailored to local conditions and awareness of cost-of-compliance considerations.

Chapter 5 offers an outlook to future wood energy production in the UNECE region based on most-current reference outlooks of wood energy consumption and production in the European Union and North America. The last decade has seen notable increases in wood energy production, consumption and trade across the UNECE region. Most of these changes have been driven by the European Union (EU) Renewable Energy Directive that led to increased wood pellet consumption, notably in utility scale facilities, and consequent increases in trans-Atlantic and intra-European wood pellet trading. Pellets are expected to continue to increase in importance in EU energy through 2030, and then stabilize after 2030. Other forms of wood energy, including black liquor, wood processing residues, waste wood, and firewood, are less frequently traded for energetic purposes - they are primarily consumed in the country in which they are produced or traded for material use in the wood processing industry. Production and consumption of wood energy is not expected to increase over the next decade at the same rate as the last, especially as the production of paper stalls, costs of alternative renewable electricity technologies fall, and if fossil fuel prices continue below long-run averages.

Chapter $\boldsymbol{6}$ describes how wood energy projects can assess past and projected impacts of wood fuel removals to determine their sustainability. The importance of how particular consideration must be given to the lands from which wood fuel is sourced from, with sensitive sites excluded from management and adoption of maximum removal guidelines for eligible sites is stressed. Wood for energy best management practices (BMPs) have been developed to protect soils (e.g. by setting aside sensitive areas and recommending maximum removal levels to preserve nutrient cycles), water quality (e.g. by establishing buffer zones) and wildlife habitat (e.g. by suggesting minimum levels of retention of live and dead wood). BMPs can be applied to assess sustainable levels of wood energy feedstock removals. Assessments can be based on forest inventory data and follow BMP guidelines to determine maximum available direct wood energy feedstocks at different geographic scales. Results from such assessments give valuable information to support public policy decisions and private sector investments on particular energy facilities. Examples drawn from recent studies, all of which relied on forest inventory data as a basis and biophysical and economic constraints to examine potential supply levels, are presented for assessments at local, sub/national, and regional scales. 
Chapter

5

THE

MULTIPLE

FUNCTIONS

OF WOOD

ENERGY
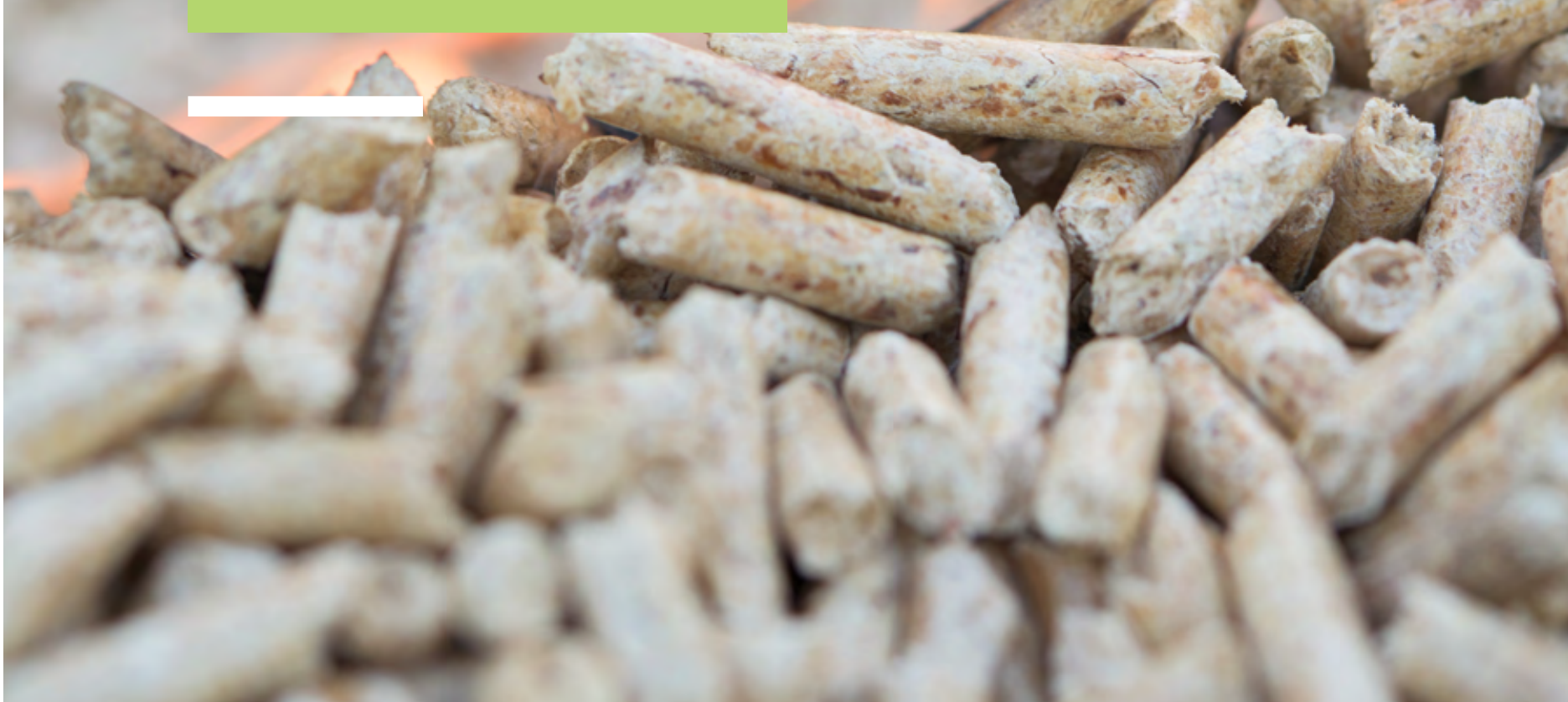


\section{Highlights*}

* Wood energy is unique in serving important functions in support of forest resource management, environmental quality, economic development, renewable energy systems and socio-cultural values

* Wood energy use is an integral part of forest management operations and the wood products industry supply-chain

* Forests have an increasingly important role as a source of feedstocks for renewable energy, other wood materials, and in storing carbon

* Intensive and effective management for wood energy feedstocks is strongly linked to local and regional forestry, industry and infrastructure conditions

* Wood energy utilization can reduce carbon emissions when it displaces fossil fuels and maintains or increases biomass in forests and products

* Wood energy has to be managed efficiently to maximize energy output and reduce potentially harmful emissions

* Wood energy contributes to resilient and secure energy systems and holds socio-cultural values central to livelihoods across the UNECE region 


\subsection{Introduction}

Wood energy is an integral component to forest management and wood utilization. It supports forest management in early stand development stages by promoting thinnings and fuel treatments and also enhances the production of high-value timber in later stages of stand development. Use of wood energy can have positive climate implications if it substitutes fossil fuels and reduces the net release of carbon into the atmosphere through sequestration in biomass and longlived products. Wood energy is highly scalable from use in small-scale residential units to large-scale industrial settings to generate heat and electricity. Use of wood for energy creates job opportunities not only along the supply-chain of woody biomass feedstocks, but also through investments in technology development and energy conversion and final consumption. Optimal use of wood for energy should take into account local and regional infrastructures along idiosyncratic characteristics of forests, soils, climatic conditions and types of energy demanded to yield the greatest economic, environmental and social benefits. Wood energy can play a central role in supporting resilient and secure energy systems; it holds important but often intangible values to support livelihoods across the UNECE region.

\subsection{Wood Energy Functions}

\subsubsection{Forest resource management}

Wood energy utilization is commonly integrated in forest management practices and the wood products industry. Wood energy feedstocks can be considered a co-product of forest management as part of silvicultural treatments inclusive of thinnings, final integrated harvests, and salvage logging. Although wood fuel prices are lower than other woody raw materials (e.g. in Finland, the average price of softwood sawlogs is $55 € / \mathrm{m}^{3}$, pulpwood $16 € / \mathrm{m}^{3}$ and logging residues and thinning wood for energy chips c.a. $3.5 € /$ $\mathrm{m}^{3}$ ), additional revenues can increase profitability of forest management operations, particularly in the early stages of stand management. The literature to-date suggests that wood fuel prices could facilitate more active management among smaller ownerships (e.g. $\leq 40 \mathrm{ha}$ ) as biomass revenues can increase profitability and make harvests that integrate wood fuel with sawtimber and/or pulpwood financially feasible (Aguilar et al. 2014, Cai et al. 2016).

Integration of wood fuel removal as part of management activities can offer significant benefits, such as, supporting forest health objectives and creating additional revenue streams from the sale of previously non-marketable materials (Figure 1.1). Use of wood fuel promotes thinnings that can also support pulpwood supply and growth of high-quality sawn timber in later stages of stand development. Across the UNECE region, planned wood fuel removal can have positive impacts on habitat and biodiversity conservation by facilitating the restoration of historically prevalent sparsely wooded landscapes not dominated by dense forest canopy such as woodlands or savannahs (Schwedler and McCarthy, 2011). Wood energy extraction within priority conservation areas can have a positive effect on rare- and short-dispersing species by removing competing woody species. For less common tree species in the landscape, slash removal could also potentially contribute to biodiversity efforts although recommended levels of fine and coarse woody debris retention should be observed to maintain health of forests and dependent communities (Berndes et al. 2016). Another benefit is that of offering market value for material derived from control of invasive species or insect outbreaks and climatic disturbances such as severe drought, fire, windstorms or snow damage. A recent review of woodfuel-treatment studies from forests in the western US suggests that thinning plus burning reduced fire severity, tree mortality following wildfires and could reduce related carbon emissions (Berndes et al. 2016). This could be a promising fire management tool in dry forests across the UNECE region.

\section{FIGURE 1.1}

\section{Harvest of wood fuel can be integrated with other management activities}

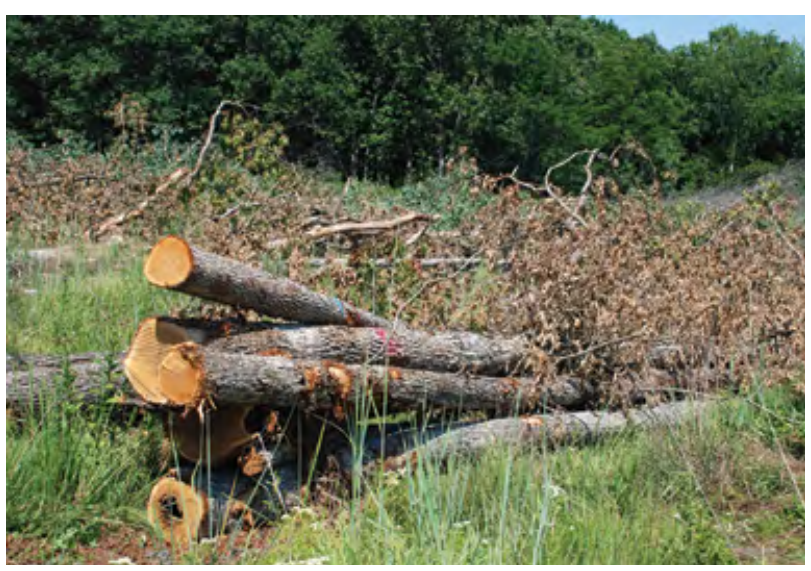

Source: Francisco X. Aguilar.

The use of wood fuel can also be associated with risks. Localized negative impacts of wood fuel extraction are associated with a reduction in organic materials and disruption of nutrient cycles. Greater removal of wood biomass for bioenergy raises concerns about whether adequate levels of nutrients (e.g. calcium, magnesium, and potassium) can be maintained to protect site productivity (Janowiak et al. 2010). Many tree components that comprise a small amount of biomass, such 
as leaves, cambium, and root tips, contain a proportionately large quantity of nutrients when compared with tree wood (Hakkila, 2002, Powers et al. 2005). Models of forest nutrient budgets suggest that intensive whole-tree harvesting can cause long-term decline in site productivity (e.g. Boyle et al. 1973, Paré et al. 2002). Within plant-dependent communities wood fuel extraction could affect saproxylic (i.e. dead wooddependent) species. Wood fuel extraction due to more intensive harvests can result in left-over dead-wood volumes below the natural range of variation of natural disturbance regimes (Berger et al. 2013).

There has been great expectation for the role of dedicated fuelwood plantations as a source of wood energy feedstocks but to-date there has been limited commercial success. Some estimates suggest energy coppice plantations could reach similar supply levels of current co-products from forest management. However, coppice crops for energy remain experimental and may be important within confined areas (e.g. Southern Sweden). The high cost of biomass production has been a salient constraint to the slow development of dedicated energy plantations. Other factors to take into consideration are the potential indirect land use effects associated with displacing other types of vegetation cover for the intensive management of biomass that could place greater pressure on local water resources and worsen energy input-output ratios in comparison with more conventional forest management (Popp et al. 2014). Estimates from dedicated pine energy plantations suggest an even larger water footprint than agricultural energy plantations (Mathioudakis et al. 2017).

\subsubsection{Environmental quality}

Wood can be a renewable source of energy. As it is the case for any other energy source there are environmental impacts associated with wood energy generation. Environment impacts are partly determined by the management of wood energy supply systems inclusive of forests and their integration with other wood product uses, and energy utilization. However, compared with fossil fuels that have a one-way flow of emissions to the atmosphere, the sustainable management of wood energy does not need to result in the continuous and permanent increase of carbon (Figure 1.2). Biogenic carbon circulates between terrestrial carbon stocks and atmosphere in large quantities regardless of its utilization for energy and anthropogenic material needs. There are intrinsic climate benefits from tapping onto this natural cycle and the implementation of systems that supply products that keep carbon fixed over long-terms while also generating energy (Lippke et al. 2012). This potential can be illustrated with a forest prone to be affected by wildfires with consequential damages to timber and carbon released with no useful energy generated - aside of potential short- and long-term harmful damages to society. Alternatively, wood fuel can be harvested and processed to generate useful energy to displace fossil fuels. This type of forest management can reduce the risk and intensity of a fire, thereby reducing associated carbon emissions.

\section{FIGURE 1.2}

\section{Cyclic and linear carbon flows of woody biomass and fossil fuels}

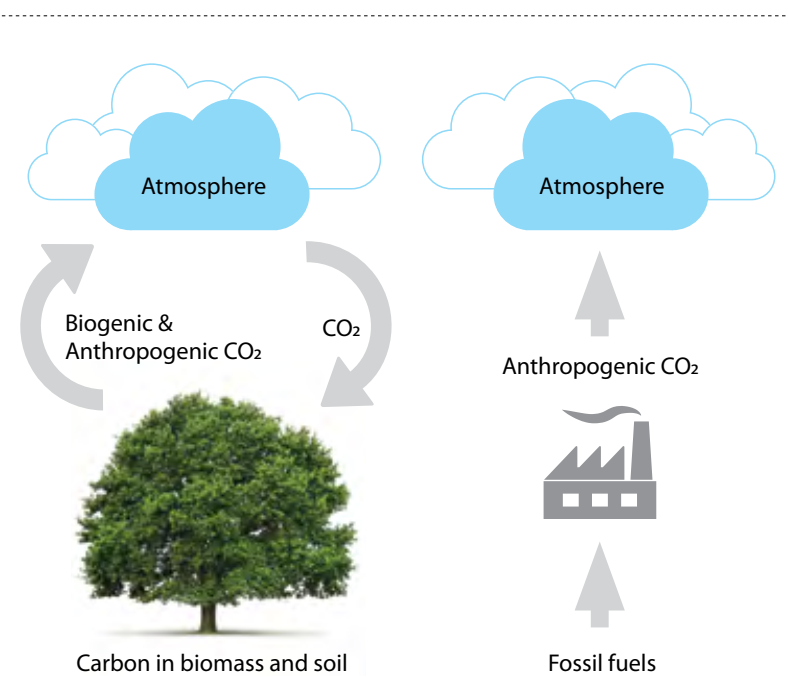

Source: Adapted from Berndes et al. 2016.

Renewable wood energy can be carbon neutral or capable of yielding net emission reductions. Carbon neutrality is based on two premises: (i) the fact that carbon released through combustion or decay had once been absorbed from the atmosphere, or (ii) the recognition that through sustainable management an equal amount of carbon can be sequestered back into growing biomass (Koponen et al. 2015). Wood energy, as compared to fossil fuels, might reduce impacts of long-term carbon emissions as long as lands from which wood is sourced remain under forest management and carbon remains captured in long-lived wood products integrated with wood energy supply-chains (Miner et al. 2014). Carbon sequestered in wood products is an important complement to wood energy assessment and should be taken into account when conducting carbon assessments. In long-lived wood products carbon stays fixed for longer periods than when used as fiber or for energy generation. For instance, the carbon sink potential of wood products in Finland has been estimated at about10 million $\mathrm{CO}_{2}$-equivalent tonnes per year if logging increases by 10 to 15 million m³ (Finnish Ministry of Agriculture, 2014).

There is an ongoing debate concerning the intensification of forest management to increase wood energy supply and other uses while meeting greenhouse gases (GHGs) 
reduction goals. There is an inherent time lag between carbon released through woody biomass harvesting and combustion, sequestration back into new biomass, and use of wood products (Koponen et al. 2015). Also, long-term storage of carbon in dense and aging forests is not certain. With age, tree growth declines and forests become more susceptible to storm, insect and disease damages, among other exogenous and uncertain factors. As a result forests can potentially turn from a carbon sink to a net source of emissions (Kurz et al. 2008, Asikainen et al. 2016). Berndes et al. (2016) stress the importance of defining how forest management and the use of wood fuel can contribute to short- and long-term climate objectives within relevant reference scenarios. Among these scenarios, how forest management, forest product markets and forest carbon stocks would evolve in the absence of bioenergy demand and production.

How wood energy can contribute to reducing carbon emission in the short- and long-term is a complex issue further nuanced by indirect and induced effects. Among them, land use and land use change are issues that have taken central stage in the assessment of climate benefits of bioenergy (e.g. Berndes et al. 2011). Indirect impacts recognize how land allocated to dedicated energy crops can in effect cause changes in other lands resulting in the leakage of carbon from biomass regrowth benefits. The use of wood fuel or any other type of biomass as a raw material or energy source should not jeopardize the carbon sink and storage capacity of land and minimize emissions associated to indirect land use changes. Moreover, the long-term analysis of potential climate benefits from the use of wood energy should also take into consideration market induced effects. For instance, Wang et al. (2015) estimate that GHG emissions could be reduced by about $74 \%$ by replacing coal with wood pellets in the generation of electricity in the UK partly due to new developments in management and technology. It is generally agreed that wood energy is poised to yield among the lowest expected indirect land use effects on land allocation and pressure on food, fibre, and fodder when its sourcing is integrated with other uses (e.g. material use of wood) on existing forested lands (IEA, 2009, Lippke et al. 2012). Lippke and Puettmann (2013) report a reduction in emissions of 0.62 units of carbon for every unit of carbon of wood energy combusted when compared to natural gas. This analysis was based on the use of wood sourced from co-products of timber harvesting (forest residues), byproducts from sawmills (sawmill residuals), and clean tertiary (clean demolition material) sources in a District Heating System. Moreover, woody by- and co-products of harvesting and manufacturing are the sources with the least level of uncertainty in carbon accounting scenarios (Hansson et al. 2017, Laganière et al. 2017). Other sources used to generate wood energy such as roundwood from forests or biomass from coppice plantations carry greater uncertainty in terms of potential for $\mathrm{GHG}$ emissions reduction due to indirect and induced effects (Bentsen, 2017, Cintas et al. 2017, Nabuurs et al. 2017).

\subsubsection{Economic development}

The use of side streams and co-products of the forest industry for energy production is one of the largest sources of wood energy in the UNECE region. Data from the Joint Wood Energy Enquiry for 2013 show that the forest-based industry was the largest consumer of wood energy (44\%), followed by the residential (36\%) and combined heat and power (17\%) sectors (Aguilar et al. 2015). Likewise, most of the wood used for energy comes indirectly through the forest industry as a co-product (58\%) and a little over of a third of the wood mobilized for energy comes directly from forests (36\%). Wood energy consumption can support important economic development objectives inclusive of forest management, wood product supply-chain and manufacturing jobs. The largest share of employment associated with bioenergy systems are created along biomass supply-chains as modern energy plants are highly automated. The use of wood fuel and other biomass resources in energy production could potentially support 20 times more local employment per energy unit than other energy alternatives (FAO, 2010). Direct employment comprises jobs involved in wood feedstocks harvest and processing, transport, construction, operation and maintenance of plants. The number of jobs and net earnings is influenced by production method and organization of energy systems. For instance, the utilization of 390,000 dry tons of woody biomass estimated to feed a $100 \mathrm{MW}$ power facility in the Southern US has been estimated to support 585 direct and 481 indirect jobs through the recovery of logging co-products, while direct and indirect employment associated with operation of the power plant were 281 and 115, respectively (Perez-Verdin et al. 2008). This translates into an estimated total of 3.75 full-time direct and indirect jobs per thousand $\mathrm{m}^{3}$ wood biomass processed into bioenergy. In another case, implementation of a woodland restoration project in the Central US with a subsequent flow of additional 175 thousand $\mathrm{m}^{3}$ of biomass for energy could generate additional labor income estimated at about 65 US\$/ $\mathrm{m}^{3}$ and value added of 75 US\$/m³ (Song and Aguilar, 2017). In northwest Russia, a co-combustion combined heat-andpower (CHP) plant using $40 \%$ forest residues of its fuel mix would use 180 thousand $\mathrm{m}^{3}$ (72 thousand dry tonnes) chips made of logging residues. This would generate 55 direct jobs in the harvesting, chipping and transport of wood for energy (Raitila et al 2008). This translates to 0.3 full time direct jobs per thousand $\mathrm{m}^{3}$ woody biomass delivered to the plant. If the raw material would be thinning wood, the needed manpower input would almost double. 
The harvesting of wood fuel is an important and complementary source of income and employment for related forest management and wood products industry sectors. Harvesting of wood fuel can provide alternative employment when the demand for other wood uses is low. This is illustrated by Finland where at the turn of the century the forest industry was in recession but the demand (and supply) of forest energy increased from less than 1 million $\mathrm{m}^{3}$ to 6 million $\mathrm{m}^{3}$ (Thiffault et al. 2016). In the US, a deep economic recession over the 2007-2009 period resulted in the loss of about $25 \%$ of the wood products industry workforce and the utilization of wood for energy helped ameliorate related impacts (Woodall et al. 2012). Employment is extended beyond management and utilization of wood fuel to equipment manufacturing. This is illustrated by Upper Austria - one of Austria's nine federal states that accounts for over 25\% of national exports. Since the mid-1990s, the government of Upper Austria has prioritized energy efficiency and renewable energy developments. Renewable energy currently supplies about 32\% of the gross energy consumption in the state, of which almost $15 \%$ is generated from wood, about 10\% from hydropower, and 6\% from solar and other renewable energy sources. The State Agency OÖ Energiesparverband manages the "Oekoenergie-Cluster" a network of renewable energy and energy efficiency companies. There are some 160 companies and institutions in the cluster that employ over 8,880 people and generate annual revenues exceeding 1.9 billion Euros (4\% of state gross domestic product). Biomass energy has emerged as an important economic driver for the state where the biomass heating sector employs over 5,000 people. It is important to mention that over $25 \%$ of all modern biomass boilers installed in the European Union have been manufactured by companies from Upper Austria which highlights the regional economic importance of the Oekoenergie energy cluster (Egger et al. 2014).

Cascading use of woody biomass has been recently brought up as a potential application of the principles of circular economy to the forest sector but its implementation calls for caution (Figure 1.3). Most limiting definitions request the use of wood for material products at least once before converted into energy. Others consider integrated use of wood components for products, chemicals and energy as a type of cascading use. It is important to note that a cascade hierarchical approach should be applied prudently and consider particular national and regional circumstances (Koponen et al. 2015, Berndes et al. 2016, Sikkema et al. 2016). Moreover, the cascading definition should take into account the efficiency of the recycling of raw materials. For example, if cascading use requires significant amounts of resource energy and complementary inputs, it might not support total material and energy efficiency. There might also be limitations in reasonable cascading cycles due to logistical challenges and material quality issues (Sokka et al 2015). Moreover, applying a cascading principle that promotes the use of forest biomass for wood products ahead of energy may not deliver the greatest climate or economic benefits. It is important to stress that if cascading were to be applied it should allow for ample flexibility to consider what is deemed optimal for complex material, industry and energy system circumstances (Berndes et al. 2016).

\section{FIGURE 1.3}

\section{Cascading use principle of biomass}

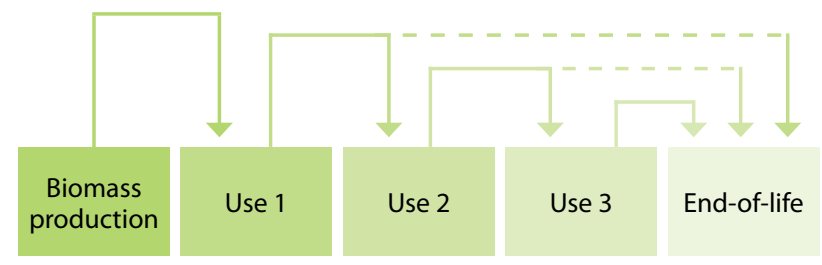

Source: Sokka et al. 2015.

\subsubsection{Renewable energy systems}

Wood energy is the most important renewable energy source in many UNECE member States. Wood accounts for $46 \%$ of all renewable sources in the 27 UNECE countries who replied to the Joint Wood Energy Enquiry (JWEE) in 2013. Wood contributes and supports national energy diversity goals. In countries with significant forest industries, such as Finland and Sweden, a high share of forest energy comes from industrial and forestry residues. In 2014, around 25\% of Finland's total energy consumption (372 TWh, 1340 PJ) was produced with wood fuels (93 TWh, 333 PJ). 80\% of Finnish wood energy was produced using co-products and residues from the forest industry and from silvicultural and harvest operations, of which 64\% (61 TWh, 220 PJ) consisted of industrial residues such as black liquor, bark, sawdust and other wood residues, and 16\% (15 TWh, 54 PJ) of logging residues, stumps and small diameter trees combusted in CHP plants. In northwest Russia, the situation is different due to competition caused by fossil fuels; the share of wood in the fuel mix was typically 1-5\% in different regions (Gerasimov \& Karjalainen, 2013). As Nordic countries consume large amounts of wood fuel, the export of wood chips and pellets has been of great interest in in the Northwest region of the Russian Federation.

Wood is a flexible source of energy contributing to resilient energy systems at multiple scales ranging from residential to industrial uses. It can be used by households to produce energy for heating and cooking. Traditional firewood is a very important source of energy across UNECE member States 
especially in rural areas but increasingly in more urbanized areas - as reflected on increasing per capita consumption of wood pellets. In European Nordic countries detached houses have fireplaces and ovens to produce heat especially during winter. This practice has significant consequences at the national energy system level. Electricity is the main heating system in Nordic countries and use of wood energy feedstocks (e.g. firewood, pellets) helps reduce pressures for electricity demand over winter in particular. Wood plays a critical role in meeting basic heat needs which can be accentuated during power outages by offering an alternative energy source. In temperate zones the use of wood for energy by households offers an important source of energy too. For instance, in the US wood energy has reportedly gained popularity as a home heating option in many areas. The increase is most notable in the US Northeast - where it represents a lower-cost heating alternative to using fuel oil and kerosene- and most recent data suggest at least a 50\% increase in the number of households that use wood as their main heating source from 2005 to 2012 (Berry, 2014). Nationwide, nearly 10\% of US households use some kind of wood for energy consumption (inclusive of logs, pellets, scraps, and others) with total annual consumption about the same as propane consumption. Rural households account for about total $63 \%$ of U.S. wood energy residential consumption (US Energy Information Administration, 2017).

At the municipal level wood is often used for heating (Figure 1.4). Wood chips, bark and sawdust have become a major fuel in the district heating systems. They can be combusted together with peat and many different wood fuel assortments can be digested in modern district heating plants. In large CHP plants providing district heat for cities and electricity to the national networks wood has become an important fuel. Wood fuel can also be co-combusted in coal fuelled plants. However, the thermal efficiency is often lower than in designated CHP plants.

Wood fuel can also be used as feedstock for liquid transportation fuels. It offers several advantages because its use does not affect directly food production or price and the conversion into energy can have a more favorable energy balance than dedicated cellulosic crops. There are two main routes to produce liquid biofuels from ligno-cellulosic biomass: biochemical and thermochemical (European Biofuels Platform, 2008). So far, production of these secondgeneration biofuels has reached a limited commercial stage (e.g. in Finland), and there are plants in operation that are using tall oil or sawdust as feedstocks. Biogas can also be produced from biomass, but the suitability of woody biomass for biogas production is poor (IEA Bioenergy, 2008).

Efficiency in the supply, conversion and final utilization is central to wood energy's potential to generate the greatest amount of renewable energy. For instance, recent estimates

\section{FIGURE 1.4}

\section{Silos storing wood chips at the University of Missouri power plant}

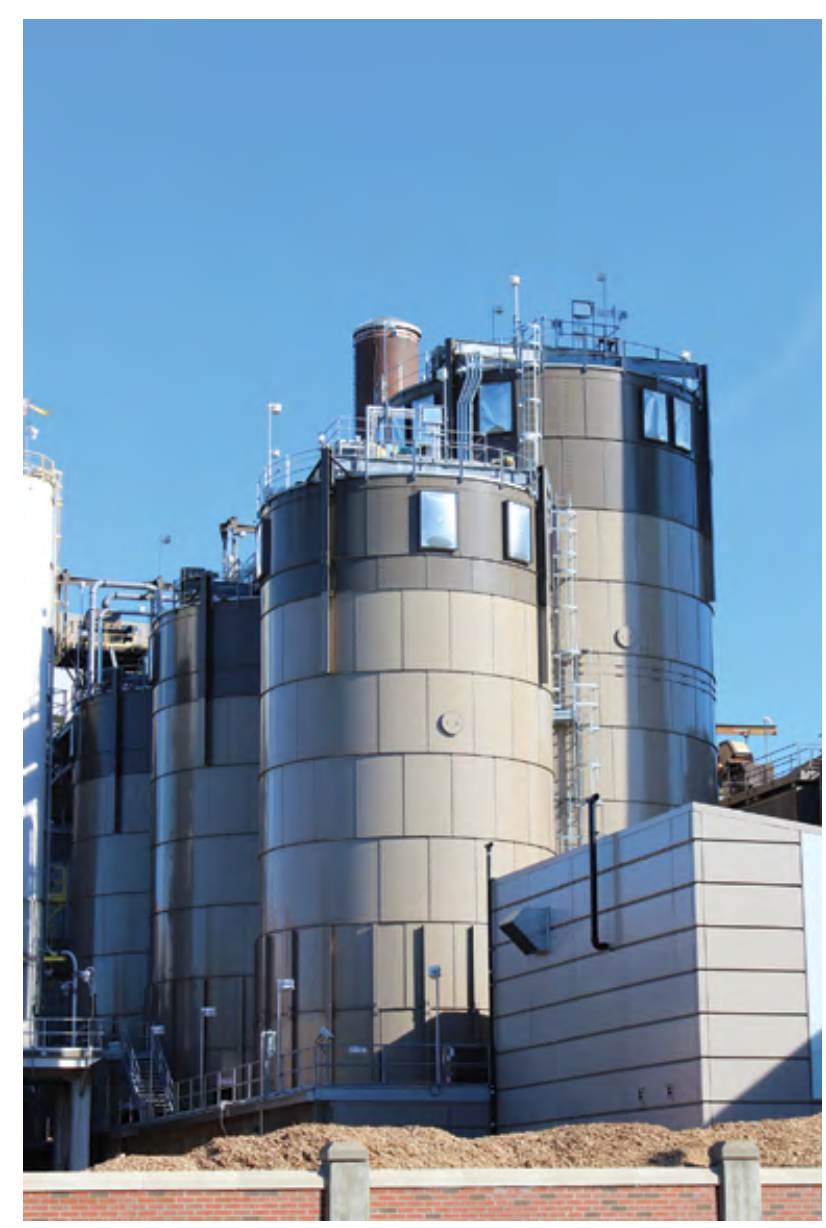

Source: Francisco X. Aguilar.

of net energy generated per tonne of wood fuel suggest that high-efficiency heat production can yield about twice as much net utilizable energy than electricity-only generation (Song and Aguilar, 2017). In general, wood energy pathways generating heat yield the greatest energy output after deducing energy consumed or lost during processing and conversion. Efficiency in energy generation and consumption, and improvements over current levels, are usually included within renewable energy targets as illustrated by the EU Directive 2009/28/EC. This Directive requires national action plans to meet an overarching EU target of 20\% efficiency gains, 20\% reduction in greenhouse gas emissions compared to 1990 levels and $20 \%$ of renewable energies as total of energy consumption by 2020. New targets for 2030 call for a $27 \%$ share of renewable energy sources in total consumption, and, from the levels of 1990, 27\% efficiency gains and a 40\% reduction in GHG emissions. It is expected that wood shall still play a major role in reaching those targets (Proskurina 
et al. 2016). However, in areas where wood is used as the most accessible heating source and procured through lessdeveloped supply chains, expected reduction in energy demands due to efficiency gains may not materialize immediately. For example, among Central Asian nations even with improvements in insulation to enhance efficiency in the consumption of heat, significantly higher energy levels of wood energy used over current demand are necessary to ensure comfortable living conditions (Kargasov, 2008, Fabian et al. 2010).

Inefficient combustion of wood energy feedstocks can have direct consequences on air quality and impact human health. Inefficient combustion of wood can increase indoor and outdoor wood smoke pollution, including carbon dioxide $\left(\mathrm{CO}_{2}\right)$, methane $\left(\mathrm{CH}_{4}\right)$ and particulate pollution ( $\left.\mathrm{PM}{ }_{10}, \mathrm{PM}_{2.5}\right)$. Most wood smoke particles are 2.5 microns or less in size smaller in diameter than a human hair. Direct breathing of wood smoke can have severe consequences on human health. Breathing wood smoke can have short- and longterm effects. Some of the short-term effects may include irritated eyes, throat, sinuses, and lungs; headaches; reduced lung function, especially in children; lung inflammation or swelling; increased risk of lower respiratory diseases; more severe or frequent symptoms from existing lung diseases (such as asthma, emphysema, pneumonia, and bronchitis); and risk of heart attack and stroke. Some long-term effects can include chronic lung disease including bronchitis and emphysema; chemical and structural changes in lungs; and cancer (State of Washington Department of Ecology, 2012). Naeher et al. (2007) reports that for each 100 micrograms of fine particulate pollution per cubic metre of air was associated with $12 \%, 19 \%$, and $26 \%$ increases in cases of upper respiratory tract illness, asthma, and rhinitis, respectively. Residential use of wood can be a significant source of fine particulate pollution. For instance, in the US state of Washington it has been estimated that residential woodstoves contribute about 35\% of state-wide PM2.5 emissions (State of Washington Department of Ecology, 2012). More efficient combustion and lower emissions can be attained by better management of wood fuel such as drying as higher moisture contents in addition to lowering effective heat recovery - are linked to higher emissions of carbon. Magnone et al. (2016) found that total carbon emissions from burning of oak wood using an indoor wood stove rose from $0.25 \mathrm{~g} / \mathrm{kg}$ to $1.12 \mathrm{~g} / \mathrm{kg}$ as moisture content increased from $10.3 \%$ to $56.3 \%$.

\subsubsection{Socio-cultural values}

Wood energy has inherent socio-cultural values beyond opportunities to expand sound forest management, support economic development, or generate renewable energy while meeting environmental objectives. Large volumes of woody biomass for energy can be delivered outside forestry e.g. from urban surroundings and farmland. Wood is considered to be humankind's first source of energy for heating and cooking (FAO, 2013). Wood energy as a type of ecosystem service - coming directly or indirectly from forests - provides a fuel source and is often fundamental to cultural values in how it supports traditions, recreation and educational opportunities. Hence, wood energy can be a direct contributor to well-being. It plays an integral role in households' energy security and resiliency and can offer opportunities for social cohesion and wellness (Perlin, 1989, Mytting, 2015). For example, in Nordic nations such as Finland women historically gave birth in wood-heated saunas because the walls of traditional smoke saunas were lined with naturally bacteria-resistant soot, making them the cleanest room in the house. Wood-heated saunas were places of purification rituals before marriage, and the bodies of the dead were washed and prepared for burial on their wooden benches. Historically, for many Finns the sauna was the holiest room in the house and to-date it is the one most closely associated with their wellbeing (Bosworth, 2013).

\section{FIGURE 1.5}

\section{Pekka Halonen's work chronicled the Finnish landscape and its people in his painting "In the sauna" (1925)}

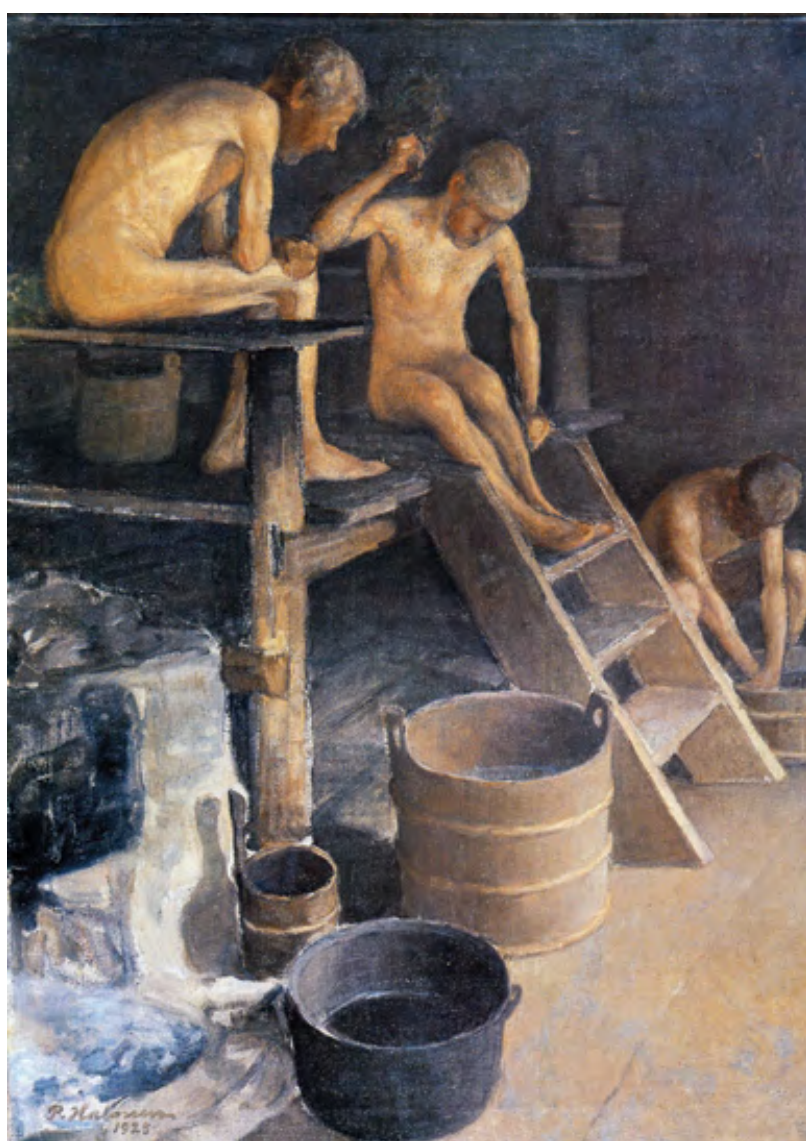

Source: Wikimedia commons. 


\section{FIGURE 1.6}

\section{Forest and wood use in EU in $\mathbf{2 0 1 0}$}

All numbers without units are in million $\mathrm{m}^{3}$ swe (solid wood equivalent) growing stock, total million $\mathrm{m}^{3}$ o.b. (ind.Stumps) 21,021

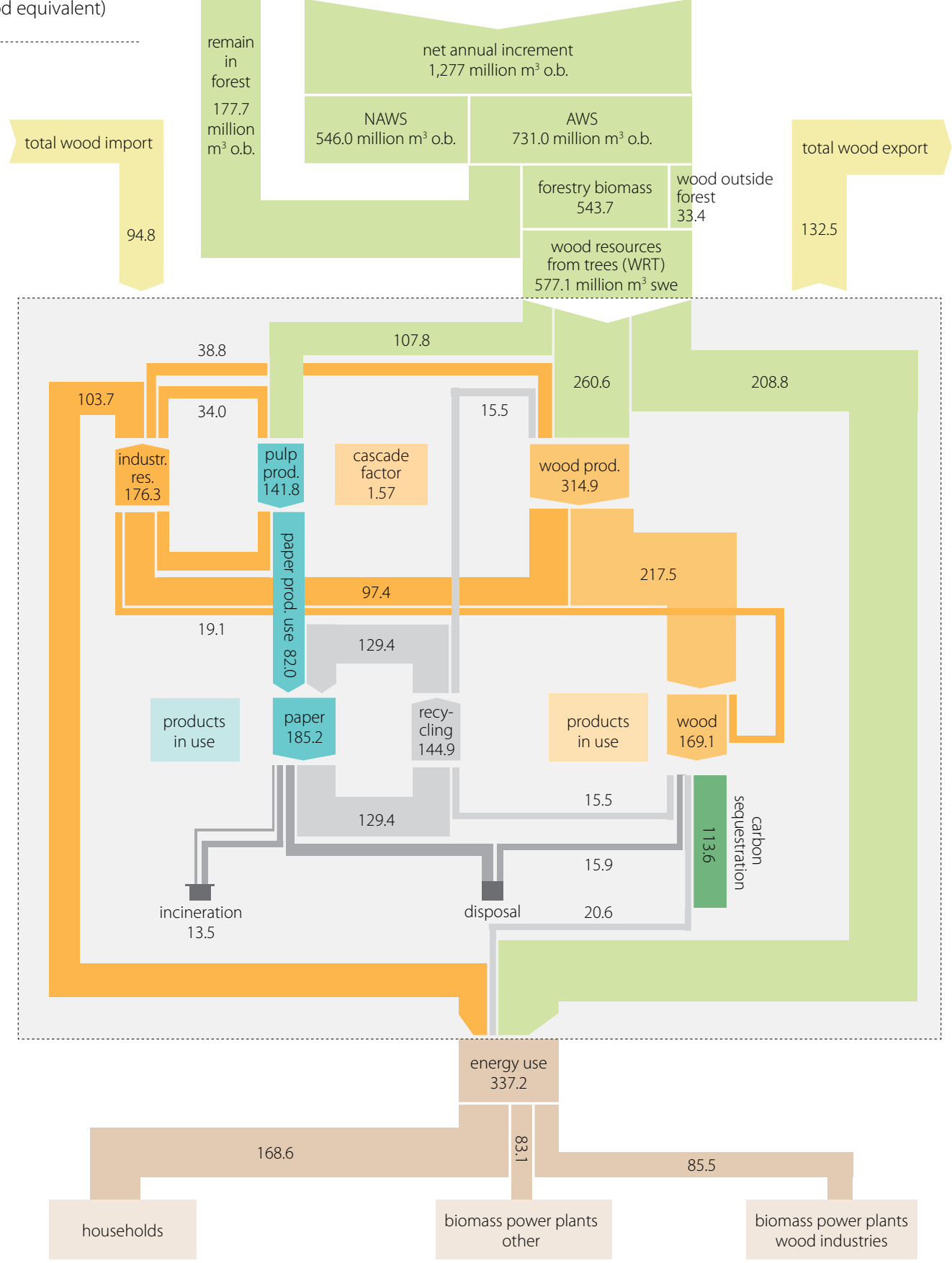


The growing of wood energy feedstock is ingrained in local cultures throughout the UNECE. For example, there is an ancient Uzbek tradition for when a boy child is born, the father plants twenty poplars along the irrigation channel in his yard. These trees grow to help the young boy build his own home when reaches marrying age and provide wood for construction and heating (Savcor Indufor Oy, 2005).

Consumption of wood energy offers significant contributions to human wellbeing and has long served basic energy needs and traditions (Figure 1.5). In countries with well-established wood product supply-chains the industrial sector tends to dominate wood energy consumption but there are exceptions. For instance, in France the role of traditional firewood in the wood supply-chain is considerable and an estimated $71 \%$ of wood energy consumed nationally is done by households. Regionally, about half of the woody biomass used for energy in the EU is used by the residential sector (Mantau, 2015), mainly as traditional firewood and the remaining half is used in biomass heat and power plants and wood industries (Figure 1.6). As another example, average annual total US residential wood energy consumption is about the same as the consumption of energy derived from propane and slightly less than the consumption of fuel oil for heating. About one in every ten US household uses wood energy as a primary or secondary source of heating (Berry, 2014). Notably, US households at income levels at or below the poverty line consume about 40\% more wood energy per year than the national average. In Georgia, some 75 to $96 \%$ of villages in the country's rural areas - depending on the region - mostly rely on wood for heating demands (Corso, 2013). Beyond the benefit from energy generation, many would find the aesthetics of using wood energy feedstocks (from firewood to wood pellets) more visually appealing than piles of coal (Mytting, 2015) - with also ancillary benefits of reduced dust. Likewise, along the wood energy supply chain handlers and final users often mention the fragrance of wood as an improvement to their working conditions over handling of fossil fuels (Coffin, 2014). The non-toxic nature of managing wood energy feedstocks and reduced risk of exposure to gases or poisoning from intake of fossil fuels is another advantage. However, as previously noted, the inefficient combustion and exposure to wood smoke can have severe impacts on human health.

Wood energy also offers important societal values through its contribution to energy security by offering a reliable, renewable and flexible supply of energy (Aguilar, 2014). This role might be even more apparent in Central Asia and Nordic Nations where extreme weather and, at times inaccessibility, make wood energy the main - and often lone - heating source (Figure 1.7). In Central Asia, households save money throughout the year to buy large amounts of firewood in late summer when they are sold at seasonally low prices. Often, consumption for food and clothes is forgone to purchase

\section{FIGURE 1.7}

\section{Wood is used by many households in the ECE region for heating and cooking}

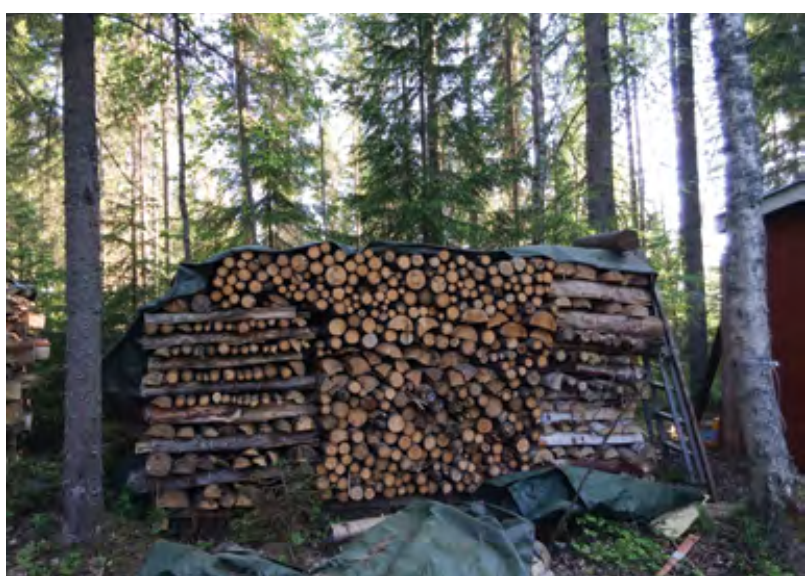

heating fuels with data from rural Tajikistan suggesting most people would prefer going a little hungry if that enabled them to stay in a warmer home (Swinkels, 2014). In Georgia, it has been estimated that out of the 2,086 public schools in the country, 1,453 depend on firewood for heating (Corso, 2013). Nevertheless, it is often the case that sufficient amounts of wood fuel are not available to meet energy needs during winter. Families are commonly forced to heat smaller spaces - usually only one room, and less frequently - often only once or twice a day (Swinkels, 2014, Kargasov, 2008, Fabian et al. 2010). Inadequate supply of wood energy, inaccessible alternative sources, and increasing pressures on forest lands to supply wood fuel have detrimental effects on the structure of forest resources; with feedback compounded effects on households' wellbeing.

\subsection{Conclusions}

Utilization of wood fuel is an integral part of a forest-based bioeconomy. It has multiple functions ranging from its complementarity to forest management practices and to extant supply-chains, income generation for forest owners and impacts to local and even global energy systems with climate implications. However, it is critical to stress that wood energy systems have to be managed efficiently to maximize energy output and reduce potentially harmful emissions. Wood energy contributes to resilient and secure energy systems and holds socio-cultural values central to livelihoods across the UNECE region. 


\subsection{References}

Aguilar, F.X. 2014. Wood Energy: Assessment and Outlook to 2030. In: Wood Energy in Developed Economies: Sustainable Resource Management, Economics and Policy. Aguilar, F.X. (Editor). Routledge. 306-325.

Aguilar, F.X., Abt, K., Glavonjić, B., Lopatin, E. and W. Mabee. 2016. Chapter 9: Wood Energy Market, 2015-2016. In: United Nations Forest Products Annual Market Review. P. 97-108.

Aguilar, F.X., Cai, Z. and A. D'Amato. 2014. Non-industrial private forest landowner's willingness-to-harvest: higher timber prices can increase woody biomass supply. Biomass \& Bioenergy. 71:202-215.

Aguilar, F.X., Glavonjić, B., Hartkamp, R., Mabee, W. and K. Skog. 2015. Chapter 9: Wood Energy Market, 2014-2015. In: United Nations Forest Products Annual Market Review. P. 91-104. http:// www.unece.org/fileadmin/DAM/timber/publications/2015FPAMR-E.pdf

Asikainen, A., Anttila, P., Heinimö, J., Smith, T., Stupak, I. \& Ferreira Quirino, W. 2010. Forests and bioenergy production. In: Mery, G., Katila, P., Galloway, G., Alfaro, R.I., Kanninen, M., Lobovikov, M. \&Varjo, J. (eds.). Forests and Society - Responding to Global Drivers of Change. IUFRO World Series 25: 183-200.

Asikainen, A., Björheden, R., Moffat, A. and R. Spinelli. 2014. From biomass to feedstock. In. Pelkonen, P., Mustonen, M., Asikainen, A., Egnell, G., Kant, P., Leduc, S. \& Pettenella. D. (eds.) Forest Bioenergy for Europe. What Science Can Tell Us 4:59-68.

Asikainen, A., Ikonen, T. and J. Routa. 2016. Challenges and opportunities of logistics and economics of forest biomass. In. Thiffault, E., Berndes, G., Junginger, M., Saddler, J. \& Smith, T. 2016 (eds.) Mobilization of forest bioenergy in the boreal and temperate biomas. Challenges, Opportunities and Case Studies. Academic Press. Pp. 60-83.

Bentsen, 2017; Carbon debt and payback time - lost in the forest? Renewable \& Sustainable Energy Reviews 73: 12111217.

Berger, A., Palik, B., D'Amato, A., Fraver, S., Bradford, J., Nislow, K., King, D. and R. Brooks. 2013. Ecological impacts of energywood harvests: Lessons from whole-tree harvesting and natural disturbance. Journal of Forestry. 111 (2): 139-153.

Berndes, G., Abt, B., Asikainen, A., Cowie, A., Dale, V., Egnell, G., Lindner, M., Marelli, L., Paré, D., Pingoud, K. and S. Yeh, S. 2016. Forest biomass, carbon neutrality and climate change mitigation. 2016. From Science to Policy 3. European Forest Institute.

Berndes, G., Bird, N. and A. Cowie. 2011. Bioenergy, Land Use Change and Climate Change Mitigation - Background Technical Report.IEABioenergy:ExCo:2011:04.Onlineathttp:// www.ieabioenergy.com/wp-content/uploads/2013/10/ Bioenergy-Land-Use-Change-and-Climate-ChangeMitigation-Background-Technical-Report.pdf

Berry, C. 2014. Increase in wood as main source of household heating most notable in the Northeast. US Energy Information Administration. Online at http://www.eia.gov/todayinenergy/ detail.cfm?id=15431

Bosworth, M. 2013. Why Finland loves saunas. Online at http:// www.bbc.com/news/magazine-24328773

Cai, Z., L., Narine, A. D'Amato and F.X. Aguilar. 2016. Attitudinal and Revenue Effects on Non-Industrial Private Forest Owners'
Willingness-to-Harvest Timber and Woody Biomass. Forest Policy and Economics. 63: 52-61.

Cintas O, G., Berndes, A.L., Cowie, G., Egnell, G., Holmström, H., Marland, G., and G. Ågren, 2017. Carbon balances of bioenergy systems using biomass from forests managed with long rotations: bridging the gap between stand and landscape assessments. GCB Bioneergy. Online at http:// dx.doi.org/10.1111/gcbb.12425

Coffin, G. 2014. Use of by-product wood chips and other biomass in a combined heat and power system at the University of Missouri Power Plant. In: Wood Energy in Developed Economies: Sustainable Resource Management, Economics and Policy. Aguilar, F.X. (Editor). Routledge. 253278.

Corso, M. 2013. Georgia: Need for Firewood Raises Threat for Christmas-Tree Trade. Eurasianet.org. Online at http://www. eurasianet.org/node/67891

Egger C., Ohlinger C., and G. Dell. 2014. Successful wood energy development and implementation: sustainable heating in Upper Austria. In: Wood Energy in Developed Economies: Sustainable Resource Management, Economics and Policy. Aguilar, F.X. (Editor). Routledge. 279-305.

Fabian, A., Volkmer, H. and C. Wiedemann. 2010. Microloans for Thermal Insulation: A Product Documentation Based on Experience in Tajik Gorno-Badakhshan.

FAO. 2013. Wood energy. Online at http://www.fao.org/ forestry/energy/en/

Finnish Ministry of Agriculture and Forestry (MMM). 2014. Information on LULUCF actions. 30 June 2014. Online at http://mmm.fi/documents/1410837/1867349/Information_ on_LULUCF_actions_FINLAND_final_1.pdf/89fc7c83-ebe9444a-8deb-ca0c3c08ff8b

Gerasimov, Y. and T. Karjalainen. 2013. Energy wood resources availability and delivery cost in Northwest Russia. Scandinavian Journal of Forest Research. Volume 28, 2013 Issue 7:689-700.

Hakkila, P. 2002. Operations with reduced environmental impact. P. 244-261 in Bioenergy from sustainable forestry: Guiding principles and practice, Richardson, J., R. Björheden, P. Hakkila, A.T. Lowe, and C.T. Smith (eds.). Klewer Academic Publishers, Dordrecht.

Hansson S., Duden, A.S., Junginer, H.M., Dale, V.H. and F. van der Hilst, 2017. Wood pellets, what else? Greenhouse gas parity times of European electricity from wood pellets produced in the south-eastern United States using different softwood feedstocks GCB Bioenergy. Online at http://dx.doi. org/10.1111/gcbb.12426

International Energy Agency. 2009. Bioenergy - The Impact of Indirect Land Use Change. Summary and Conclusions from the IEA Bioenergy ExCo63 Workshop IEA BIOENERGY: ExCo: 2009:04

Janowiak, M.K. and Webster, C.R., 2010. Promoting ecological sustainability in woody biomass harvesting. Journal of Forestry. 108(1): 16-23.

Kargasov. 2008. - Promoting Energy Efficiency. URL: https:// www.yumpu.com/en/document/view/26658000/energyefficiency-centre-for-development-and-environment (accessed on October 7, 2016) 
Koponen, K., Sokka, L., Salminen, O., Sievänen, R., Pingoud, K, Ilvesniemi, H., Routa, J., Ikonen, T., Koljonen, T., Alakangas, E., Asikainen, A. and K. Sipilä. 2015 . Sustainability of forest energy in Northern Europe. VTT Technology 237. 94 p.

Kurz, W. A., Dymond, C. C., Stinson, G., Rampley, G.J., Neilson. E.T., Carroll, A.L., Ebata, T. and L. Safranyik,. 2008. Mountain pine beetle and forest carbon feedback to climate change. Nature. 452: 987990.

Laganière, J, D. Paré, E.Thiffault, P.Y. Bernier, 2017; Range and uncertainties in estimating delays in greenhouse gas mitigation potential of forest bioenergy sourced from Canadian forests. GCB Bioenergy 9 (2) 358-369

Lippke, B. and M. Puettmann. 2013. Life-cycle carbon from waste wood used in district heating and other alternatives. Forest Products Journal. 63(1):12-23.

Lippke, B., Gustafson, R., Venditti, R., Steele, P., Volk, T., Oneil, E., Johnson, L., Puettmann, M. and K. Skog. 2012. Comparing LifeCycle Carbon and Energy Impacts for Biofuel, Wood Product, and Forest Management Alternatives. Forest Products Journal. 62(4):247-257.

Magnone, E., Park, S.K., and J.H. Park. 2016. Effects of moisture contents in the common oak on carbonaceous aerosols generated from combustion processes in an indoor wood stove. Combustion Science and Technology. 188(6): 982-996.

Mantau, U. 2015. Wood flow analysis: Quantification of resource potentials, cascades and carbon effects. Biomass \& Bioenergy. 79: 28-38.

Mathioudakis V., P.W. Gerbens-Leenes, T.H. Van der Meer and A.Y. Hoekstra. 2017. The water footprint of secondgeneration bioenergy: A comparison of biomass feedstocks and conversion techniques. Journal of Cleaner Production. 148: 571e582.

Miner, R. A., Abt, R. C., Bowyer, J. L., Buford, M. A., Malmsheimer, R. W., O'Laughlin, J., Oneil, E. E., Sedjo, R. A. and K. Skog. 2014. Forest carbon accounting considerations in US bioenergy policy. Journal of Forestry. 112: 591-606.

Mytting, L. 2015. Norwegian Wood. Chopping, stacking, and drying wood the Scandinavian way. MacLehose Press. 192 pp.

Naeher, L., Brauer, M., Lipsett, M., Zelikoff, J., Simpson, C., Koenig, J. and K. Smith. 2007. Woodsmoke Health Effects: A review. Inhalation Toxicology. 19: 67-106.

Perez-Verdin, G., Grebner, D.L., Munn, I.A., Sun, C. and S.C. Grado. 2008. Economic impacts of woody biomass utilization for bioenergy in Mississippi. Forest Products Journal, 58(11):75-83.

Popp, J., Lakner, Z., Harangi-RAkos, M., and M. Fari. 2014. The effect of bioenergy expansion: Food, energy and environment. Renewable and Sustainable Energy Reviews. 32:559-578.

Powers, R.F., D.A. Scott, F.G. Sanchez, R.A. Voldseth, D. PageDumroese, J.D. Elioff, and D.M. Stone. 2005. The North American long-term soil productivity experiment: Findings from the first decade of research. For. Ecol. Manag. 220:31-50.

Proskurina S, Sikkema, R., Heinimö, J. and E. Vakkilainen. 2016. Five years left - How are the EU member states contributing to the $20 \%$ target for EU's renewable energy consumption; the role of woody biomass. Biomass \& Bioenergy. 95: 64-77.
Raitila, J., Virkkunen, M., Flyktman, M., Leinonen, A., Gerasimov, Y. and T. Karjalainen. 2008. The pre-feasibility study of biomass plant in Kostomuksha. Final Report. VTT-R-O8372. 55 p.

Savcor Indufor Oy. 2005. Ensuring sustainability of forests and livelihoods through improved governance and control of illegal logging for economies in transition. Report to the World Bank. Online at http://siteresources.worldbank. org/EXTFORESTS/Resources/985784-1217874560960/ Uzbekistan.pdf

Schwedler, D. and L. McCarthy. 2011. People Restoring America's Forests: A Report on the Collaborative Forest Landscape Restoration Program. Online at https://www. fs.fed.us/restoration/documents/cflrp/CoalitionReports/ CFLRPAnnualReportNov2011.pdf

Sikkema R., Dallemand, J.F., Matos, C.T., van der Velde, M. and J. San-Miguel-Ayanz. 2016. How can the ambitious goals for the EU's future bioeconomy be supported by sustainable and efficient wood sourcing practices? Scandinavian Journal of Forest Research. Online at http://dx.doi.org/10.1080/028275 81.2016 .1240228

Sokka, L., Koponen, K. And J.T. Keränen. 2015. Cascading use of wood in Finland - with comparison to selected EU countries. VTT-R-03979-15. 25p.

Song, N. and F.X. Aguilar. 2015. Economic Impacts of the Implementation of the Missouri Pine-Oak Woodlands Restoration Project at the Mark Twain National Forest, 2012-2019: A Project of the Collaborative Forest Landscape Restoration Program. Report to the USDA Forest Service Mark Twain National Forest. 18 pp.

Song, N. and F.X. Aguilar. 2017. Woody biomass energy efficiency pathways: public policy implications. Biofuels. http://dx.doi.org/10.1080/17597269.2016.1259520

State of Washington Department of Ecology. 2012. How wood some harms your health. Online at https://fortress. wa.gov/ecy/publications/documents/91br023.pdf

Swinkels, R. 2014. Assessment of household energy deprivation in Tajikistan (World Bank Report) URL:http://documents. worldbank.org/curated/en/944321468341064427/ pdf/888370ESWOwhit0nOEnergy0Deprivation.pdf

Thiffault, E., Asikainen, A. and G. Devlin. 2016. Comparison of forest biomass supply chains from the boreal and temperate biomes. In. Thiffault, E., Berndes, G., Junginger, M., Saddler, J. \& Smith, T. 2016 (eds.) Mobilization of forest bioenergy in the boreal and temperate biomas. Challenges, Opportunities and Case Studies. Academic Press. Pp. 10-35.

U.S. Energy Information Administration. 2017. Residential Energy Consumption Survey: Table HC6.5 Space heating in U.S. homes by household income, 2015. Online at https:// www.eia.gov/consumption/residential/data/2015/index. php?view=characteristics\#sh

Wang, W., Dwivedi, P., Abt, R. and M. Khanna. 2015. Carbon savings with transatlantic trade in pellets: accounting for market-driven effects. Environmental Research Letters. Online at http://iopscience.iop.org/ article/10.1088/1748-9326/10/11/114019

Woodall, C.W., Ince, P.J., Skog, K.E., Aguilar, F.X., Keegan, C.E., Sorenson, C.B., Hodges, D.G. and W.B. Smith. 2012. An overview of the forest products sector downturn in the United States. Forest Products Journal. 61: 595-603. 


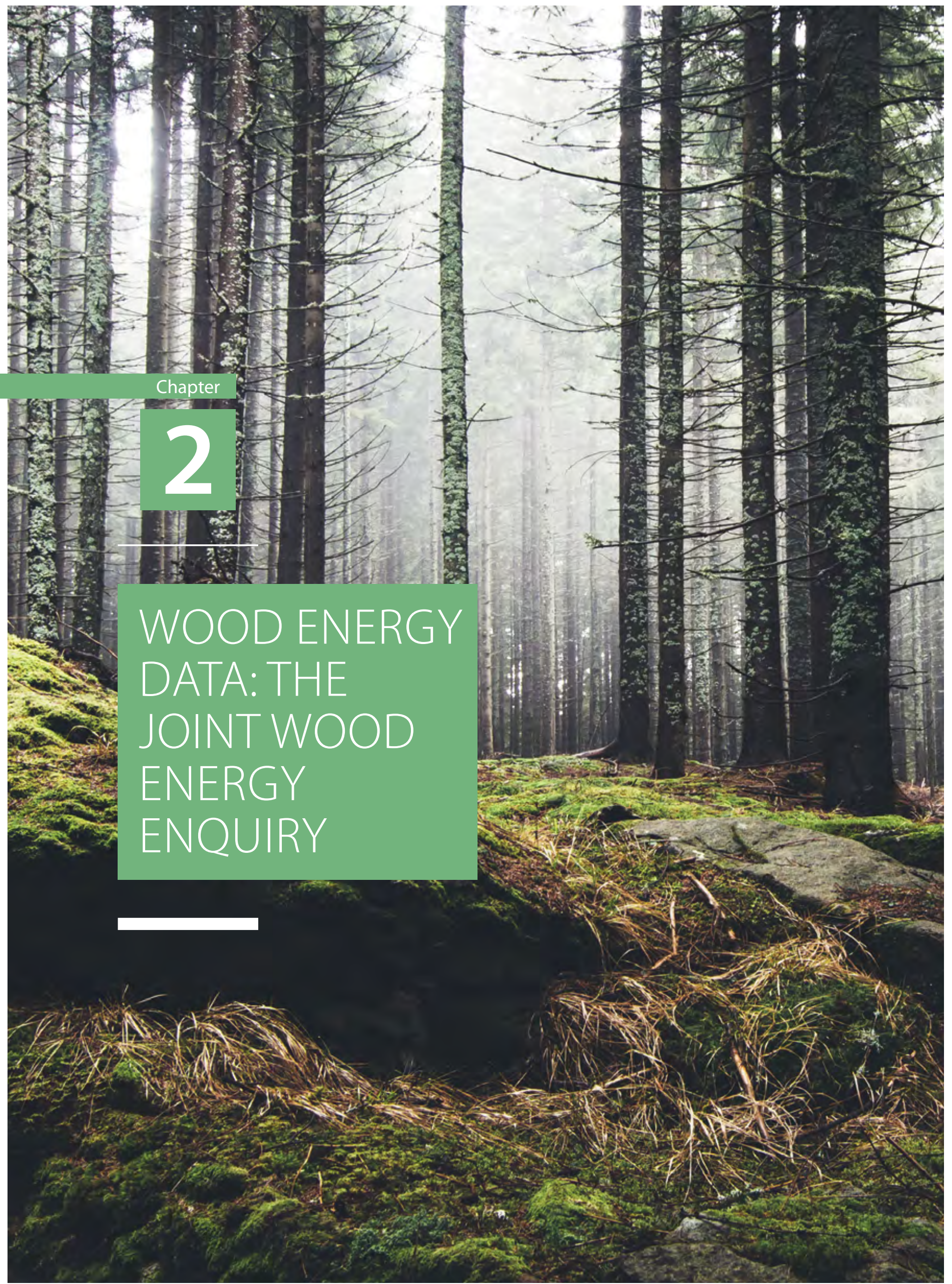




\section{Highlights*}

* The JWEE is a unique tool with detailed information on the sources and users of wood energy in countries

* It enforces data consistency between the forest sector and the energy sector

* It improves communication between the forest and energy sectors

* Fully compatible with other international questionnaires and databases

* Provides a structure and broadens the view on the role of wood energy in member states

* Provides evidence that in ECE member States, most wood energy comes from indirect use of wood fibres

* The use of wood energy continues to increase

* Households consume significantly more wood energy than previously calculated 


\subsection{Historical development of the Joint Wood Energy Enquiry}

Fuelwood is an important forest product in the UNECE member states. Namely in rural areas households never completely abandoned wood as a source for heating and cooking. Wood removals from forests for energy account for about half the wood removed from forests in the ECE region. Especially in times of major national or international crisis, fuelwood represents an important alternative fuel. During the oil crisis in the 1970s, the Balkan war and the subsequent embargos of countries in the western Balkans, the global economic crisis after 2008 with particularly severe effects for Greece or the gas supply shortages in Georgia (2009) and Ukraine (2006-2009), wood energy consumption increased significantly.

Beside the effects of crises, use of wood as an alternative energy source was also stimulated by higher competing energy prices and support provided through public policy interventions (Chapter 4). As shown in Figure 2.1 wood prices have followed a trajectory denoting a lagged correlation with fossil fuel prices as illustrated by historical records for roundwood in selected UNECE member states.

In 2015, global bioenergy power generation was 474 TWh, an 8\% increase on 2014 levels. By 2021, bioenergy generation is forecast to grow at an annual average growth rate of $6 \%$ to reach around 670 TWh. (OECD/IEA, 2016). Despite the recent drop in oil prices over the last two years demand for wood energy continues to be high in most UNECE member states although the rate of investment in biomass systems is declining (UNECE/FAO FPAMR, 2015-2016; OECD/IEA, 2016).

Driven by the increasing demand of wood for energy, stakeholders of the forest sector expected a significant impact on forests, wood markets and the wood products industry. It was essential to better understand where wood fibres for energy generation are sourced from and which sector used forest products of which qualities. In 2001 the Unified Wood Energy Terminology (UWET) and later Unified Bioenergy Terminology (UBET) made a first attempt in creating a suitable framework to identify different amounts and types of wood energy flows. In the framework supply (production side) and demand (users' side) of wood fuels, agrofuels and municipal by-products was distinguished. The production side for wood fuels comprised all sources of woody biomass for energy (direct, indirect and recovered wood fuels as well as wood-derived fuelswhile the demand side considered the state of wood used for energy (solid, liquid and gaseous). The JWEE grouped these into sources and uses (Figure 2.2).

\section{FIGURE 2.1}

\section{Wood price index for Finland and Lithuania and world oil price index (indexes for 2000), 1995-2016}

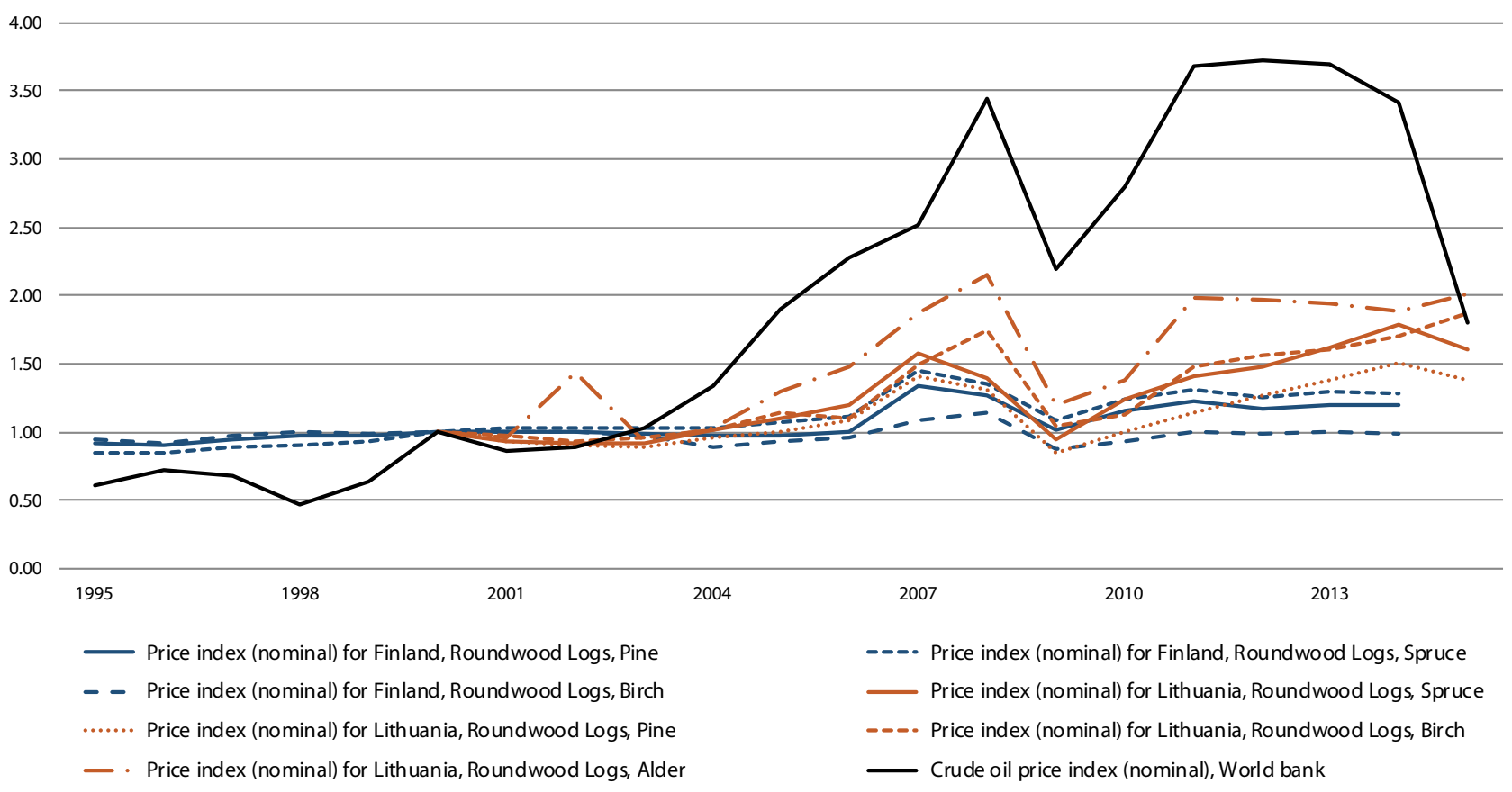

Sources: UNECE/FAO Wood Prices, 2017; World Bank, 2016. 
FIGURE 2.2

\section{JWEE aggregate table example, based on United Bioenergy Terminology}

\begin{tabular}{|c|c|c|c|c|c|c|}
\hline & \multirow[b]{2}{*}[1000\mathrm{m}^{3}]{} & \multicolumn{4}{|c|}{ USES } & \multirow[b]{2}{*}{$\begin{array}{c}\text { Sum } \\
\text { [U1;U2; } \\
\text { U3;U4] }\end{array}$} \\
\hline & & $\begin{array}{c}\text { U1 } \\
\text { Power \& heat }\end{array}$ & $\begin{array}{c}\text { U2 } \\
\text { Industrial }\end{array}$ & $\begin{array}{c}\text { U3 } \\
\text { Residential }\end{array}$ & $\begin{array}{c}\text { U4 } \\
\text { Other }\end{array}$ & \\
\hline \multirow{4}{*}{ 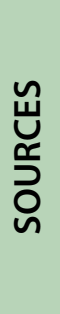 } & S1 Direct & & & 6,859 & 529 & 7,388 \\
\hline & S2 Indirect & 6,352 & 7,357 & 1,105 & 1,404 & 16,218 \\
\hline & S3 Recovered & & & & & \\
\hline & S4 Unspecified & & & & & \\
\hline & Sum $[\mathrm{S} 1 ; \mathrm{S} 2 ; \mathrm{S} 3 ; \mathrm{S} 4]$ & 6,352 & 7,357 & 7,964 & 1,933 & \\
\hline
\end{tabular}

Source: UBET, FAO 2004.

In 2003 UNECE member states requested the UNECE/FAO Forestry and Timber Section to identify international reporting schemes that provide information on forest products used for energy generation (TIM/EFC/WP.2/2004/9 - UNECE 2004). A preliminary desk study was conducted and revealed that information on forest products used for energy was not collected systematically by any international organization (e.g. FAO, International Energy Agency, Eurostat, International Renewable Energy Agency) at a level of detail necessary to allow for comparisons with forestry statistics (UNECE, 2005 http://www.unece.org/fileadmin/DAM/timber/docs/statssessions/stats-27/English/Wood_Energy_Background_Paper. doc). Often international energy statistics included wood under solid biomass but did not distinguish specific forest products. In addition, energy statistics were commonly reported in Joules $(J)$ and needed to be converted to cubic meters solid wood equivalents ( $\mathrm{m}^{3}$ swe) used in forestry statistics, which seemed to be challenging due to the range of products involved. Nevertheless, the desk study revealed that detailed wood energy data were available but scattered at the national level in many UNECE member states.

The need of more reliable wood energy data also became evident after publishing European Forest Sector Outlook Study I (EFSOS I) in 2005. Despite the importance of wood energy in the forest sector it was not possible to produce a reliable wood energy scenario due to data limitations.
Based on the results of the preliminary desk study and the lack of wood energy data, UNECE member states recognized an opportunity to establish a new reporting scheme. In 2005 at the 27th session of the Joint FAO/UNECE Working Party on Forest Economics and Statistics, member states agreed to develop the Joint UNECE/FAO/IEA Wood Energy Enquiry (JWEE) questionnaire based on the framework developed by the Unified Bioenergy Terminology (UBET, FAO, 2004).

The JWEE reporting scheme aims at:

1. Reflecting realities in the wood energy sector in a comprehensive and timely manner in gathering national wood energy data from official and non-official sources;

2. Bridging knowledge and data across the energy, waste and forestry sectors to support comparability of respective statistics;

3. Fostering cross-sectoral collaboration among national energy, waste and forestry experts and all other relevant stakeholders;

4. Show the impact on the forest sector of energy use and the impact on the energy sector of woody biomass.

In 2006 the first version of the JWEE questionnaire was finalized and disseminated among the 56 UNECE member states to collect data for the reference year 2005. Member states completed the questionnaire on a voluntary basis. A total of 14 member states replied to the first JWEE questionnaire with 
data deemed of good quality. Since then JWEE reporting has been conducted every two years with an increasing number of good quality replies: 16 member states replied to the 2007 round, 20 in 2009, 24 in 2011, 26 in 2013,and 33 in 2015 (a list of member states providing data to the JWEE can be found in the Annex). Figure 2.3 shows a timeline of the development of the JWEE questionnaire.

One of the effects of issuing the questionnaire was that member States realized the need for better data. In a number of cases household surveys showed that residential use of wood energy was four times higher than the use previously estimated.

Under the guidance of the members of the Joint FAO/UNECE Working Party on Forest Economics and Statistics the JWEE questionnaire has been revised regularly. In 2007, at the 29th session of the Joint FAO/UNECE Working Party member states introduced Table IV, the main table for wood energy data collection to the JWEE questionnaire and requested prefilling of data. In 2009 at the 31st session of the Joint FAO/ UNECE Working Party the structure was changed to add an aggregate table and additional sources of wood fiber. The results of the JWEE enabled the inclusion of a wood energy scenario in EFSOS II study. In 2012 UNECE member states requested the addition of a section to help provide information on the EU National Renewable Energy Action Plans (NREAPs) for the JWEE 2011.

In 2013 member States, at the joint session of the ECE Committee on Forests and the Forest Industry (COFFI) and the FAO European Forestry Commission (EFC), established a Team of Specialists on Wood Energy. The Team was created to provide advice and guidance on wood energy data collection, follow-up on JWEE and specific studies related to wood energy. The Team supports and monitors data collection on wood energy and leads the revision and maintenance of the JWEE questionnaire.

In 2012 and 2016 national correspondents were invited to attend capacity building workshops. The workshops focused on awareness-raising for wood energy data problems and sought to improve the data availability and quality in the ECE region. The workshops offered great opportunities for national energy and forestry experts to meet and exchange on their reporting issues. Also the secretariat had the chance to better understand the issues correspondents face while filling the questionnaire. Both workshops resulted in higher response rate to the JWEE and more complete replies.

FIGURE 2.3.

\section{History of the JWEE reporting}

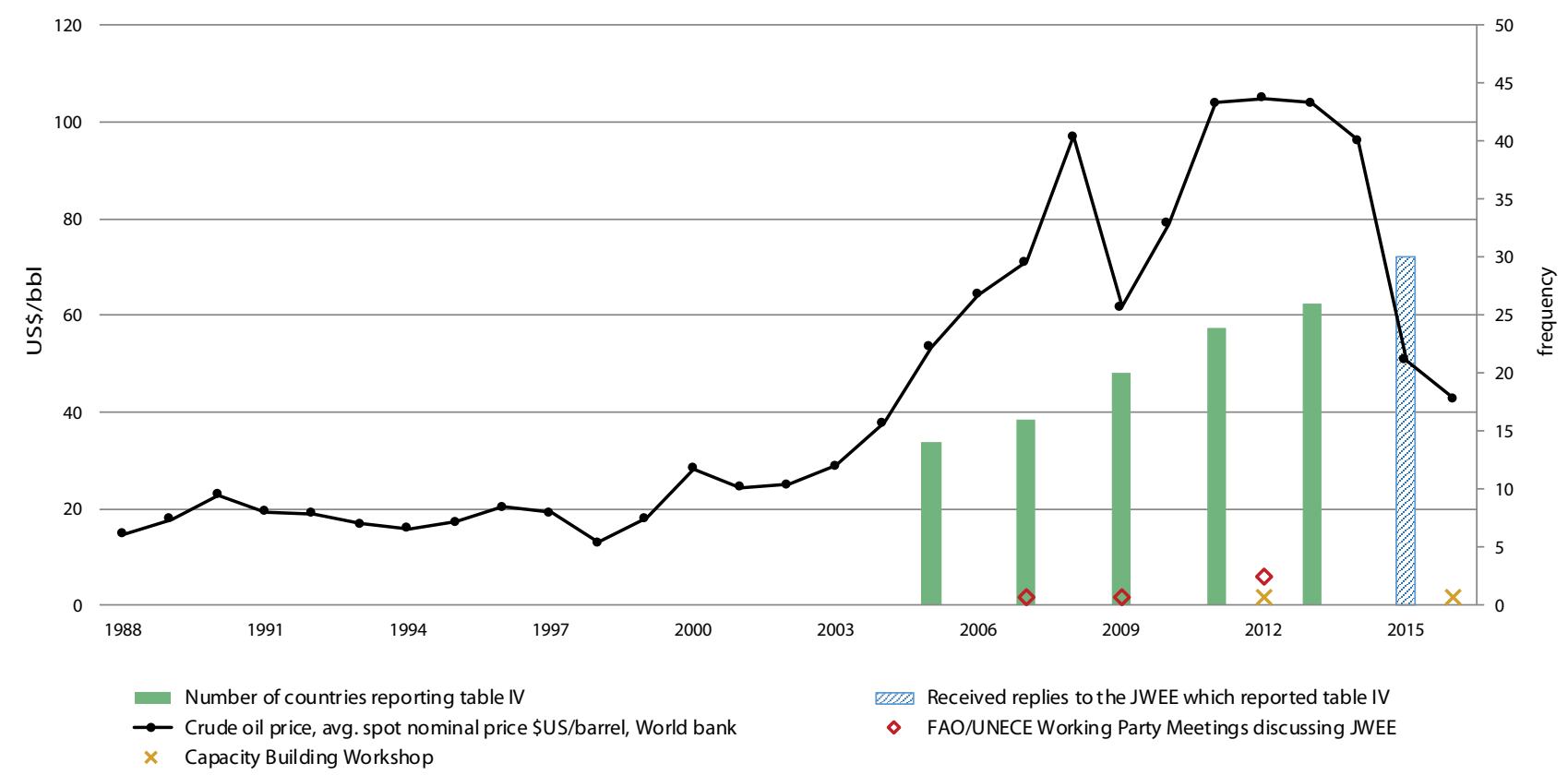


The initial goals of getting a better understanding of wood energy use in the region and the provision of a data collection framework to better understand member states'wood energy information have been achieved. Improving connections within countries and further developing use of the JWEE continues. To maintain relevance of the JWEE reporting it is necessary to redefine the targets of the JWEE. This could be achieved by targeting a broader audience of data users than just the forestry sector. Aligning JWEE data with international energy statistics could be one step in this direction.

\subsection{Structure of the JWEE questionnaire}

The JWEE is an Excel-based questionnaire, which consists of four tables. As shown in Figure 2.4, information for the completion of the questionnaire is derived from forestry and energy statistics.

FIGURE 2.4

\section{Structure of the Joint Wood Energy Enquiry}

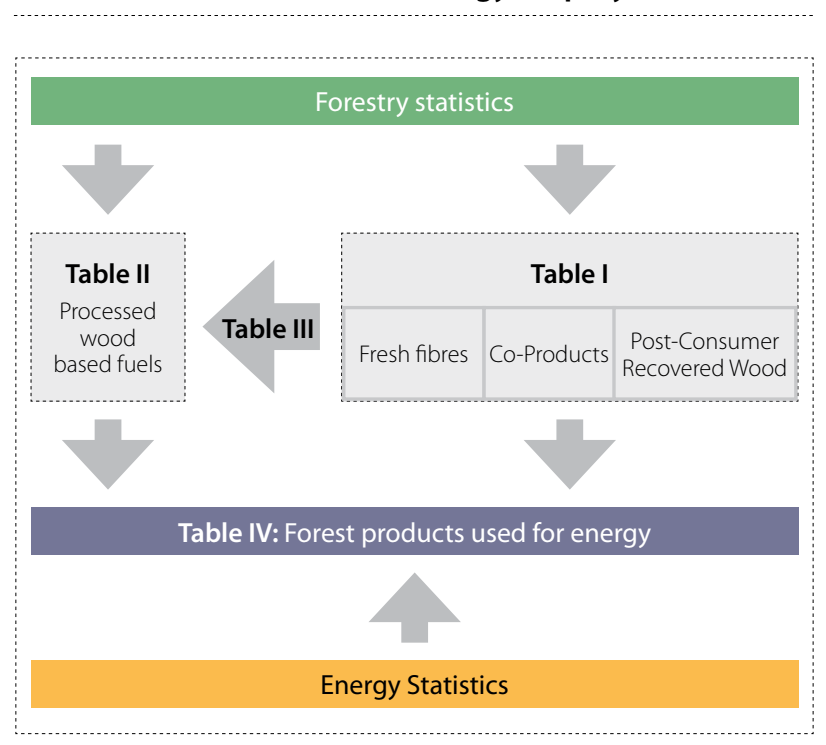

\subsubsection{Table I and II: Wood Supply}

Tables I and || gather information on the member state's production and trade in forest products. Besides wood used for energy, other purposes are included, such as the material use of wood. Most of the forest products information is derived from the Joint Forest Sector Questionnaire (JFSQ, UNECE/FAO/ITTO/Eurostat). The JFSQ is the main reporting scheme for forestry statistics in the ECE region. It gathers information on domestic production and trade in forest products. Data from the JFSQ reporting feed directly into FAOSTAT, the international forest products database.
Table 2.1 lists the forest products encompassed in Table I of the JWEE questionnaire. In the JWEE reporting, forest products are separated into three categories specifying the origin of wood fibres (primary solid biomass from forest land and from outside forests, solid and liquid biomass from forest based industry and municipal solid waste/biodegradables). Forest products from "primary solid biomass" and "solid and liquid biomass from forest-based industry" comprise forest products as defined in the JFSQ. Definitions for industrial roundwood and fuelwood from forests, chips and particles as well as wood residues are harmonized with JFSQ definitions. Figures for black liquor and bark can be calculated based on the JFSQ figures for chemical wood pulp and primary solid biomass respectively. Factors for these calculations are provided in the questionnaire. However, national correspondents are invited to adjust factors if necessary to better reflect the situation in their country.

Wood from "Municipal solid waste/biodegradables" is not available from forestry statistics (JFSQ). For the JWEE, this information needs to be collected through other sources e.g. waste statistics.

\section{TABLE 2.1}

\section{Production and trade of wood raw material in JWEE table I}

\section{Primary solid biomass (from Forests/Outside Forests) \\ - Industrial Roundwood (thousand $\mathrm{m}^{3}$ ) \\ - Fuelwood (thousand $\mathrm{m}^{3}$ ) \\ ... of which from short rotation coppice (thousand $\mathrm{m}^{3}$ )}

\section{Solid and liquid biomass from forest based industries}
Chips and Particles (thousand $\mathrm{m}^{3}$ )
Wood Residues (thousand $\mathrm{m}^{3}$ )
Bark (thousand $\mathrm{m}^{3}$ )
- Black Liquor (thousand t)
Crude tall oil (thousand t)

\section{Municipal solid waste/biodegradables}

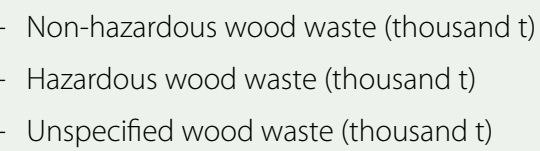

\section{Unknown origin}

Wood from unknown sources (thousand $\mathrm{m}^{3}$ )

$m^{3}=$ cubic meters solid wood equivalents, $t=$ tonnes 
Table 2.2 displays products for processed wood-based fuels which are requested in Table II of the JWEE questionnaire. Wood charcoal and wood pellets derive from the JFSQ product definitions. Wood briquettes ${ }^{1}$ and processed liquid biofuels are not available and have to be collected from more specialized sources (e.g. survey data).

Processed wood-based fuels are produced from wood resources. Thus, Table I and Table II are closely linked. If data is available the resource streams can be reported in Table III of the JWEE questionnaire. Units in the JWEE are completely harmonized with the JFSQ reporting.

\section{TABLE 2.2}

\section{Production and trade of wood based fuels in JWEE table II}

Processed solid biofuels from wood
- Wood Charcoal (thousand t)
- Wood Pellets (thousand t)
- $\ldots$ of which: torrified (thousand $\mathrm{t}$ )
- Wood Briquettes (thousand t)
Processed liquid biofuels from wood
- Pyrolysis Oils (million I)
- Cellulose based ethanol (million I)
- Wood based biodiesel (million I)
$t=$ tonnes; I = liters

\subsubsection{Table III: Transformation from wood sources into processed wood based fuels}

Table III in the JWEE questionnaire accounts for the transformation of wood resources (Table I) into processed wood based fuels (Table II). Correspondents are invited to provide information on the input of wood fibres (e.g. fuelwood, chips and particles or wood waste) used for the production of processed wood based fuels (e.g. wood charcoal, wood pellets or cellulose based ethanol). Providing this information helps to prevent double counting. Table III collects data in tonnes dry matter (t.d.m.). This table had been optional until JWEE 2015.

\subsubsection{Table IV: Energy use of wood}

Table IV of the JWEE questionnaire is the central table. In this table, the different sources are linked to the various 1 In the JFSQ terminology wood briquettes are currently included
under "other agglomerates". consumers of wood energy. It helps gather information on forest products used for energy by specific consumer types. This table is considered as the most important one of the JWEE reporting.

"Main Activity Producer", "Industry Sector" and "Other Direct Final Consumption" are the three main wood energy consuming sectors distinguished in Table IV (Table 2.3). These categories derive from the definitions of the joint IEA/Eurostat/UNECE renewable energy questionnaire (IEA/ Eurostat/UNECE, 2015).

\section{TABLE 2.3}

\section{Wood energy consuming sectors in JWEE table IV}

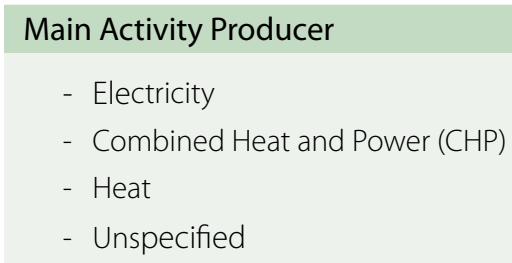

Industry Sector
$\begin{aligned} & \text { - Pulp and Paper } \\ & \text { - Wood and wood products } \\ & \text { - Other industry } \\ & \text { - Unspecified }\end{aligned}$

\section{Other direct final consumption}

- Residential

- Agriculture, Forestry and Fishing

- Commercial and Public Service

- Transport Sector

- Other

- Unspecified

Main activity producers are defined as undertakings primarily producing energy (e.g. power plants). This category further distinguishs between heat, electricity and combined heat and power (CHP). The definitions in the JWEE derive from the joint IEA/Eurostat/UNECE definitions.

For the energy sector the JWEE questionnaire gathers information about the wood energy use of the wood processing industry which comprises pulp and paper, wood and wood products and other industry. The industry sector includes undertakings that do not primarily produce energy (e.g. pulp mill, sawmills). It includes the generation of heat, electricity or CHP which is produced by the facility for its own use and/or for sale. The JWEE combines own use of energy (direct consumption) and sale (autoproduction). 
This is different from the IEA/Eurostat/UNECE definitions which separate direct consumption and autoproduction. Autoproducer undertakings generate electricity and/or heat, wholly or partly for their own use as an activity which supports their primary activity.

Other direct final consumption matches IEA/Eurostat/UNECE definitions for direct final consumption. This sector comprises residential sector, agriculture, forestry and fishing, commercial and public service, transport sector as well as other sectors ("not elsewhere specified" in IEA definition).

In Table IV of the JWEE questionnaire wood consuming sectors are matched against the forest products introduced in Tables I and II of the JWEE (see section 2.2.1). Depending on the product, units of measurement are either tonnes dry matter (t.d.m.) or tonnes (t). To ensure comparability with forestry statistics, the provided figures are converted to cubic meters solid wood equivalents ( $\mathrm{m}^{3} \mathrm{swe}$ ). The JWEE provides default conversion factors which can be adjusted by member states. For a conversion into energy units the JWEE uses TJ (higher heating) value.

\subsection{Joint Wood Energy Enquiry within the international reporting schemes}

\subsubsection{FAOSTAT}

FAOSTAT is a database maintained by FAO which provides global figures on forest products. Figures for the ECE region are collected by Eurostat and ECE through the Joint Forest Sector Questionnaire (JFSQ) reporting. After a validation process data are provided to FAOSTAT. Figures are measured in cubic meters $\left(\mathrm{m}^{3}\right)$ under bark or tonnes ( $\mathrm{t}$ ) on an annual basis. Initial data is available 8 months after the reporting period.

In terms of energy products, FAOSTAT distinguishes the production and trade of wood fuel (coniferous and nonconiferous), wood charcoal and wood pellets. However, often products such as wood residues, wood chips and particles or pulp wood are also used for energy purposes. Based on the information provided by FAOSTAT it is not possible to accurately discern for what purposes products are used.

The JWEE questionnaire seeks to improve this situation by analysing the consumption of a wide range of forest products for energy. Table 2.1 and Table 2.2 display the forest products which are harmonized with JFSQ classifications. Table 2.4 shows the correspondence between JFSQ data and the JWEE prefilled items.
TABLE 2.4

\section{JWEE-JFSQ correspondence}

\begin{tabular}{|c|c|c|}
\hline $\begin{array}{l}\text { JWEE } \\
\text { Category }\end{array}$ & $\begin{array}{l}\text { Corresponding } \\
2015 \text { JFSQ item }\end{array}$ & Comment \\
\hline $\begin{array}{l}\text { Industrial } \\
\text { Roundwood }\end{array}$ & $\begin{array}{l}1.2 \text { - Industrial } \\
\text { Roundwood }\end{array}$ & $\begin{array}{l}\text { The JWEE category } \\
\text { differentiates between } \\
\text { "forest" and "outside } \\
\text { forests" which is not } \\
\text { available in JFSQ }\end{array}$ \\
\hline Fuelwood & 1.1 - Woodfuel & $\begin{array}{l}\text { Same as above, } \\
\text { in addition JWEE } \\
\text { requests amount of } \\
\text { short-rotation coppice } \\
\text { which is not available } \\
\text { from JFSQ }\end{array}$ \\
\hline $\begin{array}{l}\text { Chips and } \\
\text { Particles }\end{array}$ & $\begin{array}{l}3.1 \text { - Wood chips } \\
\text { and particles }\end{array}$ & $\begin{array}{l}\text { These figures can be } \\
\text { underestimated, see } \\
\text { data quality discussion } \\
\text { under 4.1. }\end{array}$ \\
\hline $\begin{array}{l}\text { Wood } \\
\text { Residues }\end{array}$ & $\begin{array}{l}3.2-\text { Wood } \\
\text { residues }\end{array}$ & \\
\hline Bark & none & $\begin{array}{l}\text { This is calculated for } \\
\text { Table I as a percentage } \\
\text { of total roundwood - } \\
\text { see } 4.1 \text { for discussion. }\end{array}$ \\
\hline Black Liquor & none & $\begin{array}{l}\text { This is calculated as a } \\
\text { factor using chemical } \\
\text { pulp }\end{array}$ \\
\hline $\begin{array}{l}\text { Wood } \\
\text { Charcoal }\end{array}$ & 2 - Wood Charcoal & \\
\hline Wood Pellets & 4.1 - Wood Pellets & \\
\hline
\end{tabular}

\subsubsection{IEA/Eurostat/UNECE renewable energy questionnaire}

IEA in cooperation with Eurostat produces detailed OECD renewables and waste data for 34 countries in 2016. In addition data for non-OECD countries is collected. Data is provided in Tera-Joule (TJ) of net calorific value/lower heating value on a yearly basis. Initial data is available 12 months after the reference year.

Table 2 (supply, transformation energy sectors and end use) of the joint IEA/Eurostat/UNECE renewable energy questionnaire distinguishes several sectors using renewables for energy generation. Three main sectors are defined as "Transformation Sector", "Energy Sector" and "Total Final Consumption". These sectors comprise several potential wood energy consumers. In the transformation sector energy generation from wood can be reported under e.g. main activity producers, autoproducers as well as for transformation to derived energy 
products (e.g. wood charcoal). Only minor amounts of wood are used for energy in the energy sector which comprises mainly fossil fuel refiner (e.g. oil refineries, coal mines etc.) and won't be included in the JWEE questionnaire. Under final energy consumption wood energy could be used by the industry sector, transport and other sectors. Table 2.5 shows all the different consuming sectors which can be found in the IEA/Eurostat/UNECE renewable energy questionnaire and which are relevant for the JWEE questionnaire.

In the joint IEA/Eurostat/UNECE renewable energy questionnaire wood is reported under solid biofuels excluding charcoal. Beside all kind of forest products (e.g. firewood, wood chips, bark, black liquor etc.), solid biofuels also comprise agricultural biomass (e.g. animal waste, straw).

During the development of Table IV of the JWEE questionnaire, the IEA renewable energy balance was the reference for the energy consuming sectors as shown in chapter 2.3 .

\section{TABLE 2.5}

\section{IEA energy sectors used in the JWEE questionnaire tables III and IV}

\section{Transformation Sector}

\begin{tabular}{|c|c|}
\hline $\begin{array}{l}\text { Production of derived energy } \\
\text { products (e.g. charcoal) }\end{array}$ & JWEE: TABLE III \\
\hline Main Activity Producer & \multirow{8}{*}{ JWEE: TABLE IV } \\
\hline Electricity & \\
\hline Combined Heat and Power (CHP) & \\
\hline Heat & \\
\hline Autoproducer & \\
\hline Electricity & \\
\hline Combined Heat and Power (CHP) & \\
\hline Heat & \\
\hline \multicolumn{2}{|c|}{ Final Energy Consumption } \\
\hline Industry Sector & \multirow{11}{*}{ JWEE: TABLE IV } \\
\hline Paper, pulp and printing & \\
\hline Wood and wood products & \\
\hline Not elsewhere specified (Industry) & \\
\hline Transport & \\
\hline Other sectors & \\
\hline Commercial and public services & \\
\hline Residential & \\
\hline Agriculture/Forestry & \\
\hline Fishing & \\
\hline Not elsewhere specified (Other) & \\
\hline
\end{tabular}

\subsubsection{International Renewable Energy Agency renewable energy questionnaire}

IRENA globally covers 150 countries and has 27 states in accession. The renewable energy balances are measured in tonnes (t) on a yearly basis and initial data is published 16 month after the end of the reference year.

In its energy balance IRENA distinguishes the transformation sector as well as final consumers. The transformation sector comprises power plants, CHP plants, commercial heat plants, charcoal production, biomass pellet and briquette production and other transformation. Final consumers are further divided into industry sector, transport sector, commercial and public sector, residential and other sector.

In terms of woody energy products IRENA is more precise than the IEA definitions. Woody biomass can be assigned to woodfuel, wood waste, and black liquor as well as biomass pellets and briquettes. However, biomass pellets and briquettes are not necessarily made out of pure wood fibres but could also include, for example, nut shells or olive residues.

\subsection{JWEE data}

Since 200541 member states reported data to at least one round of the JWEE (Figure 2.5 and Annex). Including desk studies conducted by the secretariat, the database comprises data from over 42 member states (see Annex for more information on the member states).

Wood energy data provided to the JWEE reporting can be considered as the best and most detailed wood energy data available in the ECE region. After the data collection process, questionnaires are reviewed by the secretariat and, if necessary, revised in cooperation with national correspondents. To indicate the quality of data, national correspondents have the opportunity to provide quality information to each figure which ranges from $\mathrm{A}$ (excellent) to $\mathrm{C}$ (rough estimate) as well as D (no information about quality) and O (official data). JWEE data is used by the UNECE/FAO Forestry and Timber Section to improve figures in the JFSQ where figures are missing or seem misleading. Use of these data to improve figures in other datasets (e.g. IEA) is more complicated but nevertheless figures are shared with all organizations.

A common challenge for international data reporting is to ensure consistency of reporting among member states. Although the JWEE provides definitions for national correspondents and has conducted two workshops to improve knowledge on the questionnaire, comparability of JWEE data might be restricted due to differences in national data quality and availability. If information for a certain forest product (e.g. wood briquettes) or consuming sector (e.g. residential sector) is missing in a country the JWEE 


\section{FIGURE 2.5}

\section{Responding countries from 2005 to 2015}

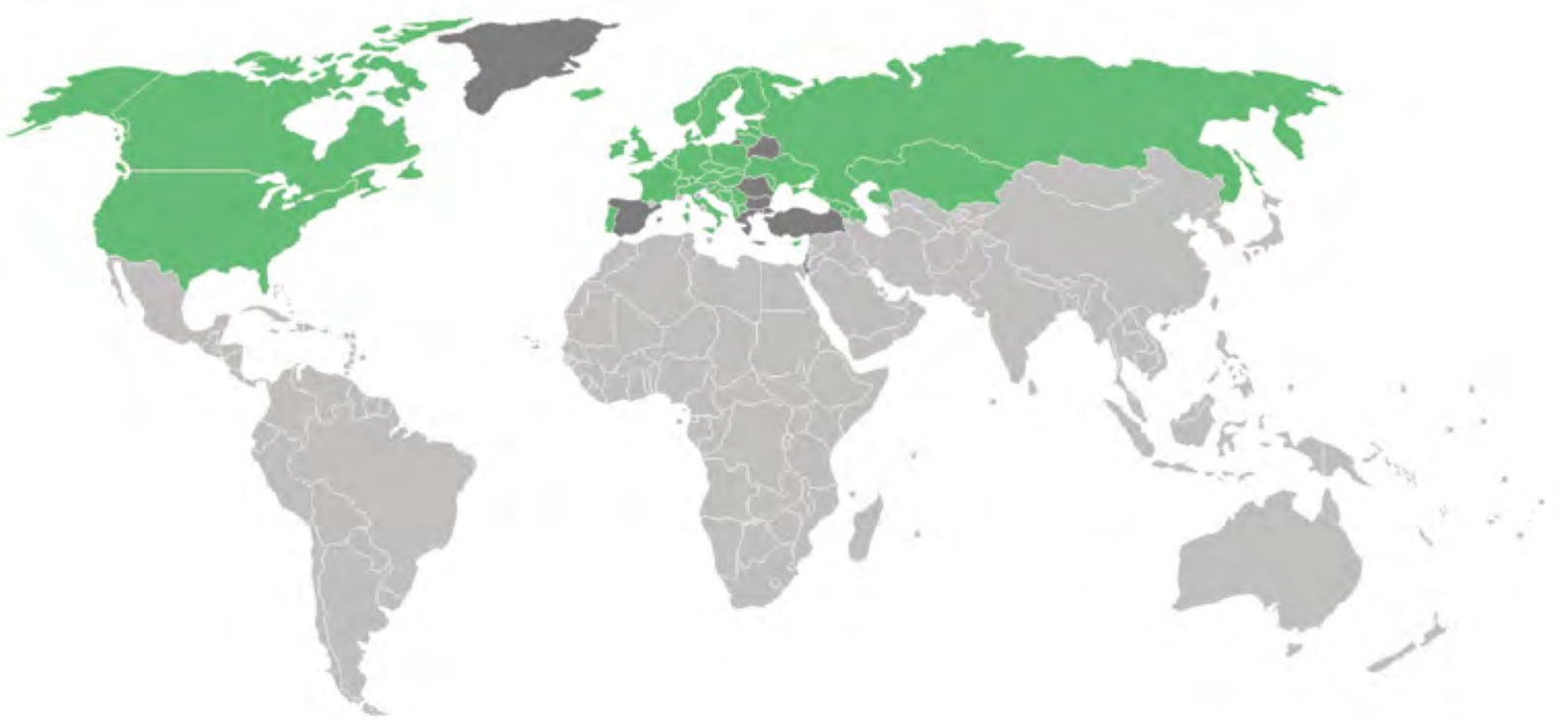

database will lack this information while for other countries this information might be available. On the contrary if a new data source (e.g. from a household survey) is available in a country this might lead to the inclusion of new figures (e.g. wood energy consumed in households) or a shift from one forest product to another (e.g. unknown is reported under wood pellets) while previous years won't be adjusted. This procedure might result in jumps in the time series of countries.

One issue is the underreporting of chips and residues. Many of these are directly used and do not appear in production or consumption statistics. Small-scale chipping production is widespread and not reported. Use of biomass for small-scale heating plants is also often unrecorded.

A persistent question affecting biomass figures is the inclusion (or not) of bark data. Typically bark is included in fuelwood that is burnt directly. However the JWEE is measuring wood supply underbark. Bark from industry processing is included in table I (using a factor to estimate) but the use of this is likely to be underreported. Thus both the structure and the actual data reported for the JWEE will tend to underestimate this component of wood energy.

In addition, the JWEE reporting is voluntary. Some member states have never reported wood energy data, some don't reply on a biannual basis and skip reporting rounds. Some member states adopted the JWEE and use it for annual reporting at national level. This leads to gaps in the time series which are not estimated by the secretariat. Nevertheless the secretariat is steadily reaching out to these member states to retrieve as consistent wood energy data as possible.

The use of appropriate conversion factors is crucial to bridge forestry and energy statistics. The JWEE provides default conversion factors (Fonseca et al., 2010; Hagauer et al., 2008). However, to better reflect the situation in member states national correspondents are invited to adjust the default conversion factors. The conversion into cubic meter solid wood equivalents ( $\mathrm{m}^{3} \mathrm{swe}$ ) works quite well. Energy statistics commonly use Joule (lower heating value). Due to challenges in conversion, the JWEE uses Joule (higher heating value) as corresponding energy unit (see discussion in section 2.7).

\subsection{JWEE aggregated results and indicators for 2015}

Results of all reporting years for the JWEE are published on the website of UNECE/FAO Forestry and Timber Section (http://www.unece.org/forests/jwee). Aggregated data for all reporting member states for the reference year 2015 is provided in the Annex. In addition the JWEE result sheet provides a set of indicators. On the next pages the share of woody biomass in total primary energy supply (TPES) and woody biomass in renewable energy supply (RES) as well as the relative shares of the origins and the use of wood for energy will be shown. The TPES and RES figures are drawn from IEA statistics (measured in lower heating value) while the woody biomass figures come from the JWEE (measured in higher heating value). 


\section{FIGURE 2.6}

\section{Consumption of Biomass, 2015}

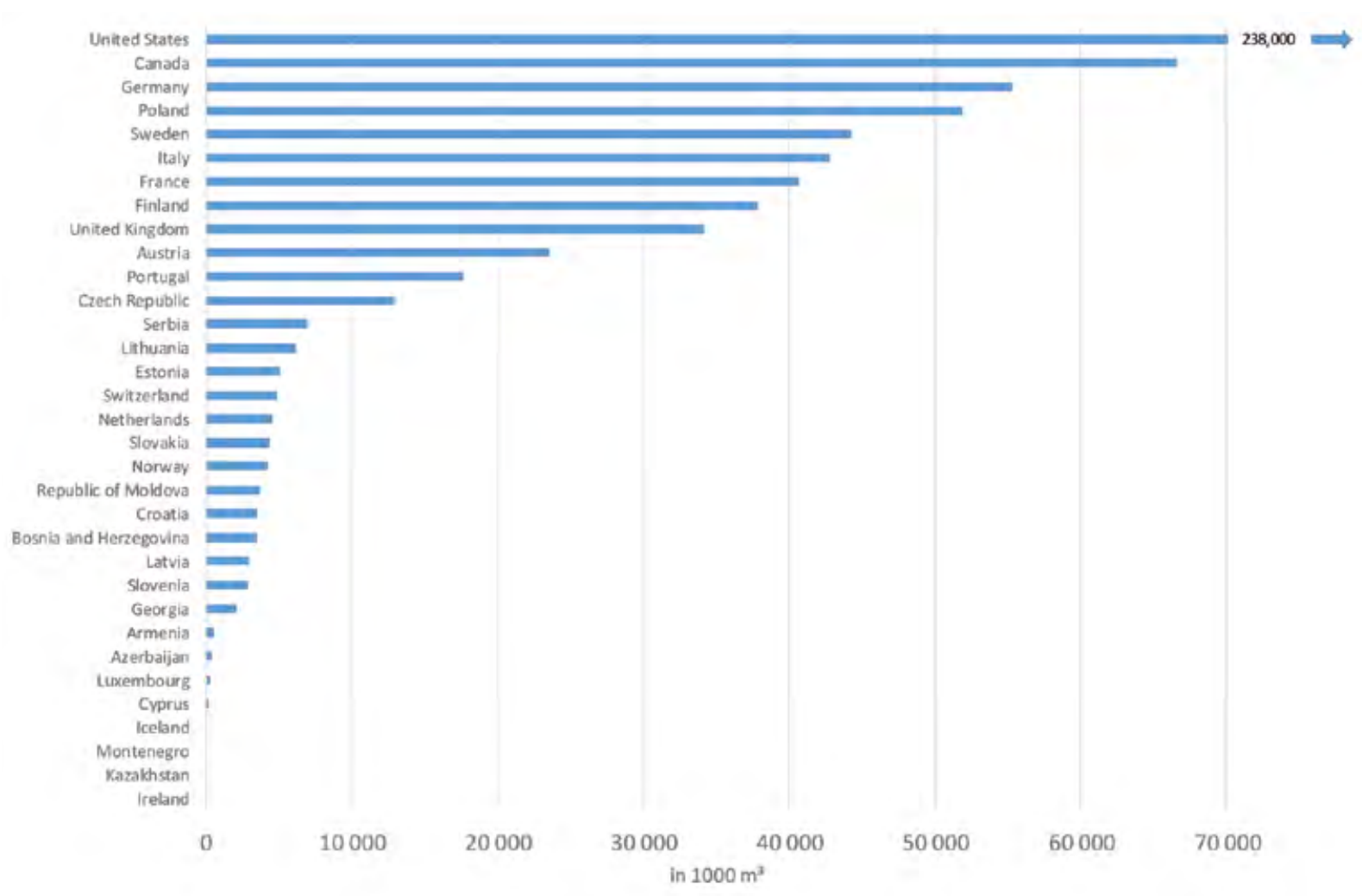

Figure 2.6 shows reported biomass consumption by country ${ }^{2}$ for 2015 in $1000 \mathrm{~m}^{3}$. Some non-heavily forested countries seem to have high total use of wood energy (e,g, UK). Countries with similar populations seem to exploit wood energy quite differently, for example Canada and Poland Canada has 19 times more forest resources and reported use is $30 \%$ more than Poland.

Figure 2.7 displays the share of woody biomass for energy in TPES in 2015. Mostly scandinavian countries (Finland 24.5\%, Republic of Moldova 21.6\% and Sweden 20.2\%) have the highest amount of wood used in TPES. The average for all member states that reported data in 2015 is 3.8\%.

Figure 2.8 displays the share of woody biomass in renewable energy supply (RES) for 2015. Republic of Moldova, Poland and Estonia reported a share of wood in RES that is beyond $100 \%{ }^{3}$ Lithuania is covering $87.5 \%$ of its RES with woody biomass while Slovakia is using $76.1 \%$ and Finland $75.8 \%$.

2 Please note that 3 countries (Montenegro, Kazakhstan and Ireland) did not supply sufficient data to see in this and following figures.

3 These discrepancies could derive from underestimation of wood energy data in national energy statistics for example household surveys could indicate use that is higher than official data. Another explanation could be the different energy units used for comparison (RES data from IEA is measured in lower heating value while JWEE data is measured in higher heating value).
One strength of the JWEE is the collection of information about the origin of wood energy resources and the identification of sectors where forest products are used for energy. Figure 2.9 displays the relative shares of the origin of wood energy sources by member states for 2015.

Referring to all member states reporting in 2015, 38.3\% of woody biomass used for energy came directly from the forest or other wooded land (S1-Direct). This category comprises any wood fibre entering energy production without any further treatment or conversion. It comprises any woody biomass from any land use (e.g. forests, hedgerows, agricultural residues from fruit tree orchards, wood from gardens etc.) and any form (e.g. firewood, green chips, roundwood, fruits and shells). $43.4 \%$ of wood for energy came from indirect sources (S2-Indirect). This category comprises processed and unprocessed co-products (residues) from the wood processing industries. These co-products can be solid (e.g. sawdust, chips, veneer rejects), liquid (e.g. black liquor, tall oil) or processed wood based fuels (e.g. wood pellets, briquettes, wood charcoal). 5.1\% was classified as recovered wood (S3Recovered). Post-consumer recovered wood comprises any waste wood fibre after at least one life cycle. It comprises wood from construction, renovation and demolition, but also packaging as well as old furniture. In some countries wood waste can be further distinguished in hazardous and 


\section{FIGURE 2.7}

\section{Share of Biomass in Total Primary Energy Supply, 2015}

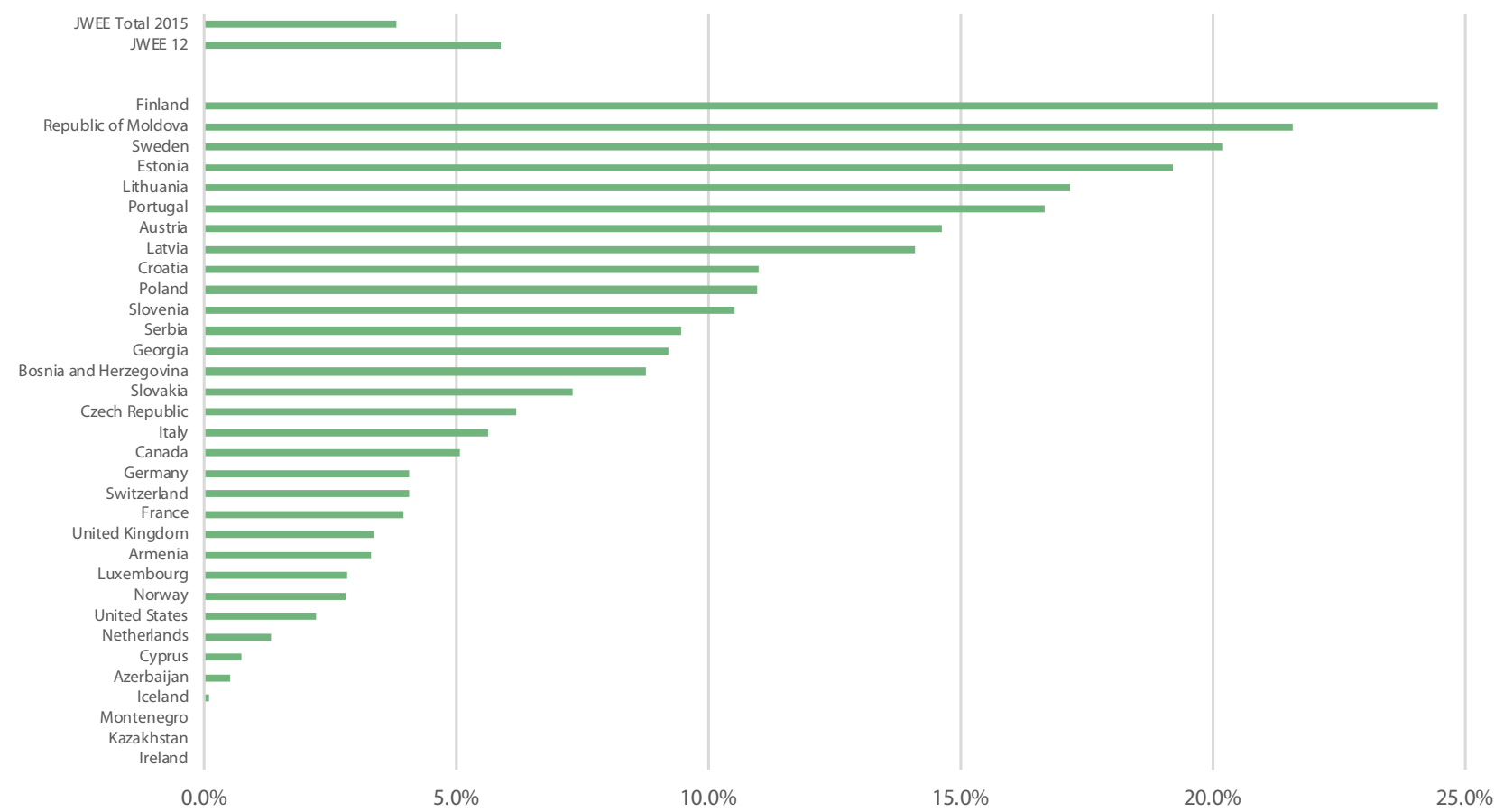

Note: JWEE 12: Austria, Cyprus, Finland, France, Germany, Ireland, Luxembourg, Serbia, Slovenia, Sweden, Switzerland and United Kingdom.

\section{FIGURE 2.8}

\section{Share of Biomass in Renewable Energy Supply, 2015}

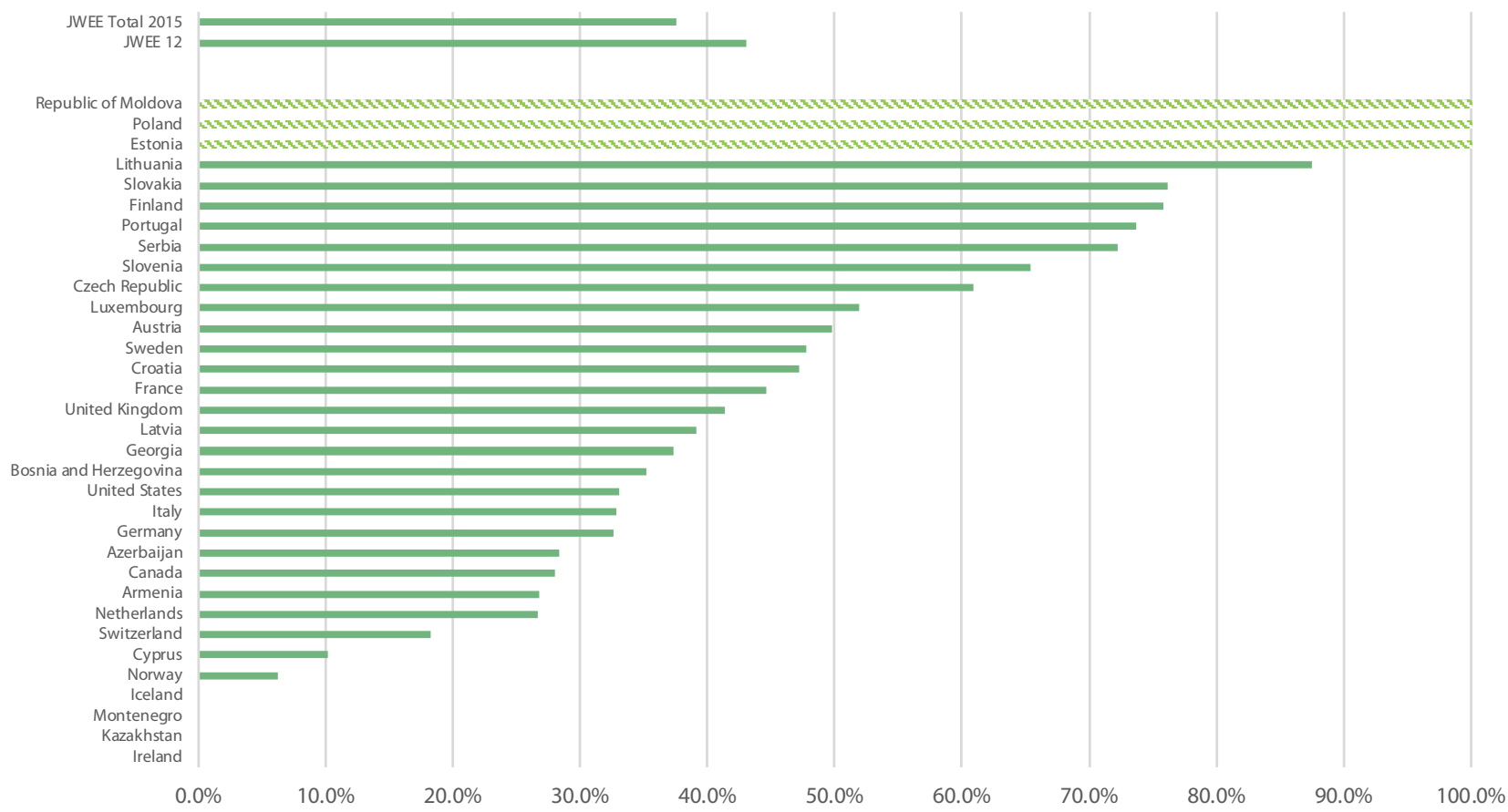

Note: JWEE 12: Austria, Cyprus, Finland, France, Germany, Ireland, Luxembourg, Serbia, Slovenia, Sweden, Switzerland and United Kingdom. 


\section{FIGURE 2.9}

\section{Relative share of wood energy sources, 2015}

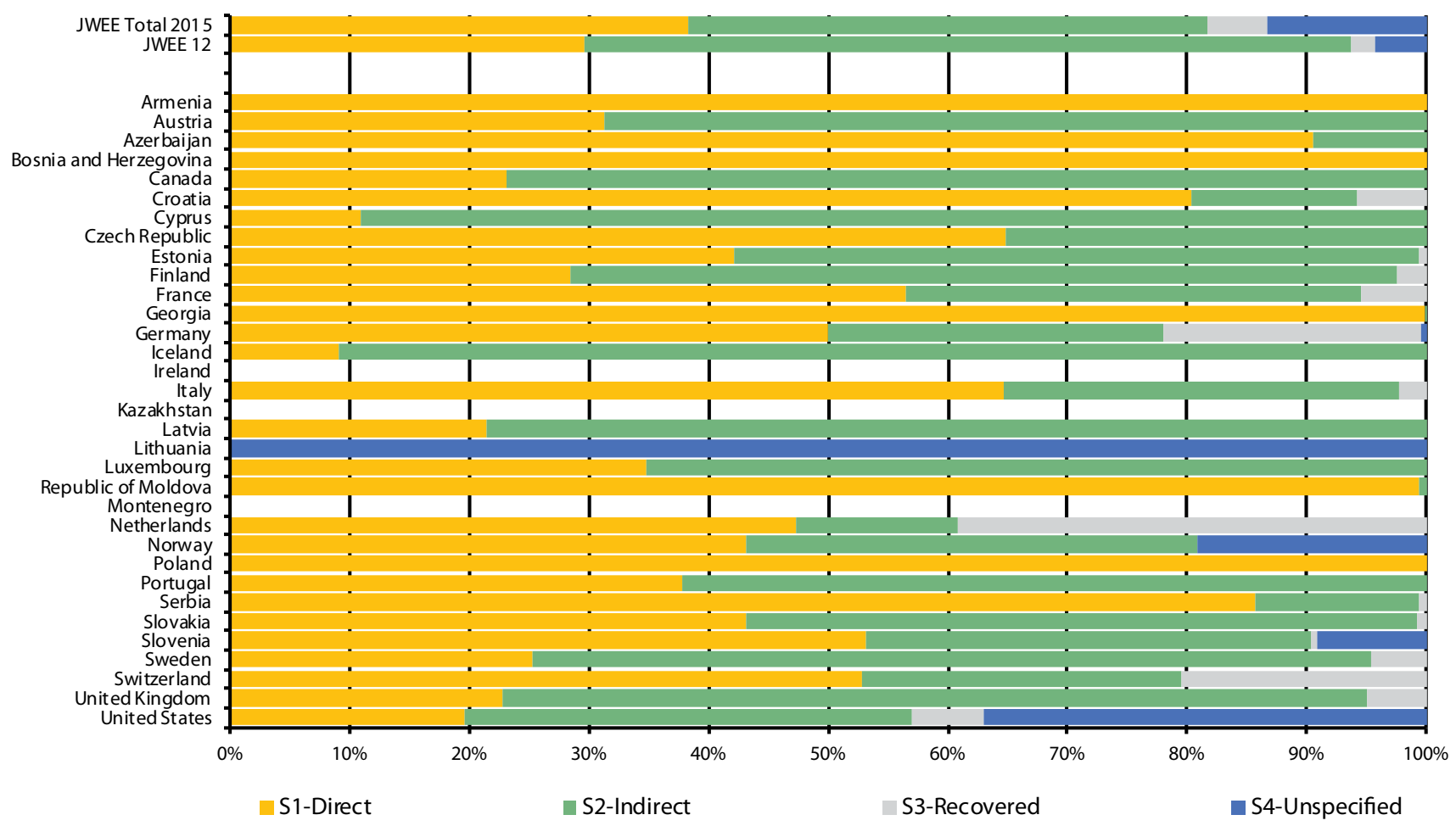

Note: JWEE 12: Austria, Cyprus, Finland, France, Germany, Ireland, Luxembourg, Serbia, Slovenia, Sweden, Switzerland and United Kingdom.

non-hazardous wood waste which is recognized in the JWEE reporting. 13.2\% of wood consumed for energy in 2015 originated from unspecified sources (S4-Unspecified). This category covers wood used for energy where the origin of the resource is unknown. Many countries know something about the amount of wood used but not its source. This category represents a further step in making the JWEE more compatible with the energy statistics.

Figure 2.10 displays the relative share of wood energy uses in 2015. Member states reported that $19.6 \%$ of wood was consumed by heat, power and CHP plants (U1-Power and Heat). This category comprises all energy facilities that primarily produce energy. Saw mills, pulp and paper mills that produce energy aren't considered under this category. These facilities are reported under industry sector (U2Industrial). This sector consumed most of wood for energy in 2015 (39.3\%). The industry sector comprises undertakings that generate electricity and/or heat, wholly or partly for their own use as an activity which supports their primary activity. The residential sector (U3-Residential) consumed slightly less wood for energy (37.1\%. This category refers to IEA definitions where the entire energy consumption of households is considered, excluding fuels used for transportation. $4.1 \%$ of wood was reported to be used for energy in other sectors (U4-Other). This definition comprises any other economic sector that is not included in the above mentioned (e.g. agriculture, forestry and fishing, commercial and public services and transport).

\subsection{Longitudinal data}

The production of time series using JWEE data is restricted. 12 member states ${ }^{4}$ continuously provided wood energy data since 2007. Data from these 12 countries would be the first choice for the production of a consistent time series. More countries could be included if missing data were to be estimated by the secretariat.

Total wood energy consumption ${ }^{5}$ in these member states increased from 193 Mio. $\mathrm{m}^{3}$ swe to 251 Mio. $\mathrm{m}^{3}$ swe between

4 12 JWEE: Austria, Cyprus, Finland, France, Germany, Ireland, Luxembourg, Serbia, Slovenia, Sweden, Switzerland and United Kingdom

5 The term total wood energy consumption is not directly comparable to energy consumption figures. Total wood energy consumption comprises wood used for transformation into electricity, heat and CHP as well as wood energy for final energy consumption. 


\section{FIGURE 2.10}

\section{Relative share of wood energy uses, 2015}

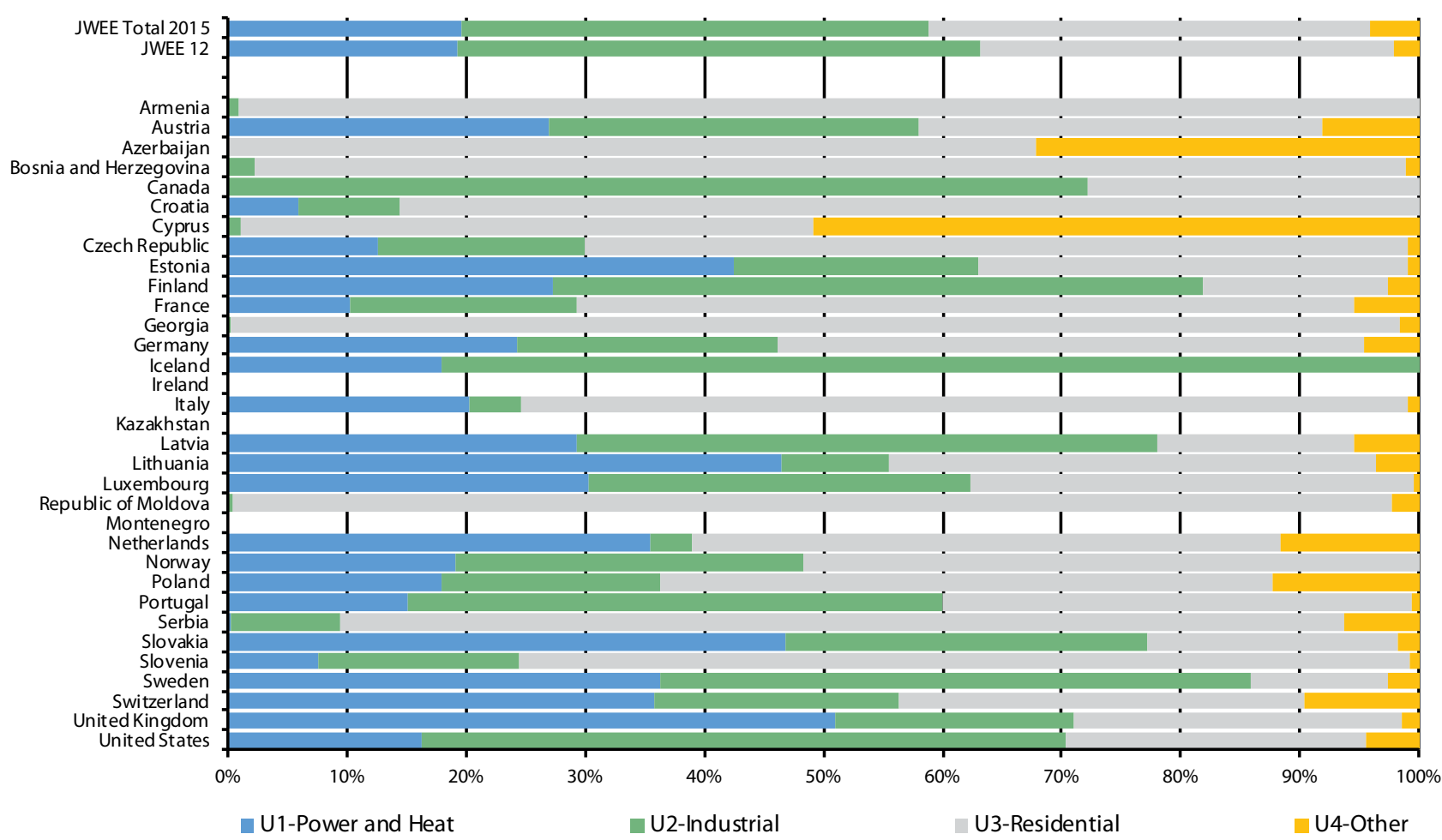

Note: JWEE 12: Austria, Cyprus, Finland, France, Germany, Ireland, Luxembourg, Serbia, Slovenia, Sweden, Switzerland and United Kingdom.

\section{FIGURE 2.11}

\section{Wood energy consumption by sectors in 12 JWEE}

countries in $1000 \mathrm{~m}^{3}$

$120^{\prime} 000$

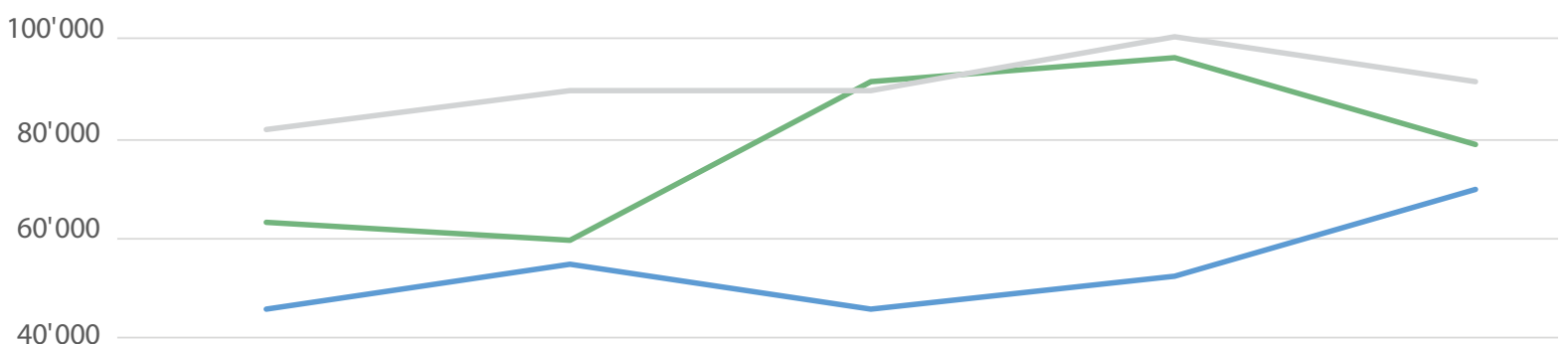

201000

0 
2007 and 2015. Figure 2.11 displays the consumption of main activity producer (U1), industry sector (U2), residential sector (U3) and other (U4). For the 12 member States the largest share of wood energy consumption is in the residential sector. Between 2007 and 2013 consumption increased by approximately $19 \mathrm{Mio} . \mathrm{m}^{3}$ swe to ca. $100 \mathrm{Mio} . \mathrm{m}^{3}$ swe. From 2013 to 2015 wood energy consumption decreased to ca. 92 Mio. $\mathrm{m}^{3}$ swe. The "other" sector increases slightly from 3 Mio. $\mathrm{m}^{3}$ swe in 2007 to 10 Mio. $\mathrm{m}^{3}$ swe in 2015.

Wood consumed for transformation into heat, electricity or CHP (U1) and wood energy consumption by the industry sector (U2) show opposing trends. In the industry sector wood energy consumption increased from ca. 60 Mio. $\mathrm{m}^{3}$ in 2009 to ca. 90 Mio. $\mathrm{m}^{3}$ in 2011 while wood energy consumption for power and heat decreased by ca. 9 Mio. $\mathrm{m}^{3}$ between 2009 and 2011. This shift is the result of an improvement of data availability in a single member State which resulted in a shift of reporting wood energy under power and heat and the industry sector. Since 2011 wood energy for transformation into heat, electricity or CHP increased by $24 \mathrm{Mio} \mathrm{m}^{3}$ swe resulting in 70 Mio $\mathrm{m}^{3}$ in 2015.

The dramatic changes in availability of densified bio-fuels (pellets) have been a major driver in increasing use of wood energy in the region. In particular the use of this in producing power as well as heat in large scale facilities has been a leading reason for the increase in bio-energy use. Policies designed to favour renewable and low-carbon options have also supported the increase (UNECE/FAO FPAMR, 2015-2016).

Figure 2.12 displays the shares of origins of wood energy sources consumed by the power and heat sector. From 2007 to 2011 the share of primary (S1) and industry sources (S2.1) slightly increased while the share of wood waste (S3) consumed for energy decreased. Since 2011 primary wood consumption decreased while industry sources remained constant and the share of processed wood based fuels (S2.2) as well as wood waste increased. One possible reason for this could be that large scale energy facilities initially used primary wood resources, as the demand of wood is increasing, prices increased which lead to an increased use of low cost wood in particular wood waste. The increase of processed wood based fuels is mainly driven by policy interventions (UNECE/ FAO FPAMR, 2015-2016).

Figure 2.13 shows the shares of consumed wood energy sources by industry sector. In 2007 almost the entire demand for energy in the wood processing industry sector was supplied by wood from industry sources (\$2.1). One could say that the wood processing industry sector mainly uses its own wood residues for energy and only a small amount of wood comes directly from the forest (S1). Since 2009 but more significant in 2011, wood waste (S3) and primary sources (S1) appeared to also be used in the wood processing industry.

\section{FIGURE 2.12}

\section{Share of wood energy sources consumed by power and heat sector in 12 JWEE countries}

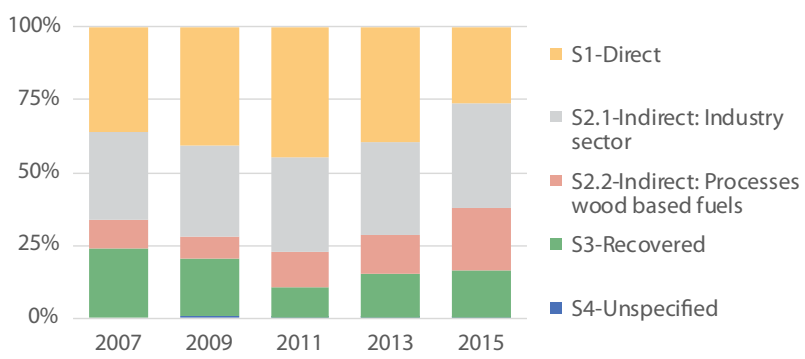

Note: JWEE 12: Austria, Cyprus, Finland, France, Germany, Ireland, Luxembourg, Serbia, Slovenia, Sweden, Switzerland and United Kingdom.

\section{FIGURE 2.13}

\section{Share of wood energy sources consumed by industry sector in 12 JWEE countries}

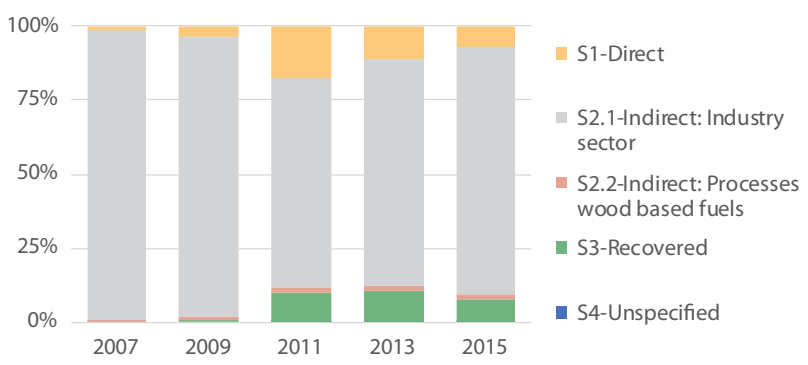

Note: JWEE 12: Austria, Cyprus, Finland, France, Germany, Ireland, Luxembourg, Serbia, Slovenia, Sweden, Switzerland and United Kingdom.

\section{FIGURE 2.14}

\section{Share of wood energy sources consumed by residential sector in 12 JWEE countries}

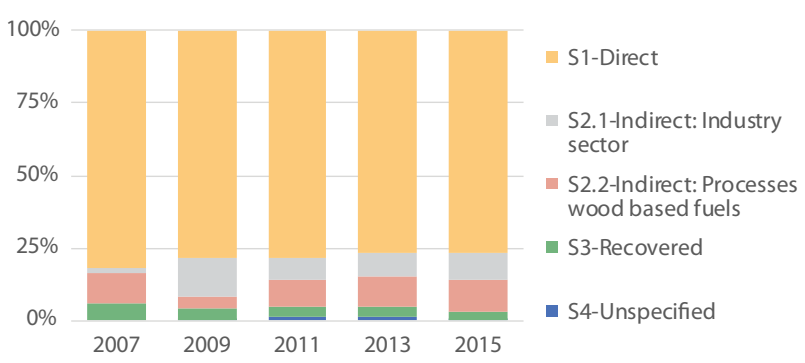

Note: JWEE 12: Austria, Cyprus, Finland, France, Germany, Ireland Luxembourg, Serbia, Slovenia, Sweden, Switzerland and United Kingdom. 
However, wood from industry sources remain the most important energy source for this sector, accounting for $84 \%$ in 2015.

Figure 2.14 displays the share of wood energy consumed in the residential sector. About $80 \%$ of wood for energy consumed by the residential sector came directly from the forest or other wooded land e.g., gardens (S1). From 2007 to 2015 this share remained relatively stable. $8 \%$ of wood from the industry sector (\$2.1), 9\% of Processed wood based fuels (\$2.2) and about 4\% of wood waste (S3) was used for energy by the residential sector.

The "other" sector (figure 2.15) is consuming wood from industry (e.g. chips and particles) (S2.1) and primary sources (e.g. from forests) (S1). The shares remain relatively stable.

\section{FIGURE 2.15}

\section{Share of wood energy sources consumed by other sector in 12 JWEE countries}

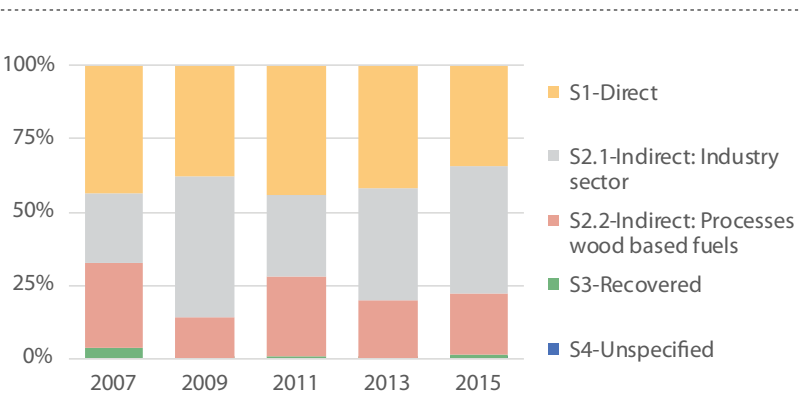

Note: JWEE 12: Austria, Cyprus, Finland, France, Germany, Ireland, Luxembourg, Serbia, Slovenia, Sweden, Switzerland and United Kingdom.
In 2015 wood from industry sources was higher (44\%) than wood from primary sources (34\%). Processed wood based fuels (S2.2) accounted for $21 \%$ of the wood used for energy in the other sector.

The results sheet of the JWEE reporting comes with predefined indicators. A sample selection of indicators is provided in Figure 2.16.

Figure 2.16 displays wood energy as well as wood pellet consumption per inhabitant. It appears that the average wood energy consumption has been steadily increasing since 2007 from $0.77 \mathrm{~m}^{3} /$ capita to $0.97 \mathrm{~m}^{3} /$ capita in 2015 . Pellet consumption per inhabitant increased more sharply than wood energy consumption per inhabitant. Between 2007 and 2015 wood pellet consumption per inhabitant increased from $16.20 \mathrm{~kg} /$ capita to $45.63 \mathrm{~kg} /$ capita. Much of this increase is driven by the increased consumption of wood pellets in energy plants of the United Kingdom, which reported an approximately 14 times higher pellet consumption compared to 2007.

\subsection{Data gathering practices and issues for improvement}

The JWEE reporting is an ongoing effort and disseminated among member states on a biannual basis. The reporting scheme is voluntary and member states do not necessarily provide a completely filled questionnaire.

In Table I many cells of the questionnaire are already prefilled by the JFSQ and don't have to be filled by the national correspondents. However, if the figures are outdated correspondents are welcome to revise the prefilled data as

\section{FIGURE 2.16}

\section{Average wood energy and pellet consumption}

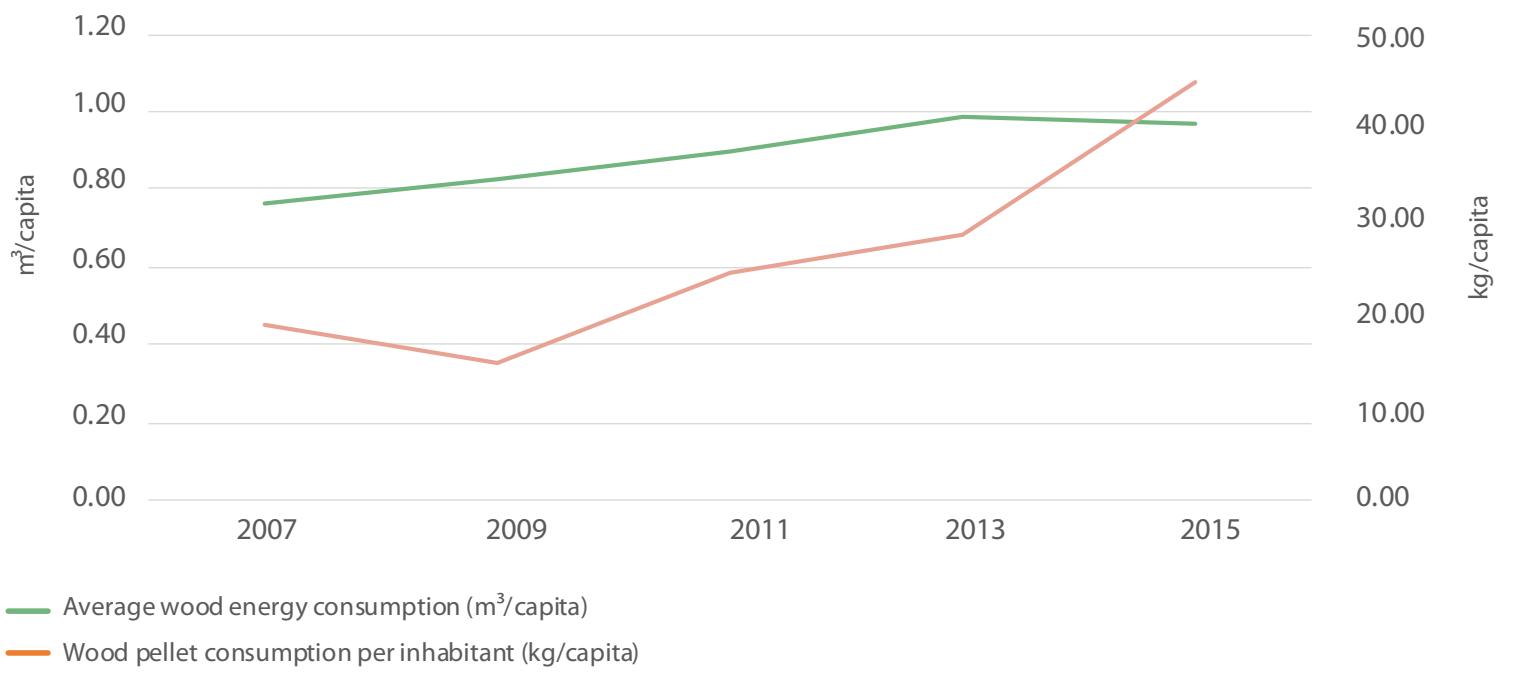


well. Figures on post-consumer recovered wood are not prefilled but can be obtained from Eurostat, Basel Convention or OECD. Links directing to these databases can be found in the questionnaire.

Figures on wood charcoal and wood pellets in Table II are prefilled by the provided JFSQ figures.

Table III on the transformation of wood resources in processed wood based fuels seems to be hard to complete. Only 17 member states provided information in this table in 2015 reporting. The Team of Specialists encouraged the use of this table and other organizations have indicated that even the limited data are of interest.

Information required in Table IV can be derived from official energy balances or surveys conducted in a member state. Also if the origin of a forest product used for energy is unknown but the quantity is known, this figure can always be reported under wood from unknown sources. On the contrary if the specific consuming sector of Main Activity Producer, Industry Sector or Other Direct Final Consumption is unknown, figures can be reported under unspecified use.

For cross checking and prefilling, the JWEE questionnaire uses default conversion factors. The questionnaire works with the default conversion factors. However, if assumptions to calculate the factors are inappropriate or conversion factors need to be changed, national correspondents are invited to change these to more closely reflect reality.

The use of higher heating values in the JWEE is a point of contention (see glossary for definitions). Lower heating values are favoured in the energy sector because they are seen as more realistic. Higher heating values were chosen in the JWEE to avoid the ambiguity of lower heating values due to variability of moisture, heat loss in the exhaust system and the change of units of input raw material. Coming to a common understanding of the actual heat value of the biomass would require additional research.

One of the more difficult areas is trying to estimate household use of wood energy. A number of estimations can be used (rural inhabitants in comparable countries) but the most accurate figures have come from countries that have been able to include wood energy use in national household surveys. These figures don't necessarily derive from official statistics but could be obtained from research institutes or academic research. Best practice would suggest that, in the absence of a household survey, a comparison of per capita consumption with similar regions be undertaken and an estimate made using approximately the same per-capita figure adjusted for local conditions.

Another area is the treatment of bark on logs used directly which has been ignored in the JWEE whereas in fact some countries include this in their household statistics. Recent revisions of the JWEE highlight bark more clearly and it remains an area to work on best practice would suggest that the table IV energy consumption statistics clearly indicate whether the fuelwood consumption includes or excludes bark.

Finally, the figures for use of wood energy often do not compare well with the source of wood. This can be due to the limited information on wood from outside forests. A good practice would be to conduct studies to determine the amount of additional wood being made available from outside the forest and apply this to either the available forest harvesting figures or as the share of known wood consumption. 


\subsection{References}

Dietmar Hagauer, Bernhard Lang, Kasimir P. Nemestothy, 2008 - Calculation of Wood Fuel Parameters, klima:aktiv energieholz / Österreichische Energieagentur - Austrian Energy Agency

UNECE 2010 - Forest Product Conversion Factors for the UNECE Region, Geneva Timber and Forest Discussion Paper 49

FAO, Unified Bioenergy Terminology (UBET), 2004.

IEA, 2016 - Renewable Energy Medium-term Market Report

IEA/Eurostat/UNECE, 2015 - Renewables Questionnaire: https://www.iea.org/statistics/resources/questionnaires/ annual, 02.2017
OECD/IEA, 2016 - Renewable Energy - Medium-Term Market Report 2016, Market Analysis and Forecasts to 2021, OECD/ IEA

UNECE/FAO FPAMR 2015-2016 - Forest Products Annual Market Review: http://www.unece.org/forests/fpamr2016. html, 02.2017

UNECE/FAO Wood Prices, 2016 - Wood price database: http:// www.unece.org/forests/output/prices.html, 02.2017

UNECE/FAO/ITTO/Eurostat Joint Forest Sector Questionnaire. This is available at http://www.unece.org/index.php?id=29752

World Bank, 2016 - Global Economic Monitor (GEM) Commodities: http://databank.worldbank.org/data/reports. aspx?source=Global-Economic-Monitor-(GEM)-Commodities, 11.2016 


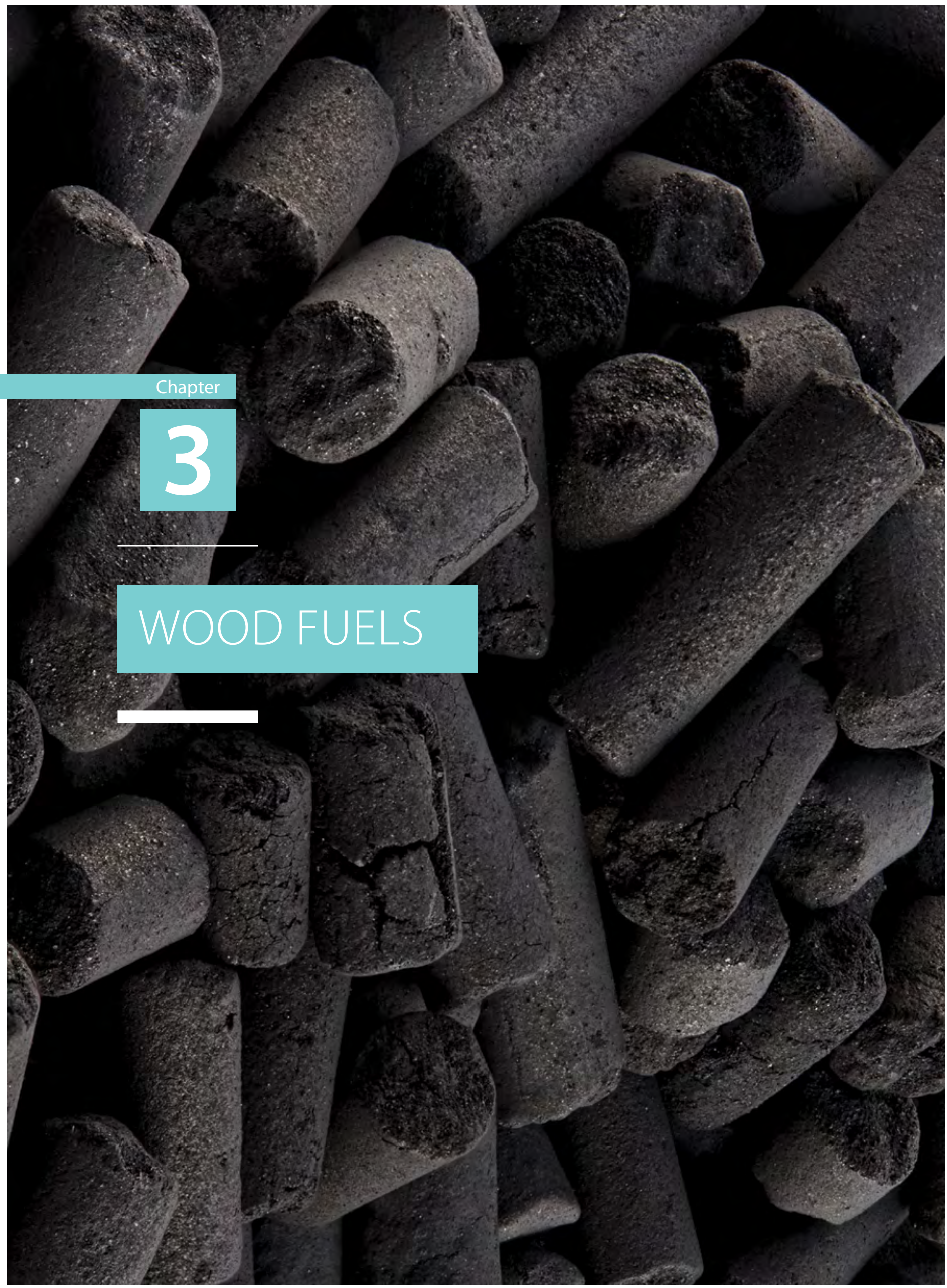




\section{Highlights*}

* Wood offers a renewable type of fuel that is flexible for uses as a source of cooking, space, heating, electricity generation and even transportation fuels.

* Most-commonly used forms of wood fuels include firewood, densified, thermally-treated wood and black liquor.

* Firewood represents the largest share in wood energy fuels production and consumption.

* Densified wood pellets are the most commonly traded wood fuel in international markets.

* Charcoal is the most common form of thermally-treated wood and is produced at a great range of processing units and levels of efficiency.

* Black liquor production dominates wood energy production in countries of installed pulp and paper manufacturing capacity

* Increased use of wood fuels in modern household, industrial, power and combined heat-and-power systems has promoted standardization. 


\subsection{Introduction}

Wood fuel ${ }^{6}$, wood used to generate energy, can be processed and stored without major capital investments, and converted into useful energy as needed as part of modestly- or highlyefficient energy pathways (Song and Aguilar, 2016). Wood fuel comprises all types of biofuels originating from woody biomass, excluding material that has been embedded in geological formations and/or transformed to fossil resources (International Standards Organization, 2014). Wood fuel can be a renewable and sustainable energy source when harvested in an environmentally-sound fashion, and can be carbon neutral if converted efficiently into useful energy and integrated with supply-chains of other longlived wood products (Hektor et al. 2016, Miner et al. 2014). The production of biochar, which is essentially a modified charcoal product, can be used for soil enhancement and may represent a very long-term carbon storage pathway (Qambrani et al. 2017).

Wood can be processed to meet requirements for different energy platforms for cooking and space heating, electricity generation, and even to yield transportation fuels. Wood fuel can be combusted from its raw condition after minimum processing and drying (e.g. firewood), processed to densify its energy content (e.g. briquettes, pellets), subjected to thermal treatments (e.g. charcoal, torrefied biomass), or as a co-product from other processes (e.g. pulping black liquors). Wood fuel can also be subjected to biochemical conversion to generate liquid fuels such as ethanol or butanol. This chapter exclusively explores the use of wood energy to generate electricity and/or heat in the UNECE region and excludes the use of transportation fuels due to limited commercial use to-date. Particular attention is paid to data from four areas within the UNECE, namely, the European Union (EU), the western Balkans, North America, and the Commonwealth of Independent States.

The amount of useful energy generated from wood is a function of factors intrinsic to woody species and the condition of wood fuel after any processing and treatment. The calorific value of most wood species ranges from 16 to $20 \mathrm{GJ} / \mathrm{t}$ of dry wood matter (Panshin and de Zeeuw, 1980).

6 For the purpose of this chapter, regions are denoted as follows. World: all countries. European Union (EU) members: Austria, Belgium, Bulgaria, Croatia, Cyprus, Czech Republic, Denmark, Estonia, Finland, France, Germany, Greece, Hungary, Ireland, Italy, Latvia, Lithuania, Luxembourg, Malta, Netherlands, Poland, Portugal, Romania, Slovakia, Slovenia, Spain, Sweden, and the United Kingdom. Western Balkans countries: Albania, Bosnia and Herzegovina, Croatia, Montenegro, Serbia and the former Yugoslav Republic of Macedonia Commonwealth of Independent States (CIS) countries: Armenia, Azerbaijan, Belarus, Kazakhstan, Kyrgyzstan, Moldova, Russian Federation, Tajikistan, Uzbekistan, Turkmenistan, and Ukraine (last two are associate states within the CIS). North America: Canada and the United States of America.
Table 1 presents higher heating values (HHV) for common tree species. HHV represents the total amount of energy that could potentially be recovered from wood, when the energy required to condense moisture within the wood is considered. The efficiency of different wood energy conversion pathways depends on the physical and chemical characteristics of wood fuel, including moisture content, calorific value, proportions of fixed carbon (generally 50\%), and volatiles (which can add significantly to energy value, as long as they are not lost in the drying process), ash/residue content (partially controlled via harvesting), alkali metal content (primarily potassium) content, and cellulose/lignin ratio (McKendry, 2002). Moisture content is usually the parameter of greatest importance to wood's useful energy content. A freshly cut tree can have moisture contents in the $50 \%$ range (measured as a portion of wet mass) or $100 \%$ (measured as a portion of dry mass), i.e. fully half of the mass of the tree is water. In the energy sector, most moisture contents (mc) are reported on a wet basis. Air-drying can bring moisture contents down to ambient range over time (9-11\% mc, wet basis). Higher moisture contents lower effective energy recovery and are related to significantly higher carbon emissions, particularly when using older technology. For instance, Magnone et al. (2016) assessed the combustion of oak using an indoor wood stove and found that total carbon emissions rose from $0.25 \mathrm{~g} / \mathrm{kg}$ to $1.12 \mathrm{~g} / \mathrm{kg}$ with a corresponding rise in moisture content from $10.3 \%$ to $56.3 \%$ (dry basis). Table 3.1 illustrates published higher heating values for selected wood species. In practice, a common value of $19.7 \mathrm{GJ} / \mathrm{t}$ for dry wood is often used and these values may differ depending on specific protocols followed to assess energy content (Ince, 1979).

\section{TABLE 3.1}

\section{Ranges of higher heating values (total amount of energy recoverable from moisture free biomass) for common wood specie}

\begin{tabular}{|lll|}
$\begin{array}{l}\text { Wood } \\
\text { species }\end{array}$ & HHV GJ/t & Source \\
\hline Alnus spp. & $19.26-20.44$ & Pesonen et al. 2014 \\
\hline Betula spp. & $19.47-20.19$ & Pesonen et al. 2014 \\
\hline $\begin{array}{l}\text { Eucalyptus } \\
\text { spp. }\end{array}$ & $19.16-19.38$ & Torres et al. 2016 \\
\hline Oak spp. & $17.82-19.90$ & Kim et al. 2016 \\
\hline Pinus spp. & $16.84-17.30$ & Kim et al. 2016 \\
\hline Populus spp. & $20.04-20.10$ & Pesonen et al. 2014 \\
\hline Salix spp. & $20.01-20.20$ & Pesonen et al. 2014 \\
\hline
\end{tabular}




\subsection{Wood fuels}

Wood is by nature a heterogeneous raw material. Processing helps improve standardization and improve its energy source properties. For example, moisture content in raw (green) wood fuel can be reduced naturally through adequate processing and storage, lowering procurement costs and enhancing the efficiency of energy recovery. The energy content per volume of woody biomass can also be densified through mechanical processing by reducing fibre size with a chipper and drying with a rotary drum. Thus, physical properties are enhanced for more efficient combustion as it is the case for briquettes and pellets. It is important to stress that the wood fuel supply chain should be managed to minimise contact with pollutants (dirt, sand, stone), the presence of which can lower energy values and increase ash content. Here, we offer a brief description of selected wood fuels of common usage in the UNECE region.

\subsubsection{Fuelwood (Firewood)}

Historically, firewood (e.g. cordwood) has been the most common source of bioenergy used by households. Fuelwood is a type of wood fuel where its original composition is preserved and is used solely for the purpose of energy generation. The quantity of fuelwood consumed or produced is commonly expressed in volumetric units (e.g. $\mathrm{m}^{3}$ ) as mass and heating values change depending upon moisture content.

\section{FIGURE 3.1}

\section{Wood fuel source by type in the western Balkans in 2015. Total production $=\mathbf{2 1 4}$.2 petajoule}

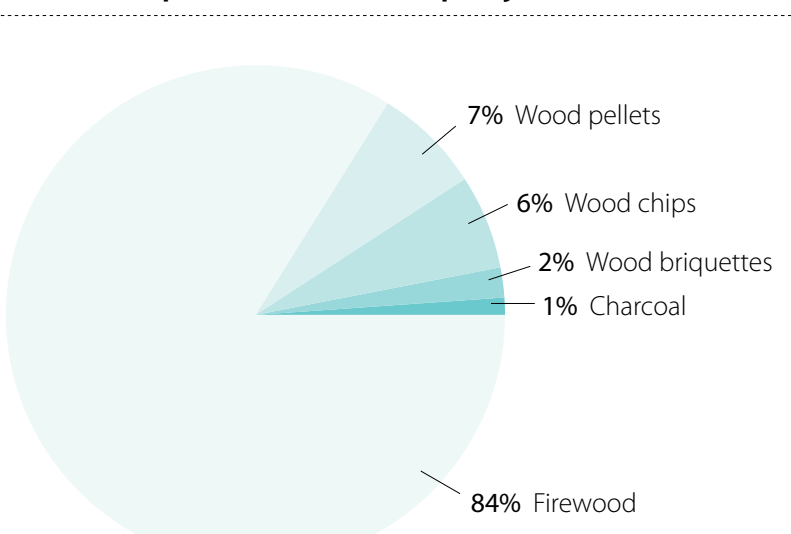

Source: Aguilar et al. (2016).

Fuelwood data are often collected as part of data on total roundwood harvest, which describes the cumulative wood production for such diverse end uses as fuel, paper and pulp products, and solid or engineered lumber products. Advances in the processing and standardization of firewood have allowed for the emergence of important trade flows. For instance, about one-third of Italian firewood imports came from western Balkan countries; and firewood accounted for about $45 \%$ of the total wood energy fuels exported by western Balkans - by energy content. Firewood accounted for $84 \%$ of total wood fuel production in the western Balkans in 2015 (Figure 3.1).

\section{FIGURE 3.2}

\section{Roundwood and fuelwood production for various regions, 1990-2016}

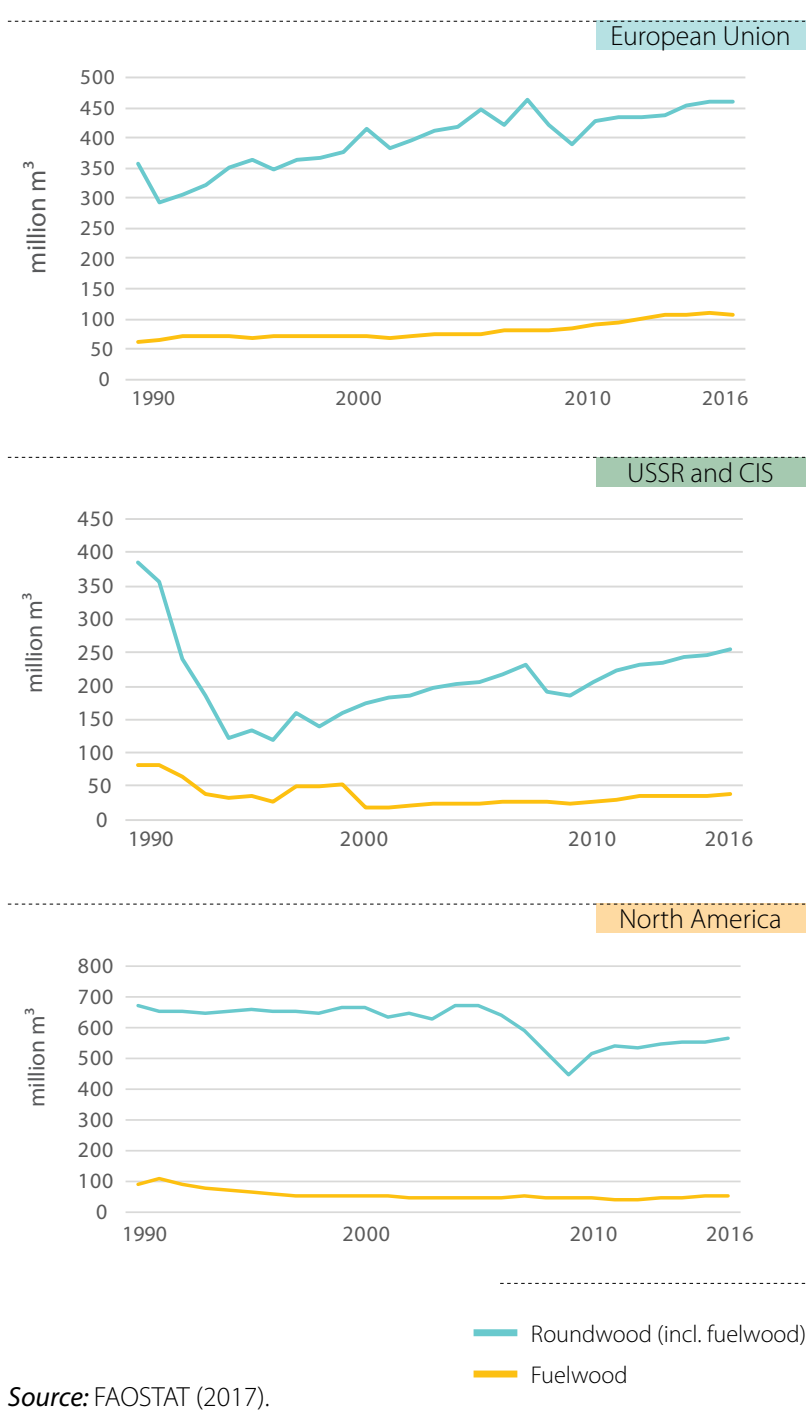

Data from 1990-2016 for total roundwood and fuelwood removals in the European Union, USSR and CIS and North America (Figure 3.2) depict several important trends. First, the proportion of fuelwood to total roundwood harvest has significantly declined in the USSR and CIS, and North 
America. Second, fuelwood and roundwood production in North America and the USSR and the CIS do not seem to be correlated. There has been some growth in fuelwood production in the European Union but not as marked as growth in roundwood removals.

\subsubsection{Densified wood fuel: Pellets}

Pelletization is a process whereby wood fuel is processed into pellets commonly having 6-8\% moisture content. Wood fibres are densified with or without additives through which fibres are heated by friction and extruded under pressure. Additives such as starch may be added as a binding agent to improve mechanical durability and reduce dust. The pelletization process has been shown to increase bulk densities up to five-fold over raw biomass Hard to believe, even for white fir or white cedar, which are very light (Chai and Saffron, 2016). A typical range in energy content for wood pellets is 16.921.2 gigajoules per tonne (GJ/t) (Gündüz et al. 2016). Wood briquettes are also made with or without additives after compressing pulverised woody biomass into cubiform or cylindrical units and a diameter of over $25 \mathrm{~mm}$ with common diameters in the 65-95 $\mathrm{mm}$ range (ISO, 16559:2014).

In 2015 global wood pellet production was estimated at just under 28 million tonnes. The primary uses of wood pellets in both the EU and North America are large-scale heat and electricity generation supplied through bulk pellet shipments, and residential heating commonly supplied through bagged pellets sold via retailers (Aguilar et al. 2016). The EU and North America dominate wood pellet production worldwide (Figure 3.3). Approximately 51\% of global wood pellet production occurred within the European Union in 2015; another 33\% took place in North America. The largest

\section{FIGURE 3.3}

\section{Wood pellet production by region in 2015}

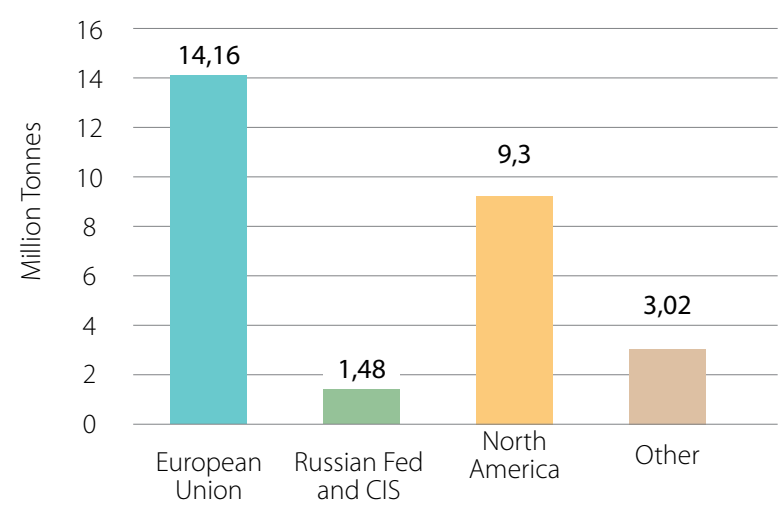

Source: FAOSTAT (2017) producers of wood pellets in 2015 were the US, Germany, Canada, Sweden and Latvia (FAOSTAT, 2017).

Pelletized wood is a common form in which wood fuel is currently traded in international markets. Wood pellets are successfully traded across longer transport distances as they can be shipped in standard dry bulk vessels and because of their low-moisture content, low ash content and consequent high energy density. Table 3.2 summarizes select characteristics of current industry standards issued by the European Pellet Council's ENplus Certification System for three pellet quality classes. International standards (e.g. through the International Standards Organization) have come into favour over national-level standards, as the former support a growing trade market for bioenergy products. ISO standards such as ISO 13065:2015 facilitate the comparability of supply chains and bioenergy products and can be used to ensure quality of wood fuels for energy generation in households, small commercial and public buildings (International Standards Organization, 2015). The current single largest user of industrial wood pellets is Drax Power in the United Kingdom (Wood Pellet Association of Canada, 2017). Italy is the leading consumer of wood pellets for heating estimated at 3.1 million tonnes in 2015 with residential consumption representing $92 \%$ of the total final use (AEBIOM, 2016).

\subsubsection{Thermally-treated wood fuel: Charcoal and torrefied biomass}

Charcoal production is one of the oldest and most commonly used thermal treatments used to improve wood energy content. It is commonly used to enhance the energy density of firewood and to improve its rot resistance and hydrophobic characteristics. Charcoal is produced via partial pyrolysis as form of combustion in the absence of significant amounts of oxygen (FAO, 1987). The temperature employed in charcoal production varies; charcoal production itself begins at about 2800C, but some species, such as oak, need higher temperatures ( 6000C) to achieve maximum energy content (FAO, 1987; Satonaka, 1982). Some of the best species of wood used in the production of charcoal are oak and beech. They are used separately or mixed with species of lower calorific value such as alder, aspen, birch, elder, hornbeam and fruit-trees.

Torrefaction involves the use of mild thermal treatment of biomass under low oxygen conditions (UNECE/FAO, 2013). The development of torrefied biomass as a commercial technology continues with some evidence of progress. For example, a successful co-firing experiment in which up to $25 \%$ of coal (about 2500 tonnes) was replaced with torrefied pellets at the Amer power plant in the Netherlands (Topell Energy, 2013). Some expect torrefied fuels to achieve commercial scale in the near future (IEA Bioenergy Task 40, 2014). 


\section{TABLE 3.2}

\section{Selected parameters for the European Pellet Council's ENplus Certification Scheme and respective ISO testing standards}

\begin{tabular}{|c|c|c|c|c|}
\hline & \multirow{2}{*}{\multicolumn{3}{|c|}{ ENplus certificates }} & \multirow{3}{*}{ ISO Testing standard } \\
\hline & & & & \\
\hline & A 1 & A2 & B & \\
\hline Diameter (mm) & $6 \pm 1$ or $8 \pm 1$ & $6 \pm 1$ or $8 \pm 1$ & $6 \pm 1$ or $8 \pm 1$ & 17829 \\
\hline Length $(\mathrm{mm})^{\text {a }}$ & $3.15<L \leq 40$ & $3.15<L \leq 40$ & $3.15<L \leq 40$ & 17829 \\
\hline Moisture (weight \%) b & $\leq 10.0$ & $\leq 10.0$ & $\leq 10.0$ & 18134 \\
\hline Ash content (weight \%) & $\leq 0.7$ & $\leq 1.2$ & $\leq 2.0$ & 18122 \\
\hline Fines, $<3.15 \mathrm{~mm}$ (weight \%) ${ }^{\mathrm{b}}$ & $\leq 1.0^{*}(\leq 0.5) \dagger$ & $\leq 1.0^{*}(\leq 0.5) \dagger$ & $\leq 1.0^{*}(\leq 0.5) \dagger$ & 18846 \\
\hline Net calorific value $(\mathrm{kWh} / \mathrm{kg})^{\mathrm{b}}$ & $\geq 4.6$ & $\geq 4.6$ & $\geq 4.6$ & 18125 \\
\hline Bulk density $(\mathrm{kg} / \mathrm{m} 3)^{\mathrm{b}}$ & $600-750$ & $600-750$ & $600-750$ & 17828 \\
\hline Chlorine (weight \%) ${ }^{c}$ & $\leq 0.02$ & $\leq 0.02$ & $\leq 0.02 \%$ & 16994 \\
\hline Nitrogen (weight \%) ${ }^{c}$ & $\leq 0.3$ & $\leq 0.5$ & $\leq 1.0$ & 16948 \\
\hline Sulfur (weight \%) ${ }^{c}$ & $\leq 0.04$ & $\leq 0.05$ & $\leq 0.05$ & 16948 \\
\hline Chlorine (weight \%) ${ }^{c}$ & $\leq 0.02$ & $\leq 0.02$ & $\leq 0.03$ & 16994 \\
\hline Arsenic $(\mathrm{mg} / \mathrm{kg})^{c}$ & $\leq 1$ & $\leq 1$ & $\leq 1$ & 16968 \\
\hline Copper $(\mathrm{mg} / \mathrm{kg})^{\mathrm{c}}$ & $\leq 10$ & $\leq 10$ & $\leq 10$ & 16968 \\
\hline Lead $(\mathrm{mg} / \mathrm{kg})^{c}$ & $\leq 10$ & $\leq 10$ & $\leq 10$ & 16968 \\
\hline Mercury (mg/kg) & $\leq 0.1$ & $\leq 0.1$ & $\leq 0.1$ & 16968 \\
\hline
\end{tabular}

a Maximum of $1 \%$ of the pellets may be longer than $40 \mathrm{~mm}$, no pellets longer than $45 \mathrm{~mm}$ allowed;

b As received;

c Dry basis. *At factory gate or when loading truck for deliveries to end-users; † At factory gate, when filling pellet bags or sealed bags.

Sources: European Pellet Council (2015)

Charcoal production in the UNECE region over the 2010-2016 period is presented in Figure 3.4. Data from FAOSTAT (2017) show that North America dominated charcoal production in the UNECE region. However, it is important to note that UNECE aggregated production only represents about 3\% of global annual production.

Earth-cover kiln is one of the oldest charcoal production methods (Figure 3.5). In South East Europe production is conducted in earth-covered kilns dug up to $50 \mathrm{~cm}$ into the ground. Commonly, a base of beech roundwood is placed at the bottom, split wood is stacked over (about 3-4 $\mathrm{m}^{3}$ ), and then the pile is covered with earth. Air holes for ventilation are placed on the front and back side of kiln. Common kiln volumes are in the 3-4 $\mathrm{m}^{3}$ range although larger sized kilns of 7-20 stacked $\mathrm{m}^{3}$ can be found. Efficiency of the production of charcoal in earth-covered kilns is the lowest with about $95 \mathrm{~kg}$ of charcoal obtained from 1 stacked $\mathrm{m}^{3}$. The common

\section{FIGURE 3.4}

\section{Annual charcoal production in North America, Europe and the Russian Federation (2010-2016)}

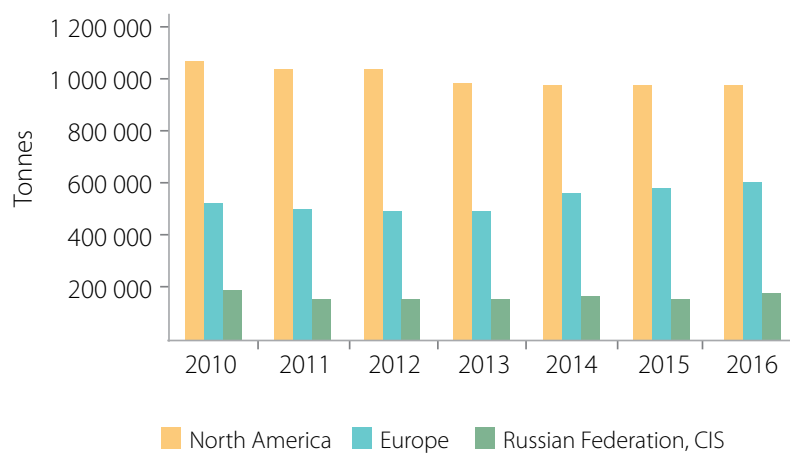

Source: FAOSTAT (2017). 


\section{FIGURE 3.5}

\section{Layout of earth-covered charcoal kiln}

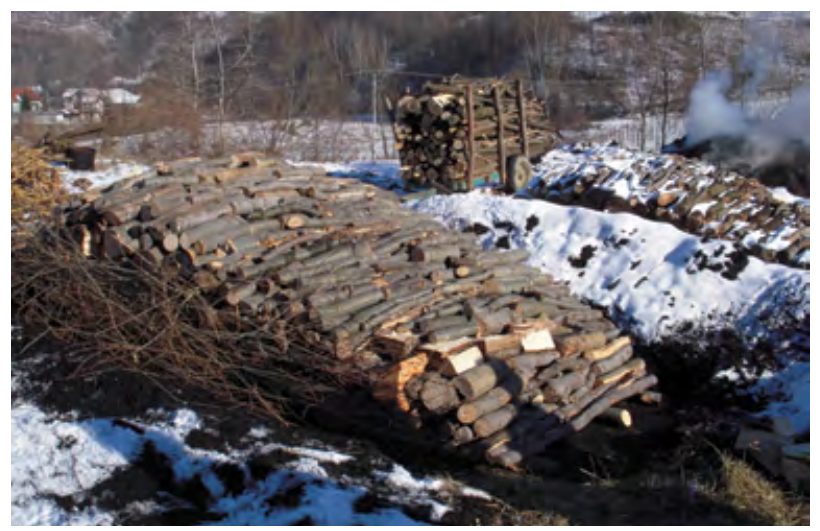

Source: B. Glavonjić

production cycle of carbonization for this system lasts 7 days and is limited from late autumn to winter (Glavonjić, 2017). A common production challenge of this process is uneven reaction times. Wood in the lower parts of the pit will burn longer, hence reducing the system's efficiency by taking up energy, and have virtually no volatile fraction, compared to wood at the top.

Much charcoal production takes place in brick or cement kilns that allow for better control and significantly faster production rates than earth-covered kilns. Production process consists of kiln filling, wood carbonization, extinguishing and cooling of kiln and then packing of charcoal (Figure 3.6). In South East

\section{FIGURE 3.6}

\section{Brick charcoal kiln}

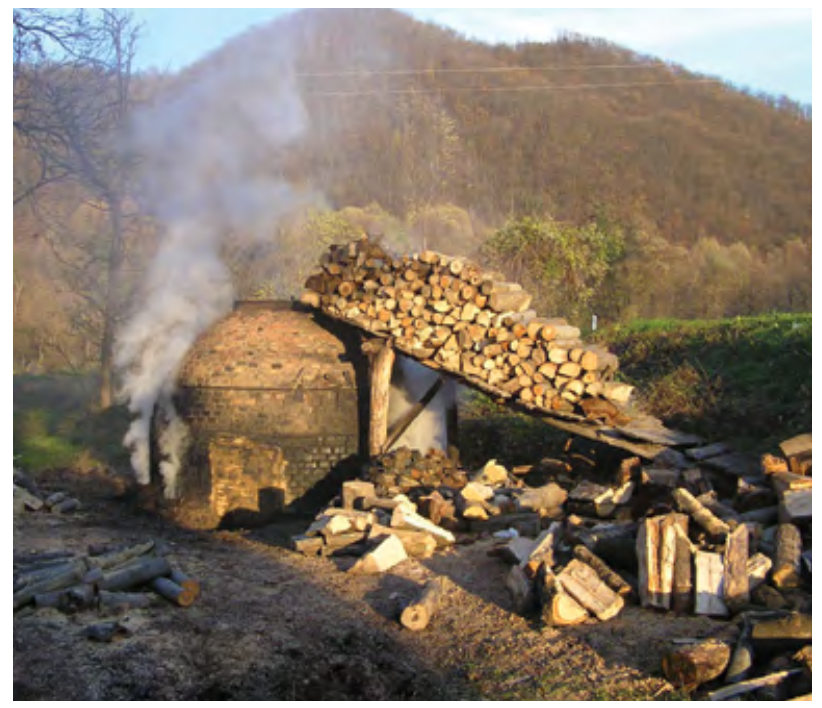

Source: B. Glavonjić.

\section{FIGURE 3.7}

\section{Layout of portable steel kilns with one ring}

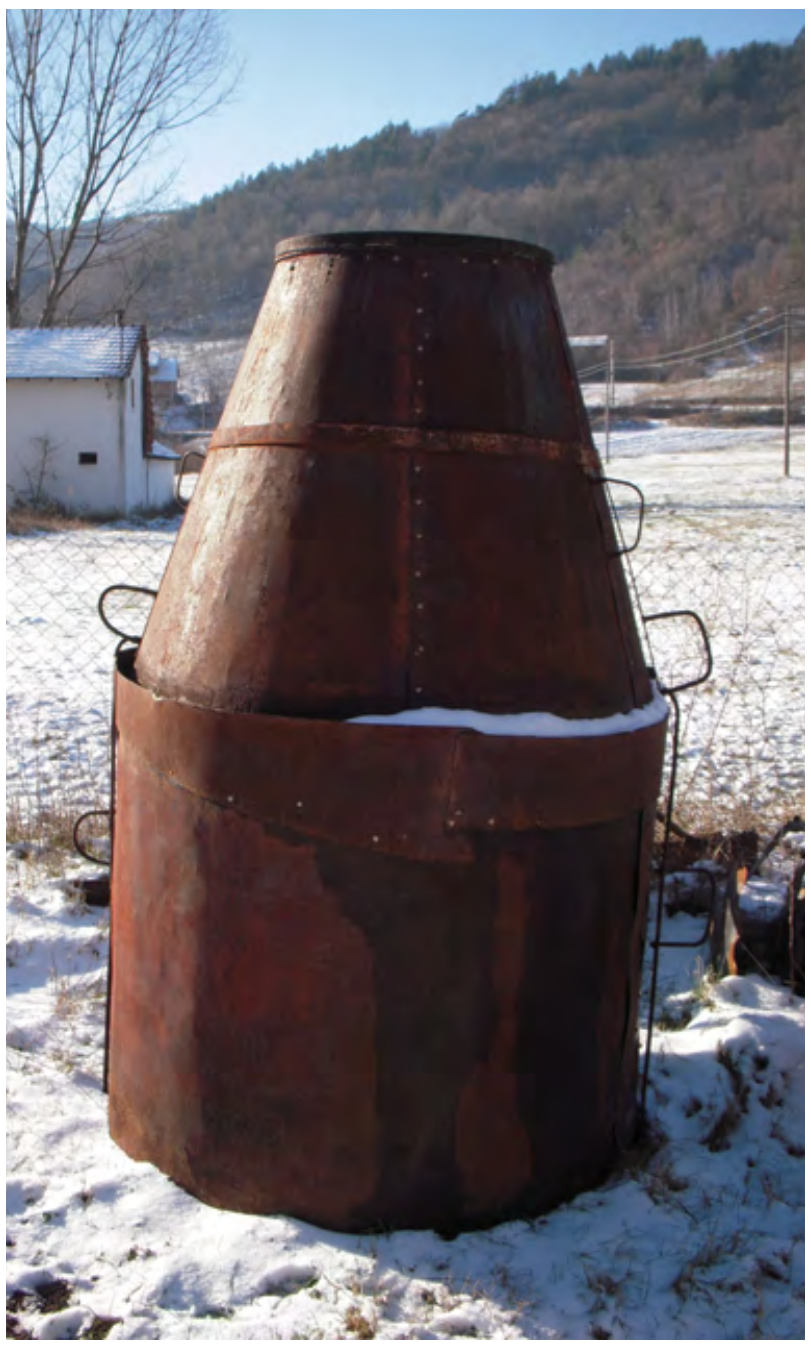

Source: B. Glavonjić.

Europe one typical production cycle in a brick charcoal kiln would have about $20 \mathrm{~m}^{3}$ of stacked wood. Commonly, $120 \mathrm{~kg}$ of charcoal are obtained from 1 stacked $\mathrm{m}^{3}$ of raw material. Over one year, 15 production cycles are common for charcoal producers with an usual duration cycle duration of 14 days ( 1 day filing, 10 days combustion and 3 days cooling and emptying) (Glavonjić, 2017).

Portable steel kilns are a more contemporary method for charcoal production (Figure 3.7). This method offers a significantly shorter processing duration per cycle. Most commonly used portable steel kilns in South Eastern Europe have a capacity of approximately $3 \mathrm{~m}^{3}$ of stacked wood. The processing efficiency of the system is that of $100 \mathrm{~kg}$ of charcoal obtained per $1 \mathrm{~m}^{3}$ of stacked wood. Cycle of production of charcoal in this model of kilns lasts from 48-

5

5




\section{FIGURE 3.8}

\section{Layout of industrial retorts for the production of charcoal}

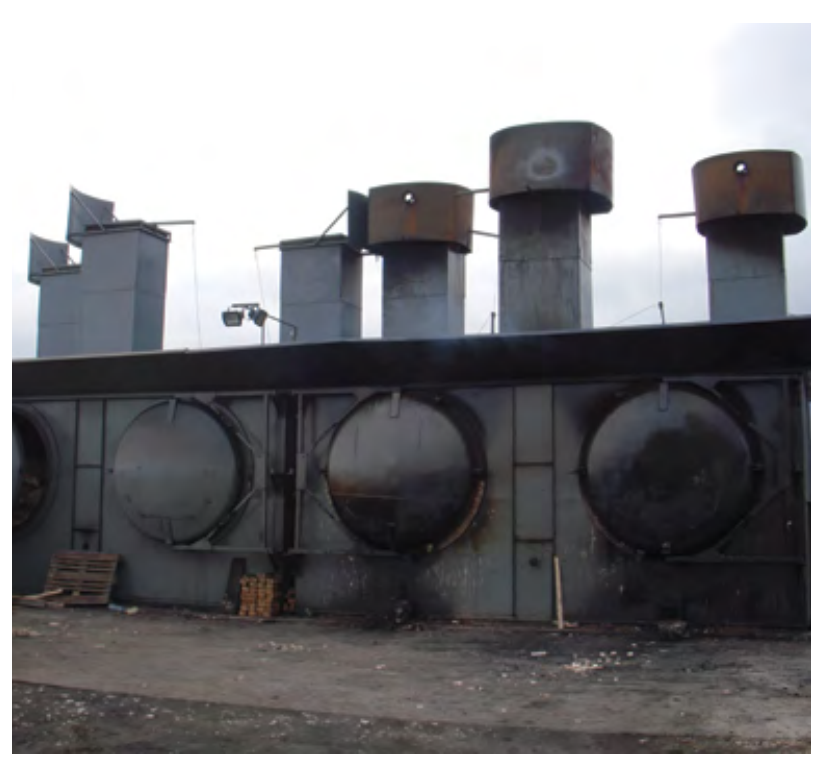

Source: B. Glavonjić.

\section{FIGURE 3.9}

\section{US wood energy consumed by the industrial sector (petajoules) and paper and paperboard production (tonnes)}

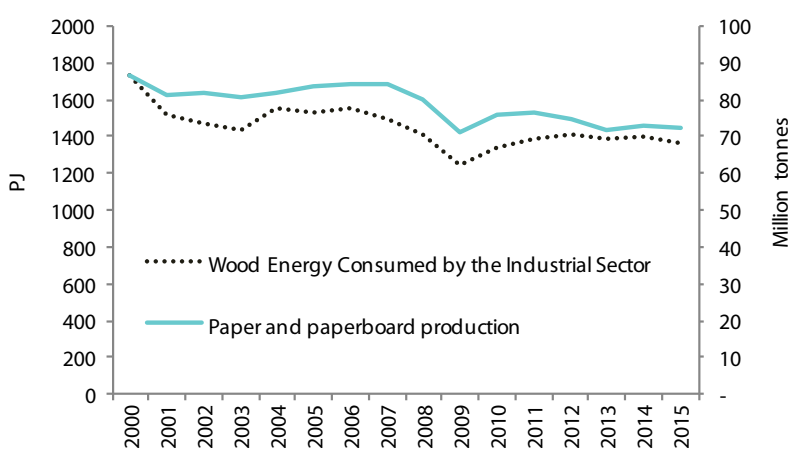

Source: US Energy Information Administration, FAOSTAT, 2017.

72 hours. Other portable steel kilns have a larger capacity of $6 \mathrm{~m}^{3}$ of stacked wood from which approximately $650 \mathrm{~kg}$ of charcoal are obtained. The cycle of production in these later kilns lasts up to 144 hours.

Industrial charcoal production in retorts relies on the combustion of gases for wood carbonization. Minimal quantities of harmful gases are emitted into atmosphere using this method. Industrial retorts commonly consist of four retorts connected in a wok regime (Figure 3.8). Wood to be carbonized is first stacked in one metal dish inserted into a retort. The carbonization process lasts for approximately 8 hours per retort. After extraction of the metal dishes from the retorts, they are covered and left to cool outside. The cooling process usually lasts for 24 hours. The processing efficiency of the system is that of approximately $130 \mathrm{~kg}$ of charcoal per $1 \mathrm{~m}^{3}$ of stacked wood. Compared to the other traditional production technologies that attain a $C_{f x}$ content of about $70 \%$, production of charcoal in retorts achieves a higher quality of $\mathrm{C}_{f x}$ over $85 \%$.

\subsubsection{Black liquor}

Black liquor is a co-product from Kraft high-quality paper process used to convert wood into pulp and paper made of remnants after cellulose fibres have been removed. It is comprised of water, lignin and hemicellulose and inorganic chemicals remaining from the Kraft process (Cassidy, 2007). The black liquor typically has $15-20 \%$ solids by weight which contain about half the energy of the original woodchips (National Energy Technology Laboratory n.d.). Black liquor is recovered and recycled via combustion or gasification in on-site boilers or gasifiers allowing paper manufacturers to recover and reuse the inorganic chemicals and extract energy from the pulping residues. The steam that is generated during the black liquor recovery process contributes significantly to the energy needs of pulp and paper mills. The method to recover energy involves concentrating the solution to about $75-80 \%$ solids by weight and then burning it in a recovery boiler to generate steam which can drive an electrical generator. A gasification system can feed the liquor into a high-pressure gasifier to produce steam, or potentially any other gasification product. Recovery boilers are the predominant system used commercially with some plants engaging in pilot gasification projects throughout the UNECE region. A pulp mill that produces bleached Kraft pulp generates 1.7-1.8 tonnes of black liquor (measured as dry content) per tonne of pulp (Maniatis, 2007). Black liquor represents a potential energy source of 250-500 MW per pulp mill. In regard to estimates of black liquors, one-third of all pulping mills in the US produce about 2.7 million $\mathrm{kg} /$ day of black liquor each (National Energy Technology Laboratory, n.d.). Pulp production and the energy derived from recovery systems are closely correlated. This is illustrated in Figure 3.9 showing wood energy consumed in the industrial sector and paper and paperboard production in the US between 20002015. 


\subsection{Conclusions}

Wood offers a source of renewable energy that is highly flexible for the generation of useful energy in the form of heat, electricity or even as fuels for transportation. Wood fuels are commonly processed through mechanical and thermal processes. Bio-chemical treatments are also possible as illustrated by the use of black liquors in the pulp and paper sector but remain at non-commercial scales in other uses (e.g. transportation). Wood fuel is commonly air-dried or its moisture content reduced through (partial) pyrolysis to enhance combustion efficiency as it is in the case of firewood and charcoal, respectively. Wood fibres can also be partly dried, homogenized and densified as it is the case of briquettes and pellets. Firewood is the most common type of fuel wood used in the UNECE region's residential sector, wood pellets have emerged as one of the preferred types of wood fuel used in industrial power and/or heat systems, and black liquor is the main type of wood fuel used by the pulp and paper sector. In other sectors of the wood products industry wood co-products are often used to generate on-site heat for kiln drying operations. Charcoal production in the UNECE region is reportedly a fraction of global estimates but is an important source of energy for cooking and space heating. Low levels of efficiency in energy densification make charcoal production appealing only as a process to enhance firewood durability. Increased use of wood fuels in modern household, industrial, power and combined heat-and-power systems has promoted standardization of once heterogeneous energy sources. 


\subsection{References}

AEBIOM (European Biomass Association). 2016. AEBIOM Statistical Report. European Bioenergy Outlook. Key Findings. $34 \mathrm{pp}$.

Aguilar, F., Abt, K., Glavonjic, B., Lopatin, E., and Mabee, W.E. 2016. Wood energy. In UNECE/FAO Forest Products Annual Market Review, 2015-16. UNECE/FAO, New York and Geneva, pp. 89-102

Cassidy, A. 2007. Wood Processing Residues. In: Hubbard, W., Biles, L., Mayfield, C. and S. Ashton (eds.). 2007. Sustainable Forestry for Bioenergy and Bio-based Products: trainers curriculum notebook. Athens, GA: Southern Forest Research Partnership, Inc. pp 165-168.

Chai, L. and C. Saffron. 2016. Comparing pelletization and torrefaction depots: Optimization of depot capacity and biomass moisture to determine the minimum production cost. Applied Energy. 163: 387-395.

European Pellet Council. 2015. ENplus Handbook. Part3: Pellet Quality. Version 3.0. Requirements. Online at http:// www.enplus-pellets.eu/wp-content/uploads/2016/03/ ENplusHandbook_part3_V3.0_PelletQuality_ EPCinternational.pdf

FAOSTAT. 2017. Forestry Production and Trade. Online at http://www.fao.org/faostat/en/

FAO [Food and Agriculture Organization of the United Nations]. 2017. Online at http://www.fao.org/forestry/ energy/en/

Glavonjić, B. 2017. Data from the University of Belgrade, Timber Trade Center database, Belgrade, May 2017.

Gündüz, G., Saraçoğlu, N. and D. Aydemir. 2016. Characterization and elemental analysis of wood pellets obtained from low-valued types of wood. Energy Sources, Part A. Online at http://dx.doi.org.proxy.queensu.ca/10.1080 $/ 15567036.2015 .1040900$

Hektor, B., Backeus, S. and K. Andersson. 2016. Carbon balance for wood production from sustainably managed forests. Biomass \& Bioenergy 93:1-5

IEA Bioenergy Task 40. 2014. Development of torrefaction technologies and impacts on global bioenergy use and international bioenergy trade. Online at http://www. bioenergytrade.org/downloads/iea-graz-workshoptorrefaction-2014.pdf.

Ince, P. 1979. How to estimate recoverable heat energy in wood or bark fuels. US Department of Agriculture Forest Service. General Technical Report 29. Online at https://www. fpl.fs.fed.us/documnts/fplgtr/fplgtr29.pdf

International Energy Agency. 2017. World Balances for 2013. Online at http://www.iea.org/statistics/statisticssearch/ report/?country=WORLD\&product=balances\&year=2013

International Standards Organization. 2015. Sustainability criteria for bioenergy. ISO 13065:2015.

International Standards Organization. 2014. Solid biofuels Terminology, definitions and descriptions. ISO 16559:2014.
Kim, Y.M., Han, T.U., Hwang, B.A., Lee, B., Lee, H.W., Park, Y.K. and S. Kim. 2016. Pyrolysis kinetics and product properties of softwoods, hardwoods, and the nut shell of softwood. Korean J. Chem. Eng. 33(8): 2350-2358

Magnone, E., Park, S.K. and J.H. Park. 2016. Effects of Moisture Contents in the Common Oak on Carbonaceous Aerosols Generated from Combustion Processes in an Indoor Wood Stove. Combustion Science and Technology. 188(6): 982-996.

Maniatis, K. 2007. Black Liquor Gasification. Summary and Conclusions from the IEA Bioenergy EXCo54 Workshop. : ExCo:2007:03. $11 \mathrm{p}$.

Miner, R. A., Abt, R. C., Bowyer, J. L., Buford, M. A., Malmsheimer, R. W., O'Laughlin, J., Oneil, E. E., Sedjo, R. A. and K.E. Skog. 2014. Forest carbon accounting considerations in US bioenergy policy. Journal of Forestry. 112: 591-606.

McKendry, P. 2002. Energy production from biomass (Part 1): Overview of biomass. Bioresource Technology 83(1): 37-46.

National Energy Technology Laboratory. N.d. Black Liquor Gasification. Online at https://www.netl.doe.gov/research/ coal/energy-systems/gasification/gasifipedia/blackliquor

Panshin, A.J. and C. de Zeeuw. 1980. Textbook of wood technology. 4th Ed. McGraw-Hill, Toronto, Canada.

Pesonen, J. M, Kuokkanen, T., Kaipiainen, E., Koskela, J., Jerkku, I., Pappinen, A. and A. Villa. 2014. Chemical and physical properties of short rotation tree species. Eur. J. Wood Prod. 72: 769

Qambrani, N.A., Rahman, M.M., Won, S., Shim, S. and C. Ra. 2017. Biochar properties and eco-friendly applications for climate change mitigation, waste management, and wastewater treatment: A review. Renewable \& Sustainable Energy Reviews 79: 255-273.

Satonaka, S. 1982. Carbonisation and gasification of wood. In: Energy from Forest Biomass Ed. W.R. Smith). Elsevier.147-154 pp.

Song, N. and F. X. Aguilar. 2016. Woody biomass energy efficiency pathways: public policy implications, Biofuels. Online at http://dx.doi.org/10.1080/17597269.2016.1259520

Topell Energy. 2014. Successful test with innovative renewable energy source at Amer power plant. Online at http://www. topellenergy.com/wp-content/uploads/2014/03/PressRelease_Topell-Energy_20140402_Successful-test-withinnovative-renewable-energy-source-at-Amer-powerplant1.pdf

Torres, C.M.M.E., Oliveira, A.C., Pereira, B.L.C., Jacovine, L.A.G., Neto, S.N.D. and A.D.O. Carneiro. 2016. Estimates of production and properties of eucalyptus wood in agroforestry systems. Scientia Forestalis 44(109): 137-148.

UNECE/FAO. 2013. Joint wood energy enquiry. Online at https://www.unece.org/forests/jwee.html

U.S. Energy Information Administration. 2017. Renewable and Alternative Fuels: Biofuels. Online at https://www.eia.gov/ renewable/data.php\#biomass

Wood Pellet Association of Canada. 2017. Online at https:// www.pellet.org/wpac-news/drax-fires-up-biomass-power 


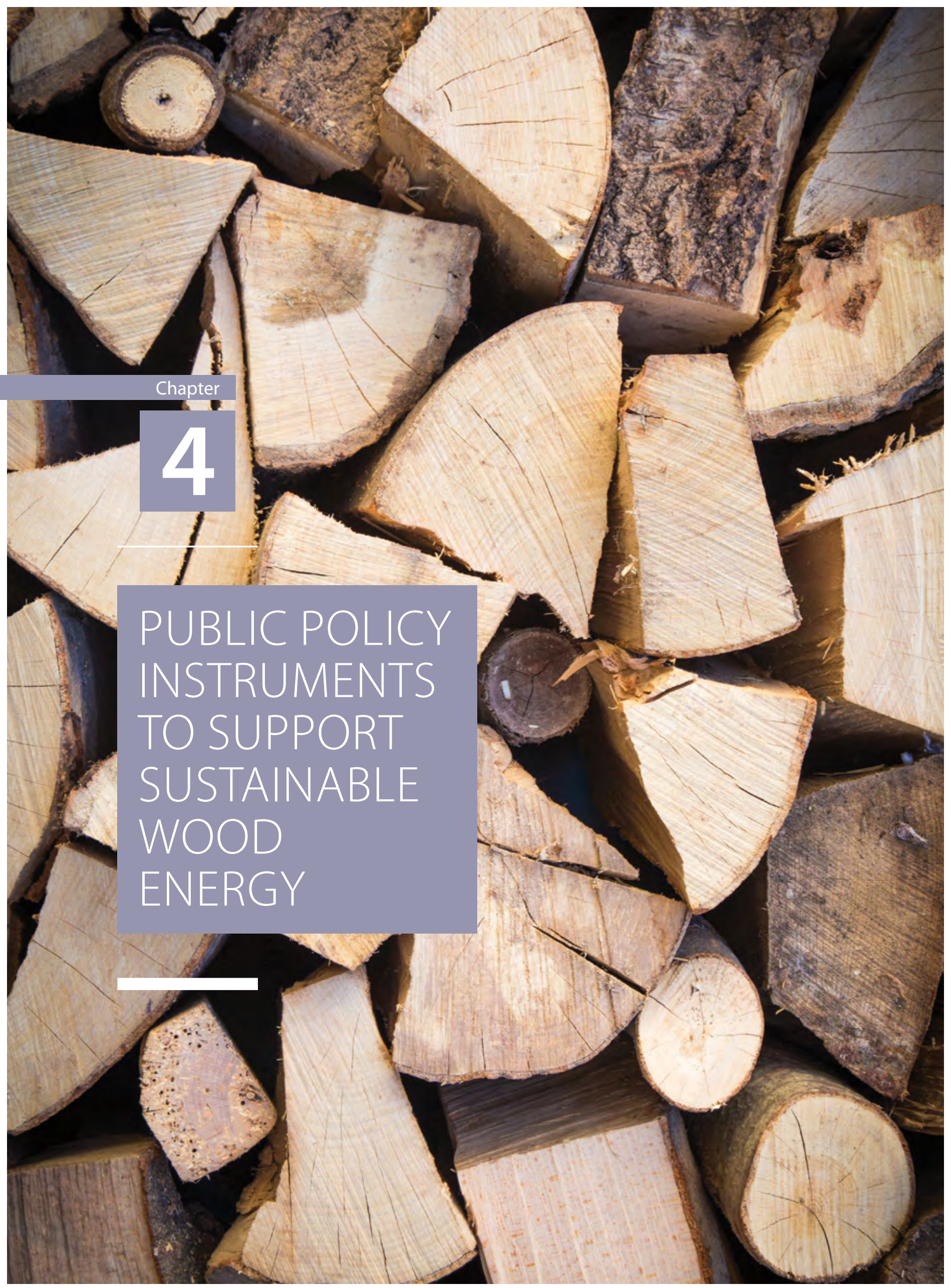




\section{Highlights*}

* Public policy affecting wood energy seeks integration of renewable energy generation with forest management activities to meet socio-economic and environmental objectives within larger and encompassing mandates.

* Policy instruments (rules and regulations, incentives, and research and education) designed to promote more sustainable wood energy generation are poised to be most influential where formal wood supply chains are already in place.

* Land tenure reform might offer opportunities to encourage investment and sound forest management in countries where wood energy supply chains are less developed and extractive and usufruct rights are severely constrained.

* Administration and implementation of policy programs are often led by separate institutions, challenging effectiveness and efficient cooperation.

* Public policy affecting wood energy markets should follow principles of stakeholder inclusiveness, incremental and permanence of targets, uniformity in incentives, flexibility in application, tailored to local conditions and awareness of cost-of-compliance considerations. 


\subsection{Introduction}

Public policy influencing wood energy markets in the UNECE region encompasses numerous objectives. Beyond the promotion of renewable energy generation, policy in the UNECE region has been commonly structured to: (i) support energy diversification and security, (ii) foster economic development, (iii) reduce anthropogenic greenhouse gas (GHG) emissions, (iv) enhance forest health, (v) increase efficiency along energy pathways, among others. UNECE member States have implemented diverse policy instruments reflecting these objectives, prevalent governance and administrative structures, and available resources.

Policy interventions have been promoted under different salient aims across the UNECE region. A review of policies in the European Union (Lantiainen et al. 2014) suggests that the main focus of regional renewable energy policies has been to address concerns over climate change - although many EU member countries justify implementation on the basis of fostering energy security. In the US, waves of new renewable energy policies followed spikes in oil prices in the late 1970s and early 2000 s with the goal of generating more renewable energy domestically to strengthen energy security (Aguilar et al. 2011; Ebers et al. 2016). In the Russian Federation, support for greater utilization of wood energy for heat and electricity generation aims to reduce dependence on fossil fuels, address energy security concerns and reduce energy intensity in the Russian Federation's economy (e.g. Russian Federation Decree 321 of 2014). In Kazakhstan, following the decisions of the 6th Ministerial Conference "Environment and Development" of the Asia-Pacific region and the UNECE Committee on Environmental Policy, the government developed an inter-regional partnership program (Green Bridge) designed to support green economy objectives.

Public policy tools have been instituted to influence wood energy supply-chains procuring direct, indirect and recovered sources (Figure 4.1). Energy pathways encompass the desirable utilization of wood fuel along wood energy supply-chains inclusive of growing, collecting and processing wood to its conversion to energy for final consumption. Hence, there are multiple institutions involved in the design and implementation of proposed energy pathways. Commonly, agencies with jurisdiction over forest resources oversee issuing and monitoring permissible, prescribed or recommended land management practices and coordinate incentives for greater supply of wood energy feedstocks. Agencies with jurisdiction over energy generation and final use commonly oversee implementation of renewable energy generation targets, environmental and efficiency standards. Moreover, public policy energy pathways often include many sources of renewable energy or identify eligible types - which might include wood fuel but also other types of biomass. Therefore, implementation requires coordination and participation among numerous agencies often making public policy administration a cumbersome endeavor (Abrams et al. 2017, Sundstrom et al. 2012). There are ongoing efforts within UNECE member States to ensure consistency in programs regarding the sustainability of bioenergy. For instance, in the US the 2017 Consolidated Appropriations Act (US Public Law 115-31, 2017) directs federal agencies dealing with land, energy and the environment to ensure that U.S. federal policy on wood energy is consistent across agencies and is set to ensure sustainability of wood energy, encourage private investment, and improve forest health. The Government of Kazakhstan's Green Bridge program outlines the consistent implementation of interrelated regional and national policy measures and the key sectors of the economy, as well as the preparation and implementation of a package of practical regional and national projects in support of a green economy.

Public policy instruments (e.g. rules and regulation, financial incentives) discussed in the next subsection will be poised to have more immediate and discernable effects where supply-chains already exist within legally operating markets to be readily influenced or regulated. In countries with less developed wood supply-chains and preponderance of lands where wood harvesting is prohibited or highly restricted the prospects for more sustainable wood energy generation may have to start with a reconsideration of land use rights. For instance, in several Central Asian countries firewood is often the most accessible and affordable source of cooking and heating. Most of it is harvested locally but illegally (Buttoud-Kouplevatskaya, 2010, World Bank 2015b, Akhmadov 2008, FAO 2007, Baumann 2006, Ulybina, 2015). It has been estimated that rural households in colder areas of Central Asia might spend between a third and one-half of their annual income procuring energy (Kargasov, 2008). Much of the wood energy supply comes from "Lezkhozes" forests under governmental management and supervision (Undeland, 2012). Private forest plantations, although sill uncommon, often are the only legal sites from which access to firewood can be provided. Ulybina (2015) estimated that forest plantations make up $7 \%$ of total forest area in the Kyrgyz Republic. In spite of insecure long-term access and usufruct rights to woodfuel sites the development of more reliable firewood supply-chains are emerging in Tajikistan (Baumann 2006). According to Swinkels (2014) there is a trend from individual subsistence logging towards buying from specialized wood cutters. The average price for a bundle of firewood is between 10-15 somoni (2-3 US\$), and a truckload of $2 \mathrm{~m}^{3}$ is worth 800 somoni, (170 US\$) (Swinkels, 2014) offering important price signals that might motivate even greater investments and increase wood fuel supply at a cost accessible to local households.

Inaccessibility to legally sourced wood, lack of access to alternative sources for heating and cooking, and lowincome levels can create conditions where energy poverty 
FIGURE 4.1

\section{Public policy instruments influencing wood energy pathways}

PUBLIC POLICY INSTRUMENTS:

Rules and regulations, Incentives,

Research and education

\section{Sources, growth, collection, processing \\ - Recommended/required management practices \\ - Eligible energy feedstocks \\ - Eligible lands}

\section{Energy conversion \& use}

- Contribution to energy portfolios

- Reduction in emissions

- Minimum conversion and consumption efficiency thresholds

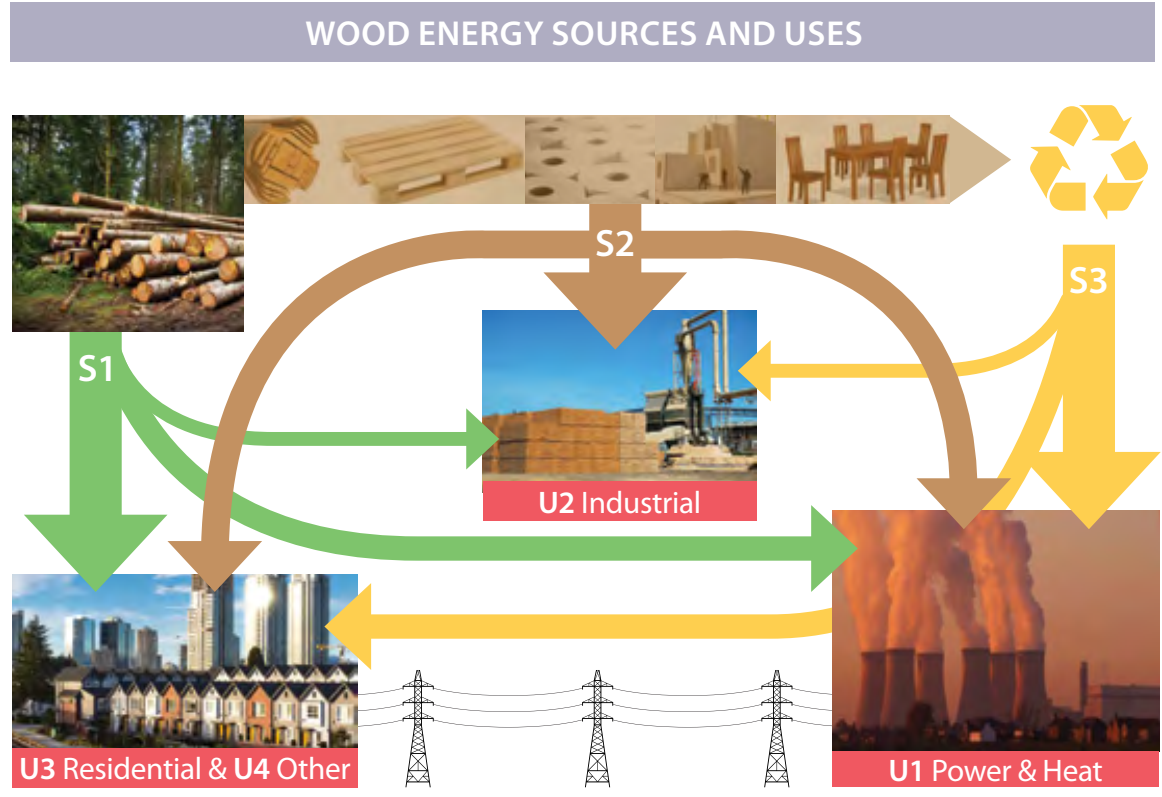

and insecurity are prevalent. Consideration might be given to opportunities for restructuring how forest resources are administered and managed to ameliorate such problems within extant natural resources (O'Hara, 2014). Wood supply is needed for its vital subsistence role, particularly among poor local populations, that might be juxtaposed with long-term conservation efforts (World Bank, 2015a). A review of landtenure regimes could revisit usufruct rights to encourage investment in multi-functional land management, use and access. Use and usufruct rights might be reframed from a state-owned approach to community-managed lands where permissible use is secured to foster longterm planning. Forested areas close to high demand areas might be adept for intensive management that increases wood energy supply while also preserving or enhancing ecosystem functions. Pressures on forest resources due to fuelwood demand from growing populations will continue and likely increase in Central Asian countries such as the Kyrgyz Republic, Uzbekistan and Tajikistan (FAO, 2006; FAO, 2007; World Bank, 2015a). Moreover, the effects of climate change, which will likely render hydraulic energy provision less reliable, heightens the importance of wood energy to help meet energydemand (GIZ, 2013; GIZ, 2016a).

Efficient use of potentially greater supplies of wood fuel could be part of a comprehensive strategy to reduce energy poverty and insecurity. For instance, the use of traditional fireplaces for heating results in as much as 20 and 57 times greater fine particle pollution than energy certified wood and pellet stoves, respectively. New wood-burning appliances are up to 50\% more energy efficient and can use about a-third less wood fuel to generate the same amount of heat and cut creosote build-up, reducing the risk of chimney fires (US EPA n.d.). It has been estimated that national annual woodfuel consumption in Tajikistan and the Kyrgyz Republic is 3 to $4 \mathrm{~m}^{3}$ per household (Swinkels, 2014). This level of consumption is linked to severe winters but magnified by poor insulation. Some estimates suggest that that $30 \%-60 \%$ of energy consumption could be cut through better insulation (Kargasov, 2008). Public programs encouraging energy efficiency, inclusive of improved insulation, entrepreneurial projects to supply legal and reliable wood fuel will need to be accompanied with adequate educational, natural and financial resources to meet their goals (O'Hara, 2014).

\subsection{Public policy instruments}

Development of public policy instruments is often initiated by a mandate to increase renewable energy generation in tandem with environmental and socio-economic aims. The EU offers an example of foundational policy mandates followed by specific actions (Lantiainen et al. 2014). In 1997 the European Commission (1997) published a white paper titled 'Energy for the Future: Renewable Sources of Energy', which set the first, albeit non-binding, target for renewable energy generation (12\% of gross EU energy production were to come from renewable energy sources by 2010). The Renewable Energy Directives 2001/77/EC and 2003/30/EC,

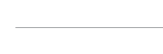

1

2

3


introduced in 2001 for renewable electricity and 2003 for biofuels, set targets for renewable energy consumption in the electricity and transport sectors to be attained throughout EU member countries by 2010 (European Commission 2001, 2003a). Directive 2009/28/EC later followed requiring national action plans to meet an overarching EU target of $20 \%$ efficiency gains, $20 \%$ reduction in greenhouse gas emissions compared to 1990 levels and $20 \%$ of renewable energies as total of energy consumption by 2020. EU member countries' renewable energy national targets ranged from 10\% (Malta) to 49\% (Sweden). The Revised Renewable Energy Directive of 2016 seeks to contribute towards the key EU goal of attaining a share of $27 \%$ of EU energy from renewable sources in final consumption by 2030. For instance, it aims to increase the use of renewable energies for heating and cooling in total supply by $1 \%$ point per year through 2030. However, the directive does not set mandatory national targets (European Commission, 2016).

Most recently, the UNFCCC's Paris Agreement (UNFCCC, 2016) to combat climate change and adapt to its effects aims to keep a global temperature rise in the 21 st century below 2 degrees Celsius above pre-industrial levels. The Paris Agreement attempts to strengthen the ability of signatory countries to meet the Agreement by developing nationally determined contributions (United Nations Treaty Collection, 2015). The potential role that wood energy could play in national portfolios is likely to vary from country to country since each signatory country is to develop a plan to meet the UNFCCC Paris Agreement's goal (Aguilar et al. 2016). The recognition of the capacity of wood energy to contribute to renewable energy portfolios and to reduce GHG emissions (Koponen et al. 2008, Lippke et al. 2012, Miner 2014, U.S. Public Law 115-31) is a critical step to be an integral part of national plans.

Following the adoption of foundational mandates, policymakers rely on an array of instruments for their attainment. There is a wide range of policy instrument categorizations relevant to wood energy markets (Aguilar and Saunders 2010, Aguilar et al. 2011, Becker et al. 2011, Ebers et al. 2016, Thornley and Cooper 2008). Here we distinguish between policy instruments inclusive of (i) rules and regulations, (ii) incentives, and (iii) research and education. These policy instruments are often implemented simultaneously to have a greater impact on wood energy markets. Germany's Energy Transition Program 'Energiewende' offers an example of the integration of programs to achieve comprehensive goals. The Energiewende program affects all aspects of the German economy in order to enhance sustainability performance including achieving a low-carbon economy (80-95\% reduction of GHGs below 1990 levels) by 2050 through a combination of energy savings, gains in efficiency, and $80 \%$ of its electricity demand supplied by renewable energy sources (Bundesregierung 2016). In the US, as of 2013 there were an estimated 115 regulatory, 279 incentive-based and 100 research and education policies at federal- and statelevels addressing bioenergy for which wood energy was an eligible feedstock (Ebers et al. 2016).

\subsubsection{Rules and regulations}

Rules and regulations commonly target different sections of the wood energy supply chain. These may regulate the sourcing of wood for energy generation, establish targets for renewable energy consumed or generated, or set thresholds for minimum efficiency levels along the entire energy lifecycle, among others.

Rules and regulations may define specific principles or practices that must be followed when managing forest lands as a source of bioenergy feedstocks. Alternatively they may classify and identify eligible lands from which bioenergy feedstocks are sourced. For instance, rules and regulations may set requirements to complete environmental impact analyses prior to forest management activities in publiclyowned lands (e.g. compliance with the US National Environmental Policy Act of 1969 when managing federal lands) or to conduct seeding of forest lands following a harvest (e.g. Finland's Forest Act on Wood Harvesting and Forest Regeneration of 1996). Others oblige supply-chain operators to ensure the legality of wood and undertake risk management to examine the potential of illegal wood entering trading markets, inclusive of energy feedstocks (e.g. European Commission's EU Timber Regulation No. 995/2010). Regulations may also ban the commercial harvest of any wood within designated protected areas, areas of high-biodiversity and high-carbon stocks, or make it illegal to conduct commercial or personal harvests within public forests as it is the case of many Central Asian nations (Undeland 2012,Vildanova, 2006, Akhmadov, 2006). One example of an outright ban to any type of management is the ten-year moratorium on logging for all industrial purposes and export by the Albanian parliament due to the deteriorating conditions of Albanian forests (IHB, 2016). However, an outright ban could severely affect rural communities by limiting access to wood for heating and these communities may not have alternative energy sources. In addition to a coercive approach, rules can also take on a voluntary or principled nature as illustrated through recommended compliance with sustainable forest management principles or adopting best management practices within privately-owned lands as has become common throughout the EU and many US states (European Commission, 2017b, US Department of Agriculture, 2012).

Rules and regulations may also set targets for minimum levels of renewable energy consumed or generated and efficiency in energy conversion, or define practices such as net-metering that can encourage the adoption of renewable 
energy systems. These rules tend to be encompassing of all renewable energies and seldom target wood energy only with the intention of allowing market flexibility and cost efficiencies. Examples include Germany's Renewable Energies Heat Act (EEWärmeG) of 2009, which aims to increase heat generated from renewable energy sources to $14 \%$ by 2020 . EEWärmeG requires owners of new residential and non-residential buildings to provide certain share of the energy used for heating/cooling from renewable energies (Federal Ministry for the Environment, Nature Conservation and Nuclear Safety of Germany, 2012). In the US, rules setting renewable energy consumption/generation targets include the Federal Green Power Purchasing Goal, state-level renewable portfolio standards, and local and city renewable energy standards mandates for governments and utility companies (Ebers et al. 2016). Regarding gains in efficiencies, the Russian Federation's Decree No. 889 of 4 June 2008 "On Some Measures to Improve Energy Efficiency and Ecological Efficiency" set a goal to reduce the energy intensity of the gross domestic product of the Russian Federation by at least 40\% by 2020 compared to 2007.

Rules and regulations may also define the conditions necessary to meet sustainability criteria based on indicators from lifecycle assessments. For example, the European Commission (2016) in its Revised Renewable Energy Directive has proposed sustainability criteria for all biomass used to generate energy. Specifically for wood energy, a new criterion applicable to wood fuel aims to ensure that the production of wood fuel is sustainable and that any land use, land-use change and forestry (LULUCF) related emissions are accounted for in the country of biomass production. Nonetheless, lifecycle assessments and evaluation of indirect effects can be complex and expensive to complete. Hence, conditions for compliance are often related to the size of operations. For example, the European Commission's Revised Directive set minimum GHG reduction thresholds for large (>20MW capacity) heating/cooling and electricity facilities - in comparison with fossil fuel use - at $80 \%$ (for plants in operation after 1 January 2021) and 85\% for those starting operation after 1 January 2026.

Implementation of sustainability indicators applied to renewable energy rules is illustrated by the UK's criteria to determine eligibility for Renewables Obligation Certificates. These apply to operators of generating stations with a total installed capacity $\geq 1 \mathrm{MW}$ using solid biomass or biogas (Ofgem, 2016). Sustainability criteria cover two areas: land criteria focusing on land from which the biomass is sourced and GHG emissions over the lifecycle of biomass. Sustainability considerations distinguish between the type of woody biomass depending on whether it is classified as processing or forest management residues but all require compliance with sustainability land criteria (e.g. at least 70\% of all the woody biomass used in a month must be obtained from a sustainable source). Life cycle GHG thresholds require reporting emission values in grams of $\mathrm{CO}_{2}$ per $\mathrm{MJ}$ of electricity - for most operators, the relevant GHG emission threshold is $79.2 \mathrm{gCO} e q / \mathrm{MJ}$ electricity. An operator of a generating station which meets the definition of a post-2013 dedicated biomass station will be required to report against the GHG emission threshold of $66.7 \mathrm{gCO} e q / \mathrm{MJ}$ electricity (Ofgem, 2016).

Standards for efficiency in energy conversion and emissions are other commonly-used regulations. For instance, the European Commission regulation Directive (EC 2009/125/ EC) established a framework for eco-design directives. Under the European Commission eco-design regulation 2015/1189 seasonal space heating energy efficiency for solid fuel boilers with a rated heat output of $20 \mathrm{~kW}$ or less shall not be less than $75 \%$ and for those with a rated heat output over $20 \mathrm{~kW}$ it shall not be less than $77 \%$. These requirements apply to boilers of up to 500MW of rated heat output. Austria has shown that new efficiency standards can lower emissions from residential heaters through technological improvement (Egger et al. 2014). Over the last three-decades, the average efficiency of biomass boilers in that country has increased from roughly 55\% to more than $90 \%$ (based on net calorific value), and average carbon monoxide emissions have decreased from 15,000 mg/m $\mathrm{m}^{3}$ to less than $50 \mathrm{mg} / \mathrm{m}^{3}$ (at 13\% $\mathrm{O}_{2}$ ). A recent analysis of wood energy pathways suggest that the use of firewood in a highly-efficient system can generate about seven times more net useful energy than a traditional fireplace (Song and Aguilar, 2016). Efficiency and emissions regulations are commonly phased-in to allow for adoption and compliance with set targets. For instance, the US Environmental Protection Agency (2015) updated its clean air standards for new residential woodstoves and pellet stoves and started to phase in emission limits in 2015 over a fiveyear period. Manufacturers have to comply with maximum particulate matter emissions of $4.5 \mathrm{~g} /$ hour of operation for catalytic and non-catalytic stoves. There is a compliance deadline set at five years after the effective date of the final rule for woodstoves and pellet stoves to limit particulate matter emissions to 2.0 grams per hour for catalytic and noncatalytic stoves (US Environmental Protection Agency n.d.).

\subsubsection{Financial incentives}

Financial incentives can be offered along the wood energy supply-chain to increase the supply of wood energy feedstocks, reduce start-up investment costs, lower capital costs, and provide fixed tariffs based on energy output, among others. Financial incentives are often conditional on meeting eligibility criteria whether on feedstock types, amounts of renewable energy generated, and efficiency thresholds, among others. They are designed to increase the cost competitiveness of renewable energy sources with 
fossil fuels, spur innovation and the long-term achievement of renewable energy and lower emission goals. Financial incentives are among the most frequently used tools to promote renewable energies and wood energy (Ebers et al. 2016), particularly in nations where wood and energy supplychains are more advanced.

Among incentives, feed-in-tariffs and feed-in premiums are two of the most commonly used programs. This is illustrated in Austria's green electricity feed-in tariff regulation of 2012 that set tariffs for bioenergy to range from approx. 8.22 cent/kWh to 22.22 cent/kWh, depending on the plant type, biomass used and overall efficiency (Egger et al. 2014). For plants using residue material, tariffs are reduced by 20\% (e.g. sawdust) to $40 \%$ (e.g. wood waste from particle board). In Finland, a tier-premium feed-in tariff system offers subsidies for a maximum of twelve years to promote investments in power plants fueled with forest chips and other eligible sources (wind and biogas). The program is structured so total subsidies paid to the power plant for the period the tariff was offered should compensate for investment costs. Similar incentives may be offered for the generation of heat as illustrated by the UK's Domestic Renewable Heat Incentive. Under this incentive, households receive payments for seven years based on the amount of renewable heat generated by the heating system. Biomass boilers and biomass stoves designed to burn wood pellets only are eligible types of wood energy heating systems (Ofgem, 2017).

Table 4.1 offers a list of different incentive-based programs across selected UNECE member States. The project S2BIOM has assembled a comprehensive and searchable catalogue of policy instruments and measures that foster the development of regional bioeconomies in European and non-European countries. This catalogue is available online at https://s2biom. vito.be/policies-s2biom.

\subsubsection{Education and research}

Education and research can play a central role in encouraging sustainable wood energy use. For instance, in Sweden the government invests heavily in information and advice for households on how to save energy (Sverige, 2017). Each of Sweden's 290 municipalities has an energy adviser to offer advice ranging from home energy efficiency to switching to heating systems. Bioenergy represents $22 \%$ of Sweden's total supply of energy, most of which is used in industrial processes and district heating. About $90 \%$ of bioenergy in Sweden comes from the forest sector (Sverige, 2017).

Public education programs should also be accompanied by technical and professional training opportunities (Egger et al. 2014). Larger wood energy markets require a skilled workforce across the entire supply chain - from fuel production, to equipment manufacturers to contractors that design, install, service and operate heating systems. For instance, the government of Upper Austria supports an Energy Academy with more than 30 technical training seminars on biomass heating every year. The target groups include companies that manufacture renewable energy and energy efficiency technologies, public agencies, architects, designers and installers, energy managers in companies and institutions, energy service company staff, energy auditors, and others interested in the sustainable energy field. One of the main challenges encountered in emerging biomass heating markets is that heating contractors often lack confidence in, and knowledge of, biomass systems. As a result, many contractors may not offer biomass heating systems, or may actively discourage potential clients from investing in them (Egger et al. 2014). To overcome this market barrier, a vocational training for "eco-installers" was developed for heating system installers that allows young professionals to specialize in renewable energy systems at the beginning of their training. Moreover, state agricultural schools include biomass fuel production in their curricula and three of them have recently started a bioenergy training program for farmers.

Investments in research are instrumental to promote sustainable use of wood energy. New knowledge can help reduce potential risks associated with expanded use of wood energy and enhance opportunities for greater wood energy generation while meeting other complementary objectives, ranging from economic development to energy security. Public funding is instrumental to the generation of new knowledge and programs specific to support wood energy research are often placed within agricultural, energy, and natural resource budgets depending on each nation's administrative structure. For instance, the US Forest Service has conducted research focused on producing products from forest biomass since its inception in 1905. Wood energy applications remains a high priority research area that aims to provide energy applications with sufficient value to mitigate costs for forest management activities, generally thinning of overgrown forests to reduce fire risks or provide defensible space around structures (Rudie et al. 2016). Wood energy use is complex and applied research that examines issues ranging from the willingness to supply and use wood as an energy source, opportunities to reduce environmental impacts, risks to forest ecosystems and health, and the role that public policy can have in encouraging sustainable wood energy uses is of great importance.

Research may also include investments in issues regarding data accuracy and consistency which has been a major challenge to the wood energy sector tracking of consumption, production and trade statistics. Wood is often traded in highly informal markets directly between forest owners and final consumers. Consequently, wood energy statistics generally underestimate the supply and consumption of 
Table 4.1

Examples of selected wood energy-eligible financial incentives

\begin{tabular}{|c|c|}
\hline INCENTIVE TYPE & DESCRIPTION \\
\hline \multirow[b]{2}{*}{ Feed-in-tariffs } & $\begin{array}{l}\text { Austria's green electricity feed-in tariff regulation: Tariffs for bioenergy range from approx. } 8.22 \text { cent/ } \\
\text { kWh to } 22.22 \text { cent/kWh, depending on the plant type, biomass used and overall efficiency. For plants using } \\
\text { waste material (e.g. wood residues, biogenic waste), tariffs are reduced by } 20 \% \text { (e.g. sawdust) to } 40 \% \text { (e.g. } \\
\text { wood waste from particle board). }\end{array}$ \\
\hline & $\begin{array}{l}\text { Netherland's SDE+ scheme. The SDE+ is an operating (feed-in-tariff) subsidy where producers receive a } \\
\text { guaranteed payment for the energy generated from renewable sources. The maximum base amount for } \\
\text { the subsidy is } € 0.130 / \mathrm{kWh} \text { as of } 2017 \text {. In the case of thermal conversion for heat the minimum capacity } \\
\text { for boilers for the production of industrial steam from wood pellets is } \geq 5 \mathrm{MW} \text { th (Netherlands Enterprise } \\
\text { Agency, 2017). }\end{array}$ \\
\hline \multirow[b]{2}{*}{ Tax incentives } & $\begin{array}{l}\text { Serbia's value-added tax on wood fuels: A common value-added tax (VAT) rate of } 10 \% \text { is levied on } \\
\text { all wood fuels as of } 1 \text { January } 2017 \text {. This measure levelled VAT rates for firewood and other wood fuels. } \\
\text { Previously, the VAT for firewood was } 10 \% \text { and for all other wood fuels was } 20 \% \text {. }\end{array}$ \\
\hline & $\begin{array}{l}\text { UK's Climate Change Levy. The levy, introduced in } 2000 \text {, is an environmental tax on industrial and } \\
\text { commercial users of electricity. Generating stations are subject to the levy for every MWh they produce but } \\
\text { exemption applies for renewable energy. Renewables Levy Exemption Certificates (Renewables LECs) are } \\
\text { issued for generating stations for every MWh of renewable source electricity generated. }\end{array}$ \\
\hline \multirow[b]{2}{*}{$\begin{array}{l}\text { Renewable heat } \\
\text { and electricity } \\
\text { incentives }\end{array}$} & $\begin{array}{l}\text { Finland's Renewable Heat Incentive for Households. The incentive is for private households which } \\
\text { wish to change their heating system from oil or electricity to pellet. The maximum incentive is } 20 \% \text { of the } \\
\text { material costs when installing a pellet boiler and building a storage facility for pellets. }\end{array}$ \\
\hline & $\begin{array}{l}\text { UK's Non-Domestic Renewable Heat Incentive (RHI). The incentive, introduced in } 2011 \text {, supports } \\
\text { renewable heat installations in business, industry and public sector over a } 20 \text { year period. Depending } \\
\text { on the size of the plant, biomass power plants are eligible for funding between } 1-8.3 \text { pence/kWh. } \\
\text { Renewables generators are issued with Renewables Obligation Certificates (ROCs) for every megawatt } \\
\text { hour (MWh) of eligible renewable electricity they produce. ROCs can be then sold to suppliers to receive a } \\
\text { premium on top of the market price. The scheme will run until } 2037 \text {. }\end{array}$ \\
\hline \multirow[b]{2}{*}{$\begin{array}{l}\text { Investment } \\
\text { schemes }\end{array}$} & $\begin{array}{l}\text { Finland's Energy Investment Subsidy Scheme offers grants for heat plants using biomass, typically up to } \\
10-15 \% \text { of the investment. }\end{array}$ \\
\hline & $\begin{array}{l}\text { Germany's Market Incentive Programme (MAP). MAP awards investment subsidies for renewable energy } \\
\text { technologies for heating (both residential and non-residential). It funds the construction and extension of } \\
\text { heating networks with at least } 50 \% \text { supply of heat from renewable energy sources. Installations for burning } \\
\text { solid biomass up to } 100 \mathrm{~kW} \text { nominal thermal output are qualified. }\end{array}$ \\
\hline \multirow{2}{*}{$\begin{array}{l}\text { Establishment } \\
\text { and } \\
\text { management } \\
\text { incentives }\end{array}$} & $\begin{array}{l}\text { UK's Rural Development Programme. The Rural Development Programme offers grants for establishing } \\
\text { Miscanthus or short rotation coppice, including woody crops, in England (Energy Crops Scheme, 2012). } \\
\text { Crops should be used in combined heat and power plants or other power generation utilities. The scheme } \\
\text { covers 50\% of the energy crop establishment costs. }\end{array}$ \\
\hline & $\begin{array}{l}\text { US Biomass Crop Assistance Program (BCAP). BCAP offers establishment payments for } 50 \text { percent of the } \\
\text { cost of establishing a new, perennial energy crop, maintenance payments (annual payments) for the crop } \\
\text { as it matures until harvest (up to five years for herbaceous crops or up to } 15 \text { years for woody crops), and } \\
\text { retrieval payments (matching payments) for mitigating the cost of harvesting and transporting agriculture } \\
\text { or forest residues (that are not otherwise economically retrievable) to the end-use facility. }\end{array}$ \\
\hline \multirow[t]{2}{*}{$\begin{array}{l}\text { Low-interest } \\
\text { loans and } \\
\text { financing }\end{array}$} & $\begin{array}{l}\text { Germany's low-interest loans. These are available for electricity generation by farmers, self-employed } \\
\text { professionals and companies in which municipalities, churches or charitable organizations are involved. } \\
\text { Low-interest loans can be used for investment in installations for electricity production, cogeneration } \\
\text { plants and for small heat production installations with up to } 5 \mathrm{MW} \text { solid thermal inputs. Through the } \\
\text { Environmental Innovation Programme, the Federal government subsidizes the interest on loans for } \\
\text { industrial scale innovative projects, including renewable energy projects. }\end{array}$ \\
\hline & $\begin{array}{l}\text { US bond programs: the Federal Clean Renewable Energy Bonds and Qualified Energy Conservation bonds } \\
\text { are issued by public sector entities to finance renewable energy projects. They usually require repayment of } \\
\text { bond principals and the bondholder is eligible for a federal tax credit instead of bond interest. }\end{array}$ \\
\hline
\end{tabular}

Source: Ebers et al. (2016), Lantiainen et al. (2014), S2BIOM (2017), US Department of Agriculture (2017). 
wood fuel (Steierer, 2014). To address issues of data accuracy, completeness and comparability across countries, the UNECE/FAO Forestry and Timber Section worked together with wood energy sector stakeholders including the International Energy Agency, Eurostat, as well as UNECE member States' experts to develop a data collection tool that would be fully compatible with the existing 'Joint Forest Sector' and 'Renewables' questionnaires. In order to highlight that the data collection tool did not have an official mandate it was named an enquiry and the Joint Wood Energy Enquiry (JWEE) was launched. Chapter 2 in this report offers full details about the JWEE.

\subsection{Public policy principles}

The development and implementation of public policy is complex as there are many potential direct and unintended ecological, economic and social consequences. The following list of principles for the development of public policy to address wood energy was drawn up after a debate organized by the UNECE/FAO Forestry and Timber Section (Aguilar, 2012). The list is based on a compilation of opportunities regarding public policy and wood energy's role in climate change mitigation by Berndes et al. (2016), and other recommendations available from stakeholder studies (e.g. Ebers et al. 2016, Markowski-Lindsay et al. 2012, Thornley and Cooper 2008).

Public policy targeting wood energy should be:

- Inclusive, encompassing forest and energy sector stakeholders as well as consumers in its development to generate realistic targets, feasible compliance and assure effectiveness in displacing fossil fuels.

- Tailored to local socio-economic and biophysical conditions in their implementation. In some particular circumstances, public policy may need to start with a review of land tenure, allowable uses, and administration of forest lands that could hamper the sustainable use of wood energy.

- Clear and have long-term objectives that foster technological advances, new investments and improvements in economic, environmental and social conditions. Long-term targets also allow those impacted adequate time for adaptation and compliance.

- Phased-in incrementally to allow compliance with renewable energy or efficiency targets. Nevertheless, targets should also be periodically evaluated and even adjusted to meet technological and cost feasibility conditions as it has been the case for motor fuel mandates.
- Examined for distribution of impacts and potential unintended distortions to other market segments that could result in less optimal outcomes. For instance, taxation based on carbon intensity of energy options has been deemed by some as an equitable and efficient approach to encourage renewable energy generation.

- Flexible to adapt to technological progress and shifts in market dynamics. Periodic assessments should be conducted to evaluate the impacts of exogenous factors on existing and new policy instruments (e.g. changes in competing energy prices, better assessment of net $\mathrm{GHG}$ emission reduction).

- Positive in its role promoting renewable energy but avoid granular prescriptions such as the banning of specific types of eligible forest biomass for wood energy as it may prevent effective management.

- Inclusive of opportunities for education and knowledge sharing. Improvements in energy output and efficiency can be achieved through better informed stakeholders, not limited to final users, but all those involved along the wood energy supply chain. Education and experience sharing offer substantial opportunities to promote better forest management, while meeting energy and socio-economic development goals.

- Observant of costs associated with implementation and compliance. Attainment of policy goals and compliance with rules and regulations adds cost to wood energy supply chains. Hence, policy-makers should be cognizant that costs created by public policy could discourage stakeholder participation along the wood energy supply-chain. Excessive costs could have the perverse effect of discouraging wood energy use over other sources that might not be renewable or not as well positioned to meet multiple ecological, economic and social objectives.

- Designed to foster generation of data and other information that can be subsequently used to evaluate outcomes and whether the policy has been effective and efficient in achieving its original aim. 


\subsection{Conclusions}

Public policy has been implemented to offer a foundational framework to promote the role that renewable energies have in supporting energy diversification, efficiency and security, promoting economic development, reducing greenhouse gas emissions, and enhancing forest health. Public policy instruments implemented most frequently include rules and regulations, incentives, and research and education. Specific public programs influencing wood energy supply-chains vary greatly among UNECE member States due to differences in governance and administrative structures as well as forest resources, among others. In many cases policies affecting wood energy systems are embedded within a portfolio of renewable energy sources. Public policy instruments are poised to have greater impacts in areas where supply-chains for wood products and energy are already in place. If no legal or recognized supply-chains exist, and particularly where households depend heavily on wood with no alternative energy sources, a review of tenure rights might be necessary. The dominance of public lands in Central Asia may offer opportunities for the reconsideration of land use and usufruct rights to address issues of energy poverty, insecurity and sound forest management. Public policy affecting wood energy markets should follow principles of stakeholder inclusiveness, incremental and permanence of targets, uniformity in incentives, flexibility in their application, tailored to local conditions and awareness of cost-of-compliance considerations. 


\subsection{References}

Abrams, J., Becker, D., Kudrna, J. and C. Moseley. 2017. Does Policy matter? The role of policy systems in forest bioenergy development in the United States. Forest Policy and Economics. 75: 41-48.

Akhmadov, K. 2008. Forest and forest products country profile: Tajikistan. UNECE/FAO. Geneva Timber And Forest Discussion Paper 46. Online at http://www.unece.org/fileadmin/DAM/ timber/docs/dp/DP-46.pdf

Aguilar, F.X. and Saunders, A. 2010. Policy instruments promoting wood-to-energy uses in the continental United States', Journal of Forestry. 108: 132-140

Aguilar, F.X., Song N., and Shifley S.R. 2011. Review of consumption trends and public policies promoting woody biomass as an energy feedstock in the US', Biomass and Bioenergy 35:3708-3718.

Aguilar, F.X., Abt, K., Glavonjić, B., Lopatin, E. and W. Mabee. 2016. Chapter 9: Wood Energy Market, 2015-2016. In: United Nations Forest Products Annual Market Review. P. 97-108.

Becker, D.R.; Moseley, C.; Lee, C. 2011. A supply chain analysis framework for assessing state-level forest biomass utilization policies in the United States. Biomass \& Bioenergy, 35(4):14291439.

Baumann, P. 2006. Forest-poverty linkages in West and Central Asia: The outlook from a sustainable livelihoods perspective. FAO LSP WP, 34.

Berndes, G. Abt, B., Asikainen, A., Cowie, A., Dale, V., Egnel, G., Lindner, M., Marelli, L., Pare, D., Pingoud, K., and S. Yeh. 2016. Forest biomass, carbon neutrality and climate change mitigation. European Forest Institute. Online at http://www. efi.int/files/attachments/publications/efi_thinkforest-brief_ carbon_neutrality.pdf

Buttoud-Kouplevatskaya, I. 2010. Changing role of public forestry institutions in Central Asian and Caucasus countries. Forestry Policy and Institutions Working Paper (FAO).

Bundesregierung. 2016. Energiewende. Online at https:// www.bundesregierung.de/Webs/Breg/DE/Themen/ Energiewende/_node.html

Ebers, A., Malmsheimer, R., Volk, T. and D. Newman. 2016. Inventory and classification of United States federal and state forest biomass electricity and heat policies. Biomass and Bioenergy. 84: 67-75.

Egger, C., Öhlinger, C. and Dell, G. 2014. Chapter 10: Successful wood energy development and implementation: sustainable heating in upper Austria. In: .X. Aguilar (ed.), Wood energy in developed economies: sustainable resource management, economics and policy. Routledge.

European Commission. 2009 'Directive 2009/28/EC of the European Parliament and of the Council of 23 April 2009 on the promotion of the use of energy from renewable sources and amending and subsequently repealing Directives 2001/77/EC and 2003/30/EC.
European Commission. 2009. Directive 2009/125/EC of the European Parliament and of the Council of 21 October 2009 establishing a framework for the setting of ecodesign requirements for energy-related products. Online at http://eur-lex.europa.eu/legal-content/EN/ TXT/?uri=CELEX:32009L0125

European Commission. 2015. Commission Regulation (EU) 2015/1189 of 28 April 2015 implementing Directive 2009/125/EC of the European Parliament and of the Council with regard to ecodesign requirements for solid fuel boilers. Online at http://eur-lex.europa.eu/legal-content/EN/ TXT/?uri=uriserv:OJ.L_.2015.193.01.0100.01.ENG

European Commission. 2016. Memo: The Revised Renewable Energy Directive. Online at https://ec.europa.eu/energy/sites/ ener/files/documents/technical_memo_renewables.pdf

European Commission. 2017. Biomass. Online at https:// ec.europa.eu/energy/en/topics/renewable-energy/biomass

European Commission. 2017. Sustainability of biomass production. Online at https://ec.europa.eu/agriculture/ bioenergy/sustainability_en

European Union. 2010. Regulation (EU) No 995/2010 of the European Parliament and of The Council. of 20 October 2010 laying down the obligations of operators who place timber and timber products on the market. Online at http://eur-lex.europa.eu/LexUriServ/LexUriServ. do?uri=OJ:L:2010:295:0023:0034:EN:PDF

Federal Ministry for the Environment, Nature Conservation and Nuclear Safety of Germany (2012). Act on granting priority to renewable energy sources. www.bmu.de/files/ english/pdf/application/pdf/eeg_2012_en_bf.pdf, accessed 13 November 2012

GIZ [Deutsche Gesellschaft für Internationale Zusammenarbeit]. 2013 - Central Asia - sustainable use of natural resources (German)

GIZ. 2016a. Anpassung an den Klimawandel durch nachhaltige Forstwirtschaft. https://www.giz.de/de/weltweit/29916.html (accessed on October 5, 2016)

GIZ. 2016b. Stärkung der Lebensgrundlagen durch Anpassung an den Klimawanderl in Kirgisistan und Tadschikistan. https:// www.giz.de/de/weltweit/28809.html (accessed on October 5, 2016)

IHB. 2016. The Albanian parliament has approved a 10 year moratorium on logging for industrial purposes and export. Online at www.ihb.de/wood/news/Albania_logging_ ban_45823.html

Kargasov. 2008. Promoting Energy Efficiency. Online at https:// www.yumpu.com/en/document/view/26658000/energyefficiency-centre-for-development-and-environment

Koponen, K., Sokka, L., Salminen, O., Sievänen, R., Pingoud, K, Ilvesniemi, H., Routa, J., Ikonen, T., Koljonen, T., Alakangas, E., Asikainen, A., \& Sipilä, K. (2015) . Sustainability of forest energy in Northern Europe. VTT Technology 237. 94 p.

Kushlin, A. V., Schillhorn-van-Veen, T. W., \& Sutton, W. 2003. Kazakhstan: forest sector in transition: the resource, the users and sustainable use. World Bank. 
Lantiainen, S., Song, N., and F.X. Aguilar. 2014. Public Policy Promoting wood energy in the EU and US. Wood Energy in Developed Economies: Resources management, economics and policy. Routledge. 189-222.

Lippke, B., Gustafson, R., Venditti, R., Steele, P., Volk, T., Oneil, E., Johnson, L., Puettmann, M. and K. Skog. 2012. Comparing LifeCycle Carbon and Energy Impacts for Biofuel, Wood Product, and Forest Management Alternatives. Forest Products Journal. 62(4):247-257.

Markowski-Lindsay, M., Stevens, T., Kittredge, D. and Butler, B. 2012. Family forest owner preferences for biomass harvesting in Massachusetts. Forest Policy and Economics. 14:127-135.

Ministry of Natural Resources and Environment of the Russian Federation. 2013. План мероприятий по созданию благоприятных условий для использования возобновляемых древесных источников для производства тепловой и электрической энергии. Online at http:// www.mnr.gov.ru/news/detail.php?ID=131039\&sphrase_ $\mathrm{id}=327550$.

Miner, R. A., Abt, R. C., Bowyer, J. L., Buford, M. A., Malmsheimer, R. W., O'Laughlin, J., Oneil, E. E., Sedjo, R. A., Skog, K. E., 2014. Forest carbon accounting considerations in US bioenergy policy. Journal of Forestry. 112: 591-606.

Netherlands Enterprise Agency. 2017. SDE+ Spring 2017. Online at http://english.rvo.nl/sites/default/ files/2017/03/170307\%20Brochure_SDE2017UK\%20def_0. pdf

Ofgem. 2016. Renewables Obligation: Sustainability Criteria. 110p. Online at https://www.ofgem.gov.uk/system/files/ docs/2016/03/ofgem_ro_sustainability_criteria_guidance_ march_16.pdf

Ofgem. 2017. Domestic Renewable Heat Incentive. Online at https://www.ofgem.gov.uk/environmental-programmes/ domestic-rhi/applicants

O'Hara, P. 2014. Sustainable Forest Management Principles and Public Policies for Greener Economies in the Caucasus and Central Asia Region. Sustainable forest management. United Nations' Economic Commission for Europe (UNECE) and UN Development Account. Astana, Kazakhstan. April 1-4, 2014.

Rudie, A., Houtman, C., Groom, L., Nicholls, D. and J. Zhu. 2016. A Survey of Bioenergy Research in Forest Service Research and Development. Bioenergy Research. 9:534-547.

Russian Federation Decree No. 321 of April 15, 2014 on "Energy Efficiency and Energy Development"

S2BIOM. 2016. Database of Policy Measures \& Instruments. Online at https://s2biom.vito.be/policies-s2biom

Song, N. and F. X. Aguilar. 2016. Woody biomass energy efficiency pathways: public policy implications, Biofuels. Online at http://dx.doi.org/10.1080/17597269.2016.1259520

Steierer, F. 2014. The UNECE/FAO Joint Wood Energy Enquiry (JWEE). Wood Energy in Developed Economies: Resources management, economics and policy. Routledge. 4-6.

Sundstrom, S., Nielsen-Pincus, M., Moseley, C. and S. McCaffery. 2012. Woody biomass use trends, barriers, and strategies: Perspectives of US Forest Service managers. Journal of Forestry.

Sverige. 2017. Energy Use in Sweden. Online at https:// sweden.se/society/energy-use-in-sweden/

Swinkels, R. 2014. Assessment of household energy deprivation in Tajikistan. World Bank Report. Online at http://documents. worldbank.org/curated/en/944321468341064427/ pdf/888370ESWOwhit0nOEnergy0Deprivation.pdf

S2BIOM. 2017. Catalogue of Instruments \& Measures. Available at https://s2biom.vito.be/policies-s2biom

Thornley, P. and D. Cooper. 2008. The Effectiveness of policy instruments in promoting bioenergy. Biomass and Bioenergy. 32: $903-913$

Ulybina, O. 2015. Participatory Forest Management: The experience of foreign funded programmes in the Kyrgyz Republic. Environmental Policy and Governance, 25(1), 70-82.

United Nations Framework Convention on Climate Change (UNFCCC). 2016. The Paris Agreement. Online at http:// unfccc.int/paris_agreement/items/9485.php

United Nations Treaty Collection. 2015. Chapter XXVII Environment. 7d Paris Agreement. Online at https://treaties. un.org/pages/ViewDetails.aspx?src=TREATY\&mtdsg_ no=XXVII-7-d\&chapter=27\&lang=en

Undeland, A. 2012. The Development Potential of Forests in the Kyrgyz Republic. Washington, DC: Program on Forests (PROFOR).

U.S. Public Law 115-31. Consolidated Appropriations Act of 2017. Online at https://www.congress.gov/bill/115thcongress/house-bill/244

US Department of Agriculture. 2012. National Best Management Practices for Water Quality Management on National Forest System Lands. FS-990a. 165 pp. Online at https://www.fs.fed.us/biology/resources/pubs/watershed/ FS_National_Core_BMPs_April2012.pdf

US Department of Agriculture. 2017. Farm Service Agency: Biomass Crop Assistance Program. Online at https://www.fsa. usda.gov/programs-and-services/energy-programs/BCAP/ index

US Environmental Protection Agency. 2015. Fact sheet: Summary of Requirements for Woodstoves and Pellet Stoves. Online at http://www2.epa.gov/residential-wood-heaters/ fact-sheet-summary-requirements-woodstoves-and-pelletstoves

US Environmental Protection Agency. N.d. Burn wise energy efficiency. Online at https://www.epa.gov/burnwise/burnwise-energy-efficiency

Vildanova, G. 2006. Forest and forest products country profile Uzbekistan. Geneva Timber and Forest Discussion Papers (ECE/FAO).

World Bank. 2015a. Kyrgyz Republic: Communities Forests and Pastures.

World Bank. 2015b. Kyrgyz Republic: integrated forest ecosystem management project 


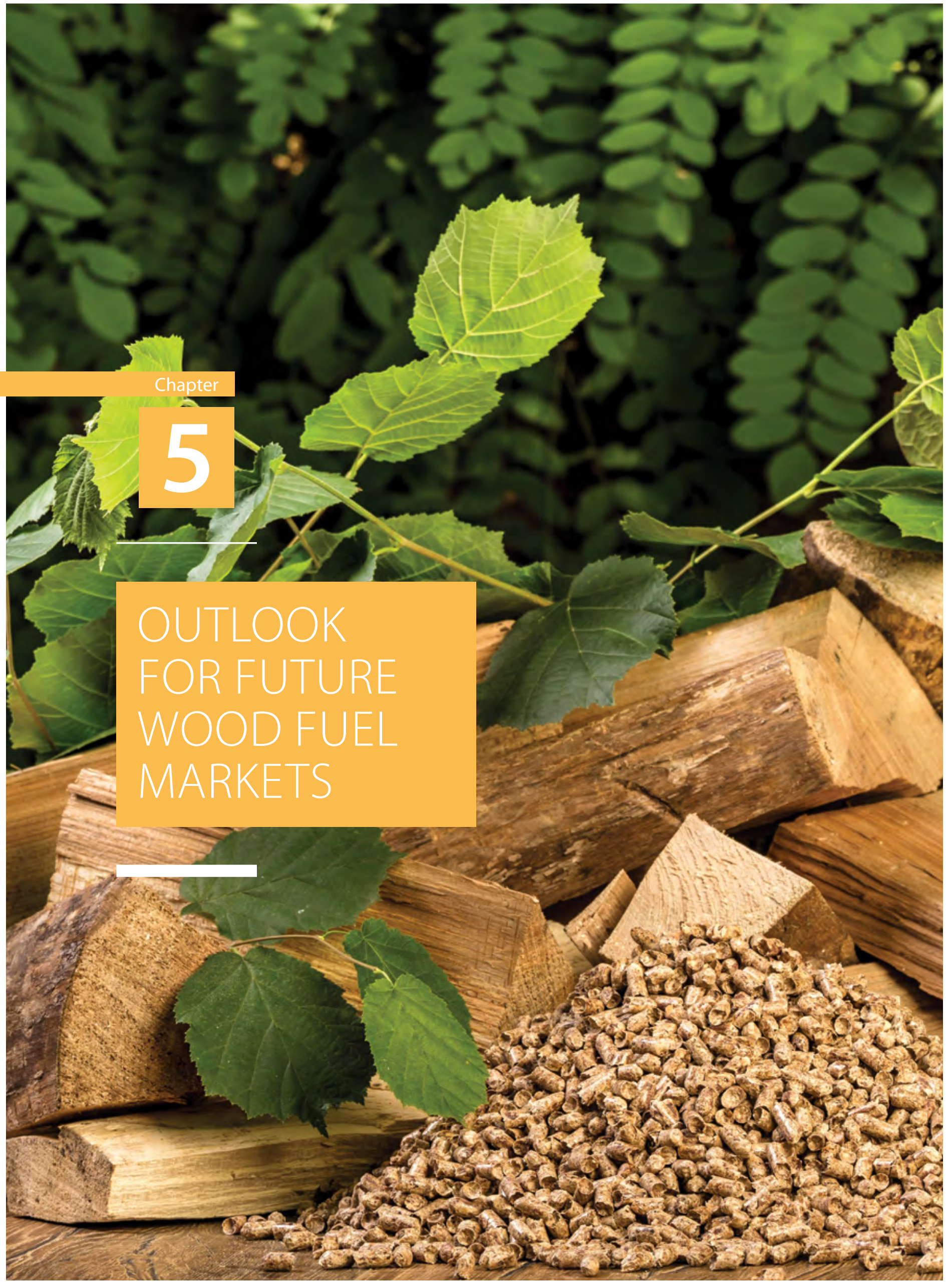




\section{Highlights*}

* Reference case outlooks across the UNECE region project small to moderate increases in the production and consumption of wood fuel. The largest increases are expected in Europe, with smaller increases in Canada, and almost no increase in the United States.

* Greater use of primary solid timber and harvesting residues for both the production of wood pellets and for direct use in electricity and heat production is expected to increase in Europe, North America and the Russian Federation through 2040. Coproduction of energy with paper production mainly from bark and black liquor is not expected to increase.

* The potential exists for increased wood fuel consumption and production in Europe and the rest of the UNECE region. Realization of this potential will depend on competing energy prices as well as public policies affecting renewable energy use, greenhouse gas (GHG) emissions, and forest sustainability.

* Trade in wood pellets has increased from 15\% to 23\% of all traded fuelwood between 2012 and 2015 and is expected to grow. Increased consumption of wood pellets could lead to increased imports to Europe from North America, the Russian Federation, and other countries within the UNECE and beyond. Trade within Europe accounted for about $87 \%$ of the global trade in wood pellets in 2015.

* Future use of wood fuels could face obstacles including production costs; permitting and planning regulations; forest sustainability requirements; and public perceptions.

* Future use of wood fuels could benefit from opportunities including potentially lower GHG emissions than fossil-based energy, relative ease of increasing production through co-firing or conversion of existing powergenerating facilities, and use in district heating applications. 


\subsection{Introduction}

The last decade has seen notable increases in wood fuel production, consumption and trade across the UNECE region. Most of these changes have been policy induced by the EU's Renewable Energy Directive ${ }^{7}$, which required increased renewable energy use leading to greater wood pellet consumption, primarily in utility scale facilities. As a consequence, trans-Atlantic and intra-European trade in wood pellets increased. Other forms of wood fuels, including black liquor, wood processing residues, waste wood, and firewood, are less frequently traded for energetic purposesthey are primarily consumed in the country in which they are produced or traded for material use in the wood processing industry.

In the UNECE region, official reference case outlooks for energy are periodically produced by the Directorate General for Energy of the European Union Commission, Energy Canada, and the United States' Department of Energy (USDOE) (DG Energy: EU Commission 2016, USDOE 2016, 2017, Energy Canada 2016). Outlooks provide general information on energy markets and are not necessarily focused on energy from wood fuels. Forecasts from other consulting and trade groups are not included in this chapter. We also summarize the International Energy Agency's (IEA) Outlook (IEA, 2016) that provides an outlook for national-level bioenergy development, inclusive of energy from wood fuels. Data for many of the UNECE member States are limited, although the UNECE/FAO Joint Wood Energy Enquiry (Chapter 2) provides detailed information for the countries that responded to the enquiry.

The EU outlook derives from the reference scenario (European Commission, 2016a) and addresses the production of timber for use as fuel rather than the consumption of energy from all sources of wood fuels. The key premise with respect to wood energy is that the demand for wood fuels is expected to increase through 2030, largely as a result of the new Renewable Energy Directive requirements and level off thereafter. This increase in demand is expected to lead to increased harvest, as well as increased afforestation and decreased deforestation. Overall, use of roundwood for wood fuels within the EU is expected to increase, with the percent of wood going to energy increasing from 18\% in 2005 to $28 \%$ in 2030 and beyond, and as total wood harvest increases as well. The European Commission (2016a) analysis was focused on accounting for carbon emissions, hence, does not address wood fuel consumption expected to be met via trade outside the EU. The analysis of energy consumption, based on EU member States' National Renewable Energy

7 Directive 2009/28/EC of the European Parliament and of the Council of 23 April 2009.
Action Plans indicates that in order to meet targets, the use of solid biomass in the Heating and Cooling sector will need to increase nearly $6 \%$ per year and nearly $5 \%$ per year in the electricity sector (EU Commission, 2017a).

The Canadian National Energy Board outlook (National Energy Board, 2016) generates a comprehensive national projection for energy production out to 2040 and does not evaluate different case scenarios. Overall, combined biomass electricity and heat generation capacity is expected to increase by $72 \%$ (1.6 GW) between 2014 and 2040. Most growth is expected to come from wood fuel use in Ontario, Quebec and Alberta, and although this outlook does not indicate the percentage increase in electricity/heat generation, this growth in capacity is about $3.6 \%$ of total electricity/heat generation capacity growth through 2040. The use of wood pellets in small biomass boilers is expected to increase but the use of residues in industrial sector consumption is expected to be stable or decline slightly.

The reference case from the United States Annual Energy Outlook (USDOE, 2017) shows small increases in wood energy production for industry, steady production from commercial enterprises, and declining wood use for residential energy through 2050 . For utility scale electricity production, biomass-based electricity continues to be one of the most costly energy sources per unit of electricity (i.e. levelized cost of energy). Hence, use of wood fuels to generate electricity is not projected to increase significantly. Electricity generated from wood fuels is projected to account for less than $1 \%$ of total new generation capacity between 2018 and 2022. The US DOE also produces an International Energy Outlook (USDOE, 2016a) that summarizes current and emerging trends. The IEO concludes that the "greatest potential for growth in renewable energy production in the OECD countries (Organisation for Economic Cooperation and Development) is in wind, solar, and wood pellets" (P. 87). The outlook for other wood energy consumption is muted — with an expected decline in paper production in OECD member States, and steady-to-slightly increasing production in nonOECD countries.

The IEA produces a World Energy Outlook (IEA/OECD, 2016) that provides scenarios of future global energy demand to 2040. The main scenario ("New Policies Scenario") concludes that global bioenergy demand (including wood fuels and other biomass based energy) is expected to grow at an annual rate of $1.1 \%$. The UNECE region shows a higher rate of growth than worldwide levels. Within the UNECE, Russia is expected to achieve the highest annual growth (3.5\%), although this is based on low initial production of bioenergy production. North America and EU's bioenergy sectors are expected to develop at slower paces of $1.7 \%$ and $1.6 \%$, respectively. European non-EU countries are expected to see a greater annual growth rate of $2.5 \%$. 
Finally, the UNECE/FAO has produced a set of forest sector outlook studies for the European and North American subregions and the Russian Federation, that evaluated possible future economic and climate scenarios including assumptions about the use of wood energy (United Nations, 2011, 2012a, 2012b). These studies did not independently assess the outlook for wood energy but catalogued the impact of an assumed increased consumption of wood fuels on the forests.

\subsection{Outlook for wood fuel production and consumption}

Existing data were used to estimate current wood fuel consumption and potential production. To better understand the drivers of consumption, a statistical model was used to explain the variability in wood fuel consumption for the 27 respondents to the JWEE 2013 as a function of various social, economic and forest-sector indicators using a conventional regression approach ${ }^{8}$. A model of wood fuel consumption solely explained by industrial roundwood (IRW) production and EU membership explained $90 \%$ of variation in JWEE responses. Thus, we would not expect wood fuel consumption to increase in non-EU countries in the absence of (1) policies encouraging, requiring and/or subsidizing wood energy, and/or (2) increases in IRW production. Intuitively, increases in fossil fuel prices would be expected to increase wood fuel consumption, and decreases in other renewable energy prices to decrease wood fuel consumption. This relationship is more likely to be observed in the electricity sector where there is a wider portfolio of low cost alternatives than to heat, where wood fuels are the main source of renewable energy. However, it is important to note that the model cannot account for price changes over time because it uses only one year of data.

Using this model based on the JWEE responses, combined with the EU membership and IRW production quantities from FAOSTAT (2017), wood fuel consumption across the UNECE was extrapolated to approximately 951 million $\mathrm{m}^{3}$ in 2013. This compares to a total IRW production level of 1,069 million $\mathrm{m}^{3}$ in 2013 in the UNECE, as reported in FAOSTAT (2017). Figure 5.1 compares total IRW production to extrapolated wood fuel consumption by EU countries and non-EU countries that are UNECE member States in 2013, as well as to the potential for wood fuel production (discussed below). Total extrapolated wood fuel consumption in EU countries in 2013 is higher than recorded IRW production. Extrapolated wood fuel

8 Because the JWEE respondents are likely to be more interested in using or producing wood fuels, there is an inherent sample selection bias in the statistical model. We did not account for this bias in the extrapolation consumption in non-EU countries, both North America and other UNECE member States, is lower than current IRW production.

EU countries could be expected to increase their wood fuel consumption if additional requirements for member countries are included in the newly proposed renewable energy package for the EU (European Commission, 2016b) that will address the period from 2020-2030, and if those countries choose to use wood fuels to meet new requirements. For instance, increases could result from the encouragement of reaching $1 \%$ per year of heating and cooling sources.

To estimate the upper limit potential for increased domestic wood fuel production considering sustainability considerations data from FAOSTAT and S2BIOM were used (Dees et al. 2017). Results indicate that the EU28 could meet all of its 2013 wood fuel consumption domestically, and that excess production potential exists in both North America and the rest of the UNECE region. EU28 production potential is estimated at 433 million $\mathrm{m}^{3}$. North American potential is estimated at 781 million $\mathrm{m}^{3}$ or nearly three times current consumption. The rest of the UNECE potential is 576 million $\mathrm{m}^{3}$ or twice as much as current consumption. Unless transportation costs or policies prevent its realization, we would expect that trade from North America and other UNECE members will likely be the source to support greater wood fuel consumption in the EU28.

\section{FIGURE 5.1}

Actual and extrapolated wood fuel consumption, reported industrial roundwood production, and estimated potential wood fuel production in the EU28, North America and other UNECE member States in 2013

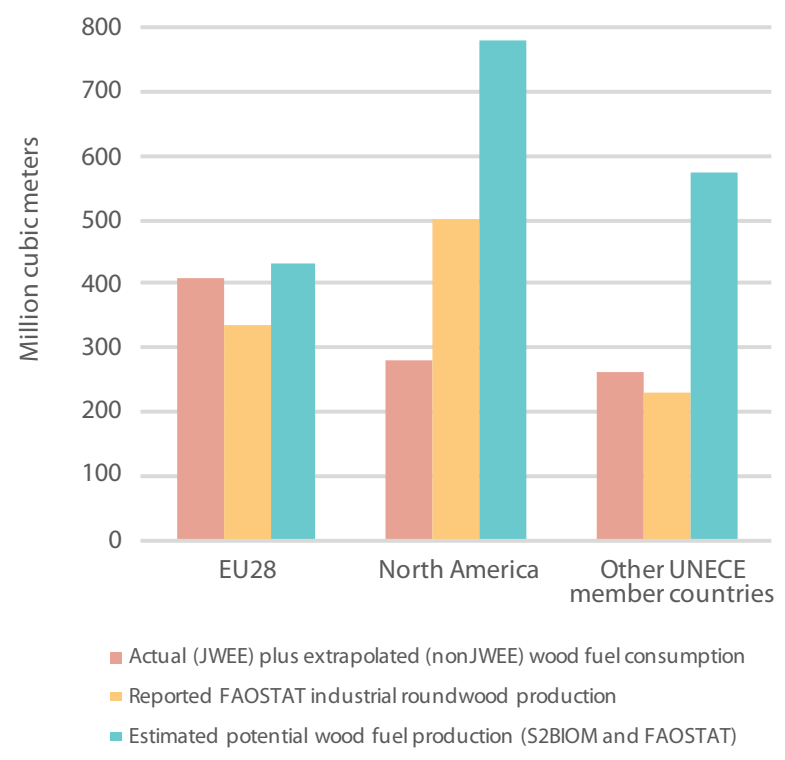

Source: UNECE/FAO, 2015; FAOSTAT, 2017; S2BIOM, 2017; and authors model predictions. 
FIGURE 5.2

\section{Global chemical pulp production, 1996-2015, for North America, EU28 and all other ECE and for the Rest of the World}

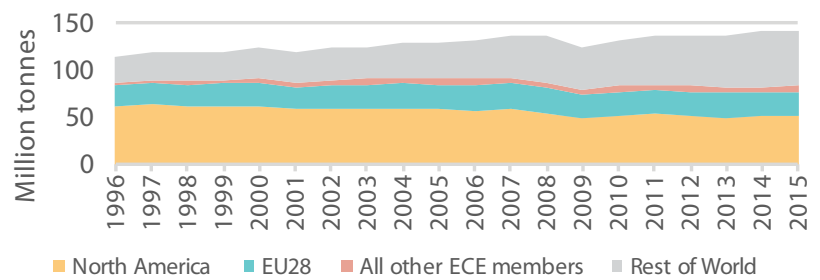

Source: FAOSTAT, 2017.

Moreover, this expectation is based on current conditions and does not account for any policy changes that may be adopted by non-EU28 members in the UNECE region. These potential estimates for wood fuel largely depend on the estimate of the share of roundwood harvests for energy out of the total potential roundwood harvest. For the potential estimates presented here, the average share from 2000-2015 as reported in FAOSTAT was used.

Both the extrapolation of 2013 wood fuel consumption and estimated production (Figure 5.1) should beviewed with caution. Many assumptions were necessary to develop these estimates. Further details on the methods used and assumptions made can be found in the Annexes. One area of wood fuel use that is unlikely to see increases is the coproduction of energy (via black liquor or use of solid wood residues and bark) with the industrial production of paper products. While global demand for paper is expected to increase, demand for paper products in the UNECE region is expected to decline or remain steady as digital media reduce demand for certain types of paper products. In addition, as shown in Figure 5.2, the supply of paper products is expected to increase in non-UNECE regions (e.g., South America and Asia). Lumber production is expected to expand driven by population growth, so there will be some increased consumption of wood fuels in solid wood production and possibly through increased tertiary utilization. This is accounted for in the various reference case scenarios discussed above.

\subsection{Outlook for trade in wood fuels}

Global trade of wood fuels has increased steadily since 2000. Trade in wood pellets accounted for $67 \%$ (by weight of this increase since 2012, and has risen to 15.7 million tonnes from only a few hundred thousand in 2000. Wood pellets comprised $15 \%$ of all wood fuel trade in 2012 , rising to $23 \%$ in 2015. Tradeable fuelwood is defined by UN Comtrade as "Fuel wood, in logs, in billets, in twigs, in faggots or in similar forms; wood in chips or particles; sawdust and wood waste and scrap, whether or not agglomerated in logs, briquettes, pellets or similar forms" and thus includes products in addition to wood pellets and firewood logs. Chips and particles and sawdust, however, can also be used to make pulp and wood panels, so an accurate estimation of all traded wood for energy purposes may not be feasible, except for those countries responding to the JWEE (See Chapter 2).

UN Comtrade data (2017) for the fuelwood category (4401) and its sub-codes offers a snapshot of current global trade of wood fuel products. Figure 5.3 shows the overall fuelwood category (code 4401), Figure 5.4 shows fuelwood in logs (code 4401 10), and Figure 5.5 wood pellets (code 4401 31). Data for the overall aggregate fuelwood category are available for 2000-2015 but other categories changed in 2012. Therefore, data are presented and discussed only for 2012-2015. We do not further discuss the sub-codes of chips or other fuelwood, although these are included in Figure 5.3.

\section{FIGURES 5.3}

\section{(A) Imports and (B) exports of all fuelwood (code 4401) from 2000 to 2015}
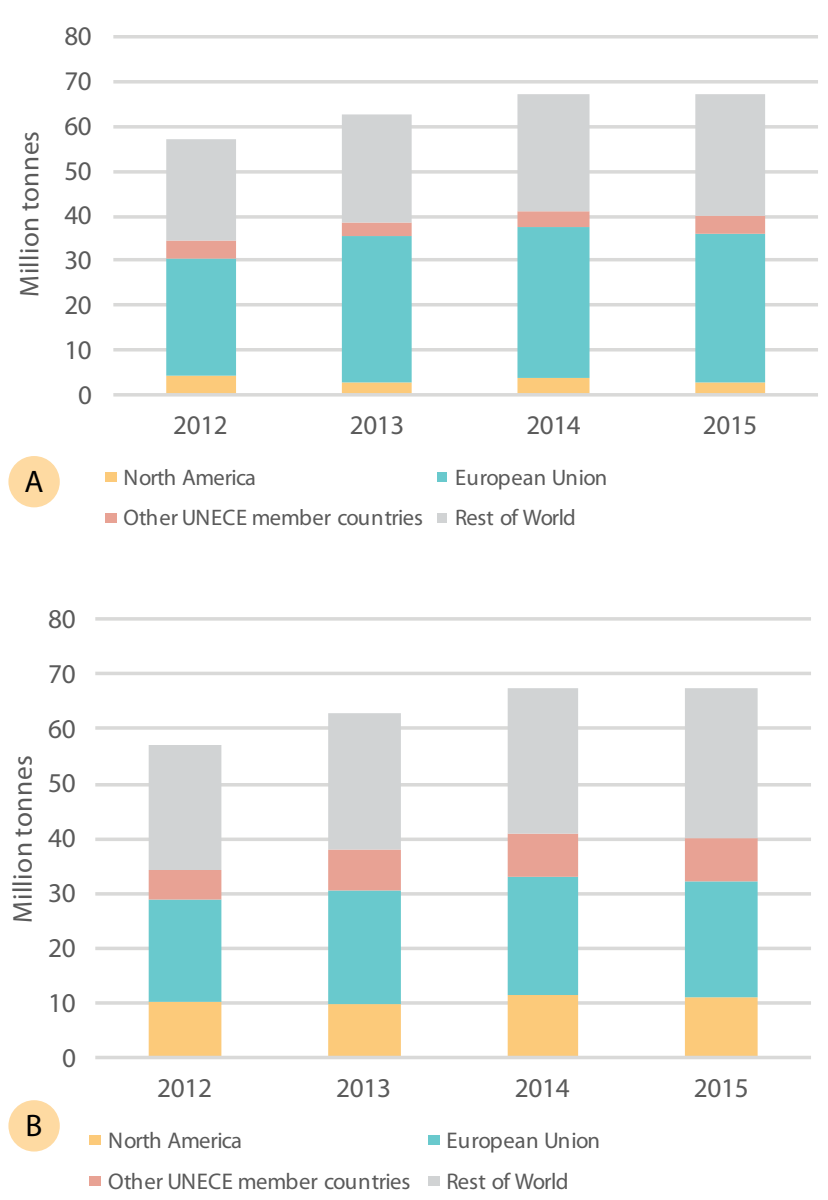

Source: UN Comtrade, 2017. 


\section{FIGURES 5.4}

\section{(A) Imports and (B) exports of fuelwood in logs (code 4401 10) from 2012 to 2015}
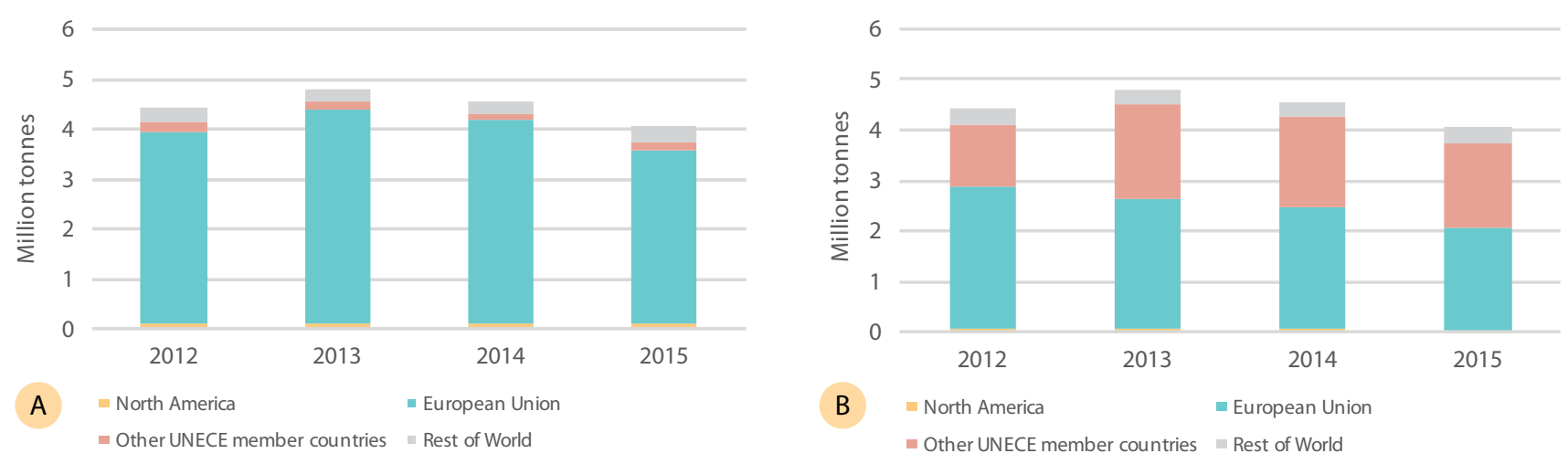

Source: UN Comtrade, 2017

\section{FIGURES 5.5}

\section{A) Imports and (B) exports of wood pellets (code 4401 31) from 2012 to 2015}

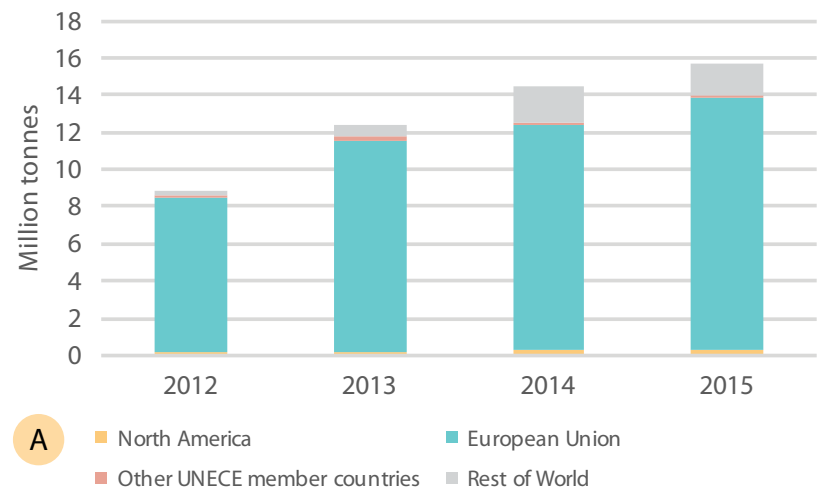

Source: UN Comtrade, 2017

Global trade in all fuelwood products, including those that are be used for non-energy products, increased by 11 million tonnes from 2012 to 2015 (Figure 5.3). About two-thirds of this increase can be attributed to trade in wood pellets. The sub-code of fuelwood in logs (4401 10) shows only a small increase over these four years (Figure 5.4), with a maximum of traded fuelwood logs observed in 2013 at 5.0 million tons. EU member States were the main importers (85\%) of this product, and the EU and other UNECE countries accounted for $91 \%$ of exports. Countries capturing most imports include Austria, Italy, Romania and Germany while Ukraine, Bosnia Herzegovina, Hungary and Croatia are the main exporters.

The increase in wood pellet trade between 2012 and 2015 (Figure 5.5) was largely driven by policy changes in the EU, which imported $86 \%$ of all pellets traded worldwide in 2015. A total

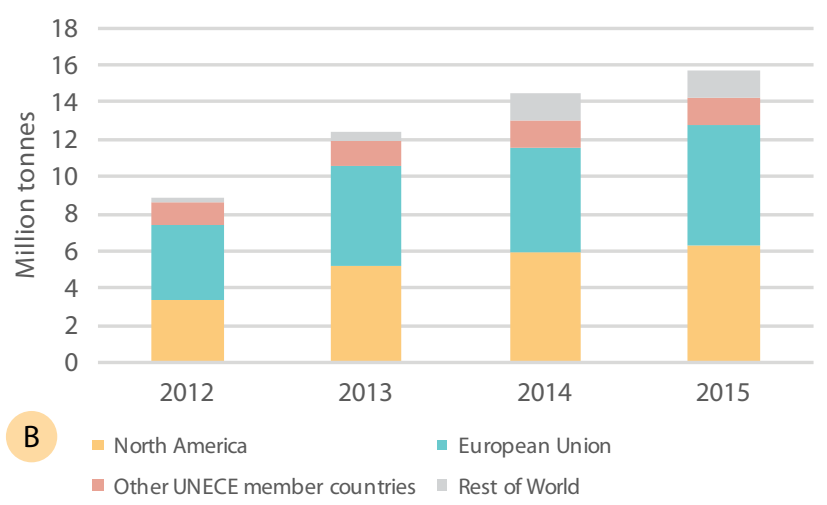

of 15.7 million tonnes of wood pellets were traded globally in 2015. The EU and North America were the dominant exporters accounting for $42 \%$ and $40 \%$ of exports. Largest exporting countries were Canada, Latvia, and the United States. The main importing region is Europe, and main importing countries are United Kingdom, Denmark and Italy. EU countries are the major importers of fuelwood logs and wood pellets in the UNECE region. Figure 5.6 shows where imports to EU countries are coming from for both of these wood fuels, with nearly all firewood imports coming from other European countries, while more than $90 \%$ of wood pellets imported to the EU were from other EU countries and North America.

Trade within Europe accounted for about $87 \%$ of the global trade in wood pellets in 2015 (Figure 5.7). In 2015, the EU produced 14.1 million tonnes, but consumed 20.3 million 


\section{FIGURES 5.6}

\section{Imports into the EU by region of origin for (A) fuelwood in logs and (B) wood pellets from 2012 to 2015}

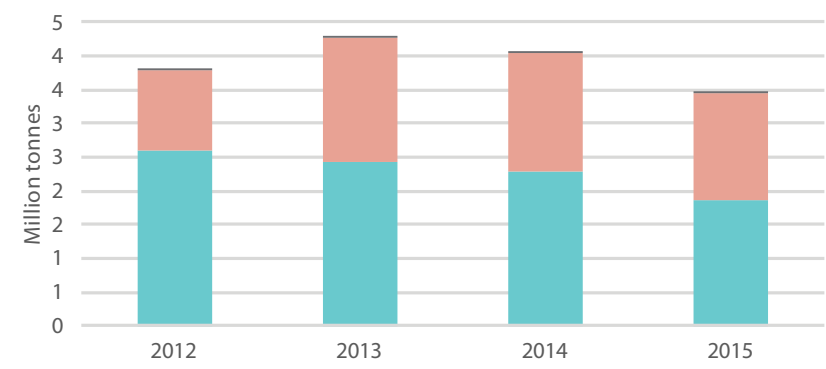

A $\quad$ North America $\quad$ Other UNECE member countries

- European Union - Rest of World

Source: UN Comtrade, 2017

tonnes, making it the largest pellet importer in the world. Much of the imports have been supplied by North America. Within Europe, Latvia is the leading exporter, doubling its pellet exports from 2012 to 2015 due to available timber resources, low production costs, low domestic demand, and low shipping costs (European Biomass Association, 2016). For instance, shipping distances from Latvia or Russia to the United Kingdom or the Netherlands are less than 1/3 the respective distances from the U.S. Increased exports from the Baltic States are likely to continue.

Trade in wood fuels is likely to increase primarily as a result of increases in trade in wood pellets. Currently, the EU is the largest importer and consumer of wood pellets for utility scale electricity production and its demand is expected to continue to increase in the coming decades. Potential exists for increased exports from North and South America to consumers in the EU and Southeast Asia. New markets and existing trade flows will depend on (1) government regulations and subsidies to encourage and/or require increases in the consumption of renewable energy, inclusive of wood energy, (2) sustainability regulations that could limit the wood energy supplies from certain regions or countries, and (3) prices for alternative energy sources, including prices of other renewables, and natural gas and other fossil fuels.

\subsection{Outlook for Wood Fuels and Energy - Barriers and Opportunities}

Economic barriers limit the use of wood fuels including cost of production and uncertainties in renewable energy markets. For instance, regulations and subsidies are a source of uncertainty, with governments adopting and changing policies on subsidies, carbon neutrality of wood fuel use,

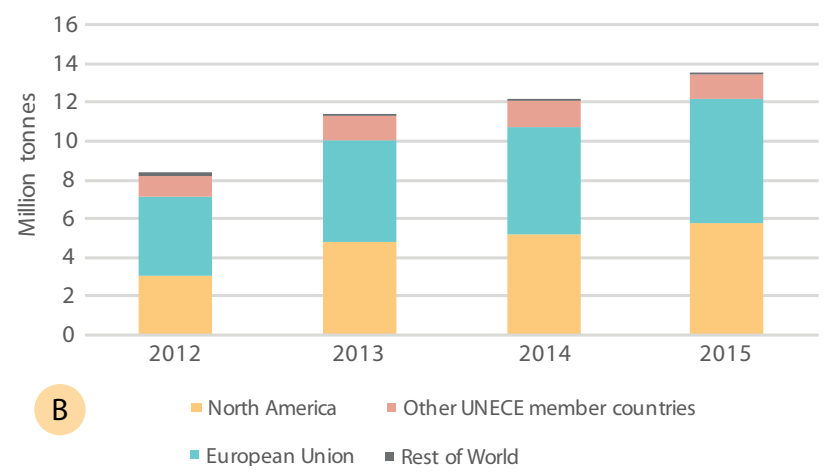

and forest sustainability requirements. Noneconomic barriers identified for the EU, but applicable across the UNECE, include the use of wood fuels for electricity generation as well as heating and cooling (European Commission, 2017b). The European Commission (2017b) also identifies the main barriers to the increased use of wood fuels for electricity associated with the planning and permitting process. Moreover, a negative public perception of the desirability of using wood for heating and cooling, compared to other available technologies, represents the most commonly identified barrier to wood energy growth in the EU, followed by a lack of reliable advice and available skilled professionals.

Opportunities for future use include potentially lower GHG emissions than fossil fuels, relative ease of increasing production through co-firing or conversion of existing facilities, and use of wood in district heating applications (Chapter 1). There are limited opportunities for increased use of wood for household heating in the EU (European Commission, 2017b), although the use of wood pellets in electricity production offers an efficient and speedy alternative to the use of wind and solar. Subsidies and regulations from some UNECE governments reduce economic barriers, making wood energy a more favourable renewable electricity source.

The EU28, North America and the rest of the UNECE region have the bio-physical potential to increase wood fuel production. Availability might support opportunities for trade expansion within the UNECE region. For instance, countries outside the EU28 but within the UNECE might seek to capitalize on the increased emphasis on renewable energy sources in the EU28.

While outlooks and models suggest increasing use of wood fuels across the UNECE region, there are limitations to greater wood fuels consumption, including especially availability constraints that derive from natural limits set by forest area 


\section{FIGURES 5.7}

\section{World wood pellet production map and trade flow in 2015 (million tonnes)}

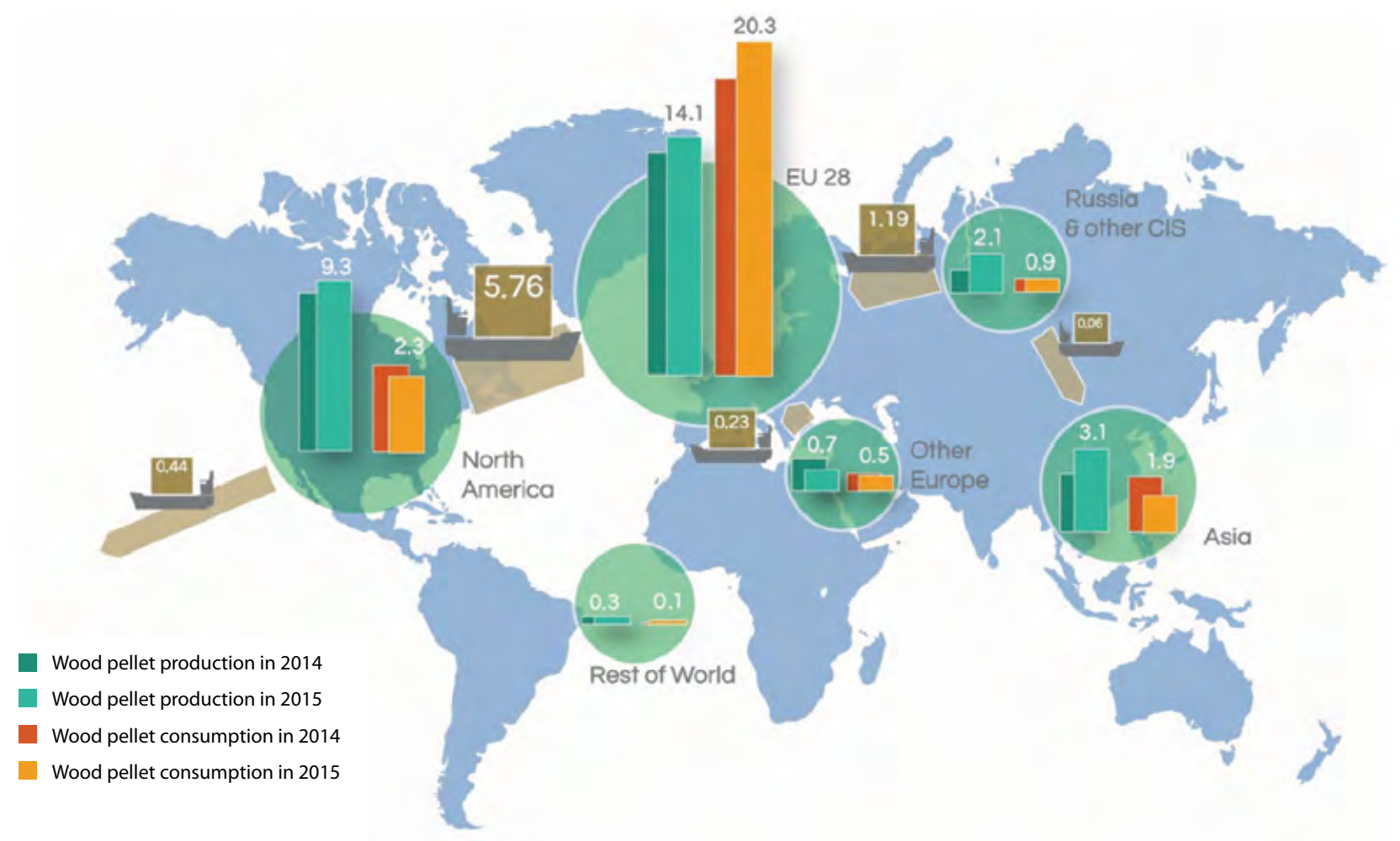

Source: European Biomass Association, 2016.

and growth rates. Additional limitations could result from policies addressing forest sustainability that could impact availability and cost efficiencies. Establishment of shortrotation woody crops in areas where land is available and not used for food crops might provide an additional source of wood fuels to reduce pressure on forested lands.

\subsection{Conclusions}

Since 2000, the UNECE region has observed notable increases in wood fuel production, consumption and trade. Future increases will depend on both markets and policies, including (1) new or revised policies that encourage or require the use of renewable energy or wood fuels, (2) reductions in the costs of alternative renewable electricity technologies (wind and solar), (3) changes in the prices of fossil fuels. Future use of wood fuels will likely face obstacles including production costs; permitting and planning regulations; forest sustainability requirements; and public perceptions. However, future use of wood fuels might also increase because of potentially lower GHG emissions than fossil-based energy; relative ease of greater production through co-firing or conversion of existing power-generating facilities; and use in district heating applications.

Production and consumption of industrial uses of wood fuels, including black liquor from pulping and other industrial residues will increase only to the extent that the production of paper and wood products increases. However, paper production in the UNECE is not expected to increase in the coming years. Wood pellet use in utility scale facilities has experienced the greatest expansion and consequently fostered growth in trans-Atlantic and intra-European trading. In the short run, wood pellet consumption is expected to continue to grow with increased imports to Europe from North America, the Russian Federation, and other countries within the UNECE and beyond. Other uses of wood fuels, including for residential heating and electricity production, can increase if encouraged or required by public policies but are unlikely to grow solely on market conditions. 


\subsection{References}

Dees, M., Elbersen, B., Fitzgerald, J., Vis, M., Anttila, P., Forsell, N., Ramirez-Almeyda, J., García Galindo, D., Glavonjic, B., Staritsky, I., Verkerk, H., Prinz, R., Monti, A., Leduc, S., Höhl, M., Datta, P., Schrijver, R., Sergey Zudin, Lindner, M., Lesschen, J. and K. Diepen. 2017. A spatial data base on sustainable biomass costsupply of lignocellulosic biomass in Europe - methods \& data sources. Project Report. S2BIOM - a project funded under the European Union 7th Frame Programme. Grant Agreement no. 608622. Chair of Remote Sensing and Landscape Information Systems, Institute of Forest Sciences, University of Freiburg. 173 p. Online at http://www.s2biom.eu/images/Publications/ D1.6_S2Biom_Spatial_data_methods_data_sources_Final_ Final.pdf

European Biomass Association. 2016. Pellet Market Overview.

European Commission. 2016a. EU Reference Scenario: Energy, Transport and GHG Emissions Trends to 2050. Online at https://ec.europa.eu/energy/sites/ener/files/documents/20160713\%20draft_publication_REF2016_v13.pdf

European Commission. 2016b. Clean energy for all Europeans. COM (2016) 860 final. 30 November 2016.

European Commission. 2017a. Renewable Energy Progress Report. Final report from the Commission to the European Parliament, the Council and the Committee of the Regions. 1.2.2017 COM (2017) 57. Online at http://eur-lex.europa.eu/ legal-content/EN/TXT/PDF/?uri=CELEX:52017DC0057\&qid= $1488449105433 \&$ from $=$ EN.

EU Commission. 2017b. Study on Technical Assistance in Realisation of the 2016 Report on Renewable Energy, in preparation of the Renewable Energy Package for the Period 2020-2030 in the European Union."RES-Study"ENER/C1/2014688 Client: European Commission DG Energy. Online at https://ec.europa.eu/energy/sites/ener/files/documents/resstudy_final_report_170227.pdf
FAOSTAT. 2017. Forestry Production and Trade. Online at http://www.fao.org/faostat/en/\#data/FO.

International Energy Agency IEA). 2016. World Energy Outlook 2016. OECD/IEA, Paris.

National Energy Board, Canada. 2016. Canada's Energy Future: energy supply and demand projections to 2040. Online at https://www.neb-one.gc.ca/nrg/ntgrtd/ftr/2016/2016nrgftreng.pdf

S2BIOM. 2017. Online at http://www.s2biom.eu/en/..

U.S. Department of Energy. 2016. International Energy Outlook. Online at http://www.eia.gov/outlooks/ieo/

U.S. Department of Energy. 2017. Annual Energy Outlook. Online at http://www.eia.gov/outlooks/aeo/.

UN Comtrade. 2017. Online at https://comtrade.un.org/data/.

UNECE/FAO. 2015. Joint Wood Energy Enquiry (JWEE) 2013. United Nations, Geneva. Online at http://www.unece.org/ forests/jwee.html

United Nations. 2011. European Forest Sector Outlook, 20062030. United Nations Economic Commission for Europe and Food and Agricultural Organization Report SP-28. 107 pages. Online at http://www.unece.org/fileadmin/DAM/timber/ publications/sp-28_01.pdf

United Nations. 2012a. North American Forest Sector Outlook, 2006-2030. United Nations Economic Commission for Europe and Food and Agricultural Organization Report SP-29. 68 pages. Online at http://www.unece.org/fileadmin/ DAM/timber/publications/SP-29_NAFSOS.pdf

United Nations. 2012b. The Russian Federation Forest Sector Outlook Study to 2030. United Nations Economic Commission for Europe and Food and Agricultural Organization Report. Online at http://www.fao.org/docrep/016/i3020e/i3020e00. pdf 


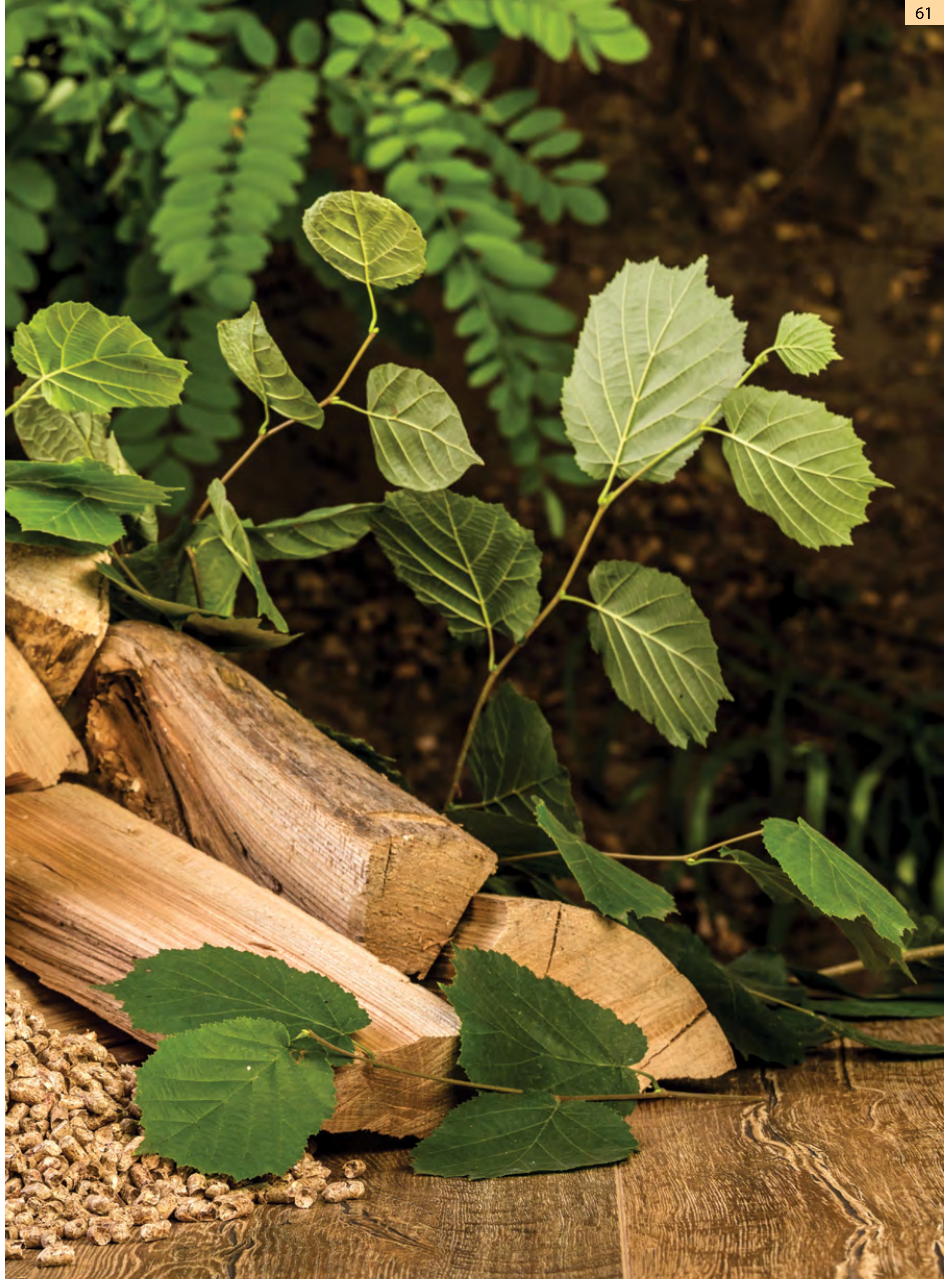




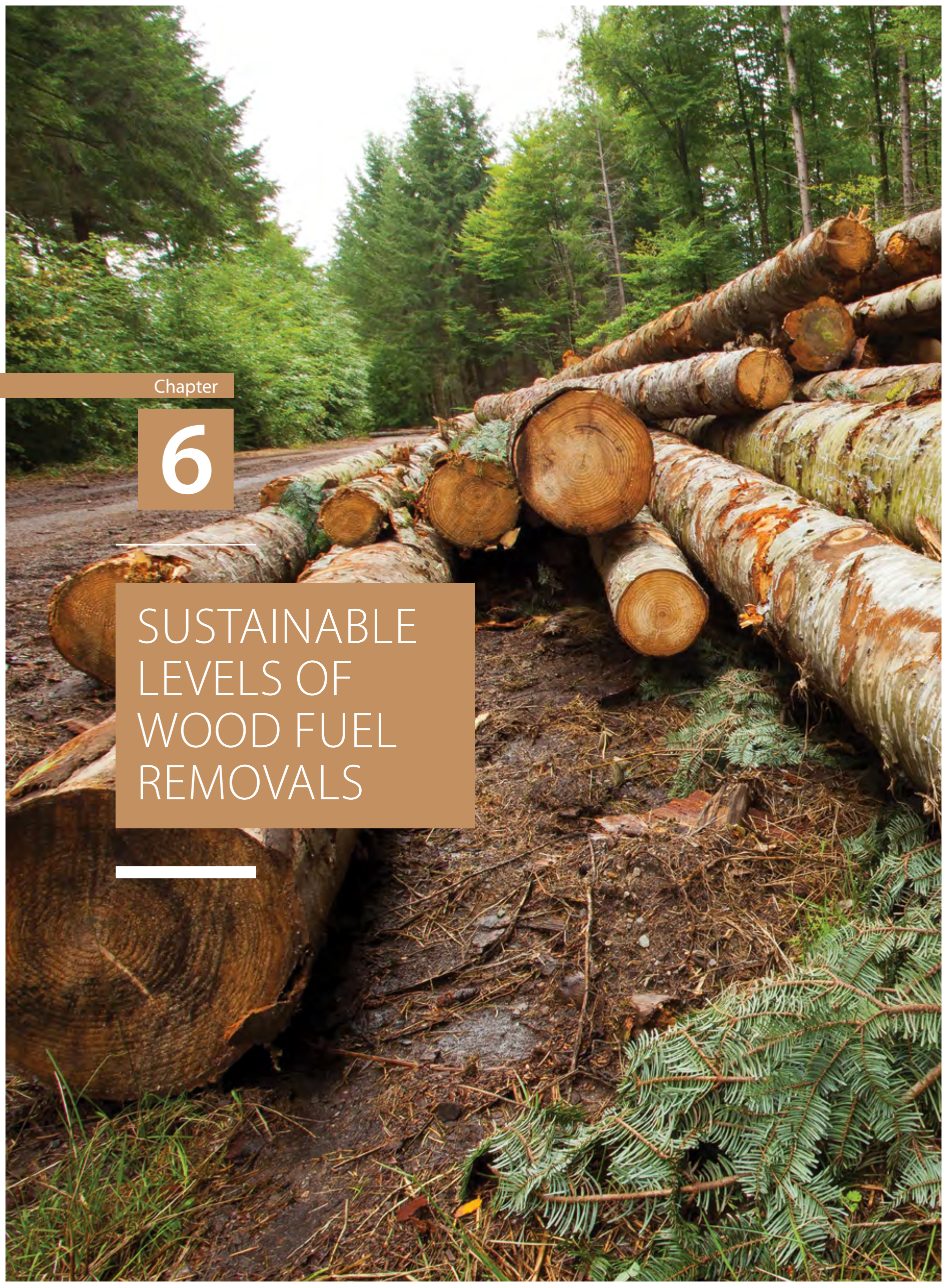




\section{Highlights*}

* Wood fuel removals can offer important ecological, economic and social benefits if forests are well managed.

* Forest management guidelines for the direct supply of wood fuel may recommend excluding areas from harvesting and offer science-based strategies to ensure sustainable removals.

* Exclusion of sensitive sites and limiting removal levels of wood for energy is important in order to mitigate potential adverse impacts.

* Wood for energy best management practices (BMPs) have been developed to protect soils, water quality and wildlife habitat.

* Forest inventory data offer fundamental information to evaluate maximum levels of wood energy removal at different procurement scales.

* Local, national and international assessments give valuable information to guide public policy as well as private sector investment decisions. 


\subsection{Introduction}

Procurement of wood for energy projects can be an integral element of sustainable development efforts. However, removal of wood fuel can have adverse impacts. Adverse impacts might occur within the lands from which wood energy feedstocks are removed but also off-site. For instance, excessive wood removals can lead to deforestation, degradation and biodiversity losses, depletion of nutrient stocks, and deterioration of soil quality. Off-site impacts might be associated to erosion and consequent effects on water quality. Aggregate impacts of mismanagement of forests can have larger landscape effects that could imperil forests' wildlife habitat functions.

This chapter discusses sustainable removal levels of wood fuel directly sourced from forests and tools implemented to ameliorate impacts and assess availability for wood energy projects. Other steps along the wood energy supplychain beyond harvesting (e.g. processing, transportation, conversion and use) are outside the scope of this chapter. We start by defining common types of wood fuel sourced directly from forests and defining various sustainability elements regarding harvesting. We offer examples of extant guidelines for harvesting wood for energy implemented by forest operations at a parcel or stand level. Best-management practices (BMPs) are offered for implementation within extant legal frameworks using the best available science. Recent local, sub/national and regional assessments of wood fuel sustainable harvesting potential are presented to illustrate the use of forest inventory data to gauge forests' capacity to support wood energy projects. A few management examples are offered to illustrate advanced and established systems operational at an industrial scale.

\subsection{Wood fuel directly sourced from forests}

Wood fuel originates from various sources and can be processed into many different forms. In this chapter we concentrate on wood fuel directly coming from forests often referred to as direct or primary wood energy sources. In many areas across the UNECE region these wood fuel sources have little to no market value and their management can offer important prospects toward healthier forest ecosystems. In this context, direct wood fuel sources exclude assortments currently used by other sectors of the wood product industry or recovered at the end of products' life cycles. The main sources considered in the chapter are:

- Logging residues or slash. Crown biomass (branches and leaves or needles) and stemwood loss (nonmerchantable timber, under-sized tops and small-sized stems). Logging residues are typically harvested from final fellings. Types of logging residues can vary from branches to timber-size stems or stem parts.

- Small-diameter trees. Small-diameter trees from thinnings are often removed as part of integrated operations co-harvesting other wood products. These include trees too small for material wood product use removed in a thinning operation to improve the remaining forest stock or as a fire control practice. This type of direct wood fuel may include some trees fulfilling the size and quality demands for material wood product use, when a separate harvest for other segments of the wood products industry are not economically feasible. Small-diameter trees can be harvested as whole trees or delimbed. In an integrated harvest wood fuel and industrial roundwood are co-harvested from the same stand.

- Stemwood. Stemwood is not suitable for other non-energy industrial processes due to undesirable characteristics (e.g. dimension, species, mechanical defect). Stemwood meeting the requirements for feasible use by the material wood products industry might be included in this category if no local demand exists.

- Stumps. Wood from stumps and roots from final harvesting.

Prevalent management systems and local markets, among other factors, may result in some, none, or all of these direct sources being available to supply wood fuel. Within the UNECE region these types of direct wood fuel are commonly recognized as eligible wood fuels toward meeting renewable energy goals and under sub-regional and national programs (e.g. European Union's fuel standards, US Department of Agriculture's Forest Service definition for woody biomass). In the case of the EU fuel standards these feedstocks fall within the category 'forest, plantation and other virgin wood' which can be further broken down into whole trees (with or without roots); stemwood; logging residues; stumps and roots; bark (from forestry operations); segregated wood from gardens, parks, roadside maintenance, vineyards and fruit orchards; and blends and mixtures of the above-mentioned (International Organization for Standardization, 2014).

\subsection{Management for sustainable sourcing of wood energy}

Wood energy projects can be an integral component of sustainable development objectives as they aim to achieve long-term and lasting positive social, environmental, and economic impacts. The World Commission on Sustainable 
Development report in 1987 and the United Nations Conference on Environment and Development in 1992 identified three dimensions encompassing sustainable development: economic, environmental and social. Cultural values are also very important to consider, especially in communities where wood energy is central to vital and thriving livelihoods.

- Social: The production and use of bioenergy can benefit communities and supply-chain stakeholders. Direct benefits are both economic and social because of employment associated with wood energy projects (Borsboom et al. 2002). Bioenergy systems may influence the number and quality of local jobs and have profound influence on households' and communities' wellbeing through accessible and affordable energy (FAO, 2010). Social considerations might limit harvesting of feedstocks that have impact on aesthetic values. For instance, harvesting of stumps on flat terrain may have limited adverse ecological impacts in some areas (in others with steep slopes, ecologically-sensitive sites, and close-to-nature-managed forests stump harvesting is not recommended), but aesthetic social preferences can call the sustainability of this practice into question.

- Environmental: Assessments of sustainable wood removal levels should rely on inventory-based information to identify forest stands suitable for wood fuel removal (or for integrated removal for industrial and energy use), and on constraints on the amounts to be removed. These constraints are often reflected in written practical guidelines. Harvesting guidelines identify limits to the quantity of biomass harvesting at the site and landscape level and may even indicate areas where no wood fuel harvests should occur.

- Economic: Bioenergy projects need to be economically feasible for their long term viability (Lunnan et al. 2008). The reliable supply of wood fuel at competitive procurement costs (e.g. after fixed and variable costs) is critical for all wood energy projects. Hence, wood fuel supply assessments using the best-available science are instrumental to bioenergy projects.

Extant guidelines for harvesting wood fuel generally aim to avoid or mitigate potential detrimental effects of its removal. They offer specific instructions on harvesting outcomes and on particular methods. Notably, BMPs are not mandatory across the UNECE region, but following them may be a pre-requisite for certification by third-party environmental programs. Thus, BMPs are commonly followed in commercialscale operations. Guidelines have been developed for a few specific forest types and even site levels based on the dominant forest type and soil conditions. Next, we offer BMP examples based on management of boreal and temperate forests and the establishment of mixed production systems. These examples come from Finland, the US, Belgium and France.

\subsubsection{Management of boreal forests: Finland}

In Finland, BMPs for sustainable forest management are widely implemented (Äijälä et al. 2014). In addition, specific BMPs have been developed for the harvesting of wood fuel (Koistinen et al. 2016). These guidelines were drafted following a participatory process with different stakeholder groups inclusive of government authorities, entrepreneurs, forest owners, industry, non-government agencies, and researchers. BMPs provide forest managers alternatives for wood fuel harvesting to select the ones better matching particular management objectives. Wood fuel BMPs start by describing the framework and general instructions for protecting nature. These are followed by detailed instructions for harvesting wood energy from timber harvests as well as for storage, quality control and work safety.

Quantitative constraints are very useful to gauge sustainable harvesting levels. For example, whole tree harvesting is not recommended on mineral soils classified as sub-xeric (or weaker), on peatlands with corresponding low nutrient levels, and on mineral soils where the share of Norway spruce (Picea abies) is over $75 \%$. On sites suitable for whole tree harvesting it is recommended that $30 \%$ of original crown biomass is left on site. The aim of these constraints on wood fuel harvest is to decrease the impact due to nutrient removal. Correspondingly, harvesting of logging residues and stumps is not recommended on nutrient-poor sites (Figure 6.1). A rule-of-thumb for economically viable harvesting is given: the removal of industrial roundwood of a marked stand should be

\section{FIGURE 6.1}

\section{Logging residue piles on a harvesting site in Finland}

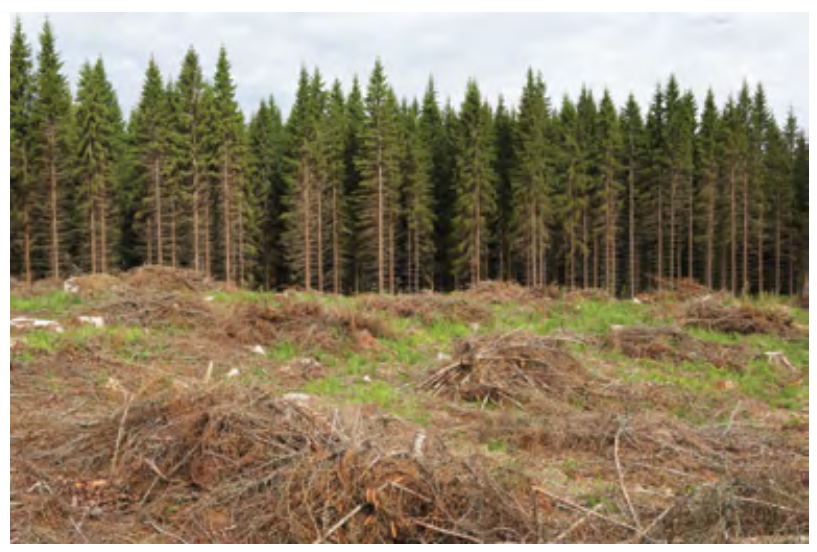

Source: Erkki Oksanen. 
over $200 \mathrm{~m}^{3}$, the area at least 2 hectares and the forwarding distance not longer than $300 \mathrm{~m}$. It is recommended to leave at least 25 stumps per hectare on common sites (at least 50 stumps per hectare on sites with clay and silt soils) in order to diminish the impact of stump removal on biodiversity and to maintain soil productivity. Additionally, all decayed stumps and stumps smaller than $20 \mathrm{~cm}$ in diameter should be left on-site. Buffer zones are necessary to protect watersheds. The width of a zone depends on the type of a water body (e.g., pond, lake, brook), slope and soil type. Private forest certification programs such as PEFC and FSC require buffers of 5-10 m and 10-30 m, respectively. BMPs clearly indicate whether a certain guideline is recommended or required by legislation or by private certification systems.

\subsubsection{Management of temperate forests: US}

Management strategies to supply wood fuel from temperate forests have been adapted from traditional silvicultural guidelines. In some regions of the US specific guidelines have been developed to mitigate potential site degradation associated with removing large quantities of woody material previously left on-site (Shepard, 2006). In all cases, removals are limited to lands not restricted from commercial harvesting by protective status. In the US, the Department of Agriculture's Forest Service differentiates timberland as a type of forest land not withdrawn from commercial harvesting by statute or administrative regulation (Smith et al. 2009). For example, forest lands within habitats protected under the Endangered Species Act of 1973 are not classified as timberland, hence they are excluded from any type of commercial operations inclusive of wood fuel harvests.

Quantitative constraints in BMPs for wood for energy include provisions for soil stability, water quality, wildlife habitat and biodiversity (Lattimore et al. 2009). A primary constraint for wood fuel removal is a set retention rate of material that needs to be left on site following a harvest, which varies by region and state. For instance, the state of Pennsylvania's guidelines call for 15-20\% retention while Missouri's guidelines call for 33\% retention (Perlack et al. 2011, Figure 6.2). Minnesota and Wisconsin guidelines suggest avoiding woody biomass harvesting all together in areas with sensitive plant or animal habitats, ranging from certain riparian management zones to areas with shallow soils with Aspen (Populus tremuloides) or other broadleaf tree cover types. A common constraint across state guidelines is the widening of riparian zones with increasing slope, usually calculated as a percentage width increase above a standard base width (e.g. 20 m).

\section{FIGURE 6.2}

\section{Common best-management practices in US temperate forests require maintaining a minimum of harvest residue on-site}

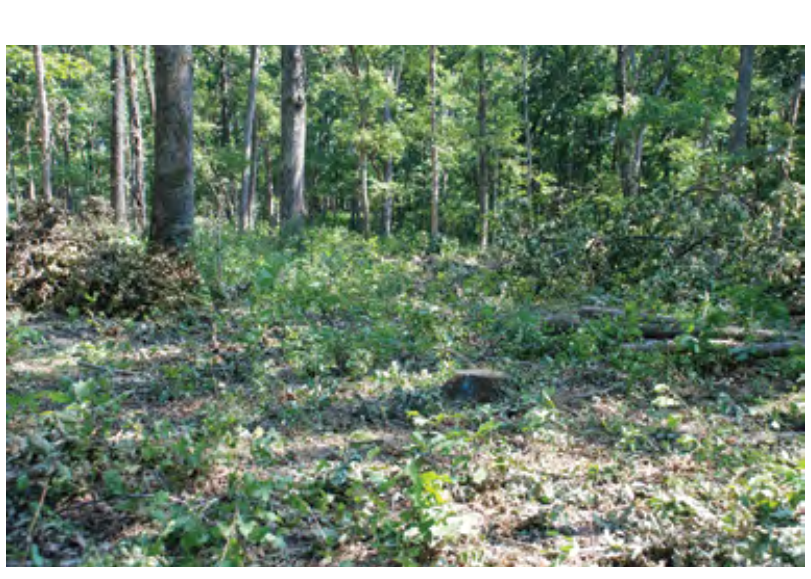

\subsubsection{Dedicated and mixed production designs: Belgium and France}

Belgium and France illustrate a trend in many European countries where private forest ownership is dominated by small parcels in a fragmented landscape. These conditions might make traditional tree harvesting cost-prohibitive and limit the ability to supply adequate amounts of wood fuel. Mixed timber-energy production systems relying on poplar (Populus spp.) plantations could help satisfy market demands while maintaining key ecological functions and cost considerations. The objective of the mixed system is to simultaneously produce sawlogs for the plywood industry and wood for energy for energy in sufficient quantities over time periods of less than 15 years. Systems might be established with a 160 tree/ha density but it might be increased to 500 trees/ha to augment yield and simplify pruning.

Poplars in experimental plots in Belgium and France can be harvested after 12 to 14 years when their diameter-at-breastheight has reached 30 to $35 \mathrm{~cm}$. Traditionally poplar trees are harvested at age 22 to 30 . The first 5-meters of the stem can be harvested for their fibre (e.g. for plywood manufacturing) and the top of the tree is processed into chips that can be used for energy. Small branches (less than $8 \mathrm{~cm}$ in diameter) are left on site to conserve soil nutriments and to meet private certification (e.g. FSC, PEFC) requirements. During the rotation it is possible to maintain a natural small-diameter trees and shrubs coppice under the poplars to improve biodiversity. This coppice can also be thinned just before the poplars final cut.

Although still at a non-commercial experimental scale (4 ha) these systems show promise to meet multiple objectives. Many owners and forest managers hope to enter the 
FIGURE 6.3

\section{Mixed production design with Poplar trees, providing 5 meter-long high-grade logs and tops chipped for energy use}

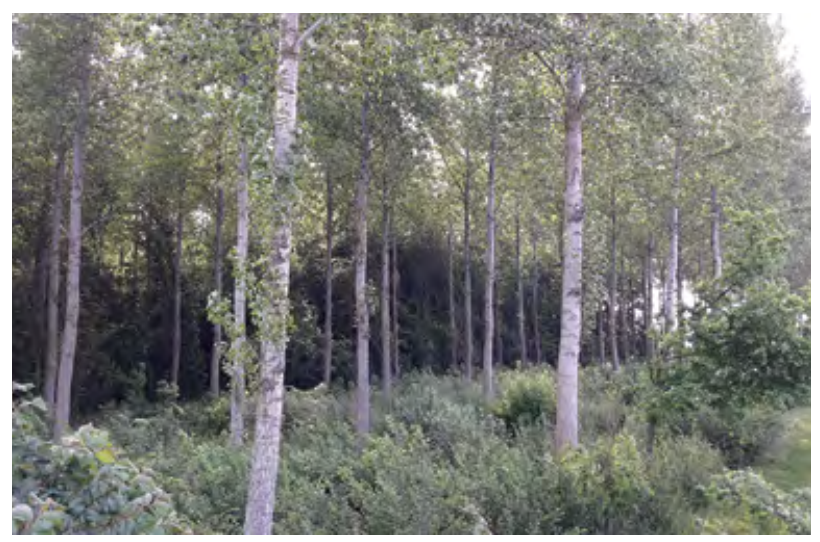

wood energy market but without seeing part of their forest converted to a short rotation crop. This mixed production system could allow forest owners to supply traditional timber markets while expanding to the energy sector and preserving landscape and biological functions.

\subsection{Assessments of sustainable wood energy feedstocks}

Ensuring adequate supply of feedstocks is a critical step for any energy facility considering wood energy production. Moreover, information on sustainable removal levels is necessary to guide public policy decisions that might create incentives to promote wood energy generation. Assessments of sustainable levels of wood for energy supply offer critical information to public and private sector decision makers and should include:

- How much wood for energy is available?

- What kind of materials do feedstocks include?

- Where are they located?

- Are travel distances cost-prohibitive?

- What is the cost of delivered wood fuel at the energy facility?

- How much of the resource is socially and economically available?

- How does this availability fluctuate over time?

Wood fuel assessments vary depending on geo-political scale. Estimations at national and international scales can show markedly dissimilar potentials due to geographical coverage but also due to differences in approach, methodology, data, timeframe and measurable units. Vis et al. (2010) offer an attempt to harmonize assessments of biomass resources. Next, we give examples of assessments of sustainable harvesting potentials at individual facility, sub/national and regional levels.

\subsubsection{Individual energy facilities}

Assessments for the availability of wood energy feedstocks are critical to determine the feasibility of siting bioenergy facilities relying on locally-sourced materials. An approach to assessing wood energy feedstocks for an individual facility is illustrated by the city of Kokkola Combined Heat-and-Power (CHP) plant in Finland. The nominal heat power of the CHP plant totals 96.5 MW and its nominal electric power $35 \mathrm{MW}$. Due to intense wood energy feedstocks competition the company has sought additional supply sources. At the same time, the Finnish State Forest Enterprise is in need for opportunities to utilize abundant small-diameter trees in the Kainuu province. Nivala et al. (2015) assessed the potential and costs of supplying small-diameter trees from Kainuu to Kokkola to generate bioenergy (Figure 6.4).

The estimation of the technical harvesting potential for wood fuel at the municipality level from young forests in the province of Kainuu was based on the national forest inventory (NFI) data. Six steps were followed to complete the assessment:

1. NFI sample plots were selected for which the development class was 'young thinning stand' and the proposed next management operation was 'first thinning during the next five years after inventory.' For each of the sample plots selected, the removal of stemwood was calculated by simulating thinning in accordance with established silvicultural guidelines (Metsätalouden kehittämiskeskus Tapio, 2006). Two separate estimates of biomass potential (whole trees and delimbed stemwood) were derived since harvest methods affect the amount of wood fuel removed and related costs.

2. Removal feasibility and sustainability considerations were factored in by imposing the following constraints to select eligible plots: (1) Harvesting of whole trees was simulated only for plots on fertile soils and on other than sprucedominated plots with mineral soils to avoid nutrient depletion; (2) Technical recovery rate (i.e. the proportion of the biomass harvested delivered to the power plant) was assumed at 90\% for whole trees and 100\% for stemwood; (3) Removal of wood for energy should be at least $25 \mathrm{~m}^{3}$ per hectare - this equates to about one truckload from a one-hectare stand.

3. The proportion of forests suitable for wood fuel harvesting in the province of Kainuu was calculated. The area represented by the selected plots was divided by the total area in the development class 'young thinning stand' 


\section{FIGURE 6.4}

\section{Location of the power plant, the intended supply region and the supply-chain network}

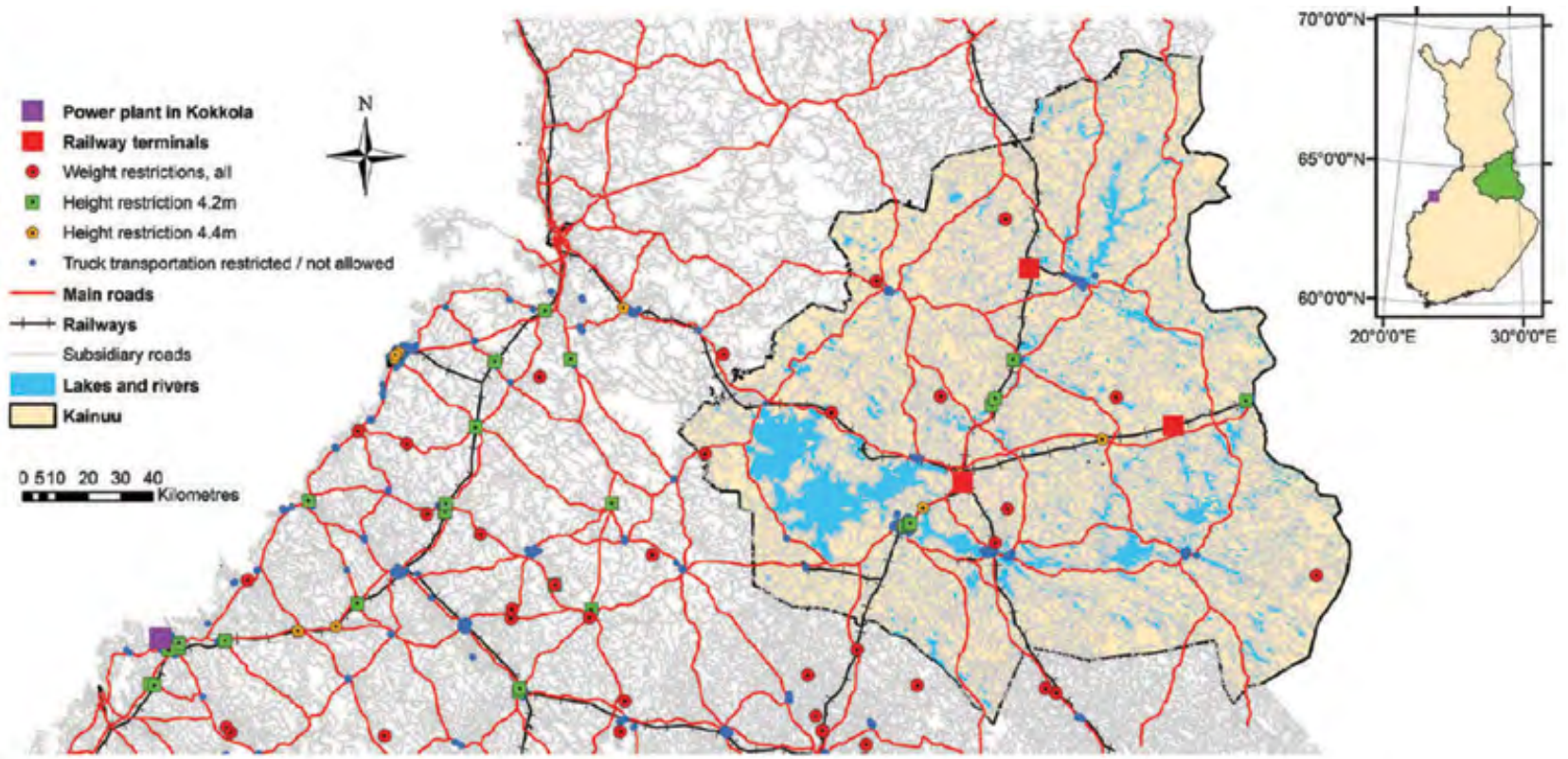

Source: Nivala et al. 2015.

in Kainuu. Subsequently, this proportion was assumed to be constant across all municipalities in Kainuu. The reason for this operation was that the areas represented by the selected plots could not be directly used at the municipality level, on account of the low number of NFI plots.

4. The area of suitable forests in each municipality was estimated by multiplying the area in the 'young thinning stand' development class in a municipality by the relevant proportions.

5. The average removals of whole trees and stemwood per hectare were calculated for the entire province.

6. The technical potentials were obtained by multiplying the average removal by the area of suitable forest land for each municipality.

Some of the estimated supply potential is already being used by households and the energy and forest industries. In the study, it was assumed that the current supply of smalldiameter thinning wood used for other purposes would not be available to the Kokkola power plant. Consequently, the existing consumption was subtracted from the technical potentials to estimate the potentials available.

Altogether nine different supply chains were selected to be compared in terms of costs. For each of these chains the supply costs were assessed by summing the cutting and transport costs for all supply points. The supply costs of three selected supply chains are presented in Figure 6.5. The results showed that the biggest trucks (e.g. 76-tonne trucks) provide a solution that is price competitive with train-based supply-chains offering the least costly alternative. Moreover,

\section{FIGURE 6.5}

\section{Selected cost-supply curves for supply from Kainuu to Kokkola}

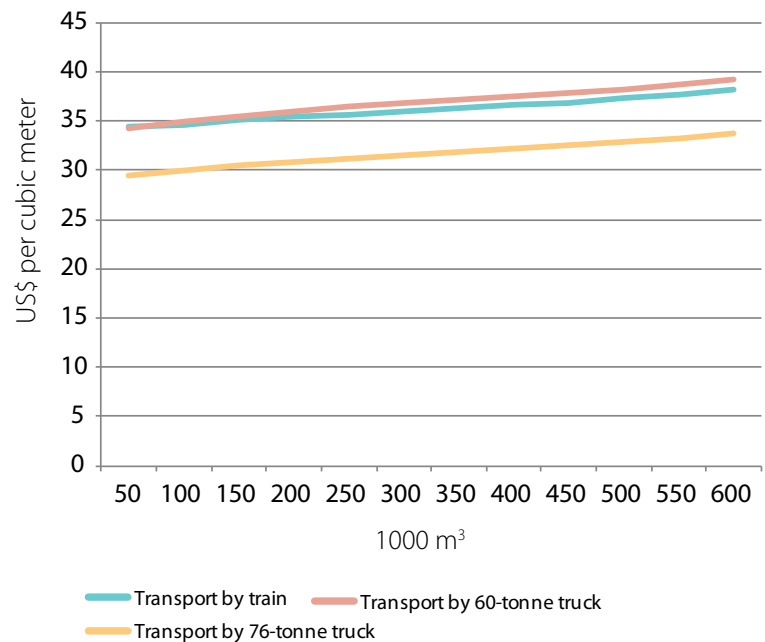

Source: After Nivala et al. 2015. 
the availability of wood from thinnings is greater when it is collected in whole-tree form compared with stem-only harvesting but at the expense of higher supply costs.

\subsubsection{Sub-national / National-level}

Neither the potential nor the demand of wood fuel is evenly distributed over the landscape. Therefore, wood fuel balances have been calculated for Finland (Nivala et al. 2016). The balances are defined as the remainder of spatially-explicit potential supply and current demand.

Spatially-explicit technical wood for energy potentials were based on NFI data. The estimation of technical potentials for small-diameter trees was described in 6.4.1. However, as the sustainable removable levels of logging residues and stumps depend on the harvest levels of industrial roundwood, two different scenarios for harvest levels were assumed: (1) Maximum sustainable removal and (2) realized cutting removals. For both scenarios, the amount of biomass from tree crowns and stump wood from final removals constituted the theoretical potential. The technical potential was obtained by leaving out biomass on nutrient-poor sites and by applying technical recovery rates on the remaining volumes (Koistinen et al. 2016). For logging residues the applied recovery rate was $70 \%$ and for stumps $82-84 \%$. Subsequently, the potentials were distributed to municipalities proportionally to their share of mature forests. The final step to make the potentials spatially-explicit was to distribute the potential of a municipality evenly on the forest land available for wood supply.

The spatially-explicit demand map was derived from the plant database including all the heat and power plants using wood fuel as of 2012. The database was further supplemented by adding future plants which already had been planned for establishment. Next, the national target of 13.5 million m3 in 2020 was distributed to all the plants by considering individual maximum capacity. After this, concentric supply circles for each plant were drawn, the number of which depended on the realized or estimated demand of wood fuel and distributed the demand on the supply circles. Finally, overlapping supply circles were aggregated. These steps resulted in demand maps for 2012 and 2020 for the three selected wood fuel feedstocks.

The balance maps revealed a geographical mismatch between the potential supply and demand (Figure 6.6). Even if the harvests of industrial roundwood rise to the maximum sustainable level, we anticipate demand hot spots in Southern Finland and on the Bothnian Bay. On these hot spots expected demand would exceed potential local supply. On the other hand, the darkest green areas on the maps indicate where the technical potential in relation to competition would be the highest. From the point of view

\section{FIGURE 6.6}

\section{Spatially-explicit, sustainable levels of removal of logging residues $\left(\mathrm{m}^{3}\right.$ per $\mathrm{km}^{2}$ per year) in 2012 and 2020 after taking competition into consideration}
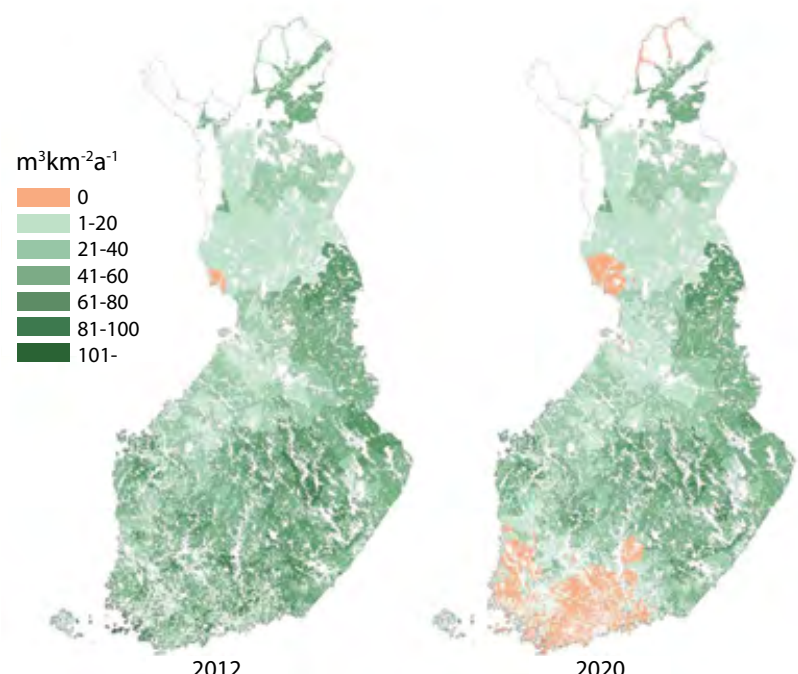

Note: The maximum sustainable removal level of industrial roundwood has been assumed. Brown-colored areas are where expected demand exceeds estimated potential.

of technical potential these would be attractive areas for new installations. However, further analyses would be needed to confirm the economic viability of particular locales.

Other inventory-based methods can be found in other UNECE member States. For instance, Aguilar et al. (2012) and Goerndt et al. (2013) describe methods using the US Department of Agriculture's Forest Service Forest Inventory and Analysis (FIA) Program plot data to establish localized wood for energy estimates within defined procurement areas for energy facilities. Fixed FIA plots provide estimates of stem, stump and limb wood which can then be expanded to county- or supply area-level design based estimates with coinciding summary statistics.

Multi-scale estimates derived by Goerndt et al. (2013a), Aguilar et al. (2012), Goerndt et al. (2013b), and Goerndt et al. (2015) bypassed consideration of stand-level forest wood for energy availability due to the use of a national systematic sampling design. As such, estimates were derived by directly expanding plot- to county-level estimates. However, these can have a high degree of error depending on the number of inventory plots residing in each county. Supply within procurement areas can be derived using resource density and harvest feasibility information for which available wood fuel was examined from: (1) small-diameter trees, (2) tops and limbs, and (3) whole tree. Areas with the largest wood 
fuel availability base can be identified through localized estimation and mapping.

Estimation of available wood fuel in supply areas requires multi-scale analyses with consideration of supply area shape, existing local users of wood, and overlap of supply areas. Assessment within circular supply areas is a common assumption in estimating available wood energy feedstocks, due to the radial nature of transport from forest site to facility. In studies such as Goerndt et al. (2012) and Goerndt et al. (2015), wood fuel estimation for supply areas consists of a weighted estimate of county-level direct wood fuel tonnage per hectare between counties intersecting the supply area which is then applied to the total supply area. To estimate annual availability of wood fuel within supply areas, Goerndt et al. (2013a) set limitations for wood for energy removal depending on procurement regime, applicable BMPs and specific ecological concerns. This was necessary due to concerns of sustainable use of forest resources over time. For harvest residues, a residue retention rate of 35\% was applied to estimates to account for average retention rates recommended by various BMPs (Perlack et al. 2005).

Transportation distances are mostly a function of incremental and fixed costs of processing and hauling wood for energy. Important cost considerations for calculating final delivered costs of wood for energy include (when applicable), procurement distance, harvest operational costs, incremental transport cost, stumpage prices and chipping/grinding cost (Goerndt et al. 2013). These costs estimates serve to determine the limiting distance of wood fuel transport as compared to the delivered cost of coal as an alternative energy source identified by power plant managers as a primary limiting factor to choosing wood fuel as a power source (Goerndt et al. 2013b).

In 2012, the co-firing potential using wood fuel was estimated for supply areas around individual power plants in the U.S. Northeastern corner (quadrant delimited by states of Maine, Maryland, Missouri and Minnesota). The analysis included three procurement regimes: logging residues, small-diameter trees, and integrated harvesting (combination between the first two regimes). Concentric supply circles were assessed around each selected power plant using county-level estimates of forest wood for energy from each regime with varying procurement radii. Transport costs for each regime were estimated using estimates of incremental (per km) costs and fixed costs. The final assessment identified which power plants could potentially generate the most electricity annually from wood for energy after accounting for transport costs and resource availability. Resulting directly sourced wood fuel was linked to procurement costs (US\$/tonne) based on incremental and fixed cost assumptions. The resulting analysis of the procurement regimes and supply areas (Figure 6.7) indicated that with no competition from

\section{FIGURE 6.7}

\section{Estimated mean annual electricity generation for selected power plants by procurement regime and transport distance}

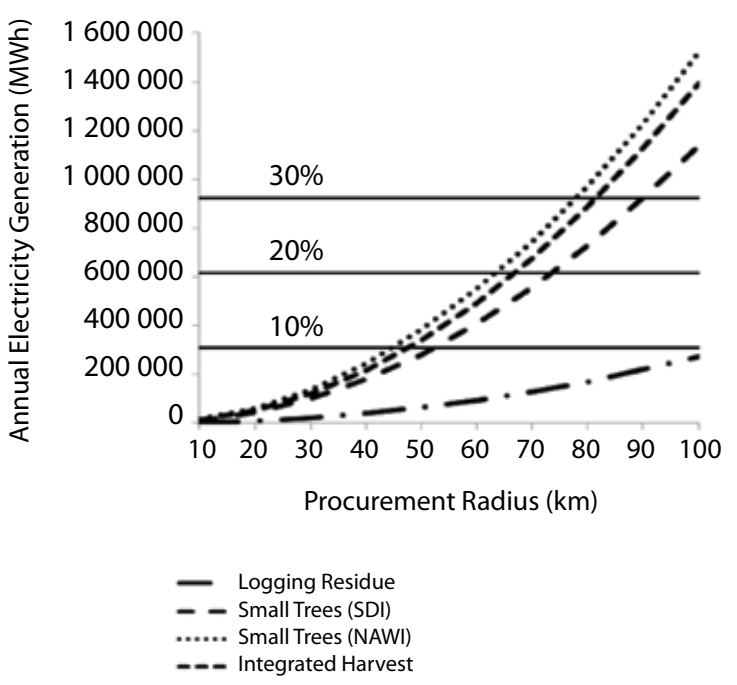

Note: Percentages of mean annual coal electricity generation (MWh) from selected power plants are shown as horizontal lines and labeled separately.

\section{FIGURE 6.8}

\section{Estimated potential percentage of annual coal electricity generation that could be replaced by logging residues for each selected power plant at a $60 \mathrm{~km}$ concentric procurement radius}

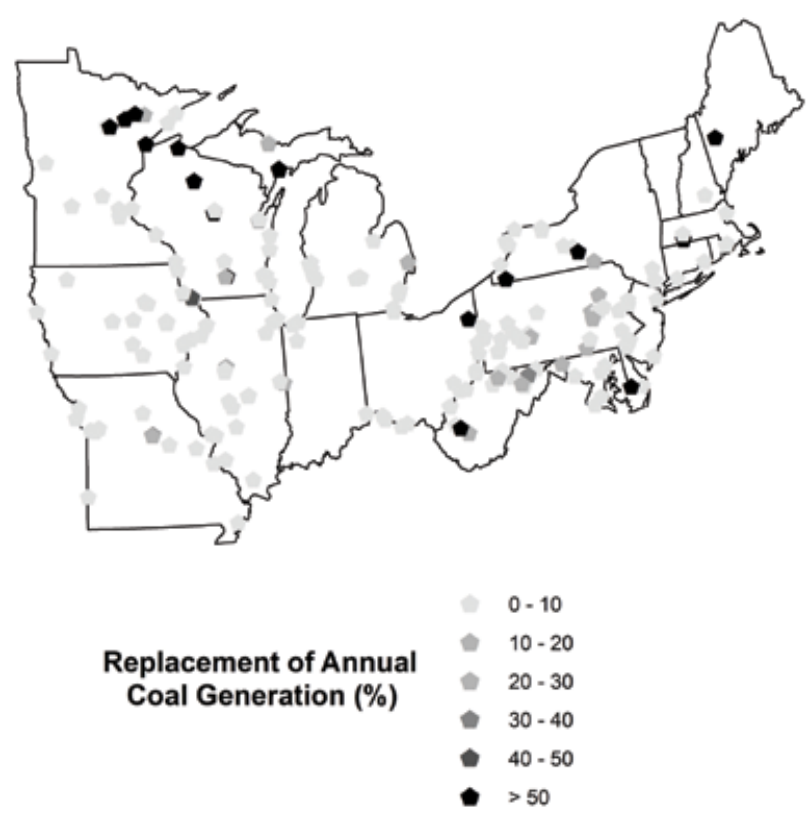


adjacent power plants, small-diameter tree removals could potentially result in wood energy production equal to $30 \%$ of current coal electricity output (Figure 6.8).

In U.S. applications using FIA data, the spatial data resolution is typically fixed across the entire country. One of the main constraints is fluctuation in data quality from state-to-state. For example, there are certain U.S. states that do not remeasure FIA plots as frequently as others, or do not measure the same variables. In such cases, it is necessary to depend on state-level estimates of wood for energy or to at least assume uniformity of the wood for energy resource over large areas as noted in Aguilar et al. (2012). The US Department of Energy (2016) has assembled county-level availability of forest resources, which shows both the scale of availability and limitations of fine-scale national-level data. Figure 6.9 shows the availability of logging residues across the U.S.

County-level estimates of harvest residue availability shown in Figure 6.9 were projected for 2017 assuming high energy demand, moderate housing demand, and an average price of US $\$ 60 /$ dry tonne for residue material. These estimates also account for current timberland harvest rates and trends in roundwood market. The increases of residue availability on the map directly coincide with the areas of the U.S. with the highest volume of existing forestland. However, there are many counties with insufficient forest industry data to provide such estimates. Availability of data by county for availability of wood for energy and other forest products varies by source of material and assumptions regarding demand and utilization of forest products (US. Department of Energy, 2016).

A study by Goerndt et al. (2014) assessed the national-level availability of wood fuel for biopower generation in the U.S. using a multi-stage approach. The first stage was an extension of the logistic modelling strategy employed by Aguilar et al. (2012) to determine which counties in the U.S. have the highest potential for co-firing with forest wood for energy. As such, the modelling approach by Goerndt et al. (2014) utilized electricity industry internal, external, and locationspecific factors as well as wood for energy resource-based variables as co-variates. The model identified counties in the U.S. with high potential for co-firing based on the constraints of the model and data available. However, it was determined that such an analysis was not suited to a national scale due to inconsistent data sources at the national-level and a high degree of generalization for key factors, both industry-based and resource-based. Results of this analysis resulted in the overall assessment being scaled down to only the Eastern half of the US (Figure 6.10).

Subsequent to determining which states hosted a large number of counties with high potential for co-firing, FIA data were used for state-level assessments of wood fuel resources available for co-firing. The coarser spatial scale of the analysis allowed for delineation of several wood fuel

\section{FIGURE 6.9}

\section{County-level estimates of harvest residue availability for bioenergy (dry tons) for 2017}

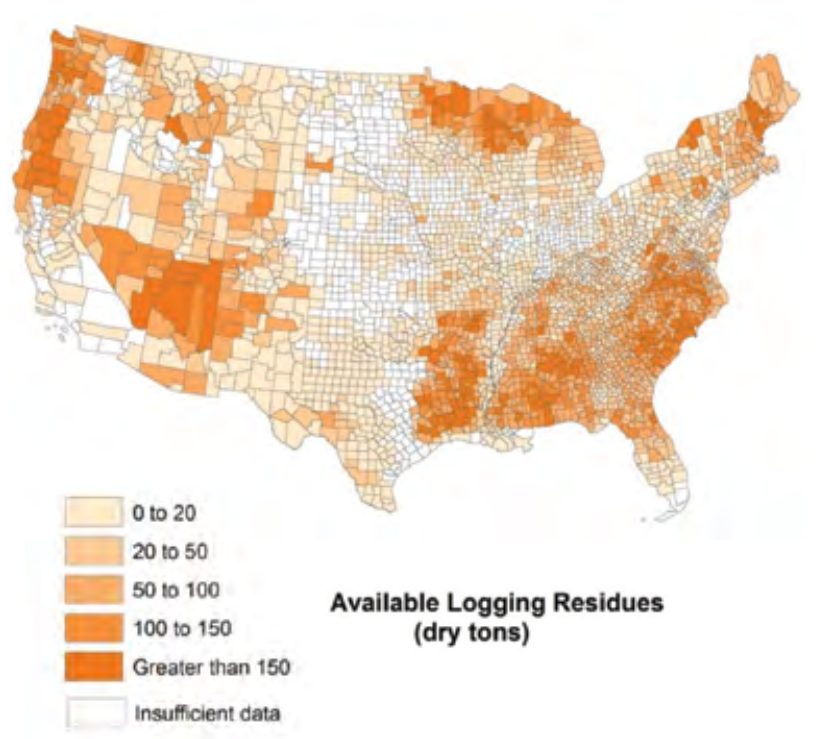

Source: U.S. Department of Energy, 2016.

\section{FIGURE 6.10}

\section{Quantity of available biomass feedstocks in the Eastern U.S. and proportion of total availability by component}

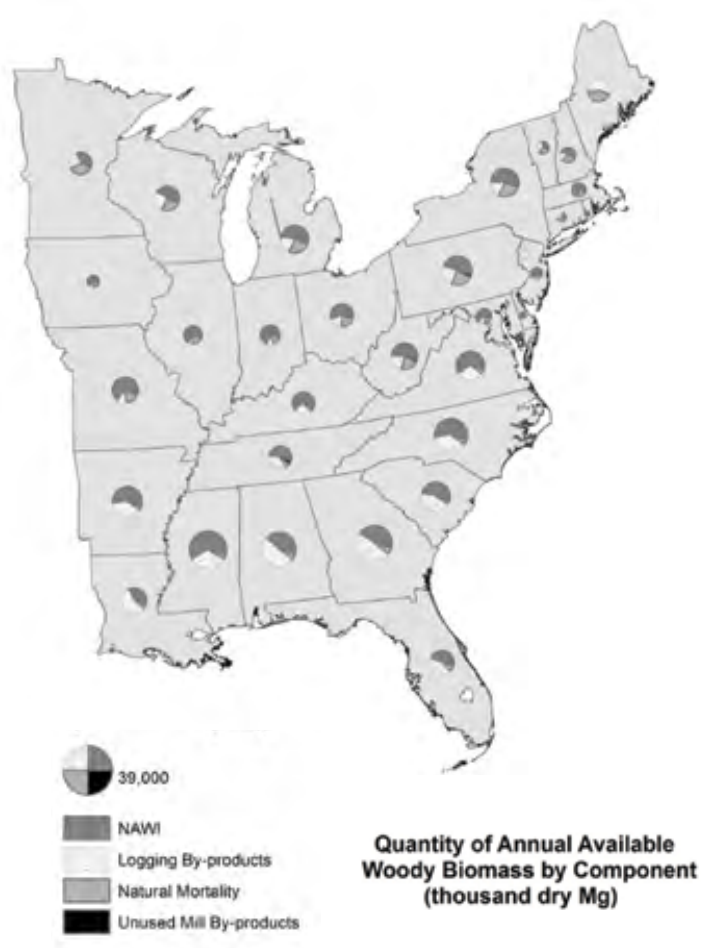


sources including: net annual woody biomass increment (i.e. grow in aboveground forest biomass net of current removal levels), logging by-products, natural mortality, and unused wood mill residues. Estimates show there is ample variability in wood fuel availability across selected states but data consistently show wood fuel would largely come from net annual woody biomass increment and logging by-products, with the potential to also source material due to natural mortality.

\subsubsection{Regional and International Scale}

Comparison of sustainable harvesting potentials between countries poses additional challenges compared with sub/ national and plant-level assessments. Because of different forest inventory systems the quality of input data varies. Measurement units can also differ from country to another. Attempts to estimate potentials in a harmonized manner at international scale are ongoing.

In Europe, the EU's 7th Framework Programme financed project S2Biom (Delivery of sustainable supply of nonfood biomass to support a "resource-efficient" Bioeconomy in Europe) to estimate biomass potentials for the EU28, Western Balkans, Moldova, Turkey and Ukraine at subnational level (S2Biom, 2017). Scenario modelling was used to calculate wood fuel potentials based on NFI data of each country (Dees et al. 2017a). A number of scenarios with different constraints were run for years 2012, 2020 and 2030. The Technical potential was described as the maximum amount of lignocellulosic biomass in forests available for wood supply that would be potentially available for energy use with minimum constraints. Additional constraints corresponding to sustainability standards were applied to the Base potential. These included limits on logging residue and stump extraction considering site productivity, terrain ruggedness, soil depth, soil surface texture, soil compaction risk, biodiversity, recovery rate and soil bearing capacity. In addition nine other scenarios of potential were defined with varying assumptions regarding the area of forests available for wood supply, recovery rate and the consideration of competing uses.

In the Base scenario, the potential supply of woody biomass (including roundwood) in the 37 countries included in the 2012 assessment was estimated at 728 million $\mathrm{m}^{3} \mathrm{yr}^{-1}$ (Dees

\section{FIGURE 6.11}

\section{Screenshot of the publicly available viewer of biomass potentials in Europe}

\section{S2Biom Tools for biomass chains}

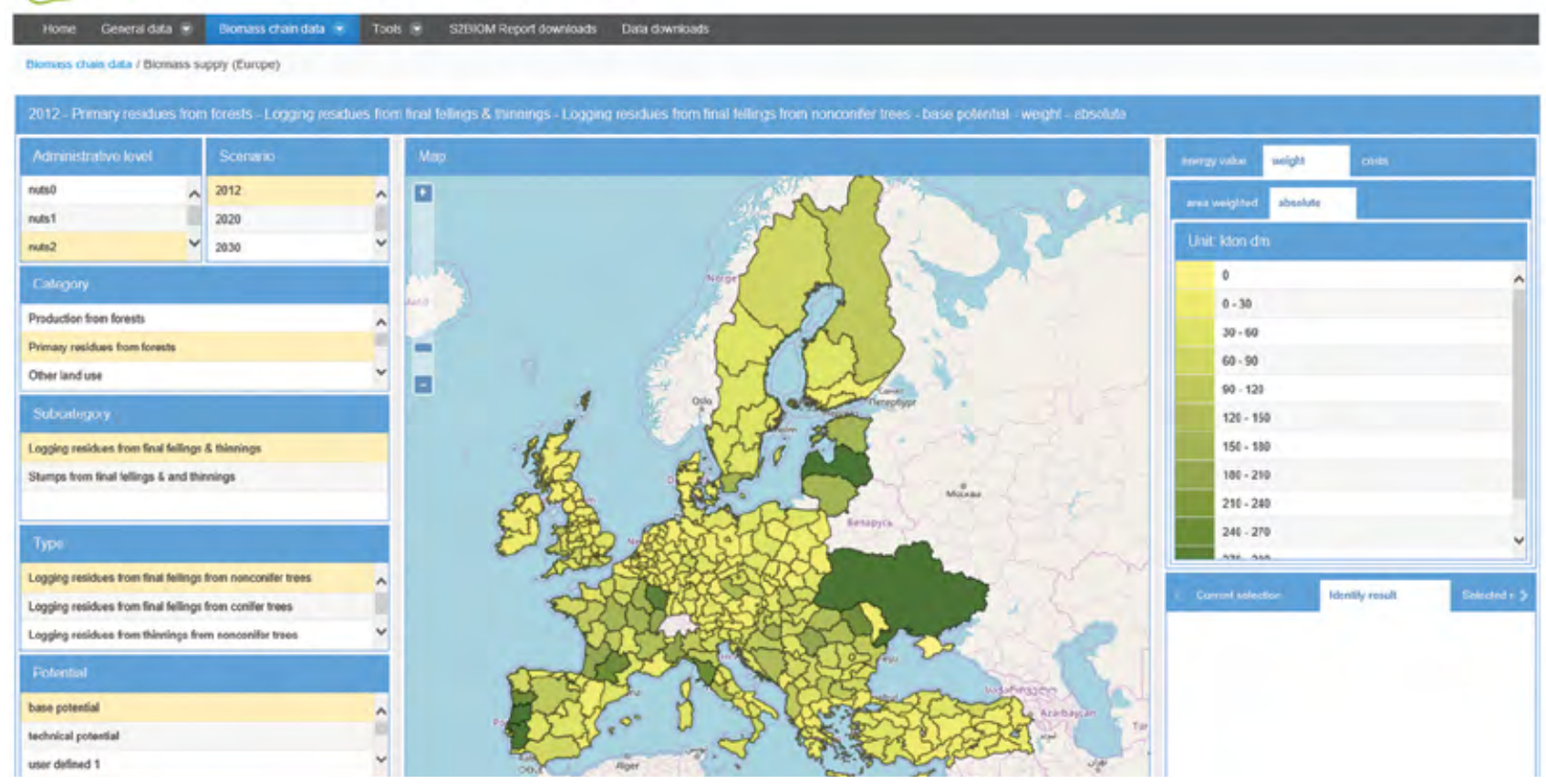

Note: The user can select, e.g., the scenario on intensity of bioenergy utilization, time frame and biomass category for which the potentials will be presented.

Source: S2Biom, 2017 
et al. 2017b). Of this roughly one-third would be unused after subtracting roundwood production reported by FAOSTAT. Supply costs were estimated up to the roadside including chipping or crushing, but excluding road transport and production costs. The methodology of cost estimation consisted of two main components: (1) the estimation of hourly machine costs, and (2) the estimation of work productivity. In order to enable better comparison of costs between sub-regions, supply chains were standardised. Generally, the supply costs in Eastern Europe tend to be lower than elsewhere in the study area. This can - at least to a certain extent - be explained by lower investment, fuel and especially labour costs.

All biomass potentials and supply cost estimations are publicly available through a web-based platform (www.biomass-tools. eu). In addition to viewers for potentials (Figure 6.11) and cost-supply curves, the platform includes a few other tools for matching biomass type with conversion technology, locating energy production facilities and designing supply chains.

\subsection{Conclusions}

Assessments of sustainable levels of feedstocks can help gauge the potential of forests to directly supply wood fuel. Multi-scale assessments can be applied from local sites to national and international levels. There is a record of recent studies, all of which relied on forest inventory data as a basis, and biophysical and economic constraints to examine potential supply levels. As bioenergy projects come to fruition, realized volumes give a point comparison against which estimates could be compared. These could be used as thresholds to determine whether removal levels are above or below sustainable levels based on the best available information and current knowledge. Monitoring sustainable wood fuel supply will be an important step to take in the future where facilitates procuring wood at numerous geopolitical scales could be used to empirically examine site and landscape impacts. 


\subsection{References}

Aguilar, F. X., Goerndt, M. E., Shifley, S. and N. Song. 2012. Internal, external and location factors influencing cofiring of biomass with coal in the U.S. northern region. Energy Economics. 34:1790-1798

Äijälä, O., Koistinen, A., Sved, J., Vanhatalo, K. and P. Väisänen (eds.) 2014. Metsänhoidon suositukset. [Guidelines for sustainable forest management.] Metsätalouden kehittämiskeskus Tapion julkaisuja. Online at: http://www. metsanhoitosuositukset.fi/wp-content/uploads/2016/08/ Metsanhoidon_suositukset_Tapio_2014.pdf

Borsboom, N., Hektor, B., McCallum, B. and E. Remedio. 2002. Social Implications of forest energy production. 2002. In Richardson, J., Björheden, R., Hakkila, P., Lowe, A., \& Smith, C.T. (eds). Bioenergy from sustainable forestry. Guiding principles and practice. Kluwer Academic Publishers. Forestry Sciences.71:265-297.

Dees, M., Elbersen, B., Fitzgerald, J., Vis, M., Anttila, P., Forsell, N., Ramirez-Almeyda, J., García Galindo, D., Glavonjic, B., Staritsky, I., Verkerk, H., Prinz, R., Monti, A., Leduc, S., Höhl, M., Datta, P., Schrijver, R., Zudin, S., Lindner, M., Lesschen, J. and K. Diepen. 2017a. A spatial data base on sustainable biomass cost-supply of lignocellulosic biomass in Europe methods \& data sources. Project Report. S2BIOM - a project funded under the European Union 7th Frame Programme. Grant Agreement $n^{\circ} 608622$. Chair of Remote Sensing and Landscape Information Systems, Institute of Forest Sciences, University of Freiburg. $176 \mathrm{p}$.

Dees, M., Elbersen, B., Fitzgerald, J., Vis, M., Anttila, P., Forsell, N., Ramirez-Almeyda, J., Glavonjic, B., Staritsky, l., Verkerk, H., Prinz, R., Leduc, S., Datta, P., Lindner, M., Zudin, S. and M. Höhl. 2017b. Atlas with regional cost supply biomass potentials for EU 28, Western Balkan Countries, Moldavia, Turkey and Ukraine. Project Report. S2BIOM - a project funded under the European Union 7th Framework Programme for Research. Grant Agreement $n^{\circ} 608622$. Chair of Remote Sensing and Landscape Information Systems, Institute of Forest Sciences, University of Freiburg. 103 p.

FAO. 2010. Criteria and indicators for sustainable woodfuels. FAO Forestry Paper 160. 103 p.

Goerndt, M. E., Aguilar, F. X., Miles, P., Song, N., Shifley, S. and H. Stelzer. 2012. Regional assessment of woody biomass physical availability as an energy feedstock for combined combustion in the U.S. Northern Region. Journal of Forestry. 110(3): 138-148

Goerndt, M.E., D'Amato, A., and J. Kabrick. 2014. Chapter 4: Wood Energy and Forest Management. In: Aguilar, F.X. (ed). Wood Energy in Developed Economies. London,UK: Earthscan Publishing. Pp. 93-127.

Goerndt, M.E., Aguilar, F.X. and K. Skog. 2013a. Resource potential for renewable energy generation from co-firing of woody biomass with coal in the Northern U.S. Biomass and Bioenergy. 59:348-361.

Goerndt, M.E., Aguilar, F.X. and K. Skog. 2013b. Drivers of biomass co-firing in U.S. coal-fired power plants. Biomass and Bioenergy. 58:158-167.

Goerndt, M.E., Aguilar, F.X. and K. Skog. 2015. Potential for Coal Power Plants to Co-Fire with Woody Biomass in the U.S. North,
2010-2030: A Technical Paper Supporting the Northern Forest Futures Project. US Forest Service Technical Report.

International Organization for Standardization. 2014. ISO 17225-1:2014(en). Solid biofuels. Fuel specifications and classes. Part 1: General requirements.

Koistinen, A., Luiro, J-P. and K. Vanhatalo. (eds.) 2016. Metsänhoidon suositukset energiapuun korjuuseen, työopas. [Guidelines for sustainable harvesting of energy wood.] Tapion julkaisuja. Available at: http://tapio.fi/wp-content/ uploads/2015/06/MHS-Energiapuun-korjuun-suositukset_ verkkojulkaisu2.pdf.

Lattimore, B., Smith, C. T., Titus, B. D., Stupak, I. and Egnell, G. 2009. Environmental factors in woodfuel production: Opportunities, risks, and criteria and indicators for sustainable practices. Biomass and Bioenergy. 33(10):1321-1342.

Lunnan, A., Stupak, I., Asikainen, A., and R. Raulund-Rasmussen. 2008. Introduction to sustainable utilisation of forest energy. In: Röser, D., Asikainen, A., Raulund-Rasmussen, K. \& Stupak, I. (eds.). Sustainable use of forest biomass for energy. A synthesis with focus on the Baltic and Nordic region. Managing Forest Ecosystems 12: 1-8.

Nivala, M., Anttila, P. and J. Laitila. 2015. A GIS-based comparison of long-distance supply of wood for energy for future needs from young forests to the coast of Finland. International Journal of Forest Engineering. 26(3): 185-202.

Nivala, M., Anttila, P., Laitila, J., Salminen, O. and M. Flyktman. 2016. A GIS-based methodology to estimate the regional balance of potential and demand of forest chips. Journal of Geographic Information Systems. 8: 633-662.

Perlack, R., Wright, L. L., Turhollow, A. F., Graham, R. L., Stokes, B.C. and and D. Erbach. 2005. Biomass as feedstock for a bioenergy and bioproducts industry: the technical feasibility of a billion-ton annual supply. Oak Ridge National Laboratory. Online at http://www1.eere.energy.gov/biomass/pdfs/final_ billionton_vision_report2.pdf, accessed Sept 10, 2010.

S2Biom. 2017. Online at http://www.s2biom.eu.

Shepard, J. P. 2006. Water quality protection in bioenergy production: The US system of forestry Best Management Practices. Biomass and Bioenergy. 30: 378-384.

Smith, W.B., Miles, P., Perry, C. and S. Pugh. 2009. Forest Resources of the United States, 2007. US For. Serv. Gen. Tech. Rep. WO-78. 336 p.

U.S. Department of Energy. 2016. 2016 Billion-Ton Report: Advancing Domestic Resources for a Thriving Bioeconomy, Volume 1: Economic Availability of Feedstocks. M. H. Langholtz, B. J. Stokes, and L. M. Eaton (Leads), ORNL/TM2016/160. Oak Ridge National Laboratory, Oak Ridge, TN. 448p. doi: 10.2172/1271651.

Vis, M.W., van den Berg, D., Anttila, M.P., Böttcher, H., Dees, M., Domac, J., Eleftheriadis, I., Gecevska, V., Goltsev, V., Gunia, K., Kajba, D., Koch, B., Köppen, S., Kunikowski, G., Lehtonen, A.H.S., Leduc, S., Lemp, D., Lindner, M., Mustonen, J., Paappanen, T., Pekkanen, J.M., Ramos, C.I.S., Rettenmaier, N., Schneider, U.A., Schorb, A., Segon, V., Smeets, E.M.W., Torén, C.J.M., Verkerk, P.J., Zheliezna, T.A. and S. Zibtsev. 2010. Harmonization of biomass resource assessments Volume I: Best Practices and Methods Handbook. 220 p. 


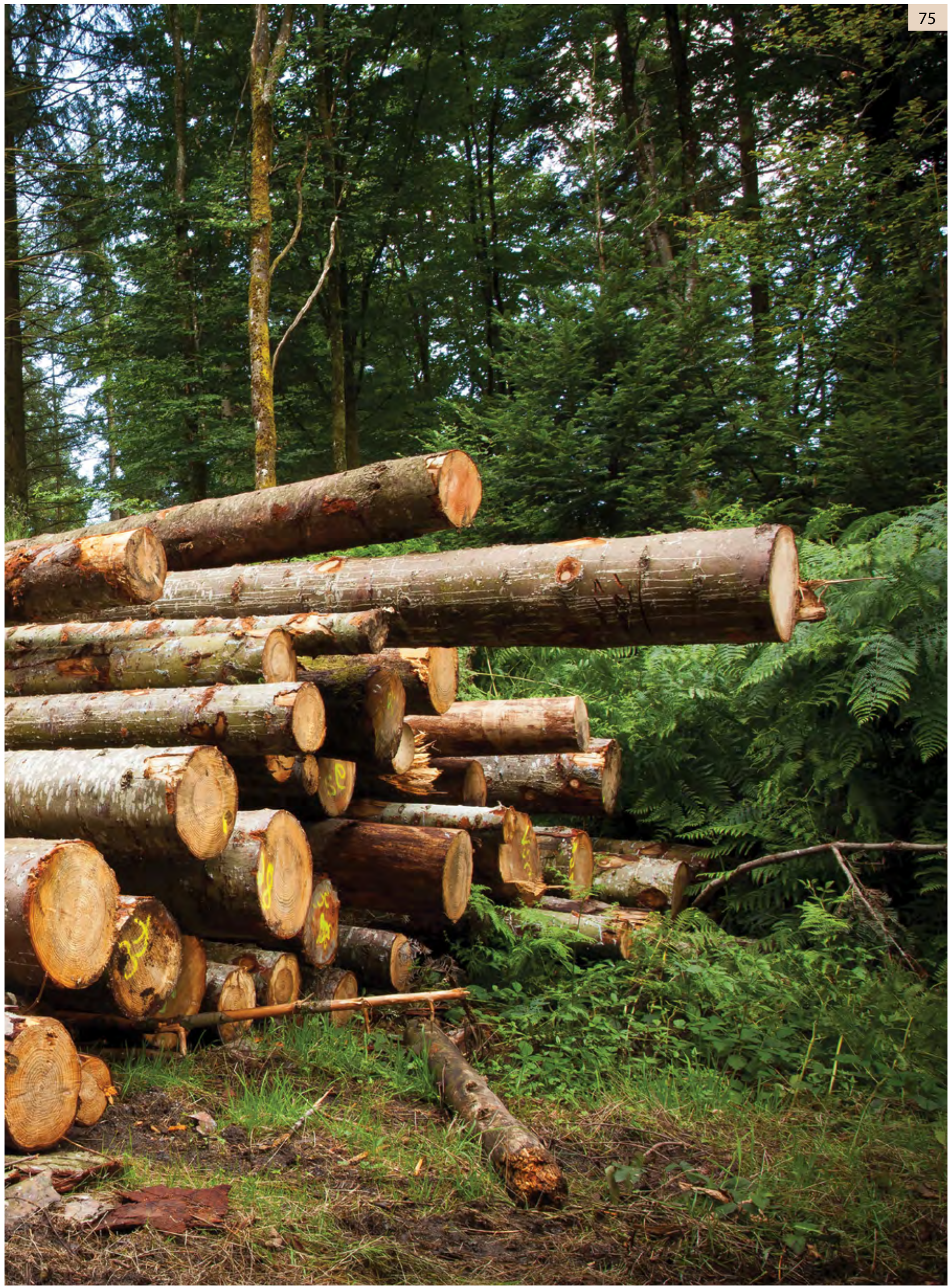




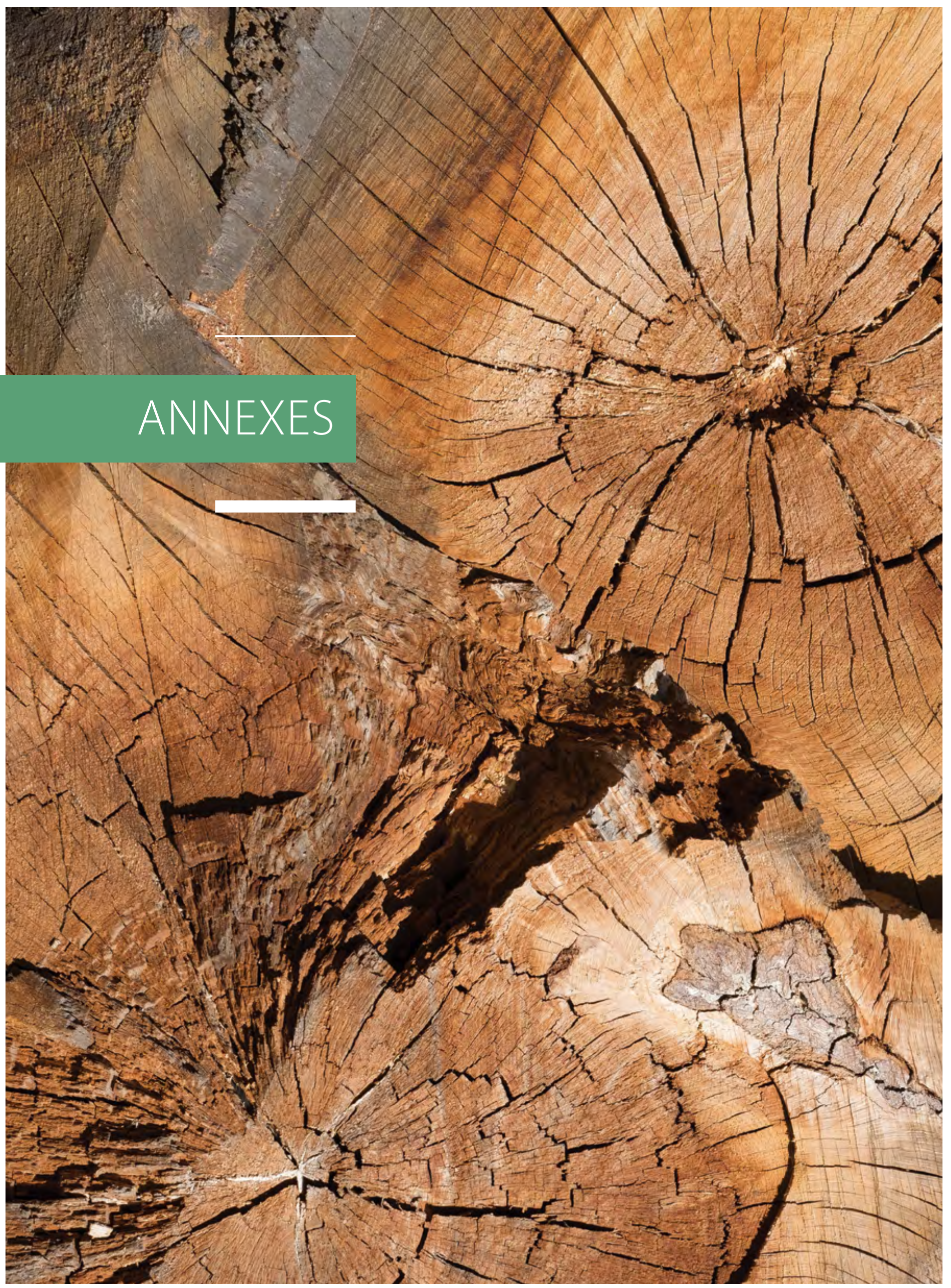




\section{ANNEX 1}

\section{JWEE COUNTRY PROFILES}

\section{TABLE A1.1}

\section{Responding Countries}

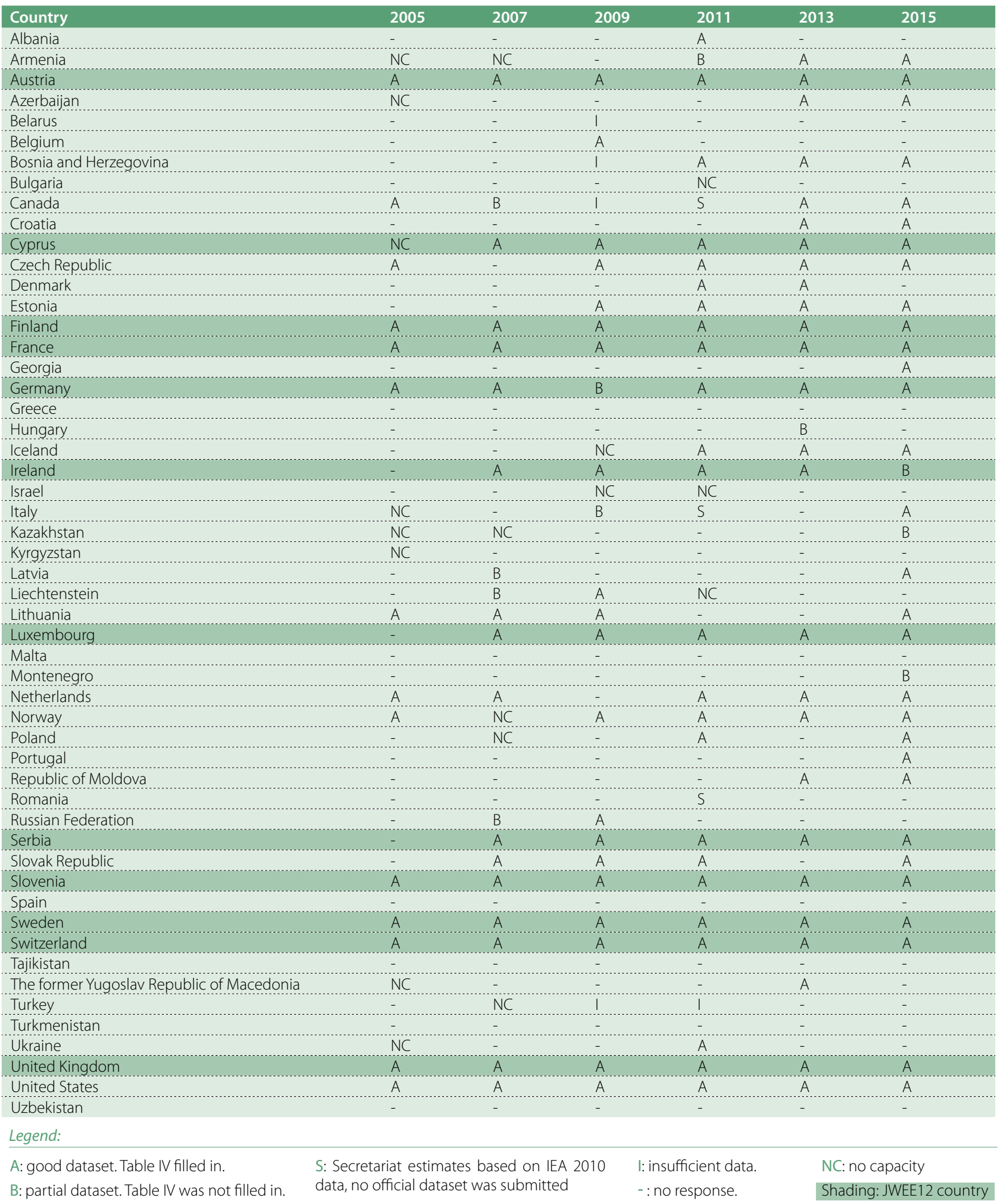

Note: Andorra, Monaco and San Marino are not included in the JWEE process. 
TABLE A1.2

\section{Aggregated country data for 2015}

\begin{tabular}{|c|c|c|c|c|c|c|}
\hline \multicolumn{2}{|c|}{ ARMENIA } & \multicolumn{5}{|c|}{ USES } \\
\hline 2015 & {$\left[1000 \mathrm{~m}^{3}\right]$} & $\begin{array}{c}\text { U1 } \\
\text { Power \& heat }\end{array}$ & $\begin{array}{c}\text { U2 } \\
\text { Industrial }\end{array}$ & $\begin{array}{c}\text { U3 } \\
\text { Residential }\end{array}$ & $\begin{array}{l}\text { U4 } \\
\text { Other }\end{array}$ & $\begin{array}{c}\text { Sum } \\
{[\cup 1 ; \cup 2 ; \cup 3 ; \cup 4]}\end{array}$ \\
\hline \multirow{4}{*}{ SOURCES } & S1 Direct & 0 & 5 & 502 & 0 & 507 \\
\hline & S2 Indirect & 0 & 0 & 0 & 0 & 0 \\
\hline & S3 Recovered & 0 & 0 & 0 & 0 & 0 \\
\hline & S4 Unspecified & 0 & 0 & 0 & 0 & 0 \\
\hline \multicolumn{2}{|c|}{ Sum $[\mathrm{S} 1 ; \mathrm{S} 2 ; \mathrm{S} 3 ; \mathrm{S} 4]$} & 0 & 5 & 502 & 0 & 507 \\
\hline
\end{tabular}

AUSTRIA

\begin{tabular}{|c|c|c|c|c|c|c|}
\hline 2015 & {$\left[1000 \mathrm{~m}^{3}\right]$} & $\begin{array}{c}\text { U1 } \\
\text { Power \& heat }\end{array}$ & $\begin{array}{c}\text { U2 } \\
\text { Industrial }\end{array}$ & $\begin{array}{c}\text { U3 } \\
\text { Residential }\end{array}$ & $\begin{array}{l}\text { U4 } \\
\text { Other }\end{array}$ & $\underset{[\cup 1 ; \cup 2 ; \cup 3 ; \cup 4]}{\text { Sum }}$ \\
\hline \multirow{4}{*}{ SOURCES } & S1 Direct & 0 & 0 & 6,859 & 529 & 7,388 \\
\hline & S2 Indirect & 6,352 & 7,357 & 1,105 & 1,404 & 16,218 \\
\hline & S3 Recovered & 0 & 0 & 0 & 0 & 0 \\
\hline & S4 Unspecified & 0 & 0 & 0 & 0 & 0 \\
\hline \multicolumn{2}{|r|}{ Sum $[\mathrm{S} 1 ; \mathrm{S} 2 ; \mathrm{S} 3 ; \mathrm{S} 4]$} & 6,352 & 7,357 & 7,964 & 1,932 & 23,606 \\
\hline
\end{tabular}

\section{USES}

\begin{tabular}{|c|c|c|c|c|c|c|}
\hline 2015 & {$\left[1000 \mathrm{~m}^{3}\right]$} & $\begin{array}{c}\text { U1 } \\
\text { Power \& heat }\end{array}$ & $\begin{array}{c}\text { U2 } \\
\text { Industrial }\end{array}$ & $\begin{array}{c}\text { U3 } \\
\text { Residential }\end{array}$ & $\begin{array}{l}\text { U4 } \\
\text { Other }\end{array}$ & $\begin{array}{c}\text { Sum } \\
{[\cup 1 ; \cup 2 ; \cup 3 ; \cup 4]}\end{array}$ \\
\hline \multirow{4}{*}{ SOURCES } & S1 Direct & 0 & 0 & 235 & 110 & 346 \\
\hline & S2 Indirect & 0 & 0 & 24 & 12 & 36 \\
\hline & S3 Recovered & 0 & 0 & 0 & 0 & 0 \\
\hline & S4 Unspecified & 0 & 0 & 0 & 0 & 0 \\
\hline \multicolumn{2}{|r|}{ Sum $[\mathrm{S} 1 ; \mathrm{S} 2 ; \mathrm{S} 3 ; \mathrm{S} 4]$} & 0 & 0 & 259 & 122 & 382 \\
\hline
\end{tabular}

\section{BOSNIA AND HERZEGOVINA}

2015

$\begin{array}{ll} & \text { S1 Direct } \\ \text { SOURCES } & \text { S2 Indirect } \\ & \text { S3 Recovered } \\ & \text { S4 Unspecified }\end{array}$
$\left[1000 \mathrm{~m}^{3}\right]$

\section{$\begin{array}{c:c}\text { U1 } & \text { U2 } \\ \text { Power \& heat } & \text { Industrial }\end{array}$}

\section{USES}

\begin{tabular}{c|c:c} 
U3 & U4 & Sum \\
Residential & Other & {$[\cup 1 ; \cup 2 ; \cup 3 ; \cup 4]$}
\end{tabular}

$\begin{array}{lc}0 & 78 \\ 0 & 0 \\ 0 & 0 \\ 0 & 0 \\ 0 & 78\end{array}$

$\begin{array}{cc}3,385 & 40 \\ 0 & 0 \\ 0 & 0 \\ 0 & 0 \\ 3,385 & 40\end{array}$

40
0
0
0
40

3,502

0

0

3,502 
TABLE A1.2

Aggregated country data for 2015 (cont.)

\begin{tabular}{|c|c|c|c|c|c|c|}
\hline \multicolumn{2}{|c|}{ CANADA } & \multicolumn{5}{|c|}{ USES } \\
\hline 2015 & [1 $\left.000 \mathrm{~m}^{3}\right]$ & $\begin{array}{c}\text { U1 } \\
\text { Power \& heat }\end{array}$ & $\begin{array}{c}\text { U2 } \\
\text { Industrial }\end{array}$ & $\begin{array}{c}\text { U3 } \\
\text { Residential }\end{array}$ & $\begin{array}{l}\text { U4 } \\
\text { Other }\end{array}$ & $\begin{array}{c}\text { Sum } \\
{[\cup 1 ; \cup 2 ; \cup 3 ; \cup 4]}\end{array}$ \\
\hline \multirow{4}{*}{ SOURCES } & S1 Direct & 0 & 0 & 15,387 & 0 & 15,387 \\
\hline & S2 Indirect & 0 & 48,048 & 3,150 & 0 & 51,198 \\
\hline & S3 Recovered & 0 & 0 & 0 & 0 & 0 \\
\hline & S4 Unspecified & 0 & 0 & 0 & 0 & 0 \\
\hline & $\operatorname{lm}[\mathrm{S} 1 ; \mathrm{S} 2 ; \mathrm{S} 3 ; \mathrm{S} 4]$ & 0 & 48,048 & 18,536 & 0 & 66,584 \\
\hline
\end{tabular}

CROATIA

\section{USES}

\begin{tabular}{|c|c|c|c|c|c|c|}
\hline 2015 & {$\left[1000 \mathrm{~m}^{3}\right]$} & $\begin{array}{c}\text { U1 } \\
\text { Power \& heat }\end{array}$ & $\begin{array}{c}\text { U2 } \\
\text { Industrial }\end{array}$ & $\begin{array}{c}\text { U3 } \\
\text { Residential }\end{array}$ & $\begin{array}{l}\text { U4 } \\
\text { Other }\end{array}$ & $\begin{array}{c}\text { Sum } \\
{[\cup 1 ; \cup 2 ; \cup 3 ; \cup 4]}\end{array}$ \\
\hline \multirow{4}{*}{ SOURCES } & S1 Direct & 121 & 49 & 2,668 & 0 & 2,838 \\
\hline & S2 Indirect & 67 & 72 & 353 & 0 & 492 \\
\hline & S3 Recovered & 23 & 180 & 0 & 0 & 202 \\
\hline & S4 Unspecified & 0 & 0 & 0 & 0 & 0 \\
\hline & $\operatorname{lm}[\mathrm{S} 1 ; \mathrm{S} 2 ; \mathrm{S} 3 ; \mathrm{S} 4]$ & 211 & 301 & 3,021 & 0 & 3,533 \\
\hline
\end{tabular}

CZECH REPUBLIC

\begin{tabular}{|c|c|c|c|c|c|c|}
\hline 2015 & {$\left[1000 \mathrm{~m}^{3}\right]$} & $\begin{array}{c}\text { U1 } \\
\text { Power \& heat }\end{array}$ & $\begin{array}{c}\text { U2 } \\
\text { Industrial }\end{array}$ & $\begin{array}{c}\text { U3 } \\
\text { Residential }\end{array}$ & $\begin{array}{l}\text { U4 } \\
\text { Other }\end{array}$ & $\begin{array}{c}\text { Sum } \\
{[\cup 1 ; \cup 2 ; \cup 3 ; \cup 4]}\end{array}$ \\
\hline \multirow{4}{*}{ SOURCES } & S1 Direct & 0 & 0 & 8,384 & 0 & 8,384 \\
\hline & S2 Indirect & 1,620 & 2,251 & 547 & 131 & 4,550 \\
\hline & S3 Recovered & 0 & 0 & 0 & 0 & 0 \\
\hline & S4 Unspecified & 0 & 0 & 0 & 0 & 0 \\
\hline \multicolumn{2}{|r|}{ Sum $[\mathrm{S} 1 ; \mathrm{S} 2 ; \mathrm{S} 3 ; \mathrm{S} 4]$} & 1,620 & 2,251 & 8,932 & 131 & 12,935 \\
\hline
\end{tabular}

\begin{tabular}{|c|c|c|c|c|c|c|}
\hline \multicolumn{2}{|c|}{ CYPRUS } & \multicolumn{5}{|c|}{ USES } \\
\hline 2015 & {$\left[1000 \mathrm{~m}^{3}\right]$} & $\begin{array}{c}\text { U1 } \\
\text { Power \& heat }\end{array}$ & $\begin{array}{c}\text { U2 } \\
\text { Industrial }\end{array}$ & $\begin{array}{c}\text { U3 } \\
\text { Residential }\end{array}$ & $\begin{array}{l}\text { U4 } \\
\text { Other }\end{array}$ & $\begin{array}{c}\text { Sum } \\
{[\cup 1 ; \cup 2 ; \cup 3 ; \cup 4]}\end{array}$ \\
\hline \multirow{4}{*}{ SOURCES } & S1 Direct & 0 & 0 & 12 & 0 & 12 \\
\hline & S2 Indirect & 0 & 1 & 39 & 54 & 94 \\
\hline & S3 Recovered & 0 & 0 & 0 & 0 & 0 \\
\hline & S4 Unspecified & 0 & 0 & 0 & 0 & 0 \\
\hline \multicolumn{2}{|c|}{ Sum [S1;S2;S3;S4] } & 0 & 1 & 51 & 54 & 105 \\
\hline
\end{tabular}


TABLE A1.2

Aggregated country data for 2015 (cont.)

\begin{tabular}{|c|c|c|c|c|c|c|}
\hline \multicolumn{2}{|c|}{ ESTONIA } & \multicolumn{5}{|c|}{ USES } \\
\hline 2015 & [1 $\left.000 \mathrm{~m}^{3}\right]$ & $\begin{array}{c}\text { U1 } \\
\text { Power \& heat }\end{array}$ & $\begin{array}{c}\text { U2 } \\
\text { Industrial }\end{array}$ & $\begin{array}{c}\text { U3 } \\
\text { Residential }\end{array}$ & $\begin{array}{l}\text { U4 } \\
\text { Other }\end{array}$ & $\begin{array}{c}\text { Sum } \\
{[\cup 1 ; \cup 2 ; \cup 3 ; \cup 4]}\end{array}$ \\
\hline \multirow{4}{*}{ SOURCES } & S1 Direct & 805 & 22 & 1,292 & 25 & 2,143 \\
\hline & S2 Indirect & 1,334 & 1,020 & 548 & 23 & 2,924 \\
\hline & S3 Recovered & 29 & 0 & 0 & 0 & 29 \\
\hline & S4 Unspecified & 0 & 0 & 0 & 0 & 0 \\
\hline \multicolumn{2}{|c|}{ Sum $[\mathrm{S} 1 ; \mathrm{S} 2 ; \mathrm{S} 3 ; \mathrm{S} 4]$} & 2,167 & 1,042 & 1,840 & 48 & 5,096 \\
\hline
\end{tabular}

FINLAND

\section{USES}

\begin{tabular}{|c|c|c|c|c|c|c|}
\hline 2015 & {$\left[1000 \mathrm{~m}^{3}\right]$} & $\begin{array}{c}\text { U1 } \\
\text { Power \& heat }\end{array}$ & $\begin{array}{c}\text { U2 } \\
\text { Industrial }\end{array}$ & $\begin{array}{c}\text { U3 } \\
\text { Residential }\end{array}$ & $\begin{array}{l}\text { U4 } \\
\text { Other }\end{array}$ & $\begin{array}{c}\text { Sum } \\
{[\cup 1 ; \cup 2 ; \cup 3 ; \cup 4]}\end{array}$ \\
\hline \multirow{4}{*}{ SOURCES } & S1 Direct & 4,762 & 617 & 4,668 & 689 & 10,735 \\
\hline & S2 Indirect & 4,912 & 20,027 & 999 & 234 & 26,171 \\
\hline & S3 Recovered & 621 & 39 & 169 & 72 & 901 \\
\hline & S4 Unspecified & 0 & 0 & 0 & 0 & 0 \\
\hline & $\mathrm{um}[\mathrm{S} 1 ; \mathrm{S} 2 ; \mathrm{S} 3 ; \mathrm{S} 4]$ & 10,295 & 20,682 & 5,836 & 995 & 37,807 \\
\hline
\end{tabular}

FRANCE

\section{USES}

\begin{tabular}{|c|c|c|c|c|c|c|}
\hline 2015 & {$\left[1000 \mathrm{~m}^{3}\right]$} & $\begin{array}{c}\text { U1 } \\
\text { Power \& heat }\end{array}$ & $\begin{array}{c}\text { U2 } \\
\text { Industrial }\end{array}$ & $\begin{array}{c}\text { U3 } \\
\text { Residential }\end{array}$ & $\begin{array}{l}\text { U4 } \\
\text { Other }\end{array}$ & $\begin{array}{c}\text { Sum } \\
{[\cup 1 ; \cup 2 ; \cup 3 ; \cup 4]}\end{array}$ \\
\hline \multirow{4}{*}{ SOURCES } & S1 Direct & 1,818 & 1,658 & 19,472 & 0 & 22,949 \\
\hline & S2 Indirect & 1,105 & 5,126 & 7,037 & 2,222 & 15,490 \\
\hline & S3 Recovered & 1,253 & 967 & 0 & 0 & 2,219 \\
\hline & S4 Unspecified & 0 & 0 & 0 & 0 & 0 \\
\hline & $\mathrm{um}[\mathrm{S} 1 ; \mathrm{S} 2 ; \mathrm{S} 3 ; \mathrm{S} 4]$ & 4,175 & 7,751 & 26,510 & 2,222 & 40,657 \\
\hline
\end{tabular}

\section{GEORGIA}

2015

\begin{tabular}{cl:l}
2015 & \multicolumn{1}{c|}{$\left[1000 \mathrm{~m}^{3}\right]$} & Power \\
& S1 Direct & \\
\multirow{2}{*}{ SOURCES } & S2 Indirect \\
& S3 Recovered \\
& S4 Unspecified \\
& Sum [S1·S2.S3.S4]
\end{tabular}

Sum $[\mathrm{S} 1 ; \mathrm{S} 2 ; \mathrm{S} 3 ; \mathrm{S} 4]$

U1
Power \&
0
0
0
0
0

\section{U1 U2}

\section{USES}

$\begin{array}{c:c:c}\text { U3 } & \text { U4 } & \text { Sum } \\ \text { Residential } & \text { Other } & {[\mathrm{U} 1 ; \mathrm{U} 2 ; \mathrm{U} 3 ; \mathrm{U} 4]}\end{array}$

$\begin{array}{ccc}2,082 & 35 & 2,121 \\ 1 & 0 & 1 \\ 0 & 0 & 0 \\ 0 & 0 & 0 \\ 2,082 & 35 & 2,122\end{array}$


TABLE A1.2

Aggregated country data for 2015 (cont.)

\begin{tabular}{|c|c|c|c|c|c|c|}
\hline \multicolumn{2}{|c|}{ GERMANY } & \multicolumn{5}{|c|}{ USES } \\
\hline 2015 & {$\left[1000 \mathrm{~m}^{3}\right]$} & $\begin{array}{c}\text { U1 } \\
\text { Power \& heat }\end{array}$ & $\begin{array}{c}\text { U2 } \\
\text { Industrial }\end{array}$ & $\begin{array}{c}\text { U3 } \\
\text { Residential }\end{array}$ & $\begin{array}{c}\text { U4 } \\
\text { Other }\end{array}$ & $\underset{[U 1 ; U 2 ; \cup 3 ; \cup 4]}{\text { Sum }}$ \\
\hline \multirow{4}{*}{ SOURCES } & S1 Direct & 3,661 & 2,715 & 20,111 & 1,112 & 27,599 \\
\hline & S2 Indirect & 3,598 & 4,825 & 5,667 & 1,413 & 15,503 \\
\hline & S3 Recovered & 6,039 & 4,479 & 1,410 & 41 & 11,968 \\
\hline & S4 Unspecified & 106 & 79 & 0 & 19 & 204 \\
\hline \multicolumn{2}{|c|}{ Sum [S1;S2;S3;S4] } & 13,404 & 12,097 & 27,189 & 2,584 & 55,274 \\
\hline
\end{tabular}

ICELAND

\section{USES}

\begin{tabular}{|c|c|c|c|c|c|c|}
\hline 2015 & {$\left[1000 \mathrm{~m}^{3}\right]$} & $\begin{array}{c}\text { U1 } \\
\text { Power \& heat }\end{array}$ & $\begin{array}{c}\text { U2 } \\
\text { Industrial }\end{array}$ & $\begin{array}{c}\text { U3 } \\
\text { Residential }\end{array}$ & $\begin{array}{l}\text { U4 } \\
\text { Other }\end{array}$ & $\begin{array}{c}\text { Sum } \\
{[\cup 1 ; \cup 2 ; \cup 3 ; \cup 4]}\end{array}$ \\
\hline \multirow{4}{*}{ SOURCES } & S1 Direct & 2 & 0 & 0 & 0 & 2 \\
\hline & S2 Indirect & 2 & 22 & 0 & 0 & 24 \\
\hline & S3 Recovered & 0 & 0 & 0 & 0 & 0 \\
\hline & S4 Unspecified & 0 & 0 & 0 & 0 & 0 \\
\hline \multicolumn{2}{|r|}{ Sum $[\mathrm{S} 1 ; \mathrm{S} 2 ; \mathrm{S} 3 ; \mathrm{S} 4]$} & 5 & 22 & 0 & 0 & 26 \\
\hline
\end{tabular}

ITALY

USES

\begin{tabular}{|c|c|c|c|c|c|c|}
\hline 2015 & {$\left[1000 \mathrm{~m}^{3}\right]$} & $\begin{array}{c}\text { U1 } \\
\text { Power \& heat }\end{array}$ & $\begin{array}{c}\text { U2 } \\
\text { Industrial }\end{array}$ & $\begin{array}{c}\text { U3 } \\
\text { Residential }\end{array}$ & $\begin{array}{l}\text { U4 } \\
\text { Other }\end{array}$ & $\begin{array}{c}\text { Sum } \\
{[\cup 1 ; \cup 2 ; \cup 3 ; \cup 4]}\end{array}$ \\
\hline \multirow{4}{*}{ SOURCES } & S1 Direct & 0 & 0 & 27,614 & 0 & 27,614 \\
\hline & S2 Indirect & 8,644 & 877 & 4,209 & 414 & 14,144 \\
\hline & S3 Recovered & 0 & 974 & 0 & 0 & 974 \\
\hline & S4 Unspecified & 0 & 0 & 0 & 0 & 0 \\
\hline \multicolumn{2}{|c|}{ Sum $[\mathrm{S} 1 ; \mathrm{S} 2 ; \mathrm{S} 3 ; \mathrm{S} 4]$} & 8,644 & 1,851 & 31,823 & 414 & 42,732 \\
\hline
\end{tabular}

\begin{tabular}{|c|c|c|c|c|c|c|}
\hline \multicolumn{2}{|c|}{ LATVIA } & \multicolumn{5}{|c|}{ USES } \\
\hline 2015 & {$\left[1000 \mathrm{~m}^{3}\right]$} & $\begin{array}{c}\text { U1 } \\
\text { Power \& heat }\end{array}$ & $\begin{array}{c}\text { U2 } \\
\text { Industrial }\end{array}$ & $\begin{array}{c}\text { U3 } \\
\text { Residential }\end{array}$ & $\begin{array}{l}\text { U4 } \\
\text { Other }\end{array}$ & $\begin{array}{c}\text { Sum } \\
{[\cup 1 ; \cup 2 ; \cup 3 ; \cup 4]}\end{array}$ \\
\hline \multirow{4}{*}{ SOURCES } & S1 Direct & 66 & 223 & 322 & 32 & 642 \\
\hline & S2 Indirect & 810 & 1,235 & 172 & 132 & 2,349 \\
\hline & S3 Recovered & 0 & 0 & 0 & 0 & 0 \\
\hline & S4 Unspecified & 0 & 0 & 0 & 0 & 0 \\
\hline \multicolumn{2}{|c|}{ Sum $[\mathrm{S} 1 ; \mathrm{S} 2 ; \mathrm{S} 3 ; \mathrm{S} 4]$} & 876 & 1,458 & 493 & 165 & 2,992 \\
\hline
\end{tabular}


TABLE A1.2

Aggregated country data for 2015 (cont.)

\begin{tabular}{|c|c|c|c|c|c|c|}
\hline \multicolumn{2}{|c|}{ LITHUANIA } & \multicolumn{5}{|c|}{ USES } \\
\hline 2015 & {$\left[1000 \mathrm{~m}^{3}\right]$} & $\begin{array}{c}\text { U1 } \\
\text { Power \& heat }\end{array}$ & $\begin{array}{c}\text { U2 } \\
\text { Industrial }\end{array}$ & $\begin{array}{c}\text { U3 } \\
\text { Residential }\end{array}$ & $\begin{array}{l}\text { U4 } \\
\text { Other }\end{array}$ & $\begin{array}{c}\text { Sum } \\
{[\cup 1 ; \cup 2 ; \cup 3 ; \cup 4]}\end{array}$ \\
\hline \multirow{4}{*}{ SOURCES } & S1 Direct & 0 & 0 & 0 & 0 & 0 \\
\hline & S2 Indirect & 0 & 0 & 0 & 0 & 0 \\
\hline & S3 Recovered & 0 & 0 & 0 & 0 & 0 \\
\hline & S4 Unspecified & 2,871 & 547 & 2,525 & 226 & 6,169 \\
\hline \multicolumn{2}{|c|}{ Sum $[\mathrm{S} 1 ; \mathrm{S} 2 ; \mathrm{S} 3 ; \mathrm{S} 4]$} & 2,871 & 547 & 2,525 & 226 & 6,169 \\
\hline
\end{tabular}

LUXEMBOURG

\section{5}

\section{[1 $\left.000 \mathrm{~m}^{3}\right]$}

\section{USES}

$\begin{array}{c:c}\text { U1 } & \text { U2 } \\ \text { Power \& heat } & \text { Industrial }\end{array}$

\begin{tabular}{|c|c|c|c|c|c|c|}
\hline \multicolumn{2}{|c|}{ LUXEMBOURG } & \multicolumn{5}{|c|}{ USES } \\
\hline 2015 & {$\left[1000 \mathrm{~m}^{3}\right]$} & $\begin{array}{c}\text { U1 } \\
\text { Power \& heat }\end{array}$ & $\begin{array}{c}\text { U2 } \\
\text { Industrial }\end{array}$ & $\begin{array}{c}\text { U3 } \\
\text { Residential }\end{array}$ & $\begin{array}{l}\text { U4 } \\
\text { Other }\end{array}$ & $\underset{[\cup 1 ; \cup 2 ; \cup 3 ; \cup 4]}{\text { Sum }}$ \\
\hline \multirow{4}{*}{ SOURCES } & S1 Direct & 0 & 0 & 110 & 1 & 112 \\
\hline & S2 Indirect & 97 & 103 & 9 & 0 & 209 \\
\hline & S3 Recovered & 0 & 0 & 0 & 0 & 0 \\
\hline & S4 Unspecified & 0 & 0 & 0 & 0 & 0 \\
\hline \multicolumn{2}{|r|}{ Sum $[\mathrm{S} 1 ; \mathrm{S} 2 ; \mathrm{S} 3 ; \mathrm{S} 4]$} & 97 & 103 & 119 & 1 & 321 \\
\hline
\end{tabular}

\section{REPUBLIC OF MOLDOVA}

\begin{tabular}{|c|c|c|c|c|c|c|}
\hline 2015 & {$\left[1000 \mathrm{~m}^{3}\right]$} & $\begin{array}{c}\text { U1 } \\
\text { Power \& heat }\end{array}$ & $\begin{array}{c}\text { U2 } \\
\text { Industrial }\end{array}$ & $\begin{array}{c}\text { U3 } \\
\text { Residential }\end{array}$ & $\begin{array}{l}\text { U4 } \\
\text { Other }\end{array}$ & $\underset{[\cup 1 ; \cup 2 ; \cup 3 ; \cup 4]}{\text { Sum }}$ \\
\hline \multirow{4}{*}{ SOURCES } & S1 Direct & 0 & 10 & 3,518 & 77 & 3,606 \\
\hline & S2 Indirect & 0 & 3 & 14 & 6 & 23 \\
\hline & S3 Recovered & 0 & 0 & 0 & 0 & 0 \\
\hline & S4 Unspecified & 0 & 0 & 0 & 0 & 0 \\
\hline \multicolumn{2}{|r|}{ Sum $[\mathrm{S} 1 ; \mathrm{S} 2 ; \mathrm{S} 3 ; \mathrm{S} 4]$} & 0 & 13 & 3,533 & 84 & 3,629 \\
\hline
\end{tabular}

\begin{tabular}{|c|c|c|c|c|c|c|}
\hline \multicolumn{2}{|c|}{ NETHERLANDS } & \multicolumn{5}{|c|}{ USES } \\
\hline 2015 & [1 $\left.000 \mathrm{~m}^{3}\right]$ & $\begin{array}{c}\text { U1 } \\
\text { Power \& heat }\end{array}$ & $\begin{array}{c}\text { U2 } \\
\text { Industrial }\end{array}$ & $\begin{array}{c}\text { U3 } \\
\text { Residential }\end{array}$ & $\begin{array}{l}\text { U4 } \\
\text { Other }\end{array}$ & $\underset{[\cup 1 ; \cup 2 ; \cup 3 ; \cup 4]}{\text { Sum }}$ \\
\hline \multirow{4}{*}{ SOURCES } & S1 Direct & 197 & 0 & 1,677 & 278 & 2,152 \\
\hline & S2 Indirect & 22 & 158 & 224 & 210 & 615 \\
\hline & S3 Recovered & 1,397 & 0 & 344 & 44 & 1,785 \\
\hline & S4 Unspecified & 0 & 0 & 0 & 0 & 0 \\
\hline \multicolumn{2}{|r|}{ Sum $[S 1 ; S 2 ; S 3 ; S 4]$} & 1,616 & 158 & 2,246 & 532 & 4,552 \\
\hline
\end{tabular}


TABLE A1.2

Aggregated country data for 2015 (cont.)

\begin{tabular}{|c|c|c|c|c|c|c|}
\hline \multicolumn{2}{|c|}{ NORWAY } & \multicolumn{5}{|c|}{ USES } \\
\hline 2015 & {$\left[1000 \mathrm{~m}^{3}\right]$} & $\begin{array}{c}\text { U1 } \\
\text { Power \& heat }\end{array}$ & $\begin{array}{c}\text { U2 } \\
\text { Industrial }\end{array}$ & $\begin{array}{c}\text { U3 } \\
\text { Residential }\end{array}$ & $\begin{array}{c}\text { U4 } \\
\text { Other }\end{array}$ & $\frac{\text { Sum }}{[\cup 1 ; \cup 2 ; \cup 3 ; \cup 4]}$ \\
\hline \multirow{4}{*}{ SOURCES } & S1 Direct & 0 & 0 & 1,827 & 0 & 1,827 \\
\hline & S2 Indirect & 0 & 1,240 & 364 & 0 & 1,605 \\
\hline & S3 Recovered & 0 & 0 & 0 & 0 & 0 \\
\hline & S4 Unspecified & 808 & 0 & 0 & 0 & 808 \\
\hline \multicolumn{2}{|c|}{ Sum $[\mathrm{S} 1 ; \mathrm{S} 2 ; \mathrm{S} 3 ; \mathrm{S} 4]$} & 808 & 1,240 & 2,191 & 0 & 4,240 \\
\hline
\end{tabular}

POLAND

\section{5}

SOURCES

\section{[1 $\left.000 \mathrm{~m}^{3}\right]$}

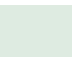


TABLE A1.2

Aggregated country data for 2015 (cont.)

\begin{tabular}{|c|c|c|c|c|c|c|}
\hline \multicolumn{2}{|c|}{ SLOVAKIA } & \multicolumn{5}{|c|}{ USES } \\
\hline 2015 & {$\left[1000 \mathrm{~m}^{3}\right]$} & $\begin{array}{c}\text { U1 } \\
\text { Power \& heat }\end{array}$ & $\begin{array}{c}\text { U2 } \\
\text { Industrial }\end{array}$ & $\begin{array}{c}\text { U3 } \\
\text { Residential }\end{array}$ & $\begin{array}{c}\text { U4 } \\
\text { Other }\end{array}$ & $\underset{[U 1 ; \cup 2 ; U 3 ; U 4]}{\text { Sum }}$ \\
\hline \multirow{4}{*}{ SOURCES } & S1 Direct & 993 & 0 & 859 & 26 & 1,878 \\
\hline & S2 Indirect & 1,020 & 1,311 & 50 & 52 & 2,432 \\
\hline & S3 Recovered & 23 & 6 & 6 & 0 & 35 \\
\hline & S4 Unspecified & 0 & 0 & 0 & 0 & 0 \\
\hline \multicolumn{2}{|c|}{ Sum $[\mathrm{S} 1 ; \mathrm{S} 2 ; \mathrm{S} 3 ; \mathrm{S} 4]$} & 2,036 & 1,317 & 915 & 78 & 4,345 \\
\hline
\end{tabular}

\section{SLOVENIA}

\section{5}

\section{$\left[1000 \mathrm{~m}^{3}\right]$}

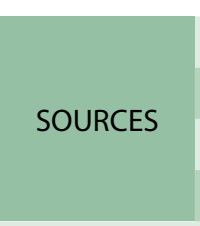

S1 Direct
S2 Indirect
S3 Recovered
S4 Unspecified

Sum $[\mathrm{S} 1 ; \mathrm{S} 2 ; \mathrm{S} 3 ; \mathrm{S} 4]$

U1
Power \&
0
220
0
0
220

\section{USES}

\begin{tabular}{l|l|l} 
U1 & U2 & U3
\end{tabular}

Industrial Residential

0

1,528

0
484
0
0
484

0
484
0
0
484

0
484
0
0
484

484

346

10

264

2,149

\section{USES}

SWEDEN

\begin{tabular}{|c|c|c|c|c|c|c|}
\hline 2015 & {$\left[1000 \mathrm{~m}^{3}\right]$} & $\begin{array}{c}\text { U1 } \\
\text { Power \& heat }\end{array}$ & $\begin{array}{c}\text { U2 } \\
\text { Industrial }\end{array}$ & $\begin{array}{c}\text { U3 } \\
\text { Residential }\end{array}$ & $\begin{array}{l}\text { U4 } \\
\text { Other }\end{array}$ & $\begin{array}{c}\text { Sum } \\
{[\cup 1 ; \cup 2 ; \cup 3 ; \cup 4]}\end{array}$ \\
\hline \multirow{4}{*}{ SOURCES } & S1 Direct & 6,712 & 0 & 3,982 & 507 & 11,201 \\
\hline & S2 Indirect & 7,351 & 21,921 & 1,084 & 663 & 31,020 \\
\hline & S3 Recovered & 2,012 & 0 & 0 & 0 & 2,012 \\
\hline & S4 Unspecified & 0 & 0 & 0 & 0 & 0 \\
\hline \multicolumn{2}{|r|}{ Sum $[\mathrm{S} 1 ; \mathrm{S} 2 ; \mathrm{S} 3 ; \mathrm{S} 4]$} & 16,076 & 21,921 & 5,067 & 1,170 & 44,233 \\
\hline
\end{tabular}

\section{SWITZERLAND}

2015

$\left[1000 \mathrm{~m}^{3}\right]$

$$
\begin{gathered}
\text { U1 } \\
\text { Power \& heat }
\end{gathered}
$$

U1 U2 U2
Industrial

\begin{tabular}{|c|c|c|c|c|c|c|}
\hline & & rower \& medi & & Restaentida & & \\
\hline \multirow{4}{*}{ SOURCES } & S1 Direct & 890 & 73 & 1,168 & 412 & 2,543 \\
\hline & S2 Indirect & 148 & 621 & 471 & 45 & 1,284 \\
\hline & S3 Recovered & 682 & 294 & 0 & 7 & 984 \\
\hline & S4 Unspecified & 0 & 0 & 0 & 0 & 0 \\
\hline \multicolumn{2}{|r|}{ Sum [S1;S2;S3;S4] } & 1,720 & 988 & 1,639 & 464 & 4,811 \\
\hline
\end{tabular}

\section{USES}


TABLE A1.2

Aggregated country data for 2015 (cont.)

\begin{tabular}{|c|c|c|c|c|c|c|}
\hline \multicolumn{2}{|c|}{ UNITED KINGDOM } & \multicolumn{5}{|c|}{ USES } \\
\hline 2015 & {$\left[1000 \mathrm{~m}^{3}\right]$} & $\begin{array}{c}\text { U1 } \\
\text { Power \& heat }\end{array}$ & $\begin{array}{c}\text { U2 } \\
\text { Industrial }\end{array}$ & $\begin{array}{c}\text { U3 } \\
\text { Residential }\end{array}$ & $\begin{array}{l}\text { U4 } \\
\text { Other }\end{array}$ & $\underset{[U 1 ; \cup 2 ; \cup 3 ; \cup 4]}{\text { Sum }}$ \\
\hline \multirow{4}{*}{ SOURCES } & S1 Direct & 520 & 77 & 7,199 & 0 & 7,796 \\
\hline & S2 Indirect & 16,009 & 6,775 & 1,379 & 497 & 24,660 \\
\hline & S3 Recovered & 863 & 15 & 796 & 0 & 1,674 \\
\hline & S4 Unspecified & 0 & 0 & 0 & 0 & 0 \\
\hline \multicolumn{2}{|c|}{ Sum $[S 1 ; S 2 ; S 3 ; S 4]$} & 17,393 & 6,866 & 9,373 & 497 & 34,129 \\
\hline
\end{tabular}

\section{UNITED STATES}

\begin{tabular}{|c|c|c|c|c|c|c|}
\hline 2015 & {$\left[1000 \mathrm{~m}^{3}\right]$} & $\begin{array}{c}\text { U1 } \\
\text { Power \& heat }\end{array}$ & $\begin{array}{c}\text { U2 } \\
\text { Industrial }\end{array}$ & $\begin{array}{c}\text { U3 } \\
\text { Residential }\end{array}$ & $\begin{array}{c}\text { U4 } \\
\text { Other }\end{array}$ & $\frac{\text { Sum }}{[U 1 ; \cup 2 ; \cup 3 ; \cup 4]}$ \\
\hline & S1 Direct & 0 & 0 & 46,741 & 0 & 46,741 \\
\hline & S2 Indirect & 0 & 75,461 & 13,315 & 0 & 88,777 \\
\hline & S3 Recovered & 7,583 & 5,243 & 0 & 1,269 & 14,095 \\
\hline & S4 Unspecified & 30,875 & 47,876 & 0 & 9,230 & 87,981 \\
\hline & um [S1;S2;S3;S4] & 38,458 & 128,581 & 60,057 & 10,499 & 237,594 \\
\hline
\end{tabular}


This glossary synthesizes wood energy terms and definitions used in this publication and structures them according to the UNECE/ FAO Joint Wood Energy Enquiry. Terms and definitions presented in the glossary are based on the International standard ISO 16559:2014 Solid biofuels - Terminology, definitions and descriptions. Main terms and definitions in this standard are adapted from previously published standards and FAO unified bioenergy terminology (UBET). References are provided for each term and definition.

\section{A2.1 Basic terms}

biofuel (in solid, liquid or gaseous state) is produced directly or indirectly from biomass and used for generation of bioenergy. Total mass of a solid biofuel includes oven dry matter (organic and inorganic) and moisture (ISO 16559:2014; adapted from EN 14588:2010).

\section{bioenergy}

energy derived from biomass

Biomass may either be directly converted into energy or processed into solids, liquids or gases. (ISO 16559:2014; adapted from EN 14588:2010)

\section{biomass}

material of biological origin excluding material embedded in geological formations and/or fossilized (adapted from EN 14588:2010)

\section{woody biomass}

biomass originating from trees, bushes and shrubs This definition includes forest, plantation and other virgin wood, wood processing industry by-products and residues, and used wood. (ISO 16559:2014; adapted from EN 14588:2010)

\section{total mass}

mass of all components of the solid fuel, including dry matter and moisture (ISO 16559:2014; adapted from EN 14588:2010)

\section{oven dry matter}

biomass free of moisture, produced by drying to constant weight under specific conditions (ISO 16559:2014; adapted from EN 14588:2010)

\section{inorganic matter}

non-combustible fraction of a fuel (ISO 16559:2014; adapted from EN 14588:2010)

\section{ash (ash content)}

mass of inorganic residue remaining after combustion of a fuel under specified conditions, typically expressed as a percentage of the mass of dry matter in fuel (ISO 16559:2014; adapted from ISO 1213-2:1992)

\section{organic matter}

combustible fraction of the fuel (ISO 16559:2014; adapted from EN 14588:2010)

\section{moisture (moisture content, total moisture)}

water in the fuel removable under specific conditions (ISO 16559:2014; adapted from EN 14588:2010)

\section{A2.2 Fibre sources}

Fibre sources for production of biofuels originate from primary biomass (stem wood, logging residues, stump, bark, energy crops), secondary biomass (bark, cross-cut ends, edgings, fibre sludge, grinding dust, saw dust, slabs and wood shavings) or tertiary biomass (solid recovered fuel, used wood). Bark can be regarded as a primary biomass when used in the form of fuelwood or as a secondary biomass if used as a wood processing industry by-product. Logging residues refer to woody biomass that can't be used for industrial roundwood production.

\section{primary biomass}

biomass produced directly by photosynthesis and harvested or collected from the field or forest where it is grown (ISO 16559:2014; adapted from ANSI/ASABE S593)

\section{bark}

organic cellular tissue which is formed by taller plants (trees, bushes) on the outside of the growth zone

(cambium) as a shell for the wooden body (ISO 16559:2014; adapted from EN 14588:2010)

\section{logging residues}

woody biomass residues (branches and tree tops that can be salvaged when fresh or after seasoning) created during wood harvesting (ISO 16559:2014; adapted from EN 14588:2010)

\section{stem wood (roundwood)}

part of tree stem with the branches and top removed, with a length of more than $100 \mathrm{~cm}$ (ISO 16559:2014; adapted from EN 14588:2010)

\section{stump}

part of the tree stem below the felling cut (ISO 16559:2014; adapted from EN 14588:2010)

\section{energy crops}

woody or herbaceous crops grown and harvested specifically for their fuel value (ISO 16559:2014; adapted from EN 14588:2010)

\section{short rotation coppice}

production of woody biomass, generally on agricultural lands, by regenerating new stems (shoots) from the (stool) stump or roots and relying on rapid growth, (harvested) generally over a $1-8$ year cycle (ISO 16559:2014) 


\section{secondary biomass}

residues and by-product streams from food, feed, fiber, wood and materials processing plants (such as sawdust, black liquor and cheese whey), and manures from animal feeding operations (ISO 16559:2014; adapted from ANSI/ ASABE S593)

\section{wood processing industry by-products (wood processing industry residues)}

woody biomass by-products (or residues) obtained from wood processing and from the pulp and paper industry (ISO 16559:2014; adapted from EN 14588:2010)

\section{cross-cut ends}

short pieces of woody biomass which occur when the ends of logs or sawn timber are cross cut off, with or without bark (ISO 16559:2014; adapted from EN 14588:2010)

\section{edgings}

parts of woody biomass which occur when trimming sawn timber and which show a remainder of the original rounded surface of the tree, with or without bark (ISO 16559:2014; adapted from EN 14588:2010)

\section{fibre sludge}

sludge formed in the sedimentation basin as a part of the waste water treatment process in a pulp and paper mill and separated by sedimentation or flotation (ISO 16559:2014; adapted from EN 14588:2010)

\section{grinding dust}

dust-like wood residue formed in grinding timber and wood boards (ISO 16559:2014; adapted from EN 14588:2010)

\section{sawdust}

fine particles created when sawing wood, in which most of the material has a typical particle length of $1 \mathrm{~mm}$ to $5 \mathrm{~mm}$ (ISO 16559:2014; adapted from EN 14588:2010)

\section{slab}

parts of woody biomass created when cuts are made into the edges of logs and whereby one side shows the original rounded surface of the tree, either completely or partially, with or without bark (ISO 16559:2014; adapted from EN 14588:2010)

\section{wood shavings (cutter shavings)}

shavings from woody biomass created when planing wood (ISO 16559:2014; adapted from EN 14588:2010)

\section{tertiary biomass}

post consumer residues and wastes, such as fats, greases, oils, construction and demolition wood debris, other waste wood from urban environments, as well as packaging wastes, municipal solid wastes and landfill gases (ISO 16559:2014, adapted from ANSI/ASABE S593)

\section{municipal solid waste}

waste stream consisting of end-of-life-materials Municipal solid waste can contain biomass fractions as well as non-biomass fractions. Only separated and not contaminated biomass fractions could be solid biofuels. (ISO 16559:2014; adapted from EN 14588:2010)

\section{solid recovered fuel}

solid fuel prepared from non-hazardous waste to be utilised for energy recovery in incineration or coincineration plants (ISO 16559:2014; adapted from EN 15359:2011)

\section{used wood}

wood substances or objects which have performed their intended purpose (ISO 16559:2014; adapted from EN 14588:2010))

\section{demolition wood}

used wood arising from demolition of buildings or civil engineering installations (ISO 16559:2014; adapted from EN 13965-1:2004)

\section{recovered construction wood}

used wood arising from construction of buildings or from civil engineering works (ISO 16559:2014; adapted from EN 13965-1:2004)

\section{A2.3 Processed wood based fuels}

Woody biomass can be processed to various wood fuels using different transformation processes. Classification of wood fuels is based on the source of wood fibre and transformation process applied. Wood fuels processed without changing the original composition of the wood (fuelwood) mostly originate directly from forest (forest fuels). However some of these products can originate from secondary or tertiary biomass as well as from primary biomass sources outside forests. Production of densified biofuels relies primary on the secondary biomass (wood processing industry by-products), and thermally-treated biomass presents a further step in upgrading the energy density of wood fuels.

wood fuels (wood based fuels, wood-derived biofuels) all types of biofuels originating from woody biomass (ISO 16559:2014; adapted from UBET, 2004)

\section{forest fuels}

forest fuel is produced directly from forest wood or plantation wood by a mechanical process, the raw material has not previously had another use (ISO 16559:2014; adapted from EN 14588:2010)

\section{fuelwood}

wood fuel where the original composition of the wood is preserved, unaltered from original form (ISO 16559:2014; adapted from EN 14588:2010)

\section{firewood}

cut, and split fuelwood usually with a length of 20 to $100 \mathrm{~cm}$ used in household appliances like stoves, fireplaces and central heating devices (ISO 16559:2014; adapted from EN 14588:2010)

\section{hog fuel}

shred fuelwood that has pieces of varying size and shape, produced by crushing with blunt tools such as rollers, hammers, or flails (ISO 16559:2014; adapted from EN 14588:2010) 


\section{log wood}

cut fuelwood in which most of the material has a length of $500 \mathrm{~mm}$ and above (ISO 16559:2014; adapted from EN 14588:2010)

\section{smallwood}

fuelwood cut with sharp cutting devices and in which most of the material has a particle length typically 50 $\mathrm{mm}$ to $500 \mathrm{~mm}$ (ISO 16559:2014; adapted from EN 14588:2010)

\section{wood chips}

chipped woody biomass in the form of pieces with a defined particle size produced by mechanical treatment with sharp tools such as knives (ISO 16559:2014; adapted from EN 14588:2010)

\section{cutter chips}

wood chips made as a by-product of the wood processing industry, with or without bark (ISO 16559:2014; adapted from EN 14588:2010)

\section{forest chips}

forest wood in the form of wood chips (ISO 16559:2014; adapted from EN 14588:2010)

\section{densified biofuel, compressed biofuel}

solid biofuel made by mechanically compressing biomass or thermally treated biomass to mould the solid biofuel into a specific size and shape such as cubes, pressed logs, biofuel pellets or biofuel briquettes (ISO 16559:2014; adapted from EN 14588:2010)

\section{wood briquette}

biofuel made with or without additives in the form of cubiform or cylindrical units and a diameter of over $25 \mathrm{~mm}$ produced by compressing pulverised woody biomass (ISO 16559:2014; adapted from EN 14588:2010)

\section{wood pellet}

biofuel made from woody biomass with or without additives in the form of cubiform, polyhedral, polyhydric or cylindrical units of random length (typically from 3.15 $\mathrm{mm}$ to $40 \mathrm{~mm}$ ) with broken ends, and a diameter up to 25 mm (ISO 16559:2014; adapted from EN 14588:2010)

\section{thermally-treated biomass}

biomass whose chemical composition has been changed by heat (usually by temperatures of 200 to $300^{\circ} \mathrm{C}$ and above) (ISO 16559:2014)

\section{charcoal}

solid biofuel derived from carbonization distillation and pyrolysis of biomass (ISO 16559:2014, adapted from ANSI/ASABE S593)

\section{torrefied biomass}

solid biofuel produced by torrefaction of biomass Torrefaction is a mild pyrolysis process performed at temperatures between $200-300^{\circ} \mathrm{C}$ in inert atmosphere. For example under those conditions, biomass is altered to an intermediate between wood and charcoal. Torrefied biomass contains typically 60 - 70\% of the initial mass and $90 \%$ of the initial net calorific value. (ISO 16559:2014)

\section{black liquor}

liquor obtained from wood during the process of pulp production, in which the energy content is mainly originating from the content of lignin removed from the wood in the pulping process (ISO 16559:2014; adapted from EN 14588:2010)

\section{A2.4 Energy use}

During combustion a part of fuel energy (gross calorific value) is consumed for the evaporation of water contained in the fuel, and the water that results from the chemical reaction of hydrogen and oxygen during the combustion (Hakkila 1989). Further reduction in net calorific value depends on the moisture of the fuel.

\section{calorific value (heating value)}

the energy amount per unit mass or volume released on complete combustion (ISO 16559:2014; adapted from EN 14588:2010)

\section{gross calorific value (higher heating value)}

measured value of specific energy of combustion of a solid fuel burned in oxygen in a calorimetric bomb under such conditions that all the water of the reaction products is in the form of liquid water (ISO 16559:2014; adapted from ISO 1928:1995) or the value in a perfectly efficient conversion of material with no heat loss [Fonseca]. The amount of heat released by a specified quantity (initially at $25^{\circ}$ ) once it is combusted and the products have returned to a temperature of $25^{\circ} \mathrm{C}$, which takes into account the latent heat of vaporization of water in the combustion products (Spellman, 2012)

\section{net calorific value (lower heating value)}

calculated value of specific energy of combustion of a solid fuel burned in oxygen under such conditions that all the water of the reaction products remain as water vapour water (ISO 16559:2014; adapted from ISO 1928:1995) or the value in a actual conversion with exhaust system loss and accounting for the evaporation of water [Fonseca]. The amount of heat released by combusting a specified quantity (initially at $25^{\circ} \mathrm{C}$ ) and returning the temperature of the combustion products to $150^{\circ} \mathrm{C}$; it is assumed that the latent heat of the vaporization of water in the reaction produces [sic] is not recovered. (Spellman, 2012).

\section{Main activity producer electricity plants}

Report quantities of renewables and waste used to produce electricity. Renewables and waste used by plants containing at least one CHP unit are to be reported under Main activity producer CHP. (IEA 2017)

\section{Main activity producer combined heat and power (CHP) plants}

Report quantities of renewables and waste used to produce electricity and heat. Main activity producer heat plants: Report quantities of renewables and waste used to produce heat. (IEA 2017) 


\section{Autoproducer electricity plants}

Report quantities of renewables and waste used to produce electricity. Renewables and waste used by plants containing at least one CHP unit are to be reported under Autoproducer CHP. (IEA 2017)

\section{Autoproducer combined heat and power (CHP) plants} Report quantities of renewables and waste that correspond to the quantity of electricity produced and heat sold. (IEA 2017)

\section{Autoproducer heat plants}

Report quantities of renewables and waste that correspond to the quantity of heat sold. (IEA 2017)

\section{A2.5 Conversion Factors}

Wood fuels in solid state are commonly marketed in mass or volumetric units. In order to prepare and analyse bioenergy balance based on production (in volume or mass units) and consumption data (in mass or energy units), appropriate conversion factors have to be used (based on the properties of raw material). The most common unit used for the purpose of converting volume to mass and then to energy is the basic density.

\section{density}

ratio of mass to volume or ratio of energy content to volume It must always be stated whether the density refers to the density of individual particles or to the bulk density of the material and whether the mass of water in the material is included. (ISO 16559:2014; adapted from EN 14588:2010

\section{basic density}

ratio of the mass on dry basis and the solid volume on green basis (ISO 16559:2014; adapted from EN 14588:2010)

\section{bulk density}

mass of a portion (i.e. a large quantity of particulate material) of a solid fuel divided by the volume of the container which is filled by that portion under specific conditions (ISO 16559:2014; adapted from ISO 12132:1992)

\section{energy density}

ratio of net energy content and bulk volume (ISO 16559:2014; adapted from EN 14588:2010)

\section{gross density}

ratio of the mass of a wooden body and its volume, including all cavities (pores and vessels), based on specific total moisture (ISO 16559:2014; adapted from EN 14588:2010)

\section{solid density}

density of solid material excluding any interior pores (ISO 16559:2014)

\section{volume}

amount of space that is enclosed within an object (ISO 16559:2014; adapted from EN 14588:2010)

\section{bulk (loose) volume}

volume of a material including space between the particles (ISO 16559:2014; adapted from EN 14588:2010)

\section{solid volume}

volume of the individual particle excluding the volume of the void between the particles (ISO 16559:2014; adapted from EN 14588:2010)

\section{stacked volume}

volume of stacked material including the space between the material pieces (ISO 16559:2014; adapted from EN 14588:2010)

\section{A2.6 References}

ANSI/ASABE S593.1: 2011 Terminology and Definitions for Biomass Production, Harvesting and Collection, Storage, Processing, Conversion and Utilization

EN 13965-1:2004 Characterization of waste - Terminology - Part 1: Material related terms. Available through www. cencenelec.eu.

EN 14558:2010 Solid biofuels. Terminology, definitions and descriptions. Available through www.cencenelec.eu.

EN 15359:2011 - Solid recovered fuels. Specifications and classes. Available through www.cencenelec.eu.

Hakkila, P., 1989: Utilization of Residual Forest Biomass. Springer-Verlag, Berlin, 1-568.

ISO 1213-2:1992 Solid mineral fuels; vocabulary; part 2: terms relating to sampling, testing and analysis. Available through www.iso.org

ISO 16559:2014 Solid biofuels - Terminology, definitions and descriptions. Available through www.iso.org.

ISO 1928:1995 Solid mineral fuels - Determination of gross calorific value by the bomb calorimetric method, and calculation of net calorific value. Available through www.iso. org.

IEA 2017. Renewables annual questionnaire 2016 and historical revisions available at: https://www.iea.org/media/ statistics/questionnaires/Renewables_questionnaire_ instructions_2016.pdf

Spellman, F. 2012. Forest-Based Biomass Concepts and Applications. CRC Press. 


\section{SOME FACTS ABOUT THE COMMITTEE ON FORESTS AND THE FOREST INDUSTRY}

The UNECE Committee on Forests and the Forest Industries is a principal subsidiary body of the UNECE (United Nations Economic Commission for Europe) based in Geneva. It constitutes a forum for cooperation and consultation between member States on forestry, the forest industry and forest product matters. All countries of Europe, the Commonwealth of Independent States, the United States of America, Canada and Israel are members of the UNECE and participate in its work.

The UNECE Committee on Forests and the Forest Industries shall, within the context of sustainable development, provide member States with the information and services needed for policymaking and decision-making with regard to their forest and forest industry sectors, including the trade and use of forest products and, where appropriate, will formulate recommendations addressed to member governments and interested organizations. To this end, it shall:

1. With the active participation of member States, undertake short-, medium- and long-term analyses of developments in, and having an impact on, the sector, including those developments offering possibilities for the facilitation of international trade and for enhancing the protection of the environment;

2. In support of these analyses, collect, store and disseminate statistics relating to the sector, and carry out activities to improve their quality and comparability;

3. Provide the framework for cooperation e.g. by organising seminars, workshops and ad hoc meetings and setting up timelimited ad hoc groups, for the exchange of economic, environmental and technical information between governments and other institutions of member States required for the development and implementation of policies leading to the sustainable development of the sector and to the protection of the environment in their respective countries;

4. Carry out tasks identified by the UNECE or the Committee on Forests and the Forest Industries as being of priority, including the facilitation of subregional cooperation and activities in support of the economies in transition of central and eastern Europe and of the countries of the region that are developing from an economic perspective;

5. It should also keep under review its structure and priorities and cooperate with other international and intergovernmental organizations active in the sector, and in particular with the FAO (the Food and Agriculture Organization of the United Nations) and its European Forestry Commission, and with the ILO (the International Labour Organisation), in order to ensure complementarity and to avoid duplication, thereby optimizing the use of resources.

More information about the Committee's work may be obtained by contacting:

UNECE/FAO Forestry and Timber Section

Forests, Land and Housing Division

United Nations Economic Commission for Europe/

Food and Agriculture Organization of the United Nations

Palais des Nations

CH-1211 Geneva 10, Switzerland

\section{info.ECE-FAOforests@unece.org}

www.unece.org/forests 


\section{UNECE/FAO PUBLICATIONS}

Note: other market-related publications and information are available in electronic format at our website.

\section{Geneva Timber and Forest Study Papers}

Forest Products Annual Market Review 2016-2017

$\mathrm{ECE} / \mathrm{TIM} / \mathrm{SP} / 41$

Forest Products Annual Market Review 2015-2016

$\mathrm{ECE} / \mathrm{TIM} / \mathrm{SP} / 40$

Forest Products Annual Market Review 2014-2015

$\mathrm{ECE} / \mathrm{TIM} / \mathrm{SP} / 39$

Promoting Sustainable Building Materials and the Implications on the Use of Wood in Buildings

$\mathrm{ECE} / \mathrm{TIM} / \mathrm{SP} / 38$

Forests in the ECE Region: Trends and Challenges in Achieving the Global Objectives on Forests

$\mathrm{ECE} / \mathrm{TIM} / \mathrm{SP} / 37$

Forest Products Annual Market Review 2013-2014

$\mathrm{ECE} / \mathrm{TIM} / \mathrm{SP} / 36$

Rovaniemi Action Plan for the Forest Sector in a Green Economy

$\mathrm{ECE} / \mathrm{TIM} / \mathrm{SP} / 35$

The Value of Forests: Payments for Ecosystem Services in a Green Economy

$\mathrm{ECE} / \mathrm{TIM} / \mathrm{SP} / 34$

Forest Products Annual Market Review 2012-2013

$\mathrm{ECE} / \mathrm{TIM} / \mathrm{SP} / 33$

The Lviv Forum on Forests in a Green Economy

Forests and Economic Development: A Driver for the Green Economy in the ECE Region

$\mathrm{ECE} / \mathrm{TIM} / \mathrm{SP} / 32$

Forest Products Annual Market Review 2011-2012

$\mathrm{ECE} / \mathrm{TIM} / \mathrm{SP} / 31$

$\mathrm{ECE} / \mathrm{TIM} / \mathrm{SP} / 30$

The North American Forest Sector Outlook Study 2006-2030

$\mathrm{ECE} / \mathrm{TIM} / \mathrm{SP} / 29$

European Forest Sector Outlook Study 2010-2030

$\mathrm{ECE} / \mathrm{TIM} / \mathrm{SP} / 28$

Forest Products Annual Market Review 2010-2011

$\mathrm{ECE} / \mathrm{TIM} / \mathrm{SP} / 27$

Private Forest Ownership in Europe

$\mathrm{ECE} / \mathrm{TIM} / \mathrm{SP} / 26$

Forest Products Annual Market Review 2009-2010

$\mathrm{ECE} / \mathrm{TIM} / \mathrm{SP} / 25$

Forest Products Annual Market Review 2008-2009

$\mathrm{ECE} / \mathrm{TIM} / \mathrm{SP} / 24$

Forest Products Annual Market Review 2007-2008

$\mathrm{ECE} / \mathrm{TIM} / \mathrm{SP} / 23$

Forest Products Annual Market Review 2006-2007

$\mathrm{ECE} / \mathrm{TIM} / \mathrm{SP} / 22$

Forest Products Annual Market Review, 2005-2006

$\mathrm{ECE} / \mathrm{TIM} / \mathrm{SP} / 21$

European Forest Sector Outlook Study: 1960 - 2000 - 2020, Main Report

$\mathrm{ECE} / \mathrm{TIM} / \mathrm{SP} / 20$

Forest Policies and Institutions of Europe, 1998-2000

$\mathrm{ECE} / \mathrm{TIM} / \mathrm{SP} / 19$

Forest and Forest Products Country Profile: Russian Federation

$\mathrm{ECE} / \mathrm{TIM} / \mathrm{SP} / 18$

Forest Resources of Europe, CIS, North America, Australia, Japan and New Zealand

$\mathrm{ECE} / \mathrm{TIM} / \mathrm{SP} / 17$

The above series of sales publications and subscriptions are available through United Nations Publications Offices as follows:

Sales and Marketing Section, Room DC2-853

United Nations

2 United Nations Plaza

New York, NY 10017

United States of America

Fax: + 12129633489

E-mail: publications@un.org

Web site: https://unp.un.org 


\section{UNECE/FAO PUBLICATIONS}

\section{Geneva Timber and Forest Discussion Papers (original language only)}

Forecast of the Committee on Forests and the Forest Industry: Forest Products Production and Trade 2016-2018

${ }^{*} \mathrm{ECE} / \mathrm{TIM} / \mathrm{DP} / 69$

Forecast of the Committee on Forests and the Forest Industry: Forest Products Production and Trade 2015-2017

ECE Committee on Forests and the Forest Industry and European Forestry Commission: 70 years working

${ }^{*} \mathrm{ECE} / \mathrm{TIM} / \mathrm{DP} / 68$

in the Service of Forests and people

Pilot project on the System for the Evaluation of the Management of Forests (SEMAFOR)

Comparative assessment of wood biomass for energy in Europe

Forecast of the Committee on Forests and the Forest Industry: Forest Products Production

and Trade 2014-2016

Forecast of the Committee on Forests and the Forest Industry: Forest Products Production

and Trade 2013-2015

Competitiveness of the European Forest Sector

ECE/TIM/DP/67

ECE/TIM/DP/66

${ }^{*} \mathrm{ECE} / \mathrm{TIM} / \mathrm{DP} / 65$

ECE/TIM/DP/64

ECE/TIM/DP/63

$\mathrm{ECE} / \mathrm{TIM} / \mathrm{DP} / 62$

Forecast of the Committee on Forests and the Forest Industry: Forest Products Production

and Trade 2012-2014

ECE/TIM/DP/61

Forecast of the Committee on Forests and the Forest Industry: Forest Products Production and Trade 2011-2013

Econometric Modelling and Projections of Wood Products Demand, Supply and Trade in Europe

Swedish Forest Sector Outlook Study

The Importance of China's Forest Products Markets to the UNECE Region

Good Practice Guidance on Sustainable Mobilisation of Wood: Proceedings from

the Grenoble Workshop

Harvested Wood Products in the Context of Climate Change Policies: Workshop Proceedings - 2008

The Forest Sector in the Green Economy

National Wood Resources Balances: Workshop Proceedings

Potential Wood Supply in Europe

Wood Availability and Demand in Europe

Forest Products Conversion Factors for the UNECE Region

Mobilizing Wood Resources: Can Europe's Forests Satisfy the Increasing Demand for Raw Material

and Energy Under Sustainable Forest Management? Workshop Proceedings - January 2007

European Forest Sector Outlook Study: Trends 2000-2005 Compared to the EFSOS Scenarios

Forest and Forest Products Country Profile; Tajikistan

Forest and Forest Products Country Profile: Uzbekistan

Forest Certification - Do Governments Have a Role?

International Forest Sector Institutions and Policy Instruments for Europe: A Source Book

Forests, Wood and Energy: Policy Interactions

Outlook for the Development of European Forest Resources

Forest and Forest Products Country Profile: Serbia and Montenegro

Forest Certification Update for the UNECE Region, 2003

Forest and Forest Products Country Profile: Republic of Bulgaria

Forest Legislation in Europe: How 23 Countries Approach the Obligation to Reforest, Public Access

and Use of Non-Wood Forest Products

$\mathrm{ECE} / \mathrm{TIM} / \mathrm{DP} / 60$

$\mathrm{ECE} / \mathrm{TIM} / \mathrm{DP} / 59$

ECE/TIM/DP/58

$\mathrm{ECE} / \mathrm{TIM} / \mathrm{DP} / 57$

${ }^{*} \mathrm{ECE} / \mathrm{TIM} / \mathrm{DP} / 56$

${ }^{*} \mathrm{ECE} / \mathrm{TIM} / \mathrm{DP} / 55$

$\mathrm{ECE} / \mathrm{TIM} / \mathrm{DP} / 54$

${ }^{*} \mathrm{ECE} / \mathrm{TIM} / \mathrm{DP} / 53$

*ECE/TIM/DP/52

*ECE/TIM/DP/51

ECE/TIM/DP/49

${ }^{*} \mathrm{ECE} / \mathrm{TIM} / \mathrm{DP} / 48$

ECE/TIM/DP/47

${ }^{*} \mathrm{ECE} / \mathrm{TIM} / \mathrm{DP} / 46$

$\mathrm{ECE} / \mathrm{TIM} / \mathrm{DP} / 45$

$\mathrm{ECE} / \mathrm{TIM} / \mathrm{DP} / 44$

ECE/TIM/DP/43

$\mathrm{ECE} / \mathrm{TIM} / \mathrm{DP} / 42$

$\mathrm{ECE} / \mathrm{TIM} / \mathrm{DP} / 41$

$\mathrm{ECE} / \mathrm{TIM} / \mathrm{DP} / 40$

$\mathrm{ECE} / \mathrm{TIM} / \mathrm{DP} / 39$

ECE/TIM/DP/38

ECE/TIM/DP/37

$\mathrm{ECE} / \mathrm{TIM} / \mathrm{DP} / 36$

$\mathrm{ECE} / \mathrm{TIM} / \mathrm{DP} / 35$

Trends in the Tropical Timber Trade, 2002-2003

Biological Diversity, Tree Species Composition and Environmental Protection in the Regional FRA-2000

$\mathrm{ECE} / \mathrm{TIM} / \mathrm{DP} / 33$

$\mathrm{ECE} / \mathrm{TIM} / \mathrm{DP} / 32$

Forestry and Forest Products Country Profile: Ukraine

The Development of European Forest Resources, 1950 To 2000: a Better Information Base

Modelling and Projections of Forest Products Demand, Supply and Trade in Europe

$\mathrm{ECE} / \mathrm{TIM} / \mathrm{DP} / 31$

Employment Trends and Prospects in the European Forest Sector

$\mathrm{ECE} / \mathrm{TIM} / \mathrm{DP} / 30$

ECE/TIM/DP/29 
Forestry Cooperation with Countries in Transition

$\mathrm{ECE} / \mathrm{TIM} / \mathrm{DP} / 28$

Russian Federation Forest Sector Outlook Study

$\mathrm{ECE} / \mathrm{TIM} / \mathrm{DP} / 27$

Forest and Forest Products Country Profile: Georgia

$\mathrm{ECE} / \mathrm{TIM} / \mathrm{DP} / 26$

Forest certification update for the UNECE region, summer 2002

$\mathrm{ECE} / \mathrm{TIM} / \mathrm{DP} / 25$

Forecasts of economic growth in OECD and central and eastern European countries for the period 2000-2040

$\mathrm{ECE} / \mathrm{TIM} / \mathrm{DP} / 24$

Forest Certification update for the UNECE Region, summer 2001

$\mathrm{ECE} / \mathrm{TIM} / \mathrm{DP} / 23$

Structural, Compositional and Functional Aspects of Forest Biodiversity in Europe

$\mathrm{ECE} / \mathrm{TIM} / \mathrm{DP} / 22$

Markets for secondary processed wood products, 1990-2000

$\mathrm{ECE} / \mathrm{TIM} / \mathrm{DP} / 21$

Forest certification update for the UNECE Region, summer 2000

ECE/TIM/DP/20

Trade and environment issues in the forest and forest products sector

$\mathrm{ECE} / \mathrm{TIM} / \mathrm{DP} / 19$

Multiple use forestry

$\mathrm{ECE} / \mathrm{TIM} / \mathrm{DP} / 18$

Forest certification update for the UNECE Region, summer 1999

$\mathrm{ECE} / \mathrm{TIM} / \mathrm{DP} / 17$

A summary of "The competitive climate for wood products and paper packaging: the factors causing substitution with emphasis on environmental promotions"

ECE/TIM/DP/16

Recycling, energy and market interactions

The status of forest certification in the UNECE region

The role of women on forest properties in Haute-Savoie (France): Initial research

$\mathrm{ECE} / \mathrm{TIM} / \mathrm{DP} / 15$

$\mathrm{ECE} / \mathrm{TIM} / \mathrm{DP} / 14$

$\mathrm{ECE} / \mathrm{TIM} / \mathrm{DP} / 13$

Interim report on the Implementation of Resolution $\mathrm{H} 3$ of the Helsinki Ministerial

Conference on the protection of forests in Europe (Results of the second enquiry)

$\mathrm{ECE} / \mathrm{T} I \mathrm{M} / \mathrm{DP} / 12$

Manual on acute forest damage

ECE/TIM/DP/7

* signifies electronic publication only

\section{The above series of publications may be requested free of charge through:}

UNECE/FAO Forestry and Timber Section

Forests, Land and Housing Division

United Nations Economic Commission for Europe/

Food and Agriculture Organization of the United Nations

Palais des Nations

CH-1211 Geneva 10, Switzerland

\section{E-mail: info.ECE-FAOforests@unece.org}

Downloads are available at:

www.unece.org/forests 
This publication highlights the use of wood for energy and includes the most recent statistics on wood energy markets across the UNECE region. It aims to communicate the relevance of wood energy in the region and help bridge information about the forest and energy sectors. It also intends to offer some of the best-available information on the role that wood energy can play in various sectors to support environmental, energy, and socio-economic strategies toward a greener economy. It focuses on commercial wood energy uses in the UNECE including energy generated for cooking, heating and electricity generation.

Further information on wood energy can be found at www.unece.org/forests/jwee

Information Service

United Nations Economic Commission for Europe

Palais des Nations

$\mathrm{CH}$ - 1211 Geneva 10, Switzerland

ISBN: 978-92-1-117154-9

Telephone: +41(0)229171234

Fax: $\quad$ +41(0)229170505

E-mail: unece_info@un.org

Website: http://www.unece.org 